Is Sustainable Development of Semi-Subsistence Mixed Crop-Livestock Systems Possible? An integrated assessment of Machakos, Kenya 


\section{Thesis committee}

\section{Promotor}

Prof. Dr E.H. Bulte

Professor of Development Economics

Wageningen University

\section{Co-promotors}

Prof. J. Antle

Professor of Applied Economics

Oregon State University

Dr J.J. Stoorvogel

Associate Professor, Soil Geography and Landscape

Wageningen University

\section{Other members}

Prof. Dr M.K. van Ittersum, Wageningen University

Prof. Dr J.H.H. Wesseler, Wageningen University

Dr C. Crissman, World Fish Center, Penang, Malaysia

Dr P.Q. Craufurd, International Maize and Wheat Improvement Center, Nairobi, Kenya

This research was conducted under the auspices of the Wageningen School of Social Science (WASS) 


\title{
Is Sustainable Development of Semi-Subsistence Mixed Crop-Livestock Systems Possible? An integrated assessment of Machakos, Kenya
}

\section{Roberto O. Valdivia}

\author{
Thesis \\ submitted in fulfillment of the requirements for the degree of doctor \\ at Wageningen University \\ by the authority of the Rector Magnificus \\ Prof. Dr A.P.J. Mol, \\ in the presence of the \\ Thesis Committee appointed by the Academic Board \\ to be defended in public \\ on Friday 17 June 2016 \\ at 8.30 a.m. in the Aula.
}


Roberto O. Valdivia

Is Sustainable Development of Semi-Subsistence Mixed Crop-Livestock Systems Possible? An integrated assessment of Machakos, Kenya

233 pages.

$\mathrm{PhD}$ thesis, Wageningen University, Wageningen, NL (2016)

With references, with summary in English

ISBN 978-94-6257-827-2

DOI: $10.18174 / 383208$ 
In loving memory of Oscar, Cristina and Silvio: my dear grandparents. I know you would be proud of this Thesis. 


\section{Acknowledgements}

It's been a long journey to complete my $\mathrm{PhD}$. In fact, and to be correct, it has been a very long journey! The path has not been easy (of course, every PhD student would say the same), and there have been ups and downs professionally and personally. I now look back and regardless of all the time that has passed, I see how much I have learned all these years and how many people around me have contributed in one way or another to this new achievement in my life. The following lines are dedicated to express my deepest gratitude to these people.

I have to start with my two co-promotors, this thesis would not be a reality without them. Jetse Stoorvogel: I am grateful to you in many respects. First, for giving me the opportunity to enroll in the $\mathrm{PhD}$ program at Wageningen University and your continued support and encouragement has been essential for me. I appreciate all your critical and constructive comments along the way, which definitely contributed to the thesis but also to my personal and professional growth. I'm thankful because you have also become a good friend who understood and supported me in difficult times, and as such also thanks to your family for having me in your house many of the times I've been in Wageningen.

My co-promoter and friend, John Antle: There are no simple words that can capture all the gratitude I have for you. I've known you for many years already; you've been my advisor for my Master degree thesis and now my co-promotor for my $\mathrm{PhD}$. In both cases I felt privileged and lucky. Privileged because you have taught me many things that go beyond the academics or science and that has helped me to grow as professional and as a person. I thank you for believing in me, for your support and help. You've always been there as a colleague, advisor and as a friend during good or bad 
times and I'm really grateful for this. During this time, thanks to you, I have also learned to appreciate a good scotch no matter where in the world we are! I also want to thank Susan Capalbo for also keeping me encouraged to continue this path. John and Susan, thanks for allowing me to be a friend to your family.

I also want to thank my Promoter, Dr. Erwin Bulte. You inherited this thesis due to the retirement of Dr. Kuyvenhoven and accepted the challenge. Thanks for this and for all your support to make this possible. Needless to say, I also thank Dr. Arie Kuyvenhoven for all the initial support and comments to the thesis proposal when I started the program.

This process has also let me find friends whose support has been very valuable to me. Lieven Claessens, thanks for keep reminding me in different words that while getting a $\mathrm{PhD}$ is a (royal) challenge, it is achievable and that I have the support needed to do it. Alejandra Mora, we've been on a similar situation at some point, and your words of encouragement and your thesis motivated me this last stretch of the way. Thanks! Laila Kassam, I think we met at the right time, both working towards our PhDs. Thanks for those long chats about research, $\mathrm{PhD}$ and many other interesting things, but also for listening! Also thanks for your friendship and continued words of support, encouragement and for always sending that "positive energy" along my way.

I would like to express special thanks to my parents, Elsa and Roberto. You both have always inspired me to growth and to be better as a person and as a professional. Thank you for being always there to help me, to support me and to cheer me up when needed. I can't express how proud I am of being your son, and this achievement also belongs to you. Also special thanks to my sister Carla and brother Enrique. Thank you both for always caring about me and checking how I am doing.

I also want to thank my parents-in-law, Dina and Jorge. Thanks for your enormous support, during this process I had to be away from home on many 
opportunities and you have never doubted to come to our home and help us while I've been traveling, sometimes for long periods of time. Thank you.

I started my acknowledgments saying that this has been a long and not easy road. However, I made it here thanks to my family. The deepest gratitude from all my heart is for my wife Ana. Thank you for your ongoing support and for doing everything you could to help me achieve this goal. I said that it hasn't been easy, but your continued understanding and encouragement has definitely been important to me in the process of achieving this goal. Thank you! I finally want to thank to the three people that are my inspiration and day-to-day motivation, my children: Roberto J., Leonardo R. and Alessandra N. I thank you simply for giving me the reason to do everything I do. I love you all! 


\section{Table of Contents}

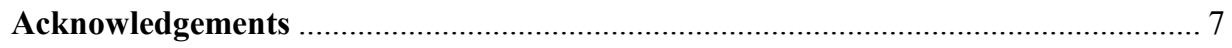

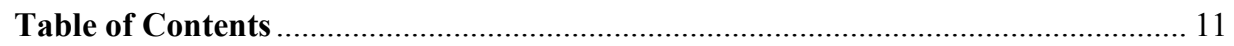

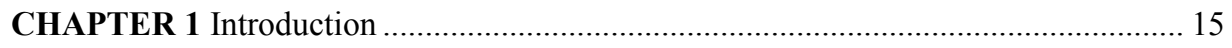

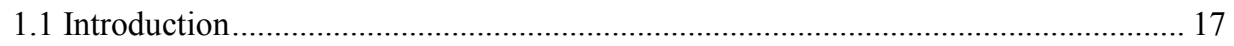

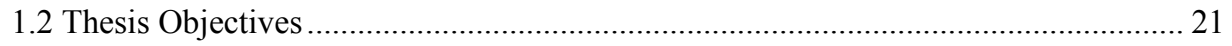

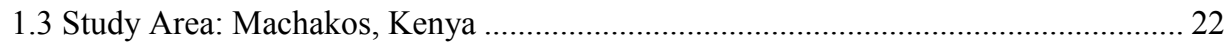

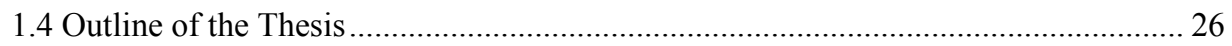

CHAPTER 2 Background and Conceptual Framework …............................................. 29

2.1. Modeling Agricultural Production Systems: Review of Modeling .......................... 31

2.1.1 Integrated Assessment Models ...................................................... 32

2.1.2 Market equilibrium models .................................................... 33

2.2 Scale Issues, Heterogeneity and Aggregation Problems........................................... 36

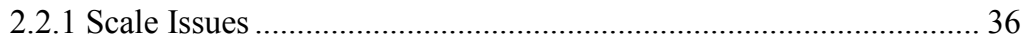

2.2.2 Aggregation and Disaggregation Issues.................................... 38

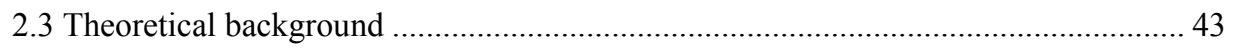

2.3.1 Basic micro-economic model ....................................................... 43

2.3.2 Aggregation of heterogeneous firms.......................................... 48

2.3.3. Econometric process model ...................................................... 51

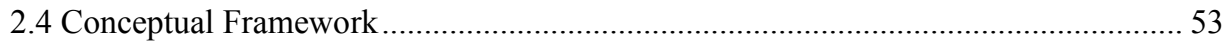

2.5 Derivation of Tradeoff Curves and Aggregate Supply ............................................ 56

CHAPTER 3 In Search of Sustainable Development: Modeling Semi-Subsistence CropLivestock Systems to Solve the Poverty-Productivity-Sustainability Puzzle in Sub-

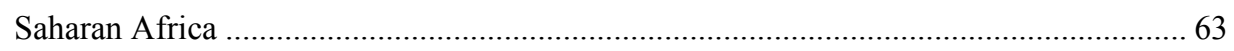

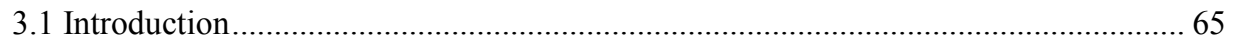

3.2 Characteristics of CLS: Implications for Sustainable Development ........................... 67

3.3 Modeling Semi-Subsistence Crop-Livestock Systems for Policy Analysis ................ 74 
3.3.1 The Tradeoff analysis approach ............................................... 74

3.3.2 Characteristics of CLS and the implications for modelling............ 76

3.3.3 Econometric Model Specification................................................. 81

3.4 Assessing Sustainable Development Pathways for Machakos, Kenya........................ 85

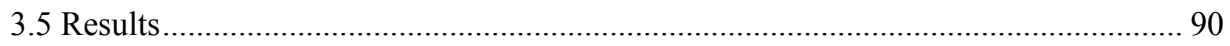

3.6 Moving along a Sustainable Agricultural Development Pathway .............................. 106

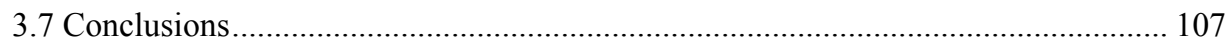

CHAPTER 4 Coupling the Tradeoff Analysis Model with a market equilibrium model to analyze economic and environmental outcomes of agricultural production systems..... 111

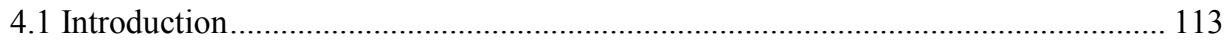

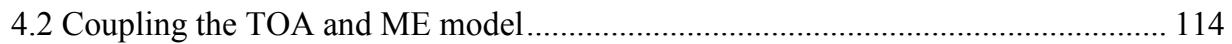

4.2.1 The Tradeoff Analysis model ..................................................... 114

4.2.2 Linking the TOA model to a market model................................. 117

4.2.3 Implementation: The TOA-ME ............................................... 121

4.3 TOA-ME Application for Semi-subsistence Agricultural System .......................... 124

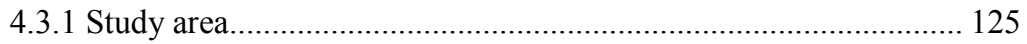

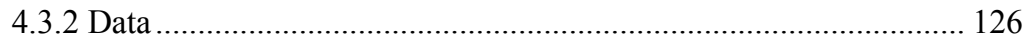

4.3.3 The TOA model application for Machakos and scenarios............ 128

4.3.4 Results ................................................................................ 130

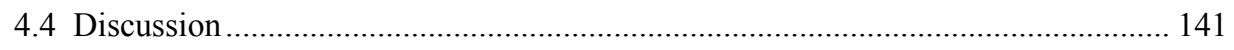

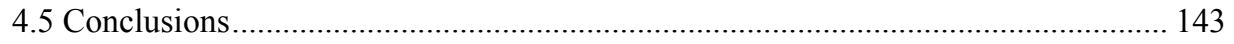

CHAPTER 5 Economic and Environmental Impacts of Climate Change and SocioEconomic Scenarios: A case study on a Semi-Subsistence Agricultural Production System 145

5.1 Introduction. 147

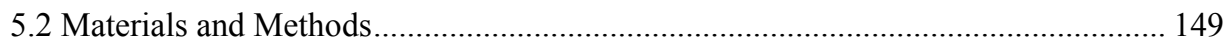

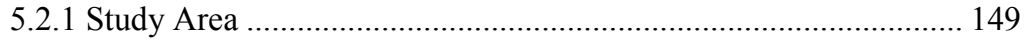

5.2.2 Step 1: Climate Change Projections ............................................. 150

5.2.3 Step 2: Productivity Effects of Climate Change ........................... 152

5.2.4. Step 3: Economic Analysis ...................................................... 153 
5.3 Results and Discussion

5.3.1 Step 1: Changes in Temperature, Precipitation, and Solar Radiation 158

5.3.2 Step 2. Effects of Climate Change on Inherent Productivities 159

5.3.3 Step 3. Effects of Climate Change on Land use, Nutrient Depletion and Poverty 161

5.4 Discussion 164

5.5 Conclusions 166

CHAPTER 6 Synthesis. 169

6.1 Introduction. 171

6.2 Poverty, land degradation and agricultural productivity linkages 174

6.3 Modeling Semi-Subsistence Crop-Livestock Systems to solve the PovertyProductivity-Sustainability Puzzle ..... 177

6.4 Discussion and Possible Extensions 184

6.5 Towards a Sustainable Agricultural Development Pathway for CLS 186

6.6 Highlights 190

References.

Summary. 217

About the Author 223 
CHAPTER 1

Introduction 


\subsection{Introduction}

Sub-Saharan African (SSA) countries face a major challenge of reducing rural poverty. At the same time the countries need to deal with the declining soil fertility that affects the sustainability of agricultural production systems in the region. There have been considerable efforts in terms of research and rural development activities aimed to improve soil fertility, increase productivity and reduce poverty in the region (Pingali 2012; Pingali, Schneider and Zurek 2014). Yet evidence suggests that the SSA region has continued the downward spiral of poverty and soil nutrient depletion and the associated problems of food insecurity, and population pressure. According to the Millennium Development Goals Report 2015 (UN, 2015) about 41\% of the population in SSA still lived below the poverty line of $\$ 1.25 /$ day in 2015 . Although the same report mentions that there has been a slight progress in reducing poverty from $57 \%$ in 1990, still it is far from the Millennium Development Goal (MDG) that set a target of reducing poverty by half by 2015 (UN, 2013).

Most rural households in SSA are dependent on agriculture. Therefore, increasing crop productivity is clearly a key element to improve living standards and to take these people out of poverty. However, agricultural productivity in most of the region has been stagnant or increased slowly (IFPRI, 2013). Muchena et al. (2005) and Herrick and Beh (2015) argue that SSA is the only region of the world where cereal yields have not significantly increased and per-capita food production has declined in the last 25 years. Sanchez et al. (1997) and more recently Bationo, Lamers and Lehman (2015) argue that land degradation and soil fertility depletion are the fundamental biophysical cause for the decline in per-capita food production. In Kenya for example, $65 \%$ of the population lives in rural areas where land degradation, inefficient agricultural practices, rapid population growth, land fragmentation and limited access to markets contribute to the high poverty levels in this region.

But why these conditions persist despite decades of investments in research and development, and numerous policy and technology interventions is one the key questions researchers and policy makers are facing. There is an increasing recognition about the need to have a better understanding of the complex agricultural systems typical of the 
SSA in order to appropriately propose and implement policy and technology interventions. Mixed crop-livestock systems constitute the main production system in SSA and other parts of the world. However, how these complex systems actually work needs to be better understood (Thornton and Herrero, 2001). Appropriate tools and methods to analyze these systems need to be developed or improved and used with suitable data to assess the impacts of policy interventions, technological changes or environmental changes (e.g., climate change).

The key challenge to agricultural sustainability in SSA is to reverse the declining trends of agricultural productivity and the increasing rates of soil nutrient depletion and high levels of poverty. Policy and technological interventions that lead to the "win-win" outcome of reversing the negative trends while increasing agricultural productivity sustainably need to be formulated. The recently proposed post-2015 MDGs, Sustainable Development Goals (SDGs; SDSN, 2013) emphasize the need to achieve sustainable development by 2030 by promoting economic development, environmental sustainability, good governance and social inclusion. Several ongoing efforts are being conducted to curb land degradation, increase productivity in a sustainable way and thus contribute to reduce the poverty rates. Governments and scientists are making efforts to develop policies and technology interventions that will achieve the "win-win" outcome mentioned above and move from the usual "tradeoffs" between poverty-productivity-sustainability to "synergies". Examples of these proposed technologies include "Sustainable Agricultural Intensification” (The Montpellier Panel, 2013; SDSN, 2013, Garnett et al., 2013) and 'Climate-Smart Agriculture” (McCarthy, Lipper and Branca, 2011).

Policy interventions such as the "Strategy for Revitalizing Agriculture 20042014" (SRA), and the "Vision 2030" elaborated by the Government of Kenya (GoK, 2004, 2008, 2013) propose a series of policies and activities to improve household livelihoods. Although Kenya's prospects for economic growth are favorable compared to other countries in the region, poverty alleviation remains a challenge. About half of the population (43 million) live on an income of less than US\$1 per day or are unable to meet their nutritional requirements. Agriculture in Kenya is the most important sector in the economy (about $25 \%$ of the GDP, Atela et al., 2016). More than three quarters of the population lives in rural areas where most of the agriculture is of semi-subsistence 
characterized by complex intercropping, small field size, and high rates of crop failure and lack of an established capital market. Farm households face deteriorating relative price relations between farm outputs and inputs and increased land pressure, which leads to a severe exploitation of soil nutrients (De Jager et al., 1998). Rural poverty is strongly linked to environmental problems: water management, soil erosion, declining soil fertility and land degradation. Soil nutrient depletion is one of the major constraints to a sustainable agriculture. All these conditions plus the change in climate patterns make of this region one of the most vulnerable of the world (IFAD, 2009).

In order to face these issues, the Government of Kenya developed the Kenya Vision 2030, a long-term development blue print designed to guide the country to meet the 2015 MDGs and beyond (GoK, 2007). The Vision 2030 aims to create a "globally competitive and prosperous nation with a high quality of life by 2030 " and is based on three "pillars": economic, social and political. The agricultural sector is recognized as one of the economic actors that can lead to reduce poverty if appropriate policies are in place. For the Vision 2030, the key is to improve smallholder productivity and promote nonfarm opportunities. The goal is to raise agriculture, livestock and fisheries income by adding value and improving productivity through use of improved species (crops and livestock) and better access to inputs, in particular to mineral fertilizer. The Government plans to build a fertilizer plant with the objective of reducing fertilizer prices. In addition, there are plans to utilize a million of hectares of currently uncultivated land, and add 1.2 million of newly opened lands.

The GoK Vision 2030 is currently in the process of being implemented. However, to my knowledge, there are no comprehensive studies that assess the likely economic, social or environmental impacts of the Vision 2030 interventions, in particular on the agricultural sector. Furthermore, little is said about the different development paths that the Kenyan economy can take over the years and how these may affect the proposed interventions. Ndung'u, Thugge and Owino (2011) recognize that a limitation of the Vision 2030 is that it included only one single economic growth and development path without offering options for low or middle growth and development paths.

The main challenge is that, in order to assess the likely impacts of these interventions on complex mixed crop-livestock systems typical of SSA and other 
developing countries, we need suitable data, tools and approaches for ex-ante impact assessment that capture the complex interactions of the systems and at the same time that allow us to incorporate different development paths and exogenous changes (e.g., climate change).

Therefore, in this thesis a modeling approach for integrated assessment of semisubsistence mixed crop-livestock systems that takes into account key features of these complex agricultural production systems and market equilibrium was developed and applied to a case study in Kenya. This study uses the Tradeoff Analysis model (TOA), a spatially explicit integrated assessment model of agricultural production systems. The TOA model links site-specific bio-physical process models and economic decision models, and thus deals explicitly with the intrinsic variability of farms and growing conditions, but treats prices as exogenous. This study will develop methods to link the tradeoff analysis model to a partial equilibrium model in an application for the Machakos Region in Kenya. Machakos has been the center of many studies looking at soil fertility issues and its implications for poverty and food security, including the well-known study by Tiffen et al. (1994). Recently, Machakos County developed a Strategic Development Plan "From Third World to First World in One Generation" (Machakos County, 2010). This document establishes guidelines and policy interventions in line with the GoK Vision 2030. However, it sets the goals to be met and revised by 2017 , and it is heavily based on agricultural policies to increase crop, livestock and fish farming productivity.

The GoK Vision 2030 and the Machakos Strategy Plan are used as the framework to analyze the proposed policy or technological interventions (e.g., reduction of mineral fertilizer price, increased non-farm activities). In order to capture the possible socioeconomic conditions (or development pathways) that could be attained as consequence of these policies and other factors (e.g., climate change), it is necessary to use the concept of scenarios to represent those socio-economic conditions. Future scenarios are simulated using Representative Agricultural Pathways (RAPs; Valdivia et al, 2015). RAPs provide plausible narratives and quantitative information about future economic, social, institutional conditions. Model scenarios consistent with specific development pathways can then be formulated using these RAPs. 


\subsection{Thesis Objectives}

As mentioned above, the GoK Vision 2030 has the main goals of reducing poverty, increasing food security and protecting the environment. The Vision 2030 aims to deal with the loss of soil nutrients, reduced crop productivity and increasing risk of poverty. The question is then, given the challenges mentioned above, could agricultural policy and technology interventions like the ones proposed by the Kenyan government lead to a sustainable path for those mixed crop-livestock agricultural systems typical of SSA? In other words, is sustainable development for semi-subsistence agricultural production systems possible? What is needed to conduct an ex-ante impact assessment of these proposed interventions under current or future environmental and socio-economic conditions?

This study tackles these research questions using an integrated assessment modeling approach applied to the Machakos District in Kenya, a region well known for its complex production system, low input use (e.g., mineral fertilizer), low crop productivity, high rates of crop failure, and high poverty rates.

The goal of the empirical applications will be to test the modeling methods and to assess the impacts of policy and technology interventions and climate change under different socio-economic scenarios. The case of the semi-subsistence agricultural production system of the Machakos region was used to assess how different degrees of implementation of the Vision 2030 could lead to a sustainable development pathway and be used as adaptation strategies to deal with climate change. 
Specific Objectives:

- Review of economic modeling approaches to assess sustainability of agricultural production systems.

- Develop an integrated modeling approach that captures key features of agricultural production systems (mixed crop-livestock) typical of SSA and apply this approach to quantify economic and economic sustainability indicators for policy tradeoff analysis.

- Link this approach to a partial equilibrium model to assess the effects of technology and policy interventions on the spatial distribution of economic and environmental outcomes at market equilibrium.

- Use the integrated modeling approach and partial equilibrium model linked to socio-economic scenarios to assess the impacts of climate change and policy interventions on semi-subsistence agricultural production systems.

The next section describes the study area and its main characteristics. The last section describes the outline of the thesis with a brief description of the other chapters in this thesis.

\subsection{Study Area: Machakos, Kenya}

The Machakos region (including Makueni and Machakos districts) is located in Eastern Province of Kenya, southeast of Nairobi between $0^{\circ} 70^{\prime}$ and $3^{\circ} 00^{\prime}$ southern latitude and between $36^{\circ} 87^{\prime}$ and $38^{\circ} 51^{\prime}$ ' eastern latitude (see Figure 1.1). The study area is approximately $14,000 \mathrm{~km}^{2}$ with an altitude range between 340 and 1710 meters above sea level. The climate is semi-arid with an average annual rainfall that ranges between 500 to $1300 \mathrm{~mm}$. Rainfall patterns are highly variable and distributed in two rainy seasons. The short season occurs from November to January and the long season from March to June. Severe droughts are frequent and usually last two or more seasons hurting crop production and food security (Tiffen et al., 1994). Mean annual temperature ranges from $15^{\circ} \mathrm{C}$ to $25^{\circ} \mathrm{C}$. 


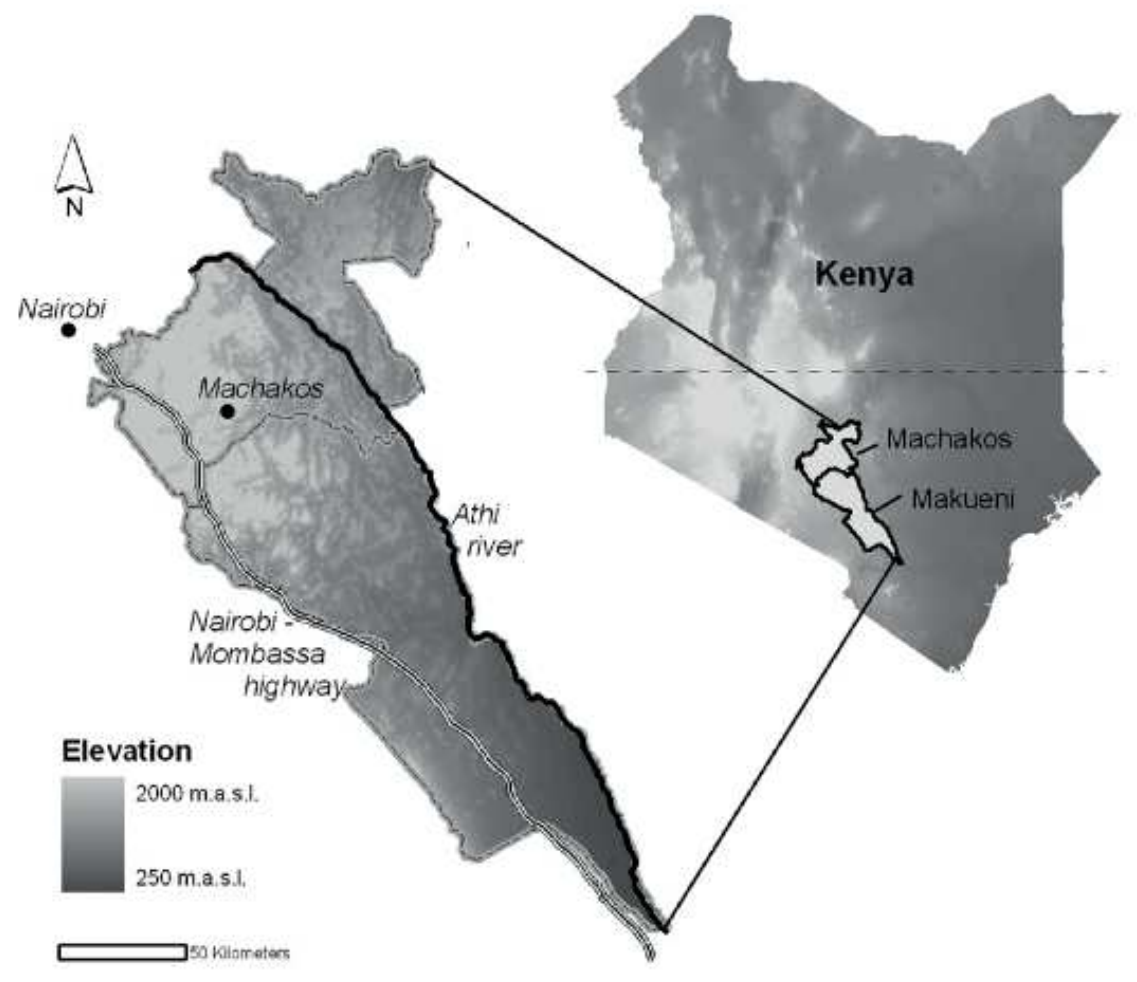

Figure 1.1 Study Area: Machakos Region, Kenya

Agriculture is the most important economic activity in the region; about half of the area in Machakos under agricultural use. Most agriculture is semi-subsistence characterized by complex intercropping, small field size, low yields, high rates of crop failure, and lacking an established capital market. Agricultural production systems include both crop and livestock activities. Maize is grown as the main staple crop but other crops (e.g., beans), vegetables (e.g., tomatoes) and fruit trees (e.g., mangoes) are also cultivated. Livestock, which is mostly managed as zero-grazing with some freegrazing in the lower areas, is also an important activity in the region. Farm households face deteriorating price relations between farm outputs and inputs and increased land pressure which lead to a severe exploitation of soil nutrients (de Jager, et al., 1998). Soil 
nutrient depletion is one of the major constraints to a sustainable agricultural development in the Machakos region. Some studies showed that soil nutrient balances in Machakos are often negative with annual losses of about $55 \mathrm{~kg} \mathrm{~N} / \mathrm{ha} / \mathrm{yr}$, (Nandwa et al., 2000).

Despite several efforts of the government and research programs to increase maize yields, average yields remain far below their potential creating serious food deficits in many regions of Kenya where maize is a primary staple. Donovan and Casey (1998), Sanchez et al. (1997), Bationo, Lamers and Lehman (2015) among others, recognize that in order to reverse the declining trends in per capita food production and negative nutrient balances, soil fertility management on farms must be improved. Increasing crop productivity is clearly a key element to improve living standards and to reduce poverty levels. The GoK Vision 2030's proposed policy and technology interventions aim to deal with soil nutrient losses, reduced crop productivity and increasing risk of poverty. However, to my knowledge, there has not been any comprehensive analysis of the likely impacts of these interventions, in particular for the Machakos region.

In order to assess the impacts and sustainability of policy and technology interventions aimed to reverse the current trends, it is necessary to use or develop methods and tools capable of integrating all the complex relationships of the system and its biophysical and socio-economic conditions. Furthermore, suitable data that could represent the different components and dynamics of the complex crop-livestock systems typical of the Machakos region is needed. Recognizing that the key issues in this region are land degradation, low agricultural productivity and poverty, this thesis focuses on assessing the impacts of policy, technology and environmental changes on environmental, socio-economic and bio-physical outcomes represented by the following indicators: soil nitrogen losses, poverty rate and crop yields. Thus, the data used need to be able to not only characterize the complexity of the production systems but also to enable the quantification of distributional impacts of interventions on the selected key indicators. Data based on one-time recall approaches or data based on representative farms are not suitable for this kind of analysis. Instead, data from monitoring farms 
studies that include detailed information about input-output flows, soil nutrient balances and other farm bio-physical and socio-economic characteristics would be ideal.

Acquiring such data is usually a major challenge due to the time and costs involved in the process. Available data from this kind is scarce and difficult to obtain. In this thesis we used data collected in the Machakos regions by the projects LEINUTS from 1997 to 1999 and NUTSAL from 1999 to 2001, which together cover 6 to 7 growing seasons. Both projects applied the participatory Nutrient Monitoring methodology (NUTMON).

NUTMON is a multi-disciplinary and multi-scale approach to address the problem of soil nutrient depletion (De Jager et al., 1998b). The NUTMON approach includes standardized survey instruments and quantifies soil nutrient balances using a comprehensive accounting of inputs and outputs of the farm and household system, including crops and livestock. The NUTMON data include details such as nutrient contents of manure, crop management details like planting dates, plant density, input use (dates, quantities, prices), livestock management and outputs (crop and livestock yields, by-products, residues, etc.) The data was geo-referenced which allowed the linkage to soil and climate data and maps. This comprehensive accounting of inputs and outputs makes the data well-suited for econometric modeling (Mora-Vallejo et al. 2012).

It is important to highlight that the NUTMON data collected between 1997-2001 may seem to be outdated for this kind of analysis. However, several recent studies show that there have been little changes in the production system and productivity of key crops in the region. According to the Government of Kenya's Agricultural Sector Development Support Programme (ASDSP. 2013), average farm size for smallholders in the Machakos region is about 3.5ha, comparable with the NUTMON data where the average farm size is 3.8ha. Average maize yields estimated from the NUTMON data are about $1950 \mathrm{~kg} / \mathrm{ha}$ (standard deviation=1471). Data from a household panel survey collected from for 1996/1997, 1999/2000, 2003/2004 and 2006/2007 (TEGEMEO Institute of Agricultural Policy and Development, 2009) shows that maize yields have been almost stagnant. The average maize yields reported in this study is about $1265 \mathrm{~kg} /$ ha. However this includes data from households in eight agro-regional zones in Kenya. Using the same panel data and selecting farms with comparable farm size than those in Machakos, the average 
maize yield is about $1835 \mathrm{~kg} /$ ha with a standard deviation of 1760 . A different study by Omoyo, Wakhungu and Oteng'i (2015) reviewed historical maize yields from 1979 to 2009 for the lower eastern Kenyan counties of Machakos, Makueni, Kitui and Mwingi. They estimated the average maize yield for Machakos as $1722 \mathrm{~kg} / \mathrm{ha}$, with a lowest yield of $441 \mathrm{~kg} / \mathrm{ha}$ in 1998 and the highest yield of $4657 \mathrm{~kg} / \mathrm{ha}$ in 1988 . Regarding livestock, the NUTMON data shows that about $39 \%$ of the farms have dairy, while the TEGEMO data shows that in average $41 \%$ of the farms produce dairy. One difference is that the TEGEMEO report indicates that in recent years farmers moved away from local cow breeds and started to adopt improved breeds.

The NUTMON data is a unique database appropriate to demonstrate the use and implementation the integrated assessment framework developed this thesis, but also to provide a realistic assessment of proposed interventions under different scenario settings.

\subsection{Outline of the Thesis}

The next chapter presents a review of modeling approaches and presents the conceptual framework used in this thesis. The subsequent chapters of this thesis present three studies that can also be read independently. The final chapter is a general discussion of key findings of this thesis.

Chapter 3 presents an integrated modeling approach designed to incorporate key features of semi-subsistence crop-livestock production systems. This chapter highlights the need for understanding fundamental features of these complex systems (heterogeneity, subsistence and cash crops and livestock) because they may be the key to design and implement policy and technology interventions that could lead to a sustainable development. The modeling approach was implemented to simulate the impacts of proposed policy and technology interventions described in the GoK Vision 2030 and the Machakos Strategy Plan under different RAPs and assess the conditions under which these interventions could achieve a "win-win" outcome of reducing poverty and increasing productivity sustainably.

In Chapter 4 assesses the importance of linking models across scales by linking the TOA to a partial equilibrium model. In this chapter the procedures to derive a supply 
curve from the tradeoff curves are described. The resulting TOA-ME model is used to assess the impacts of technology and policy interventions (similar to those in chapter 2) on the spatial distribution of economic and environmental outcomes at market equilibrium prices and quantities.

Chapter 5 presents an application of the TOA-ME in the context of climate change. In this chapter the TOA-ME is used to assess the impacts of proposed policy and technology interventions under climate change conditions and different socio-economic scenarios. In this chapter, output from 5 Global Circulation Models (GCMs) and 3 emission scenarios (SRES) were analyzed and used. These outputs were used to simulate crop (maize, beans and vegetables) yields response to climate change using a crop simulation model (DSSAT; Decision Support System for Agrotechnology Transfer, Jones et al., 2003). Finally, the impacts of the interventions under each climate scenario at the market equilibrium price are assessed.

Chapter 6 presents a synthesis of the key findings of this thesis and provides a discussion about possible extensions for further research. 


\section{CHAPTER 2}

\section{Background and Conceptual Framework}




\subsection{Modeling Agricultural Production Systems: Review of Modeling}

There is a growing interest in developing methods and tools to assess the sustainability of agricultural production systems, including their economic, environmental and human health impacts (Ewert et al. 2011, Antle, 2011, Rosenzweig et al. 2013, Antle, Stoorvogel and Valdivia, 2014). A growing body of evidence shows that economic and environmental impacts of agricultural systems depend on farm management decisions and on the interaction of these decisions with site-specific environmental conditions. Furthermore, assessing sustainability of agricultural systems involves different spatial and temporal scales that need to be dealt with.

On the one hand, methods have been developed to integrate biophysical and economic models at a disaggregated level with the objective of capturing the heterogeneity of the physical environment and economic behavior of farmers (see for example, Hochman and Zilberman, 1978; Just and Antle, 1990; Goddard et al., 1996; Fleming and Adams, 1997; Antle et al., 2000; Brown, 2000; Antle and Capalbo, 2001; Antle and Stoorvogel, 2001; Mathur, 2003; Stoorvogel et al., 2004b, van Ittersum, 2008). On the other hand, aggregated models based on the construct of "representative agent" have been widely used in policy decision making. Market equilibrium models are a good example of these models. They have been used to evaluate welfare implications of a particular change (policies, climate change, etc.), using representative data of producer and consumer behaviors.

This implies that aggregated models do not capture the biophysical and economical heterogeneity that characterizes the production system. Conversely, results from regional integrated assessment models that capture this heterogeneity have not been linked to market equilibrium models. Clearly, scale, heterogeneity and aggregation issues have important implications for modeling agricultural production systems. Below is a review of the use of different approaches by regional integrated assessment models, market equilibrium models and then discuss the key issues mentioned above. 


\subsubsection{Integrated Assessment Models}

Regional Integrated assessment models (IAMs) have been used with different approaches. Antle and Capalbo (2001) describe four main types of approaches. First, programming models (e.g., linear or multiple goal linear programming models) can be used to solve for optimal resource allocations subject to constraints. The two major weaknesses of these models are that they do not explicitly capture the interaction between the agents in the model, and they do not fully take into account the spatial dimension of agricultural activities (Berger, 2001. Also see Hajkowicz and Prato, 1998; Zander and Kachele, 1999, and Antle and Capalbo, 2001 and Schreinemachers and Berger, 2011 for other studies). Within this approach it is possible to combine econometric methods with multiple goal linear programming models.

The bio-economic modeling approach is the combination of a farm household model in which a behavioral expenditure component is specified and linked to an iterative mathematical programming simulation model that optimizes the production structure (Kruseman and Bade, 1998; Kruseman, 1999, 2001; Kuyvenhoven et al. 1998). The bio-economic modeling approach has been the basis for several studies that included market analysis (i.e., partial analysis), (Kruseman, 1999; Kruseman, 2001). ${ }^{1}$

Berger (2001) developed another type of linear programming model. In this model, he uses a spatial multi-agent programming model to assess policy options in the diffusion of technology and resource use changes. Berger's model explicitly capture the social and spatial interactions of heterogeneous farm-households by linking an economic sub-model and a bio-physical model to a GIS type data. He concludes that GIS-based integrated multi-agent models will become an important tool for policy analysis and natural resource management (Schreinemachers and Berger, 2011). For a more complete review of studies and household models see van Wijk et al., 2014.

A second group of models is based on estimation of neoclassical production function, cost or profit functions. These models can represent spatial variation on

${ }^{1}$ This approach is called Metamodelling where the bio-economic farm household simulation model results and the relevant exogenous variables are linked in a functional way. The resulting model explains the relationships between inputs and outputs but does not explain the decision making process (Kruseman, 2001). 
economic and bio-physical behavior and may explain the impacts of bio-physical conditions on productivity. However, parameters of the economic models are limited to the spatial and temporal scale of the data used for their estimation, (see Rygnestad et al., 2002, Fingleton and Fischer, 2010; and for more studies see Brown, 2000 and Antle and Capalbo, 2001).

A third approach is the based on reduced-form econometric models specified as functions of both economic and bio-physical variables (see Kauffman and Snell, 1997; Wu et al., 1999, 2003; Ascough II et al., 2001; Schldach and Alcamo, 2003; Lubowski et al. 2005; also see Antle and Capalbo, 2001 and Brown, 2000 for other studies). An advantage of these models is that they embed observed economic behavior of economic agents. A disadvantage is that these models do not embody the process-based information contained in, e.g., biophysical crop and livestock growth models.

Building on this latter approach, Antle et al. (1998) developed a conceptual and empirical framework that integrates bio-physical and economic relationships at a disaggregated level and then statistically aggregates to a level that is relevant for policymakers and that can be used for welfare and policy analysis. This approach follows the logical sequence of how macro-level policy affects farmer's decisions, the impacts of which are seen at the micro-level, and then these impacts are aggregated back to the units in which policymakers need to work. This approach is described in more detail in section 3 below.

\subsubsection{Market equilibrium models}

The previous section describes several models and approaches to assess agricultural production systems. These models represent decision-making by individual farmers and take prices as exogenous. In contrast, partial- and general-equilibrium models treat prices as endogenous. These models are usually based on aggregated data and therefore cannot be linked directly to environmental processes that depend on disaggregated, site-specific data. However, some equilibrium models have linked environmental process models and economic decision models using representative environmental and economic data for agro-ecozones in the United States. 
Partial equilibrium (PE) analyses are generally sector-specific, and are used to examine particular sectors of the economy, taking prices in other sectors as exogenous. As computer science advanced, more complex modeling studies started to appear (e.g., single and multiple commodity models). Partial equilibrium analysis yields results for one or a few markets at a time, and does not account for interactions with other markets. However, there often exist market interactions and thus market feedbacks. Pricing outcomes in one market may have effects in other markets, and these effects create changes throughout the economy, feeding back to the original market (Vargas et al, 1999, van Ittersum, et al., 2008). To represent this complex set of economic relationships, it is necessary to go beyond partial equilibrium analysis and construct a model that permits analysis of many markets simultaneously. Some PE models have been extended to incorporate general equilibrium (GE) elements. A GE model examines the economy as a whole and analyzes the interaction between sectors. In the GE setting it is possible to analyze efficiency and income effects throughout the economy (Schiller, 1997).

Most of the literature on environmental policy modeling that use GE or PE is based on aggregate data (e.g., Perroni and Wigle, 1997). Zhang and Folmer (1998), Britz et al. (2011), van Delden et al. (2011) argue that given the relative strengths and weakness of the bottom-up models (models that use micro-level data such as farm level), and top-down models (e.g., computational general equilibrium models, CGE), it would be worthwhile to link together both types of modelsAntle and Diagana (2003) identified the important role that soil carbon sequestration might have in helping developing countries to deal with soil degradation problems. Their analysis is at farm level but they suggest that PE or GE models would help to assess economic impacts at a regional level.

Kayser, (1999) reviewed several studies on the impacts of climate change on agriculture for several regions of the world. ${ }^{2}$ Most of these studies used GE or PE models; however all were based on aggregated data. Kayser, in his recommendations for future research, suggests that "...an important priority for future research will be to link the more aggregated, macro models with the farm-level, micro models to study climate

${ }^{2}$ Rosenzwig et al. (1993); Tobey at al. (1992); Kettunen et al. (1988); IPCC, (1990); Pittock, (1989); Pittock and Nix, (1986); Walker et al. (1989); Santer, (1985); Smit, (1989); US EPA, (1990); Williams et al. (1988) 
change impacts in a comprehensive way. Such comprehensive studies, while undoubtedly major undertakings, should shed valuable insight on climate change impacts on agricultural prices, supply, demand, farm profits, resource shadow prices and farm management strategies".

There are several market equilibrium models that are widely used in agriculture research. Below is a brief description of some of these models.

GTAP (Global trade Analysis Project, Hertel, 1997) is a multi-region, multisector, computable standard general equilibrium model (there are some applications to partial equilibrium analysis) with perfect competition and returns to scale. ${ }^{3}$ This model has been used for a variety of applications (agricultural analysis, trade, labor markets, etc). Recently the model was updated to include dynamic behavior (GTAP-Dyn). Another addition to the model was a component for energy analysis (GTAP-E). This module has the objective of linking energy, economy, environment and trade (current applications of this version include analysis of carbon sequestration and climate change).

Another model that has been widely used in several studies is the Agricultural Sector Model (ASM). This model is based on the work of Baumes (1978), later modified by McCarl and Spreen (1980), Adams et al. (1986), Chang et al. (1992) and Lambert et al. (1995). The ASM is based on mathematical programming and is designed to simulate the effects of changes in agricultural systems on consumers' and producers' welfare. The model includes production processing, domestic consumption, imports and exports (Schneider, 2000, Chen et al. 2001). The ASM disaggregates the U.S. into 63 geographical production sub-regions, each one with different characteristics (e.g., crop yields). The model includes 33 major crop and livestock commodities and 37 secondary commodities. Three types of land are specified for each region. This model has been linked to a forestry model (FASOM, Adams et al, 1996) and used to study climate change and carbon sequestration (e.g., Schneider, 2000).

The USDA Economic Research Service (ERS) has developed a similar U.S. Agricultural Sector Model (USMP), which is also a spatial and market equilibrium model

${ }^{3}$ GTAP's base model assumes constant returns to scale and perfect competition in all industries, however there are several applications where GTAP was modified to assume increasing returns to scale and imperfect competition (Swaminathan and Hertel, 1996; Francois, 1998). 
based on the General Algebraic Modeling System (GAMS). It has been applied to assess economic, environmental and policy issues in the U.S. This multi-region partial equilibrium model includes more than 5500 cropping systems with 10 major crops, several types of management (e.g., tillage, rotations, fertilizer use, etc), 13 livestock systems, markets for 44 commodities, and links between production and environmental indicators (Lewandrowski et al. 2004; Cooper et al. 2001).

The International Food Policy Research Institute (IFPRI) developed a global food projection model called IMPACT (International Model for Policy Analysis of Agricultural Commodities and Trade). This model currently covers 320 "food producing units" in 159 countries and 154 water basins and 62 agricultural commodities (e.g., cereals, tubers, soybeans, meats, oils, vegetables etc.). IMPACT is a representation of competitive world of agricultural market for crops and livestock. It uses a system of linear and nonlinear equations of demand and supply elasticities to estimate production and demand functions (see Rosegrant et al. 2012 for more details).

Another model developed by IFPRI is the DREAM (Dynamic Research Evaluation for Management), which was designed to evaluate economic impacts of agricultural research and development $(\mathrm{R} \& \mathrm{D})$ for different conditions of policies, technology and adoption. DREAM primarily focuses on the evaluation of new technologies applicable at the farm level. DREAM estimates the impacts of R\&D in yield and production costs at the farm level, but also can be used to assess the broader effects that depend upon bio-physical, social and market factors. One limitation of DREAM is that it uses aggregated data (or representative data) for the analysis (see Wood et al, 2001 for more details).

\subsection{Scale Issues, Heterogeneity and Aggregation Problems}

\subsubsection{Scale Issues}

As more micro-data have become available, more studies in the literature have compared outcomes from aggregated models versus micro models. Wu and Adams (2002) show that aggregate models may predict aggregate variables (e.g., regional land use) better than micro models. Similarly, Park and Garcia (1994) found that the loss of 
predictive accuracy by modeling corn and soybean acreage response at the state level instead of the sub-state was minimal. They also showed that the state-level model provided estimates more consistent with the expected macro variables.

Antle, Capalbo, Paustian and Ali (2005) found that in predicting soil carbon sequestration for a large region, average carbon rates and spatially varying carbon rates produced similar results. However, they also showed that aggregate models fail to predict behavior at disaggregate scales. For example, they found in their analysis of carbon sequestration that averaged carbon rates resulted in large prediction errors in sub-regions, suggesting that the level of aggregation should match the level of the policy analysis.

Consistent with these findings, Shumway and Davis (2001) cite Griliches, (1972): "a seminal idea ... suggests that there are different 'truths' at different levels of aggregation, and that they are connected by both the aggregation rules and properties of the distribution of the micro variables. I think that when we come to know more, we shall find that good monthly and annual models do not really look alike, and that there is rhyme and reason for this difference."

The previous paragraph suggests that models used for policy analysis can be applied at different scales (e.g., state) using data at different scales (e.g., sub-state), and that the selection of the scale in the model design plays an important role. The spatial scale of the models is based on the "resolution" and the "extent" of the model. Resolution refers to the smallest geographic unit of analysis for the model. Extent describes the total geographic area to which the model is applied (Agarwal et al. 2002).

Scale is a widely used term, but has different meanings across disciplines. In geography for instance, scale is defined by the ratio of length of a unit distance on a map and the length of that same unit on the ground. As a result of this, a "large-scale" map usually shows more detail but covers less area. In contrast, a "small-scale" map shows less detail but covers more area ${ }^{4}$. Other disciplines such as economics or other social sciences define a small-scale study as a detailed study covering a small area, and a largescale generally means it covers a large area. Agarwal, et al. 2002 define the terms "fine

\footnotetext{
${ }^{4}$ A "large-scale" map such as a map of a town at 1:10,000 will show more detail than a "smallscale" map such as the map of the USA at 1:12,000,000
} 
scale" and "broad scale". The former term encompasses small extents and a high resolution and the latter refers to large extents and low resolution.

Another aspect of spatial scale in modeling is that interactions between different agents that drive the models generally occur at different scales. For example, most of the environmental and crop process models work at the plot level, but decisions generally take place at different scales (e.g., nutrient management may be done at field scale, but water can be managed effectively only beyond the field and farm scale (Kruseman et al. 1996; Kam et al. 2000; Ewert et al., 2011). On the other hand, policy making typically is interested in larger units (e.g., region, nation), this means that the different components of a model will have to be aggregated or disaggregated so they can communicate (Antle et al. 2000). Scale issues, such as how to scale-up biophysical data to the level at which policy making is developed without losing key characteristics of the data, or how to scale-down results to measure effects on the micro data, need to be resolved (Antle and Wagenet, 1995; Dumanski et al., 1998, Adam et al., 2011; Antle, Stoorvogel and Valdivia, 2014).

\subsubsection{Aggregation and Disaggregation Issues}

In contrast to the emerging literature that recognizes spatial heterogeneity of agricultural systems (Taylor and Adelman, 2003; Holden, 2005, Rosegrant et al., 2008), standard policy analysis generally uses aggregated data and often relies on "representative data" (e.g., one or few representative farms) because micro data of broad coverage frequently are unavailable (Stoker, 1984; Wu and Adams, 2002). Attempts at assessing aggregate policy effects based on analysis of individual firms have been a research topic for several years. Specifically, aggregation of supply functions dates back to the work of Mighell and Black (1951). The method used to estimate supply response to budgeted changes on farms was based on the Marshallian concept of typical firms stratified into homogenous categories within a region (using characteristics such as land quality). Supply functions for "representative" farms in each category were estimated and then aggregated to provide a regional estimate of supply response. This method evolved to what is now known as the representative farm approach (RFA). The RFA has received 
considerable attention and has been widely used for policy analysis. The use of the RFA or aggregate data in general has some methodological problems or disadvantages that have also been studied in the literature (see Sharples, 1969, Kirman, 1992, Antle and Capalbo, 2001) and are summarized below.

The most important implication of the use of the RFA approach is the aggregation bias in economic behavioral relationships. There are several potential sources of bias in this procedure. An obvious problem is the selection of data (i.e., selection of the representative farm that implies representative input-output coefficients, prices, etc.). Another problem may appear because representative farms not necessarily respond to shocks or economic stimuli. Responsive farms are likely to be located on the tails of the distribution rather than in the middle. One of the major challenges in the aggregation studies is to capture the heterogeneity across individuals.

For policy analysis it is crucial in the aggregation to capture the heterogeneity in key economic and bio-physical attributes of the individual decision maker's policy intends to influence (Wossink, 2001). Heterogeneity in time and space is one of the important issues to account for while scaling up agricultural production from a disaggregated level to a level relevant for policy making (Bezlepkina et al., 2006; van Ittersum, 2008). Antle \& Stoorvogel (2001), for example, showed that measures of sustainability based on "representative" data may result in aggregation bias, so that assessments of the productivity and sustainability of the production systems might be inaccurate. In addition, the error associated with using aggregate data for models with non-linear relationships is well recognized (Easterling et al., 1998; Baron et al., 2005; Bussel et al, 2011). Stoker (1993) also concludes that “...approaches that neglect individual heterogeneity, such as pure representative agent modeling, should be abandoned."

\section{a. Micro-Macro structural stability}

Another consequence of bias from the use of "representative data" is related to the structural components of the micro or macro functions. An example is the estimation of market demand and supply functions. In the case of the demand function, it is clear that if consumers are heterogeneous, there will be problems with aggregation (Blackcorby and Shorrocks, 1996). Similarly, in the case of the supply function, the standard procedure, 
based on conventional theory of supply, assumes that firms are homogenous and produce a homogenous product. Yet, these assumptions are often violated. As described above, heterogeneity is a crucial element to be included in the analysis; therefore an alternative way to construct a market-level supply curve is to consider heterogeneous firms producing homogeneous products. Conventionally the market supply curve is defined as the aggregation of the firms' supply curves (or marginal cost curves) that can be estimated using the primal and dual production theory. This process of aggregation might also bring on some problems.

Mundlak, (2001), for example, remarks that empirical findings in the supply analysis literature suggests that estimated elasticities decrease with the level of aggregation, meaning that higher values are obtained for individual products than for the aggregated output. Also, Mundlak asserts that indirect estimation of supply elasticities using the input demand estimation yields higher values than those when supply elasticity is estimated directly. Holmow and Haegeland, 2000, showed that observed heterogeneity in firms' productivity affects aggregate industry productivity. Biorn and Skjerpen, 2002, and Biorn et al. 2003 showed that production functions aggregated by different methods produce aggregation biases in the output volume and instability of the derived input and scale elasticities ${ }^{5}$.

These findings are important in the selection of a method of aggregating from the firm-level to the market level. These micro-macro stability (or aggregationdisaggregation) issues occur because parameters of the macro-function include structural and behavioral micro components, which will differ from the parameters in the micro function (Theil, 1954; Stoker 1993; Blundell and Stoker, 2005; Heckman, 2001). Thus, the difference of the micro and macro parameters will cause and aggregation bias if we use aggregate data to estimate behavioral parameters without correcting for structural components (Stoker, 1986), or conversely, it will create a disaggregation bias if micro parameters are used as if they were macro parameters to estimate aggregate functions (e.g., supply function), (Denton and Mountain, 2004; Halvorsen and Larsen, 2008).

\footnotetext{
${ }^{5}$ Within the production theory in economics, one key feature of production functions is the scale properties which in turn are characterized by the value of the scale elasticity. This term refers to the concept of economies of scales rather than the concept of spatial scales.
} 


\section{b. Macro-Micro linkages: distributional effects}

Another important implication about the use of the RFA approach is that aggregated data cannot represent distributional impacts of agricultural systems in either economic or environmental terms (Brown, 2000; Antle et al. 2004). In fact, the use of aggregated data in a heterogeneous population may result in biased estimation of behavioral relationships and in estimates of economic and environmental impacts. For example, the studies of economic, environmental and health impacts of pesticides in Andean production systems by Crissman, Antle and Capalbo (1998), and subsequent work by Antle and Stoorvogel (2006), showed that heterogeneity in both bio-physical conditions and economic behavior of farmers was essential to understanding impacts of pesticides on that system.

In a similar vein, Shepherd and Soule (1998) assert that there is heterogeneity among economic conditions and environmental impacts for households with different initial resource endowments and hence policies need to address heterogeneous characteristics to ensure their efficacy. Brown, (2000) complements this idea saying that "...the efficacy of different interventions in terms of environmental or economic indicators may depend on who is directly affected". In a recent study about fertilizer yield response in Kenya, Marenya and Barret (2009) arrive to a similar conclusion and argue that fertilizer interventions may not have the expected effect (i.e., increase yields) if poor households cultivate in soils highly deficient in soil organic matter. They argue that while on average fertilizer use is profitable, it might be adverse for farms with low soil organic matter.

The many attempts to encourage soil conservation investments through subsidy policies provide a good illustration of the limitations of policy analysis based on simple representative data. Many studies of conservation investments based on simple costbenefit analysis using representative data suggest that various conservation investments should be profitable, yet farmers often fail to adopt these practices, or fail to maintain them after subsidies are removed. For example, a subsidy policy was implemented in the northern Andes of Peru to encourage farmers to construct terraces to prevent soil erosion. Although this program lasted several years, the technology was not widely adopted. 
Valdivia (2002) and Antle et al. (2005) showed that rates of adoption of conservation investments depend on complex interactions among site-specific biophysical and economic conditions and that this information cannot be captured in aggregated data based on a "representative farm".

Similar conclusions can be drawn about studies of climate change impacts, and in particular, analysis of vulnerability and adaptation to climate change. Crop models have been developed to predict yields for the scale of homogenous plots and tested using experimental trials; however they are being used to analyze climate variability which usually occurs at broader spatial scales. Hansen and Jones (2000) conclude that aggregating results from these models may over-estimate observed yields. This aggregation bias is the result from imperfect integration of heterogeneous inputs and from spatial and temporal variability that the crop models cannot capture in an efficient way.

Similarly, Antle and Stoorvogel (2001) found in their analysis that the use of representative soil quality characteristics will be biased thus the assessment of the system's productivity and sustainability may be inaccurate. Therefore, to accurately assess the sustainability of the system, the interactions between farmers' land use decisions and soil quality must be measured on a site-specific basis. The aggregated relationships show that the on-farm productivity and potential productivity are functions of the distribution of economic and physical characteristics of the population. The above examples show that biophysical data collection and their analysis are usually conducted at finer scales, but policy questions deal with a broader resolution, therefore integration of both requires appropriately integrated data and models.

The aggregation problem is an inevitable aspect of applied research in economics, thus several approaches that try to deal with this problem have been developed (Pesaran, 2003). They can be generalized in two groups: the "deterministic" approach analyzed first by Gorman (1953), Klein (1953) and then by Malinvaud (1970) and Muellbauer (1975); and the "statistical" (or stochastic) approach explored by Houthakker (1955, 1956) and Johanson (1972). The statistical approach was later extended and applied by Kelejian (1980), Stoker (1984), Lippi (1988), Forni and Lippi (1997) among others.

The statistical approach is less restrictive than the deterministic approach which requires the aggregate function to match exactly the sum of the micro functions for all 
realizations of the disaggregate variables. Furthermore, the statistical or stochastic approach induces relationships between the population aggregates from the joint probability distribution of the micro variables and parameters of the micro equations (Pesaran, 2003). The next section presents a framework for aggregation of heterogeneous firms.

\subsection{Theoretical background}

\subsubsection{Basic micro-economic model}

Understanding the behavior of farmers is the key element to understand agricultural prices and markets, the effects of agricultural and environmental policies, and the effects and benefits of new technologies (Just, 1992). Farmers' decisions about how to manage their land are generally driven by the goal of improving their well-being. Each managed land unit embodies a set of natural (e.g., soil quality, slope, climate, etc.) and socio-economic characteristics (transportation costs, property rights, etc.) ${ }^{6}$. Farmers combine this information in order to make short-run and long-run decisions. In the shortrun farmers make production decisions regarding outputs and variable inputs, given the technology available at that time and the existing stocks of capital and other resources. Long-run decisions on the other hand, include land use decisions (e.g., crop shares, total farm land put into production) and decisions on capital use (Antle et al. 1992). Several studies have analyzed how agricultural policy may impact farmers' production decisions, in both the short and the long run, and how those decisions may in turn affect the environment (Just and Antle, 1990).

Just (1993) depicts the agricultural production problems assuming they are characterized by i) production relationships, ii) constraints (resources availability, shortrun capital, other restrictions), iii) accounting relationships, iv) behavioral criteria of producers, and v) characteristics criteria of the producer. Then the basic microeconomic model underlying agricultural production analysis, supply and demand estimation,

\footnotetext{
${ }^{6}$ Additionally farmers have different types of capital (e.g., physical, financial, human and social) that are also taken into account when making decisions, (FAO, 2007).
} 
agricultural policy and trade and other related topics can be defined by representing the production function as:

$$
q=f(X, Y, \mathbf{z})
$$

Where $\mathrm{q}$ is a vector of outputs corresponding to $j$ activities, assuming that the number of outputs is the same as the number of activities. X represents variable inputs $i$ allocated to $j$ production activities, Y represents a matrix of allocations of $k$ fixed inputs to $j$ production activities, and $\mathbf{z}$ is a vector of non-allocatable fixed factors and producer characteristics.

The short-run constraints of fixed inputs and resource availability (e.g., production credit, etc) can be represented by:

$$
\mathrm{Y} s=y
$$

Where $y$ is a k vector of farm level allocatable resources and fixed inputs and $s$ is a j-vector for ones. The accounting relationships constraints in the short run for variable inputs can be represented similarly by:

$$
\mathrm{X} s=x
$$

Where $x$ is an i-vector of farm-level purchased input quantities ${ }^{7}$.

The behavioral criteria can be described by $U(p, q, w, x, \mathrm{X}, y, \mathrm{Y}, z)$ where $\mathrm{p}$ is a vector of output prices associated with $\mathrm{q}$ and $w$ is a vector of variable input prices associated with y. These behavioral criteria imply input decision and allocation equations at the micro-level:

$$
\begin{aligned}
& Y^{*}=Y^{*}(p, w, y, z) \\
& X=X(p, w, y, z)
\end{aligned}
$$

Where $\mathrm{Y}^{*}$ is an $[(\mathrm{j}-1) \mathrm{x}$ ] matrix consisting of the first $\mathrm{j}-1$ columns of $\mathrm{Y}$. Then substituting (2) (4) and (5) into (1) we obtain the supply equations for activity:

$$
q=q(p, w, y, z)
$$

${ }^{7}$ For the case of fixed inputs and resource availability the short run constraint specifies that the sum of all fixed inputs (e.g., land) or resources available allocated to all production activities cannot exceed the total available. Similarly, for the variable inputs short-run constraints, farm level purchases of variable inputs must equal the sum allocated to all production activities. 
And then substituting (5) into (3) we obtain the variable input demands:

$$
x=x(p, w, y, z)
$$

Using this basic microeconomic model, several approaches have been developed and used to analyze supply response. Coleman (1983) and later Alston et al. (1995) considered three approaches to estimate supply response: a) primal (two- stage) models, b) dual (two-stage) models, and c) directed single-equation supply models.

All these approaches, which are shown in figure 2.1, were described under the neoclassical theory of the firm (Coleman, 1983). In figure 2.1, route 1 estimates the production function where some behavioral assumptions are imposed in order to infer the implied supply function. Route 2 on the other hand, estimates a cost function and the corresponding input demand functions and uses the derivative properties to estimate the supply functions. Route 3 estimates the supply function directly by reducing the behavioral assumptions, but as a result the estimates may not be consistent with some behavioral assumptions. The use of flexible functional forms such as the constantelasticity of substitution (C.E.S) and the use of transcendental logarithmic have augmented the use of route 1 . Supply functions derived from profit functions follow route 2 and have been also widely used. The application of the duality principle allows estimating a supply response function following route 3 .

Just (1993) classifies the models used in the literature to estimate and analyze supply response as: a) programming models, b) myopic econometric analysis, c) directed econometric analysis, and d) indirect econometric analysis (duality theory) ${ }^{8}$.

\footnotetext{
${ }^{8}$ For a detailed survey and description of these models, see Just (1993).
} 


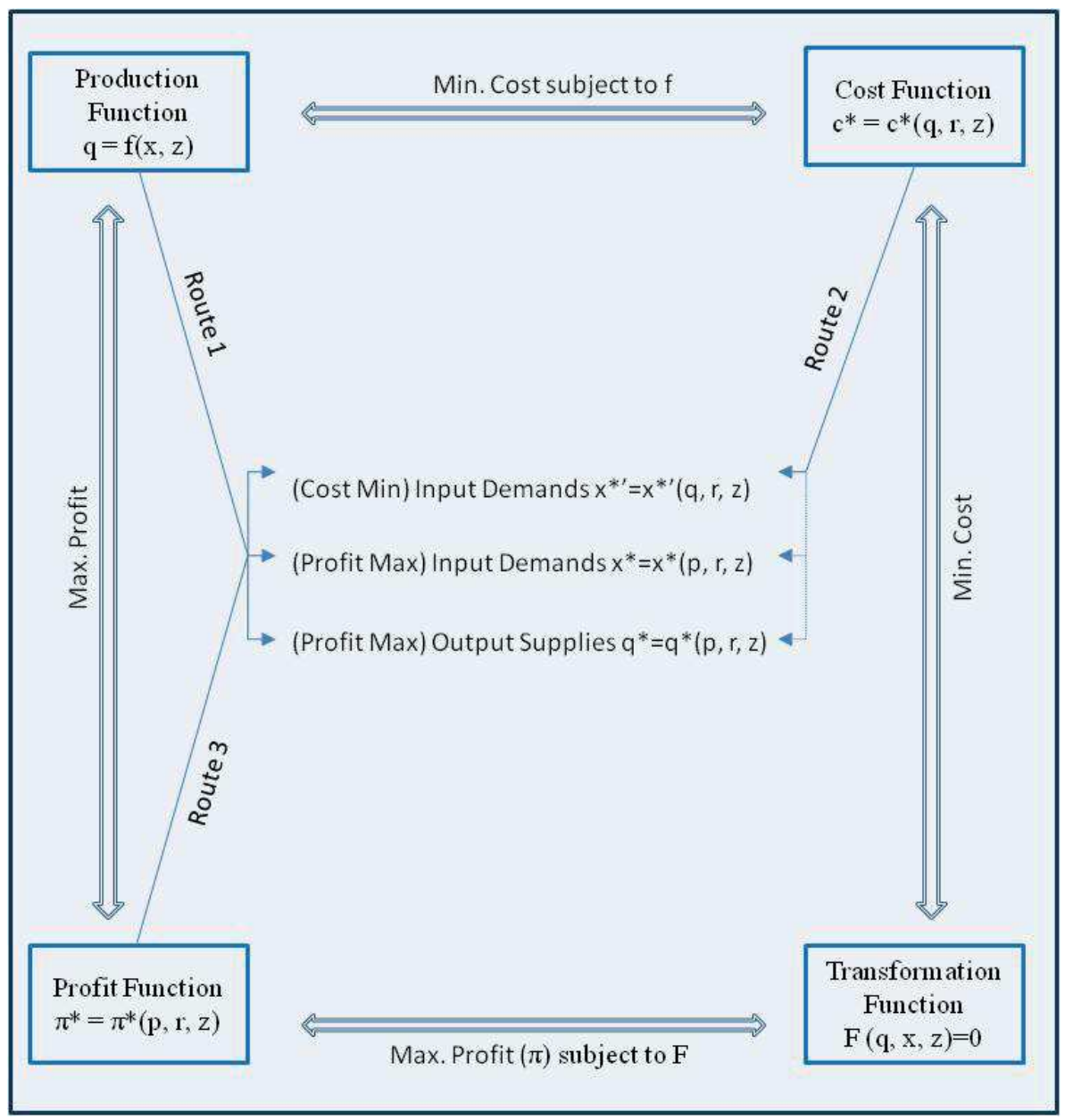

Figure 2.1 Relationships between supply functions and other functions in the theory of competitive firm. Source Coleman, 1983. (Where $\Longleftrightarrow$ means a dual relationship; $q=$ vector of outputs; $x=$ vector of inputs; $p=$ vector of output prices; $r=$ vector of input prices, $z=$ vector of fixed input quantities, $\pi=$ profit, $c=$ cost, and ${ }^{*}=$ profit maximizing or cost minimizing level)

In the case of programming models (mathematical programming approaches, linear programming) the RFA was by far the most popular research approach used for both the firm and aggregate supply response analysis in the 1960s. The RFA approach 
provided the missing link between micro-level and the aggregate level. According to Sharples (1969) the broad objectives of this approach was 1) determine individual farm adjustments so they can maximize profits, 2) assess the aggregate effect from the individual adjustments and 3) determine further adjustments needed at the farm level to reflect changing supply-demand conditions. The RFA's components outlined by Sharples were i) stratification of farms within a region into homogenous groups, ii) define a representative farm for each stratum, iii) derive supply functions for each farm, iv) aggregate the supply functions and v) remove the model's simplifying assumptions. Sharples (1969) and Kirman (1992) argue that the RFA model poses some important problems which are grouped as: a) interdependence or externalities, b) change in farm size, c) unrealistic firm-level assumptions, d) the selection of representative farms, and e) mechanical problems. In addition, one major problem of the RFA as discussed in section 2 above, is that it limits their usefulness for explaining spatial variation behavior. Additionally, the data and parameters used in programming models are usually not derived from statistically representative samples of the population.

The other group of models called "myopic econometric models" (Just 1993) or "partial approach" (Coleman, 1983) refers to those models that attempted to estimate single-equation production functions (often characterized by Cobb-Douglas technology) or in the context of market analysis, a single-equation supply function (often characterized by the Nerlovian supply model). Some of the major problems with this type of models rely on the fact that these models are usually estimated with an incomplete view of the decision model ignoring important interactions. Estimating equations individually, theoretical inconsistencies result in the estimated relationships which in turn result on the lack of econometric identification and efficiency. Generally, these models also represent a gross simplification of reality and as a consequence, estimated parameters seem to be unstable over time, which creates a problem for policy analysis.

A "structured directed econometric model" attempts to estimate all observable relationships simultaneously in a consistent framework. Just, Zilberman and Hochman (1983) developed this approach for the case of multiple outputs and constraints across production activities. Three major problems with these models are: first, data for all necessary endogenous variables are often not available. A second problem arises from the 
need to solve and estimate a system of first-order conditions, and then only production functions and behavioral criteria with simple specifications are tractable. A third problem is that errors in specification of the model can adversely affect estimates for other components of the model due to the cross-equation parameter constraints necessary for theoretical consistency (Just, 1993).

The duality approach ("indirect econometric models") has gained increasing interest since Sheppard (1953) and McFadden (1978) recognized that econometric simplifications could be possible due to the existence of duality between production and profit (e.g., Antle, 1984) or cost functions (e.g., Binswanger, 1974). One clear advantage of this approach is that it provides a consistent interpretation of agricultural data and more efficient estimation of agricultural supply because it facilitates consistent specifications for supplies and demands. Other advantages depicted by Alston et al. (1995) are the use of factor prices rather than quantities as explanatory variables which helps to avoid simultaneity problems when input choices are jointly endogenous with output. In addition, the dual representations and their derivative properties allow for the estimation of a system of equations that include the cost function and the system of output-constrained factor demand equations.

\subsubsection{Aggregation of heterogeneous firms}

Recognition of the problem of aggregation when firms' characteristics are heterogeneous has led to efforts to develop models that deal with it. Johansen (1972) showed that reliable aggregation is possible, at least in the short-run. He derived a shortrun aggregated function (called a macro function) based on the distribution of the production units with respect to technological characteristics. This model, called a microparameter $\operatorname{model}^{9}$, was first studied by Houthakker (1955), Johansen (1959) and Solow (1962). The basic assumption underlying the microparameter model is that producers have a choice of several production techniques before an investment takes place, but once a particular technique has been chosen, it cannot be changed. Therefore, it exhibits ex-ante smooth substitutability and ex-post rigid complementarity. This

\footnotetext{
${ }^{9}$ In some studies this model is called "putty-clay" model (e.g., Green and Sunding, 2000)
} 
characteristic implies that all short-run response to changes in relative prices occur at the extensive margin (Green and Sunding, 2000). An important element of this model is that microunits are assumed to vary continuously according to some probability density that captures heterogeneity in variables such as location.

Hochman and Zilberman (1978) used this approach to examine environmental policies based on production and pollution microparameter distributions. The main point regarding aggregation is that disaggregated units can be statistically aggregated to a macro level. Other applications of the micro parameter model were developed by Just and Antle (1990), Bacock et al. (1997) and Green and Sunding (2000), among others. Just and Antle (1990) demonstrated that environmental heterogeneity conditions determine agricultural production and environmental impacts. They also showed that, with statistically reliable field-specific production and environmental data, it would be possible to measure the key parameters needed to assess aggregate relationships between agricultural and environmental policies and the environment.

Wossink et al. (2001) states that scaling up agricultural production from a disaggregated level should account for i) heterogeneity in time and space, ii) existence of bio-physical and economic feedback loops; and iii) the non-linearity of many functional relationships. Many studies in the literature that ignore heterogeneity assume that individuals are identical and that the associated micro relations are homogeneous, therefore aggregation is not a problem. However, this is not the case in practice. Pesaran (2003) argues that sources of heterogeneity may include: a) input variables (heterogeneous initial endowments), b) micro parameters (heterogeneous coefficients), and c) micro functional (heterogeneous preferences and/or production functions).

Aggregation over individuals when there is some form of heterogeneity can't be done using the traditional approach. Pesaram (2003) summarizes a general framework of the two aggregation approaches (deterministic and statistical) that deal with heterogeneity.

Let's define the behavioral relationship at the micro level:

$$
\mathbf{y}_{i t}=\mathbf{f}_{i}\left(\mathbf{x}_{i t}, \mathbf{u}_{i t}, \boldsymbol{\varphi}_{i}\right) \quad i=1,2, \ldots, \mathrm{N} ; \quad t=1,2, \ldots, \mathrm{T}
$$

Where $\mathbf{y}_{i t}$ is a vector of decision variables, $\mathbf{x}_{i t}$ is a vector of observable variables, $\mathbf{u}_{i t}$ is a vector of unobservable variables, and $\boldsymbol{\varphi}_{i}$ is a vector of unknown parameters. When 
the source of heterogeneity is different inputs (or endowments) across individuals then (8) becomes:

$$
\mathbf{y}_{i t}=\mathbf{f}_{i}\left(\mathbf{x}_{i t}, \mathbf{u}_{i t}, \boldsymbol{\varphi}\right) \quad i=1,2, \ldots, \mathrm{N} ; \quad t=1,2, \ldots, \mathrm{T}
$$

For this type of heterogeneity, aggregation is not a problem when micro-relations are linear (e.g., Cobb Douglas production functions). When input variables and parameters differ across individuals then we have:

$$
\mathbf{y}_{i t}=\mathbf{f}\left(\mathbf{x}_{i t}, \mathbf{u}_{i t}, \boldsymbol{\varphi}_{i}\right) \quad i=1,2, \ldots, \mathrm{N} ; \quad t=1,2, \ldots, \mathrm{T}
$$

For this type of heterogeneity the aggregation process is not simple, especially when some or all of the parameters have non-linear relationships (Hansen and Jones, 2000).

The deterministic approach treats all input variables and parameters as given and seeks an aggregate function which is identical to the function that results from the aggregation of the micro relations (see Gorman (1953), Theil (1954) and Blundell and Stocker (2007)). Let $\mathbf{Y}_{t}=N^{-1} \sum_{i=1}^{N} \mathbf{y}_{i t}$. Then aggregating (8) under $\mathbf{f}_{i}(\cdot)=\mathbf{f}(\cdot)$ across all $i$ with $\mathbf{x}_{i t}, \mathbf{u}_{i t}$ and $\boldsymbol{\varphi}_{i}$ as given, we have:

$$
\mathbf{Y}_{t}=N^{-1} \sum_{i=1}^{N} \mathbf{f}\left(\mathbf{x}_{i t}, \mathbf{u}_{i t}, \boldsymbol{\varphi}_{i}\right)
$$

Then, there is an aggregation problem if:

$$
\mathbf{F}\left(\mathbf{X}_{t}, \mathbf{U}_{t}, \boldsymbol{\varphi}_{a}\right) \neq N^{-1} \sum_{i=1}^{N} \mathbf{f}\left(\mathbf{x}_{i t}, \mathbf{u}_{i t}, \boldsymbol{\varphi}_{i}\right)
$$

Where:

$$
\begin{aligned}
& \mathbf{X}_{t}=N^{-1} \sum_{i=1}^{N} \mathbf{x}_{i t} \\
& \mathbf{U}_{t}=N^{-1} \sum_{i=1}^{N} \mathbf{u}_{i t}
\end{aligned}
$$

$\boldsymbol{\varphi}_{\mathrm{a}}$ is the vector of parameters of the aggregate function. On the other hand, perfect aggregation exists if:

$$
\left\|\mathbf{F}\left(\mathbf{X}_{t}, \mathbf{U}_{t}, \boldsymbol{\varphi}_{a}\right)-N^{-1} \sum_{i=1}^{N} \mathbf{f}\left(\mathbf{x}_{i t}, \mathbf{u}_{i t}, \boldsymbol{\varphi}_{i}\right)\right\|=0
$$

This condition is rarely met in economic analysis and specifically, (13) is not satisfied when $\mathbf{f}(\cdot)$ is a non linear function of $\mathbf{x}_{i t}$ and $\mathbf{u}_{i t}$, even when $\boldsymbol{\varphi}_{i}$ is identical across individuals (Pesaran, 2003; Hansen and Jones, 2000; Antle and Stoorvogel, 2001). 
An alternative and less restrictive approach such as the statistical (or stochastic) requires that equation (13) holds 'on average'. Kelejian (1980) suggested an approach that was later rigorously formalized by Stoker (1984).

Let $\boldsymbol{\mu}_{\mathbf{y}}(t)$ and $\boldsymbol{\mu}_{\mathbf{x}}(t)$ be the means of $\mathbf{y}_{i t}$ and $\mathbf{x}_{i t}$ across individuals at a point in time and define an aggregate relation as one that links $\boldsymbol{\mu}_{\mathbf{y}}(t)$ to $\boldsymbol{\mu}_{\mathbf{x}}(t)$ at a point in time $t$. In this approach $\mathbf{x}_{i t}, \mathbf{u}_{i t}$ and $\boldsymbol{\varphi}_{i}$ across individuals are treated as stochastic with a joint probability distribution function $P\left(\mathbf{x}_{i t}, \mathbf{u}_{i t}\right.$ and $\left.\boldsymbol{\varphi}_{i} ; i=1,2, \ldots \mathrm{N}, \theta_{\mathrm{t}}\right)$ where the parameter vector $\theta_{\mathrm{t}}$ could vary over time but not over individuals. Then, integrating out the individual effects we have:

$$
\begin{aligned}
& \boldsymbol{\mu}_{\mathbf{y}}(t)=\boldsymbol{\Psi}_{\mathbf{y}}\left(\theta_{t}\right)=\int \mathbf{f}\left(\mathbf{x}_{t}, \mathbf{u}_{t}, \boldsymbol{\varphi}\right) P\left(\mathbf{x}_{t}, \mathbf{u}_{t}, \boldsymbol{\varphi} ; \theta_{t}\right) d \mathbf{x}_{t} d \mathbf{u}_{t} d \boldsymbol{\varphi}, \\
& \boldsymbol{\mu}_{\mathbf{x}}(t)=\boldsymbol{\Psi}_{\mathbf{x}}\left(\theta_{t}\right)=\int \mathbf{x}_{t} P\left(\mathbf{x}_{t}, \mathbf{u}_{t}, \boldsymbol{\varphi} ; \theta_{t}\right) d \mathbf{x}_{t} d \mathbf{u}_{t} d \boldsymbol{\varphi}
\end{aligned}
$$

Where $\mathbf{x}_{t}=\left(\mathbf{x}_{1 t}, \mathbf{x}^{\prime}{ }_{2 t} \ldots . \mathbf{x}^{\prime}{ }_{N t}\right) ; \quad \mathbf{u}_{t}=\left(\mathbf{u}^{\prime}{ }_{l}, \mathbf{u}^{\prime}{ }_{2} \ldots, \mathbf{u}^{\prime}{ }_{N}\right)$ and $\boldsymbol{\varphi}=\left(\boldsymbol{\varphi}^{\prime}{ }_{1}, \boldsymbol{\varphi}^{\prime}{ }_{2} \ldots \boldsymbol{\varphi}^{\prime}{ }_{N}\right)$. Now, let $\theta_{t}=\left(\theta_{1 t}, \theta_{2 t}\right)$ where $\theta_{2 t}$ has the same dimension as $\mathbf{x}_{i t}$ for all $i$, and suppose that for a given $\theta_{l t}$ there is a one to one relationship between $\theta_{2 t}$ and $\boldsymbol{\mu}_{\mathbf{x}}(t)$, then:

$$
\theta_{2 t}=\boldsymbol{\psi}_{\mathbf{x}}^{-1}\left[\theta_{1 t}, \boldsymbol{\mu}_{\mathbf{x}}(t)\right]
$$

and

$$
\boldsymbol{\mu}_{\mathbf{y}}(t)=\boldsymbol{\Psi}_{\mathbf{y}}^{-1}\left[\theta_{1 t}, \boldsymbol{\Psi}_{\mathbf{x}}^{-1}\left[\theta_{1 t}, \boldsymbol{\mu}_{\mathbf{x}}(t)\right]=\mathbf{F}\left[\boldsymbol{\mu}_{\mathbf{x}}(t), \theta_{1 t}\right]\right.
$$

The relationship between $\boldsymbol{\mu}_{\mathbf{y}}(t)$ and $\boldsymbol{\mu}_{\mathbf{x}}(t)$ is then defined as the exact aggregate equation. This type of aggregation may lead to a better consideration of distributional issues and heterogeneity in aggregate specifications and may allow the use of more disaggregated data.

\subsubsection{Econometric process model}

The econometric-process approach (EPM) developed by Antle and Capalbo (2001) represents economic decisions on a site-specific basis, at spatial and temporal scales compatible with bio-physical crop simulation models and environmental process models so that they are coupled to economic models. In the EPM farmers make discrete land use decisions for each managed land and given these decisions they make 
continuous input decisions for variable input use. Antle and Capalbo describe the production process at field $i$ for crop $j$ in period $t$ in terms of the production function:

$$
\mathrm{q}_{i j t}=f\left(\mathbf{v}_{i j t}, \mathbf{z}_{i j t}, \mathbf{e}_{i t}\right)
$$

where:

$\mathbf{v}$ is a vector of variable inputs,

$\mathbf{z}$ is a vector of allocable quasi-fixed factors of production and other fixed effects;

e is a vector of environmental characteristics of the field (e.g., soil quality, climate, etc).

Then, the expected profit function corresponding to this production function is defined as:

$$
\pi_{i j t}=\pi_{j}\left(\mathrm{p}_{i j t}, \mathbf{w}_{i j t}, \mathbf{z}_{i j t}, \mathbf{e}_{i t}\right) \text { where } \mathrm{p}_{i j t} \text { is the expected output price. }
$$

Define $\delta_{i j t}=1$ if the $j^{\text {th }}$ crop is grown at field $i$ at time $t$ and $\delta_{i j t}=0$ otherwise. In the event that the land is not in crop production then it is in a conserving or other productive use that earns a return $\pi_{i c t}$, where $c$ indicates this conserving use. Letting $\delta_{i c t}=1-\Sigma_{j} \delta_{i j t}$ we can define the land use decision is defined as solving:

$$
\begin{gathered}
\max \quad \Sigma_{j} \delta_{i j t} \pi_{j}\left(\mathrm{p}_{i j t}, \mathbf{w}_{i j t}, \mathbf{z}_{i j t}, \mathbf{e}_{i t}\right)+\delta_{i c t} \pi_{i c t} \\
\left(\begin{array}{l}
\delta_{i l t, . .} \delta_{i n t} \\
)
\end{array}\right)
\end{gathered}
$$

The solution takes the form of a discrete step function:

$$
\delta_{i j t}^{*}=\delta_{j}\left(\mathbf{p}_{i t}, \mathbf{w}_{i t}, \mathbf{z}_{i t}, \mathbf{e}_{i t}, \pi_{i c t}\right) \text {, }
$$

where $\mathbf{p}_{i t}$ is a vector for the $\mathrm{p}_{i j t}$ and likewise for the other vectors. The quantity of planned production on the $i^{\text {th }}$ field and the variable input demands are calculated using Hotelling's lemma:

$$
\begin{gathered}
\mathrm{q}_{i j t}^{*}=\delta_{i j t}^{*} \partial \pi_{j}\left(p_{i j t}, \mathbf{w}_{i j t}, \mathbf{z}_{i j t}, \mathbf{e}_{i t}\right) / \partial p_{i j t}=q_{i j t}\left(\mathbf{p}_{i t}, \mathbf{w}_{i t}, \mathbf{z}_{i t}, \mathbf{e}_{i t}, \pi_{i c t}\right) \\
\mathbf{v}_{i j t}^{*}=-\delta_{i j t}^{*} \partial \pi_{j}\left(p_{i j t}, \mathbf{w}_{i j t}, \mathbf{z}_{i j t}, \mathbf{e}_{i t}\right) / \partial w_{i j t}=v_{i j t}\left(\mathbf{p}_{i t}, \mathbf{w}_{i t}, \mathbf{z}_{i t}, \mathbf{e}_{i t}, \pi_{i c t}\right)
\end{gathered}
$$

Antle and Capalbo (2002) state that the solution to (21) applies to a given field and is based on the assumption that each field can be managed separately. This model conveniently simplifies the linkages between economic and bio-physical processes.

However some factors may cause the management of fields to be inter-related, especially where production and consumption decisions are non-separable. Also, 
interdependence of management decisions across fields can be caused by risk. A stochastic term can be added to the production functions assuming that these stochastic terms are jointly distributed across fields. If farmers are risk averse and choose production activities to maximize their expected utility, it can be shown that production decisions may be inter-related across fields. According to Antle and Capalbo (2002), despite this interrelationship fields can be modeled as being managed independently by risk-neutral farmers, provided that these farmers participate in input and output markets, and provided that they have access to rental markets for land and capital inputs. When these conditions do not hold, more complex models may be needed. Antle and capalbo (2002) argued that "..a strong test of the value of risk is the ability to improve predictive power of empirical models". They tested a spatially explicit dynamic model with the assumption of risk neutrality. Their results showed that adding a risk aversion component did not increase the predictive power of the model.

\subsection{Conceptual Framework}

In this study we use the regional integrated assessment model developed by Antle et al (1998), and which conceptual framework (from now on called Tradeoff Analysis TOA) is described below. The advantage of using TOA is that it integrates bio-physical processes and economic decision making of farmers on a site-specific basis and thus accounts for spatial heterogeneity. Results can be statistically aggregated to a level that is relevant for policymakers and used for welfare and policy analysis and linked to market equilibrium models.

As shown in Figure 2.2, existing policies and market conditions (prices), technologies, and farmer and farm characteristics affect farmers' management decisions regarding input and land use. Physical relationships between the environmental attributes of land and management practices jointly determine the agricultural, environmental and health outcomes associated with a particular unit of land in production. Antle et al. also demonstrated that each unit of land in production has management and environmental characteristics that are functions of prices, policies, technology and other farm-specific variables. The probability distributions of these characteristics generate a joint distribution of management practices, environmental characteristics and health outcomes 
for each unit of land in production. This joint probability distribution provides a statistically valid representation of the outputs, inputs, environmental and health impacts for the population. With this joint distribution the analyst can construct statistically representative indicators of impact (e.g., average impacts as well as measures of risk and vulnerability).

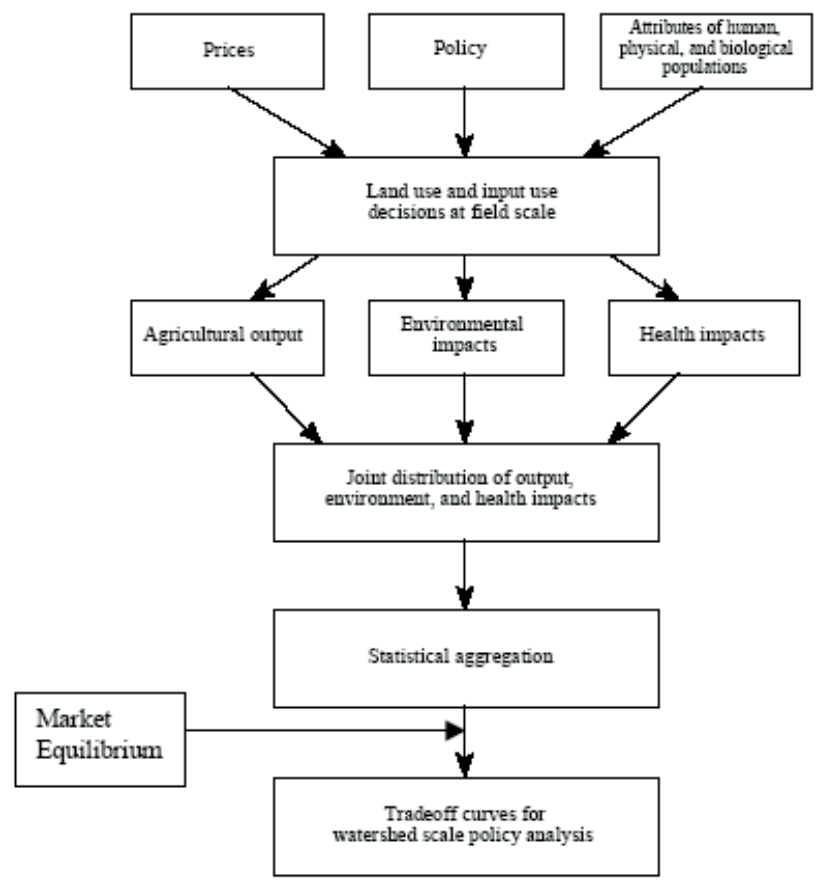

Figure 2.2 Conceptual Framework for Disciplinary Integration and Policy Analysis (Antle, Capalbo and Crissman, 1998)

These indicators can be presented in the form of 2-dimensional tradeoff curves for policy analysis (Antle et al. 1998 and 2000). These tradeoff curves define combinations of economic and environmental outcomes that can be associated with different output and input prices, environmental and other type of regulations or policies. A key fact used below is that these tradeoff curves represent the supply side of the agricultural system. Figure 2.3 describes the general conceptual framework that includes the market- level 
analysis. As mentioned above, results of the TOA model comprise joint distributions of impacts in terms of agricultural output, environmental quality and health indicators for alternative technologies and policies. These distributions are aggregated to generate the tradeoff curves among these indicators. The tradeoff curves are a set of possible equilibrium points associated with different prices, therefore tradeoff curves can be interpreted as generalized supply curves that include both market and non-market effects.

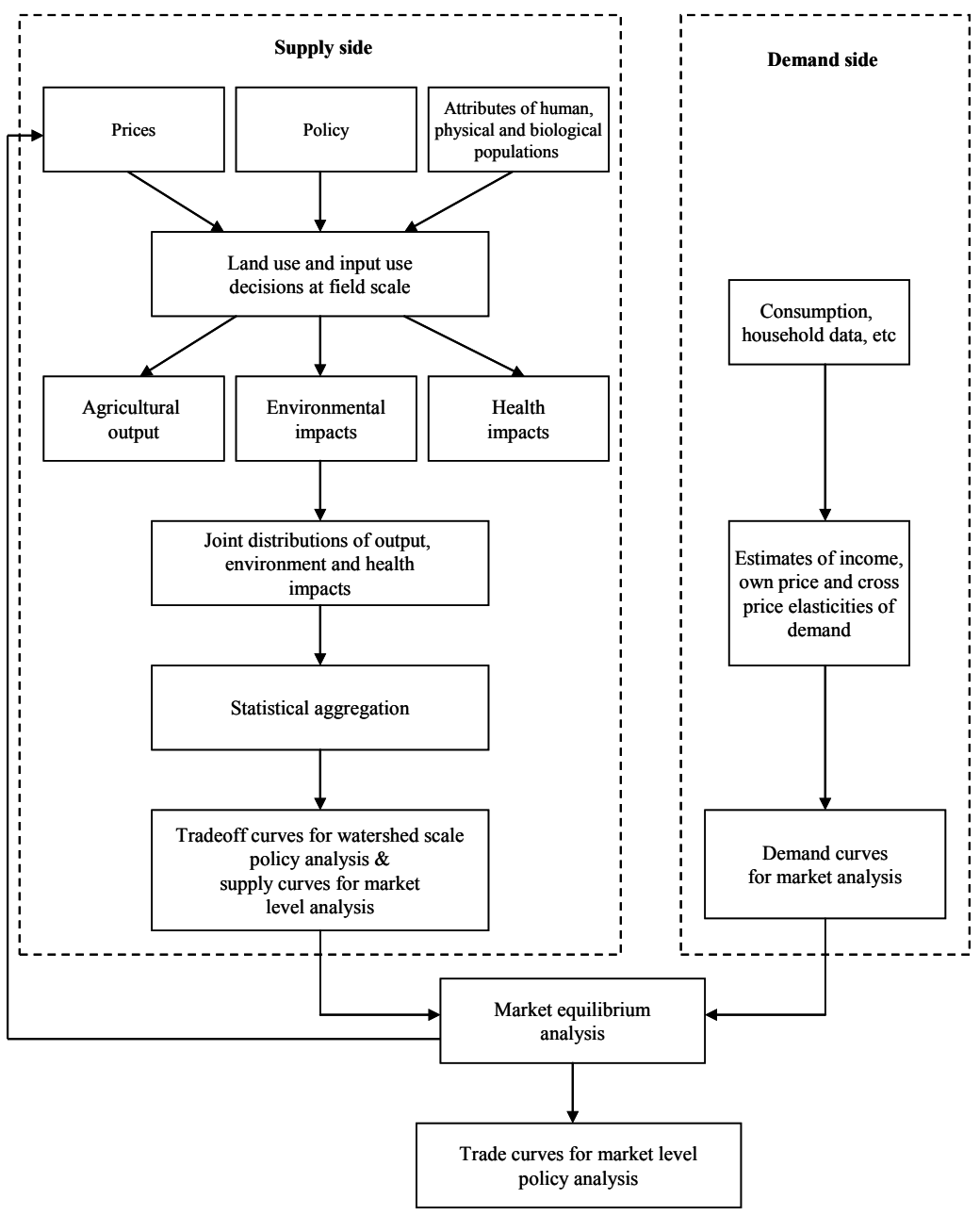

Figure 2.3 Conceptual Framework for Disciplinary Integration and Policy Analysis that include market level linkage (Adapted from Antle, Capalbo and Crissman, 1998). 
We can then link these heterogeneity-based supply curves to market conditions (i.e., add the demand side) and estimate market equilibrium as described in chapter 3 of this thesis. The key point of this analysis is that this model will allow us to use sitespecific data to capture the heterogeneity of that population and generate tradeoffs among economic and environmental indicators, estimate market equilibrium and link these results back to the underlying spatial distributions and measure their effects.

\subsection{Derivation of Tradeoff Curves and Aggregate Supply}

The analysis of agro-ecosystem sustainability requires a good communication between bio-physical and socio-economic sciences. Integration of disciplinary knowledge is necessary in order to support informed agricultural-environmental policy analysis (Antle and Just 1991; Antle and Capalbo, 1991; Wossink et al., 2001, Antle and Stoorvogel, 2006; Kruseman and Bade, 1998, etc). Just and Antle (1990) developed a conceptual framework to analyze interactions between agricultural and environmental policies and environmental impact (e.g., pollution). Their approach allows the integration of bio-physical and economic models at a disaggregate level thus capturing the heterogeneity of the physical environment and the economic behavior of farmers. Results can then be statistically aggregated to evaluate impacts at a macro-level useful for policy analysis.

The disaggregated model has two components: i) Physical model, which is used to determine environmental impacts (e.g., pollution) as a function of management decisions and environmental characteristics of land in production; and b) economic model for making management and land use decisions as functions of prices, policies and environmental characteristics of the land managed by the farmer.

Let's define a population of land units (e.g., fields) in relation to an environmentally meaningful geographic area such as a watershed. Then $\boldsymbol{\omega}_{j}$ is a vector of land qualities or the $\mathrm{j}^{\text {th }}$-field's environmental characteristics with elements that affect $\mathrm{i}$ ) crop productivity and ii) environmental impact. The environmental impact is represented by the stylized model:

$$
\mathbf{z}_{j}=\mathbf{z}\left(\mathbf{x}_{j}, \boldsymbol{\omega}_{j}, \boldsymbol{\varepsilon}_{j}\right)
$$


Where $\mathbf{x}_{j}$ is the a vector of management actions on the $\mathrm{j}^{\text {th }}$ field (e.g., level of input use); $\boldsymbol{\varepsilon}_{j}$ is a random term representing effects of weather and other exogenous effects; and $\mathbf{z}_{j}$ is the environmental impact generated by production on the $\mathrm{j}^{\text {th }}$ field and measured in physical terms per unit of land.

The economic model is based on optimal land and inputs allocation in the process of production as function of prices, policies and environmental characteristics of the land managed by the farmer with the objective of maximizing expected economic returns. Assume that farmers are risk-neutral and that all face the same technology being differentiated only by environmental characteristics of their land. Then, in the production period, the $i^{\text {th }}$ farmer manages $n^{i}$ fields with their corresponding environmental characteristics $\omega^{i}=\left(\omega_{1}^{i}, \omega_{2}^{i}, \ldots . \omega_{n}^{i}\right)$. Define the indicator function:

$$
\delta_{j k}^{i}= \begin{cases}1, & \text { if field } \mathrm{j} \text { is in production of crop } \mathrm{k} \\ 0, & \text { otherwise }\end{cases}
$$

Also let, $\delta_{j}^{i}=\sum_{k} \delta_{j k}^{i}$ and $\delta^{i}=\left(\delta_{1}^{i}, \ldots \delta_{n}^{i}\right)$. The vector of physical attributes of land in production is then defined by:

$$
\omega\left(\delta^{i}\right)=\left(\omega_{1}^{i} \delta_{1}^{i}, \omega_{2}^{i} \delta_{2}^{i}, \ldots \ldots \omega_{n}^{i} \delta_{n}^{i}\right)
$$

The total land in production $A$ on the $i^{\text {th }}$ farm in the production period is defined as:

$$
A^{i}=\sum_{j} a_{j}^{i} \delta_{j}^{i}
$$

Where $a_{j}^{i}$ is the size of the $j^{\text {th }}$ field on the $i^{\text {th }}$ farm.

Production of crop $k$ on field $j$ is defined by:

$$
q_{j k}^{i}=q_{k}\left(a_{j}^{i}, x_{j}^{i}, \omega_{j}^{i}, \varepsilon_{j}^{i}\right)
$$

Assuming all farms in the region face the same vectors $p$ and $\psi$ of prices and policy and technology parameters define $x^{i}=\left(x_{j}^{i} \ldots \ldots x_{n}^{i}\right)$ as the input allocation vector. Then the $i^{\text {th }}$ farmer's decision problem is to maximize expected returns by choosing $x^{i}$ and $\delta^{i}$ subject to the physical attributes of the land $\omega^{i}$, price $p$, and policy and technology parameters $\psi$. Formally,

$$
\max _{x^{i}, \delta^{i}} \pi\left[x^{i}, \omega\left(\delta^{i}\right) \mid p, \psi, \omega^{i}\right]
$$


Where $\pi$ is the farmer's objective production function embedding the production technology. The solution to this maximization problem generates the following demand functions:

$$
\begin{aligned}
x_{j}^{i} & =x\left(p, \psi, w_{j}^{i}\right), \text { and } \\
\delta_{j}^{i} & =\delta\left(p, \psi, w_{j}^{i}\right)
\end{aligned}
$$

The environmental characteristics $\omega_{j}^{i}$ are distributed across the fields in the region with a distribution defined by the parameter vector $\Theta$. This induces a joint distribution for input use $x^{i}$ and land use $\delta^{i}$ in the population for given price parameters $p$, policy and technology parameters $\psi$ and for the given distribution of physical characteristics $\Theta$ : $\xi(x, \delta \mid p, \psi, \Theta)$. The environmental attributes of land in production defined above are determined by land use decisions. Yields and environmental impacts are function of input use and the environmental attributes of the land in production. Thus, the joint distribution $\xi$ in turn induces distributions of the physical characteristics of land in production, crop production and environmental impact, more precisely; farmer's production decisions generate a joint distribution of land use, output, input, environmental attributes and environmental impacts in the region.

This approach allows establishing individual impacts (i.e., at field level) based on farmers' decisions which are subject to farmer and physical characteristics of the land in production, and to the prices and policy conditions in the region. The farmer decision model provides a statistical representation of the population in the region that needs to be aggregated to a level required for policy analysis. As it was discussed in previous sections, deterministic approaches for aggregation are too restrictive (see Theil, 1954) therefore an alternative is to use a statistical approach to deal with the aggregation problem.

From the disaggregated model described above, the joint distribution of input use and other characteristics associated with a specific field is defined as $\xi(x, \omega \mid p, \psi, \Theta)$ where $\Theta$ is the parameter of the distribution of physical characteristics of the population. Also, let the farm's input demand function be $x(p, \omega)$ for price vector $p$, then we can define the population mean input level as:

$$
\mu(p, \psi, \Theta) \equiv E(x \mid p, \psi, \Theta)=\iint x(p, \psi, \omega) \xi(x, \omega \mid p, \psi, \Theta) d x d \omega
$$


Antle (1986) argues that under reasonable assumptions, aggregate output Q (e.g., aggregate supply) and aggregate environmental impact Z (e.g., aggregate pollution) can be interpreted as conditional expectations of output and environmental impacts in the population, given prices, policy and technological parameters in the population. Antle also points out that these conditional expectations cannot be inferred from aggregate data because they require knowledge about the individual farms' inputs and outputs, and in this case they also require knowledge of the physical characteristics of the population. The aggregate output and aggregate environmental impact are defined as:

$$
\begin{aligned}
Q(p, \psi, \Theta) & =\int q[x(p, \psi, \omega), \omega] \xi(x, \omega \mid p, \psi, \Theta) d x d \omega \\
Z(p, \psi, \Theta) & =\int z[x(p, \psi, \omega), \omega] \xi(x, \omega \mid p, \psi, \Theta) d x d \omega
\end{aligned}
$$

Assuming that the function $\mu(p, \psi, \Theta)$ is invertible such as the function $p=h(\mu, \psi, \Theta)$ exists, then the aggregate output and environmental impact functions can be expressed as $Q(\mu, \psi, \Theta)$ and $Z(\mu, \psi, \Theta)$. Additionally, the aggregate input vector $X$ is an average of $x^{i}$ because it satisfies:

$$
\operatorname{plim}_{n \rightarrow \infty} X=\mu
$$

Where $\mathrm{n}$ is the number of firms in the production period. This means that when the number of firms is larger, the aggregated input $\boldsymbol{X}$ can be interpreted as approximately equal to $\mu$. As a consequence, the aggregate output and aggregate environmental impact in the population can be expressed as functions $Q(X, \psi, \Theta)$ and $Z(X, \psi, \Theta)$ and the aggregate input demand can be expressed as $X(p, \psi, \Theta)$. The aggregate production functions $\mathrm{Q}, \mathrm{Z}$ and the aggregate input demand $\mathrm{X}$ can be interpreted as population means and used for policy analysis. Also, these aggregate functions depend on the vector $\Theta$ that defines the distribution of individual firm characteristics in the population (Antle 1993). A change in $\Theta$ will cause a shift in the aggregate production function. Policy analysis must then take into account the fact that any change in the firm characteristics in the population will change the underlying distribution; therefore relationships between aggregate output and input will be different. Likewise, changes in the environmental characteristics of the land in production will lead to a change in the production function $\mathrm{Z}$ (Antle and Capalbo, 1991).

Equations (10) and (11) can be used to show the tradeoffs between aggregate outcomes (e.g., economic vs. environmental). Tradeoff curves are constructed by varying 
one parameter, ceteris paribus. Figure 2.4 shows a tradeoff curve generated by letting price parameters $p$ vary within a range $\Omega$. Then the tradeoff curve between Q (e.g., crop production) and $\mathrm{Z}$ (an environmental quality indicator such as soil quality) is defined as:

$$
T\left(X, \psi, \Theta^{1}\right) \equiv\{(Q(X, \psi, \Theta), Z(X, \psi, \Theta) \mid p \in \Omega\}
$$

Figure 2.4 shows that $\mathrm{Q}_{0}$ units of output can be produced at a cost of the environmental quality level at $\mathrm{Z}_{0}$. However, if production increases to $\mathrm{Q}_{1}$ the soil quality decreases to $Z_{1}$ (e.g., loss of soil nutrients). The analysis could also imply that the starting point is $\mathbf{b}_{\mathbf{1}}$ on the tradeoff curve $\mathbf{T}$, and then a program or policy aimed to reduce soil nutrient at a level such as $Z_{0}$ would cause a reduction on output from $Q_{1}$ to $Q_{0}$.

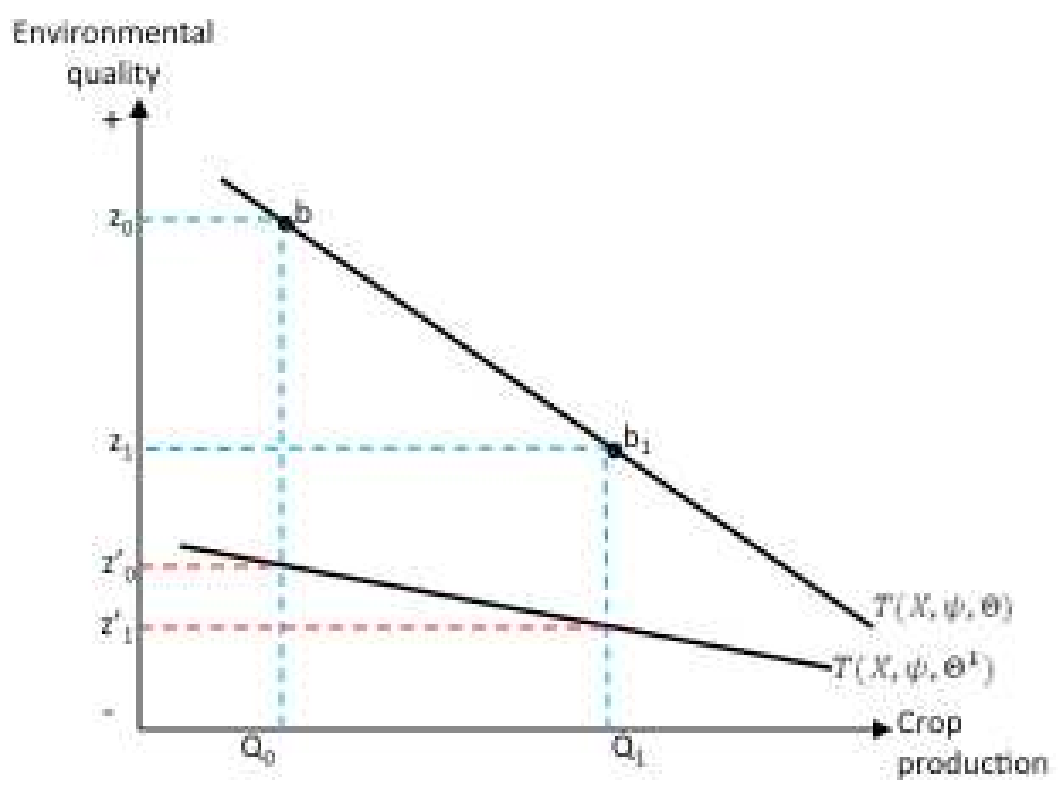

Figure 2.4 Theoretical framework tradeoff curves.

Now assume that there is a change on the distribution of farm characteristics $\Theta$ such as improved availability of fertilizer due to road construction (access to the market). Then, if fertilizer use increases crop yield and contribute to balance nutrient loss, then farmers would be able to increase or maintain the same level of crop production but a lower environmental cost. This case is represented by the tradeoff curve $\mathrm{T}^{1}$ in Figure 2.4. 
Now a production level of $\mathrm{Q}_{0}$ produces $\mathrm{Z}{ }_{0}$ units of environmental quality. Conversely, $\mathrm{Q}_{1}$ units of crop production will produce $Z^{\prime}{ }_{1}$ units of environmental quality. For informed policy decision making, this information could play a very important role in assessing the viability of alternatives or technologies that look for either increase in crop productivity and reduce the effects on the environment.

In this context however, prices are treated as exogenous and reality is that at certain level, prices become endogenous, thus a market level analysis would also play a key role in the analysis. Determining the market equilibrium point will allow us to know where exactly we are in the tradeoff curve. Moreover, changes in prices or farm characteristics as the ones discussed above may also impact the aggregate output, therefore market equilibrium prices may also be impacted. The key fact that allows us to derive the supply curve from the tradeoff curves is that the tradeoff curves are constructed by varying the mean of a price distribution (e.g., maize price) while holding the other parameters constant. At the same time, this framework allows us to modify a set of parameters to represent different socio-economic conditions to characterize future plausible development pathways. In order to capture the possible socio-economic conditions that could be attained as consequence of these policies and other factors (e.g., climate change), we use the concept of Representative Agricultural Pathways (RAPS; Antle and Valdivia, 2014). RAPs provide plausible narratives and quantitative information about future economic, social, institutional conditions. Model scenarios consistent with specific development pathways can then be formulated using these RAPs. 


\title{
CHAPTER 3
}

\section{In Search of Sustainable Development:}

\section{Modeling Semi-Subsistence Crop-Livestock}

\author{
Systems to Solve the Poverty-Productivity-
}

\section{Sustainability Puzzle in Sub-Saharan Africa}

Achieving the goal of sustainable development in African agriculture will require better understanding of the poverty-productivity-sustainability puzzle: why high poverty and resource degradation levels persist in African agriculture, despite decades of policy interventions and development projects. We hypothesize that the answer to this puzzle lies, at least in part, in understanding and appropriately analyzing key features of semisubsistence crop-livestock systems typical of Sub-Saharan Africa: high degree of biophysical and economic heterogeneity, complex and diversified production system involving a combination of subsistence and cash crops with livestock. We describe an integrated modeling approach designed to incorporate these features. We illustrate how this approach can be implemented to quantify economic and sustainability indicators for policy tradeoff analysis in the Machakos region, Kenya. The analysis suggests that a successful implementation of the Vision 2030 strategy of the Kenyan Government could lead to a sustainable development pathway and achieve newly proposed Sustainable Development Goals.

Based on: Valdivia, Roberto O., Antle, John M. and Jetse J. Stoorvogel. 2015. In Search of Sustainable Development: Modeling Semi-Subsistence Crop-Livestock Systems to Solve the Poverty-Productivity-Sustainability Puzzle in Sub-Saharan Africa. Submitted to Agricultural Economics 


\subsection{Introduction}

Although the Millennium Development Goal of reducing poverty by half could be achieved globally by 2015 , recent estimates indicate that four out of every five people will still be living in extreme poverty in Sub-Saharan Africa (SSA) and Southern Asia, with the majority of those in rural areas and dependent on agriculture for their livelihoods (UN 2012). These conditions in SSA present a major challenge for the recently proposed post-2015 Sustainable Development Goals (SDGs; SDSN 2013). The SDGs emphasize the need to achieve sustainable development by 2030 by promoting economic development, environmental sustainability, good governance and social inclusion.

Why these conditions persist in many regions of rural SSA - despite decades of research and development investment, policy interventions and development projects remains one of the most important questions facing researchers and policy decision makers. Numerous explanations have been offered for the low success of conventional intervention strategies for agriculture, based on improved crop varieties, recommended use of external inputs, raising crop prices and improving infrastructure and institutions and market conditions (World Bank 2008; Barrett and Marenya 2009; Stephens et al., 2012; Sanchez et al. 2007, Pingali 2012; Pingali, Schneider and Zurek 2014).

In this article we hypothesize that the answer to this puzzle lies, at least in part, in understanding and appropriately analyzing the key features of the semi-subsistence croplivestock systems (CLS) typical of many parts of Sub-Saharan Africa and other parts of the developing world. We hypothesize that it is the complexity and diversity of these systems that often constrains the ability of policies to achieve a "win-win" outcome of simultaneously reducing poverty while raising productivity sustainably. For example, encouraging the use of nutrient-using improved crop varieties such as hybrid maize without the appropriate management (e.g., adequate fertilizer application rates) is likely to lead to losses in soil fertility and a low productivity "poverty trap" (Antle, Stoorvogel and Valdivia 2006; Marenya and Barrett 2009b; Barrett and Carter 2013). Likewise, failure to appreciate the important role that livestock play in small-farm livelihoods may lead to inappropriate and ineffective development strategies (Herrero et al. 2009).

To investigate this hypothesis, we extend the concept of econometric-process simulation models proposed by Antle and Capalbo (2001) to represent semi-subsistence 
crop-livestock systems (CLS) using the Tradeoff Analysis Model system (Stoorvogel et al. 2004; Valdivia, Antle and Stoorvogel 2012) to conduct simulation experiments that represent the kinds of policies and interventions that have been implemented or are being planned in many parts of Sub-Saharan Africa. We use this model to evaluate the potential for the development strategy proposed by the Government of Kenya (GoK) to achieve the Sustainable Development Goals of reducing poverty and enhancing sustainability defined as maintaining soil productivity. Thus, we framed the GoK proposed interventions as "Sustainable Agricultural Intensification" (SAI) policies. SAI is defined as producing more outputs with more efficient use of inputs while reducing or avoiding environmental damage (The Montpellier Panel 2013, SDSN 2013, Garnett et al. 2013). SAI has become the focus of an ongoing debate among researchers and policy makers. While SAI policies are attracting the interest of national and international institutions, SAI is being highly criticized for those who argue that SAI means a switch to industrial agriculture. However, as Garnett et al. (2013) point out, SAI is an evolving concept subject to debate, but it is only part of the story, there are other dimensions to consider (e.g., social, environmental) in order to improve the food system sustainability. In recent years the International Livestock Research Center (ILRI) has been promoting SAI technologies (such as the ones presented in our analysis, e.g., promoting improved breeds, increasing feeding efficiency, etc.) to move small-holder farmers with CLS in Africa out of poverty while having a positive impact on environment, health and equity (Tarawali et al. 2013).

Another dimension of sustainability that could be considered is greenhouse gas emissions. However, as yet this issue has not been addressed by the GoK (or by most other African governments), and we have elected not to incorporate greenhouse gases in the analysis presented here. However, the framework we present could be used to extend the analysis of SAI to include greenhouse gases, and that remains an important topic for future research.

A key challenge facing the national and international agricultural research community is to assess the impacts of agricultural policies, technologies, and environmental change (e.g., climate change) on the sustainability of CLS and the wellbeing of people depending on them (World Bank 2008). Modeling agricultural systems has progressed in the direction of integrated assessment where bio-physical and economic 
data and models are coupled (Holden 2005; Antle 2011; Berkhout, et al. 2011; Giller et al. 2011). CLS exhibit a number of features that pose substantial challenges for modeling these systems. These features include: a high degree of bio-physical and economic heterogeneity; extremely small field, herd and farm size; a complex mix of subsistence, cash and livestock activities including intercropping; high rates of crop failure; and low and variable use of external inputs. Although these features are typical of CLS, there has been little discussion of how to deal with them in the empirical production economics literature, how these features may affect the ability of policy interventions to achieve desired goals of reducing poverty and increasing productivity sustainably, and how these interventions may respond under future socio-economic scenarios.

In the first section of this article we describe the characteristics of CLS and illustrate them with data from the Machakos region in Kenya. Next we show how these features can be incorporated into a whole-farm version of an econometric-process simulation model which is implemented using the Tradeoff Analysis (TOA) software (Stoorvogel et al. 2004). The TOA software simulates agricultural systems by coupling spatially-explicit data with site-specific biophysical and economic models. We present a model developed for the Machakos region that we use to carry out simulation experiments designed to assess the impacts that policy and technology interventions, such as those designed to encourage fertilizer use and raise farm-gate crop prices, may have on the poverty of farm households and the sustainability of their farming systems. We do this by assessing the impacts of these interventions under different plausible agricultural development pathways. We conclude with policy and research implications.

\subsection{Characteristics of CLS: Implications for Sustainable Development}

There is a wide variety of CLS worldwide each with their own specific characteristics (Dixon et al. 2001). In this study we focus on the CLS in the Machakos region, a hilly drought-prone farming area of nearly $13,500 \mathrm{~km}^{2}$ located $50 \mathrm{~km}$ south-east of Nairobi. The region includes both Machakos and Makueni districts. The farming systems are characterized in a number of farm surveys clustered around 6 villages and using the nutrient monitoring system NUTMON (de Jager, Nandwa, and Okoth 1998; de Jager et al. 1998; Van Den Bosch et al. 1998a and 1998b). NUTMON was originally 
designed to quantify soil nutrient balances. However, this comprehensive accounting of inputs and outputs makes the data well-suited for econometric modeling (Mora-Vallejo et al. 2012). The agricultural systems of the region exhibit typical characteristics of CLS (Table 1 and 2). 


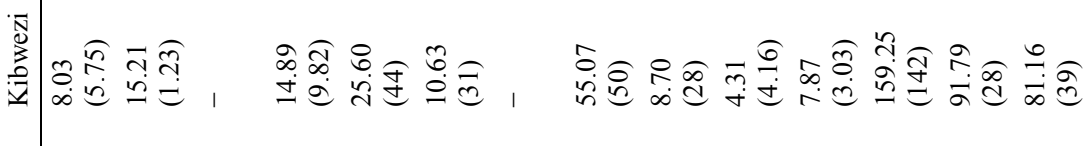

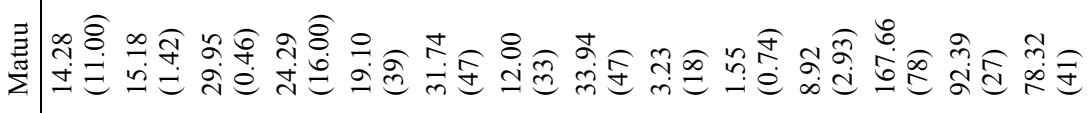

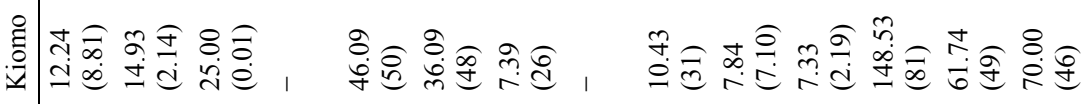

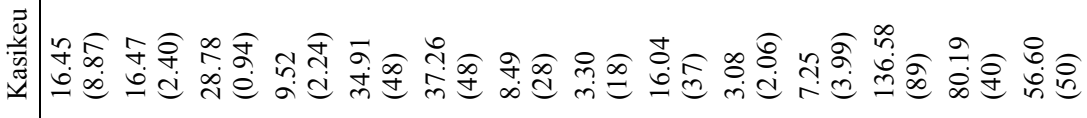

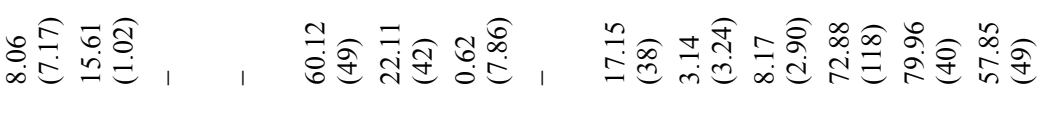

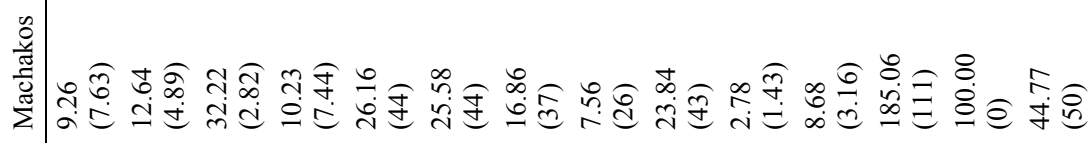

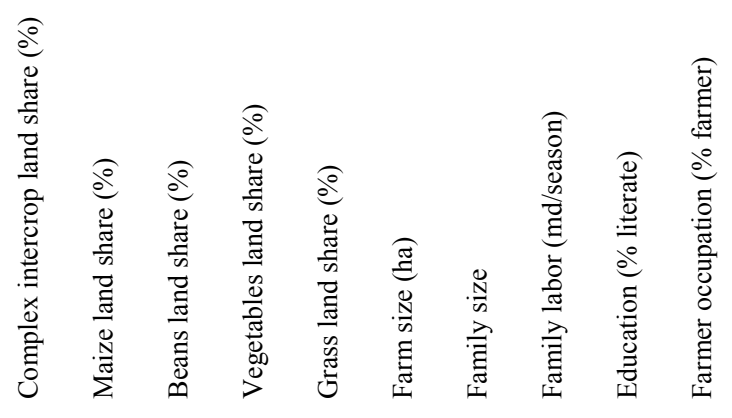




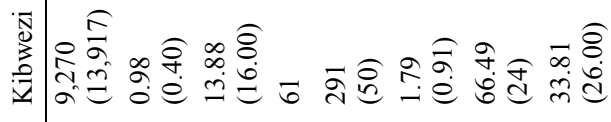

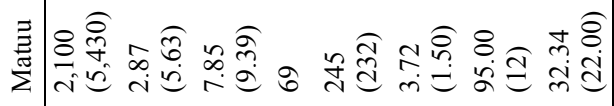

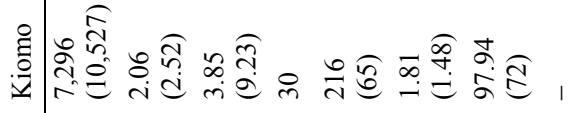

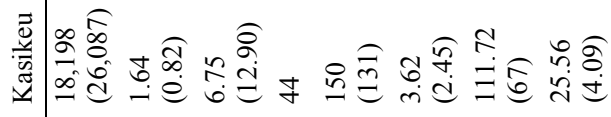

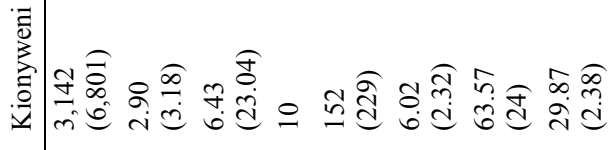

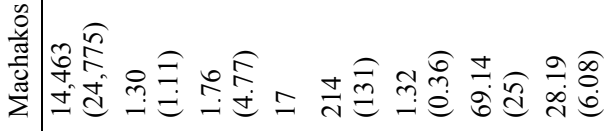

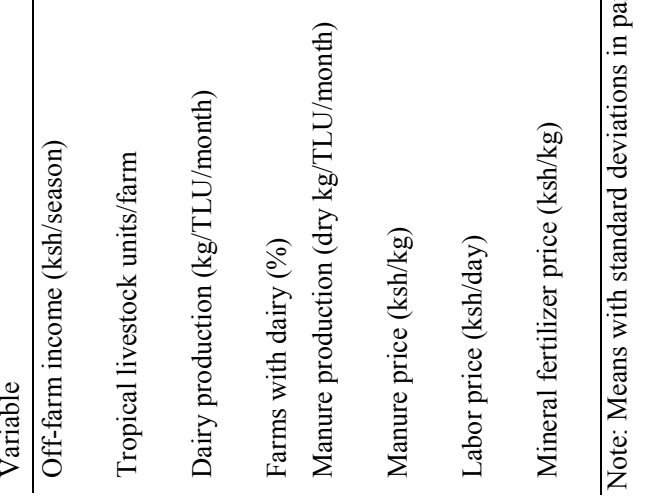


Table 3.2. Summary Statistics by Crop, Machakos NUTMON Data

\begin{tabular}{|c|c|c|c|c|}
\hline Variable & Intercrop & Maize & Beans & Vegetables \\
\hline Output value $(\mathrm{ksh} / \mathrm{ha})$ & $\begin{array}{l}19,185 \\
(20,826)\end{array}$ & $\begin{array}{l}30,786 \\
(22,863)\end{array}$ & $\begin{array}{l}43,975 \\
(28,936)\end{array}$ & $\begin{array}{l}59,464 \\
(47,104)\end{array}$ \\
\hline Output quantity $(\mathrm{kg} / \mathrm{ha})$ & $\begin{array}{l}1,092 \\
(1,143)\end{array}$ & $\begin{array}{l}1,950 \\
(1,471)\end{array}$ & $\begin{array}{l}1,799 \\
(1,310)\end{array}$ & $\begin{array}{l}3,985 \\
(4,854)\end{array}$ \\
\hline Byproduct value $(\mathrm{ksh} / \mathrm{ha})$ & $\begin{array}{l}2,786 \\
(7,677)\end{array}$ & $\begin{array}{l}3,741 \\
(5,069)\end{array}$ & $\begin{array}{l}3,063 \\
(5,213)\end{array}$ & - \\
\hline Crop failure (\%) & 34 & 24 & 30 & 1 \\
\hline Area (ha) & $\begin{array}{l}0.36 \\
(0.48)\end{array}$ & $\begin{array}{l}0.28 \\
(0.38)\end{array}$ & $\begin{array}{l}0.20 \\
(0.16)\end{array}$ & $\begin{array}{l}0.15 \\
(0.31)\end{array}$ \\
\hline Manure (dry kg/ha) & $\begin{array}{l}434.22 \\
(838.92)\end{array}$ & $\begin{array}{l}1,216.74 \\
(1,351.83)\end{array}$ & $\begin{array}{l}327.36 \\
(814.35)\end{array}$ & $\begin{array}{l}560.49 \\
(1,206.84)\end{array}$ \\
\hline Manure use (\%) & $\begin{array}{l}49 \\
(50)\end{array}$ & $\begin{array}{l}53 \\
(50)\end{array}$ & $\begin{array}{l}34 \\
(48)\end{array}$ & $\begin{array}{l}48 \\
(50)\end{array}$ \\
\hline Hired labor (md/ha) & $\begin{array}{l}15.30 \\
(40.36)\end{array}$ & $\begin{array}{l}36.68 \\
(42.53)\end{array}$ & $\begin{array}{l}5.29 \\
(21.75)\end{array}$ & $\begin{array}{l}27.32 \\
(86.01)\end{array}$ \\
\hline Off farm labor use $(\%)$ & $\begin{array}{l}38 \\
(49)\end{array}$ & $\begin{array}{l}23 \\
(42)\end{array}$ & $\begin{array}{l}20 \\
(40)\end{array}$ & $\begin{array}{l}20 \\
(40)\end{array}$ \\
\hline Mineral fert (kg/ha) & $\begin{array}{l}7.32 \\
(23.52)\end{array}$ & $\begin{array}{l}67.88 \\
(88.53)\end{array}$ & $\begin{array}{l}11.44 \\
(34.42)\end{array}$ & $\begin{array}{l}35.28 \\
(78.98)\end{array}$ \\
\hline Mineral fert use (\%) & $\begin{array}{l}15 \\
(36)\end{array}$ & $\begin{array}{l}20 \\
(40)\end{array}$ & $\begin{array}{l}19 \\
(40)\end{array}$ & $\begin{array}{l}37 \\
(48)\end{array}$ \\
\hline Purchased seed $(\mathrm{kg} / \mathrm{ha})$ & $\begin{array}{l}42.90 \\
(56.85)\end{array}$ & $\begin{array}{l}44.59 \\
(53.00)\end{array}$ & $\begin{array}{l}50.30 \\
(56.48)\end{array}$ & $\begin{array}{l}21.94 \\
(43.12)\end{array}$ \\
\hline Seed use $(\%)$ & $\begin{array}{l}73 \\
(45)\end{array}$ & $\begin{array}{l}78 \\
(42)\end{array}$ & $\begin{array}{l}58 \\
(50)\end{array}$ & $\begin{array}{l}79 \\
(40)\end{array}$ \\
\hline Pesticide (kg/ha) & $\begin{array}{l}1.43 \\
(8.41)\end{array}$ & $\begin{array}{l}15.89 \\
(52.70)\end{array}$ & $\begin{array}{l}0.53 \\
(3.40)\end{array}$ & $\begin{array}{l}145.98 \\
(1,053.55)\end{array}$ \\
\hline Pesticide use (\%) & $\begin{array}{l}24 \\
(43)\end{array}$ & $\begin{array}{l}9 \\
(29)\end{array}$ & $\begin{array}{l}8 \\
(27)\end{array}$ & $\begin{array}{l}54 \\
(50)\end{array}$ \\
\hline Irrigation use (\%) & $\begin{array}{l}3 \\
(18)\end{array}$ & $\begin{array}{l}18 \\
(39)\end{array}$ & $\begin{array}{l}10 \\
(30)\end{array}$ & $\begin{array}{l}93 \\
(25)\end{array}$ \\
\hline Sample size & 235 & 322 & 168 & 239 \\
\hline
\end{tabular}

\section{Biophysical and economic heterogeneity:}

The Machakos study area presents a large variation in biophysical and socio-economic conditions. Altitudes range from 400 to 2,100 meters above sea level in the semi-arid region with low soil fertility. Farm size varies highly between the villages with small farms $(<2$ ha) in the higher, more humid areas and larger farms (about $8 \mathrm{ha}$ ) in the lower and dryer rangelands. 
Typical fields are less than 0.5 hectare, with many fields less than 0.1 hectare and a small number of fields larger than 1 hectare. Per capita income varies greatly between villages, consequently poverty rates range from $37 \%$ in the village with high levels of vegetables production to $93 \%$ in areas where no vegetables are produced and dairy production is low.

\section{Complex crop and livestock systems}

Farms include a variety of cropping systems in combination with livestock production. Semi-subsistence farms typically include monocrops, simple intercrops, and complex intercrops. In a simple intercrop, a small number of different species, such as beans and maize, are planted together. In a complex intercrop, a relatively large number of species are planted together, often in diverse combinations of crops in different proportions on different farms. In the CLS of Machakos the principal cropping systems include i) complex intercrops, where a single field may have 10 or more species planted together, ii) maize and beans grown as a monocrop or together as a simple intercrop, iii) vegetables in areas that have access to irrigation, and iv) grass to feed livestock. Farm households typically own one to three tropical livestock units (a dairy cow equivalent). In some areas, livestock is grazed, but many farms use a so-called zero-grazing system in which livestock is confined to increase the efficiency of nutrient recycling, using Napier grass and crop residues as feed and storing manure for use on the subsequent season's crops. Across the region, about one-third of farms produce milk, but the importance of dairy production varies greatly from one village to another. The villages with more cash crop production also produce much more milk, and dairy productivity varies substantially by village.

\section{Dependence on semi-subsistence farming}

The data show a substantial variation across villages in dependence on subsistence crops, cash crops and off-farm income. The diverse intercrop is mainly for subsistence whereas vegetables are grown as cash crop. Maize and beans can be grown for home consumption but are also sold on the local markets. Off-farm income is increasing in importance in many parts of Africa.

\section{Low input use}

Only about $20 \%$ of maize parcels have fertilizer applied to them, and where it is used the rate is about $65 \mathrm{~kg}$ of commercial product per ha, a relatively low rate compared to the fertilizer recommendations. Seeds, particularly for the market oriented crops, are typically purchased. 
Pesticide use is limited mostly to irrigated vegetables. Most fieldwork is carried out by hand labor, primarily family labor with limited use of hired labor.

\section{Low Productivity}

Crop yields are low but also highly variable. Crop failure rates are high for maize and beans in this semi-arid environment (Kenyan government statistics indicate crop failure rates as high as $50 \%$ in cases of droughts), except for irrigated high-value vegetable crops. Crop byproduct is a small part of total crop value, but is important for livestock feed and nutrient recycling, with about $50 \%$ of fields having manure and composted crop residues applied.

The features of CLS described above show that these systems depend on complex interactions among crops (often intercropped), livestock and the bio-physical and economic environments in which they operate. The bio-physical and economic complexity of these systems results in limited scientific understanding of the systems and the interactions between these systems and critical environmental factors such as soil nutrients (Titonell et al. 2005a, 2005b, Giller et al. 2011). This complexity also means that conventional reductionist research programs designed around the improvement in productivity of individual crops such as maize are less likely to be successful than in systems dominated by monoculture. For example, hybrid maize has been widely adopted in parts of Kenya, yet maize productivity remains remarkably low in many parts of Kenya, including parts of the Machakos region, even though adoption rates of hybrid maize are relatively high (Karanja, Jayne and Strasberg 1998; Suri 2011).

Moreover, the importance of subsistence "orphan" crops further complicates productivity-enhancing research. Even though some progress has been made in improving productivity potential of some of these crops through research investment (Pingali 2012; Pingali, Schneider and Zurek 2014), the fact that they are often grown in a wide array of complex intercrops, with very low use of external inputs, limits their productivity.

The extremely small farm size in most of the regions and complexity of these systems also limits the potential for interventions to reduce poverty and enhance sustainability. Consider the impact of improving maize productivity on poverty: because maize represents only about 30 percent of the value of farm production, even relatively large improvements in maize productivity have relatively small effects on per capita income, especially if those improvements come at a relatively high cost of external inputs such as hybrid seed and mineral fertilizer. The 
potential for these systems to raise productivity sustainably - meaning, in this context, maintaining soil fertility - depends on the ability of farmers to recycle nutrients between crops, livestock and the farm household. Attempts to raise productivity by enhancing the production of a nutrient-depleting crop like maize therefore risks actually reducing sustainability of these systems by effectively exporting nutrients in the form of the higher grain yields that can be obtained in the short run by essentially mining soil fertility. However, in the longer run, the loss of soil organic matter and soil nutrients results in lower yields and higher rates of crop failure, with the risk of moving the system to a low-level equilibrium from which it may be both ecologically and economically very costly to escape (Antle, Stoorvogel and Valdivia 2006).

Another important dimension of the complexity of CLS, and the challenges and limits to interventions designed to improve their performance, is due to the important role that livestock play in these systems. The importance of livestock in CLS is underappreciated and poorly understood, despite the research by the International Livestock Research Institute which has shown the critical role that livestock plays in the livelihoods of many of the world's poorest farm households (Thornton and Herrero 2001; Herrero et al. 2009). The data from Machakos clearly bear out this fact: when the data are stratified by farm type, they show that households with significant income from dairy production have poverty rates about $50 \%$ lower than households that depend primarily on crops. Moreover, livestock play a critical role in the sustainability of these systems, providing a mechanism to recycle crop nutrients through the use of animal manure (Claessens et al. 2012).

In conclusion, intervention strategies that do not take into account the key features and dynamics of CLS can lead to serious unintended consequences that may affect the sustainability of the system (e.g., decline in agricultural productivity) which is one key the drivers of poverty and food insecurity.

\subsection{Modeling Semi-Subsistence Crop-Livestock Systems for Policy Analysis}

\subsubsection{The Tradeoff analysis approach}

To investigate the potential for the policy strategies of the GoK to achieve the SDGs, we utilize the TOA approach in which the inter-relationships between key sustainability indicators are used to evaluate outcomes of policy experiments (for more detailed description of the TOA 
see Stoorvogel et al. 2004; Antle, Stoorvogel and Valdivia 2014). Embedded within the TOA is an econometric-process simulation model or EPM (Antle and Capalbo 2001, see Chapter 2 for details). An EPM is an empirical production model that can be linked to site-specific biophysical models. The underlying idea of the EPM approach is to estimate behavioral equations from econometric production models for each activity in the system and use these equations to simulate farmer's decisions as functions of farm characteristics, prices, policy parameters and site-specific crop productivity. The farm-level simulations are aggregated to the regional scale relevant for policy analysis.

Here we extend the field-level approach of Antle and Capalbo (2001) to a farming system to represent the features of CLS mentioned above. The CLS have both crop and livestock activities that are interacting through the production of animal feed (mainly Napier grass), the use of crop residues as animal feed, and the collection and use of manure for the fertilization of crops, thus a whole farm approach is needed.

The structure of the whole-farm EPM for Machakos is presented in Figure 3.1. The farm is defined in terms of a set of characteristics: size and location, number and size of fields, family size and amount of family labor available, age and education of the head of household, availability of off-farm income, and the number of livestock. By specifying reduced-form behavioral (output supply and input demand) equations as functions of household characteristics, the model can represent the effects of non-separable consumption and production decisions (Benjamin 1992). The simulation takes the farm through a series of growing seasons. Each season, a set of expected prices are sampled from the observed distributions, and quantities of milk and manure production are simulated as a function of animal feed (crop residues and Napier grass) from the previous growing season. Next the production cycle begins: manure production (including composted crop residues) from the previous season is used to determine the quantity available to be allocated to crops; then crop input use and input demand functions, crop failure probabilities, and crop and byproduct equations are simulated to compute cost of production, expected revenue, and expected returns for each crop for each field on the farm. The expected returns of each crop are compared on each field and the crop with the highest expected returns is selected. Field-level crop-specific outputs, inputs and returns associated with each field are saved for aggregation to the farm level. At this point, the growing season is completed and a new growing season is initiated by re-sampling prices and the production cycle is repeated. 


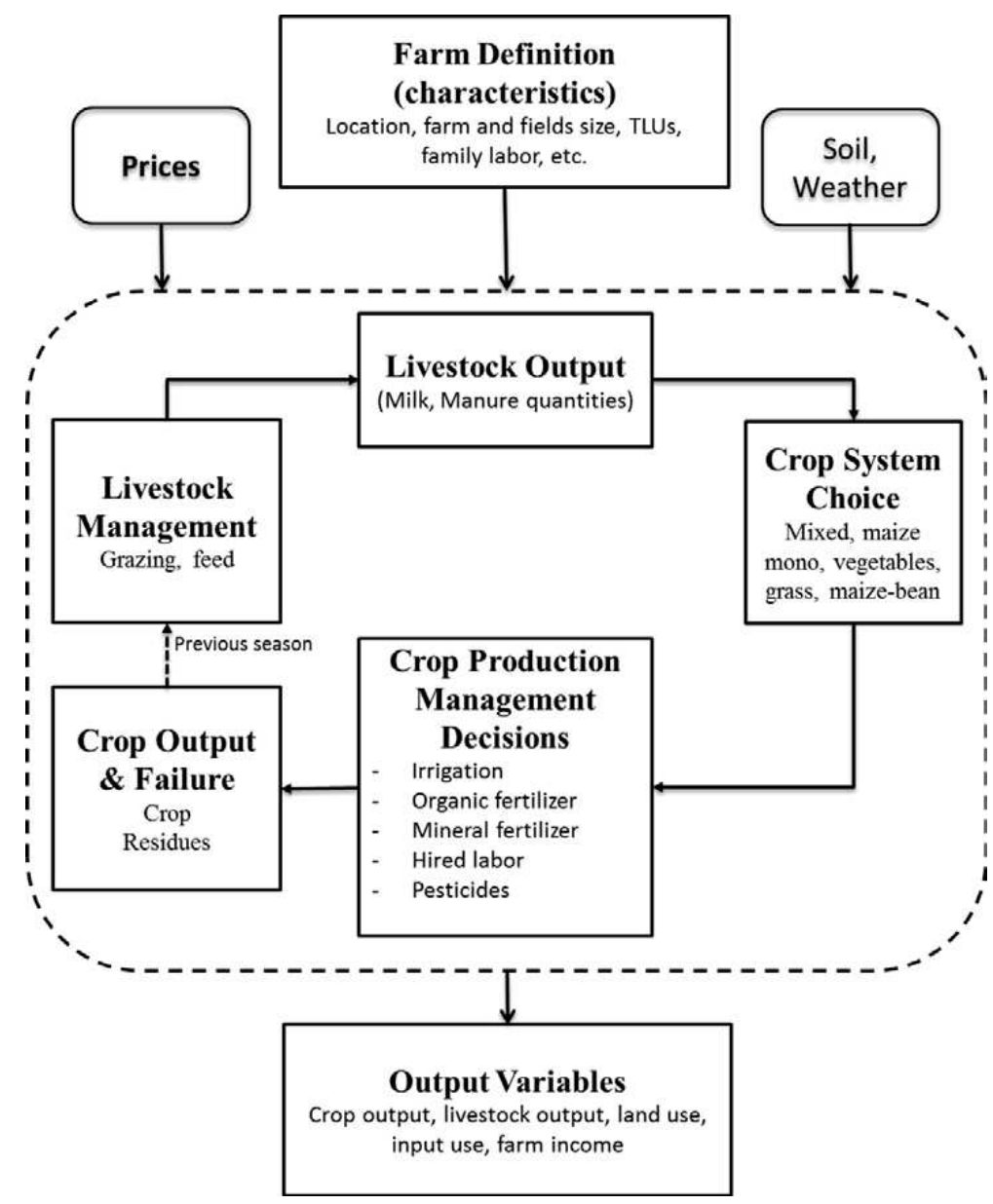

Figure 3.1 Structure of the econometric-process simulation model of the crop-livestock system in the Machakos region, Kenya

\subsubsection{Characteristics of CLS and the implications for modelling}

\section{Multiple outputs}

The monocrop, simple intercrop and complex intercrop in CLS require different modeling approaches. A simple intercrop can be modeled as a multiple-output process using established econometric techniques for both primal and dual representations of the technology. For complex intercrops, each unique combination of crops could be modeled as a multiple-output 
system in the same way that a simple intercrop is modeled as long as the multiple-output technology's parameters are consistent across the different output combinations (Weninger 2003). However, when many different combinations of crops are observed, this solution is impractical for estimation due to the limited degrees of freedom available for each unique crop combination, and also for simulation because of the large number of distinct systems. The approach pursued here for modeling complex intercrops is to assume input-output separability. Thus for an input vector $x \geq 0$ and output vector $q \geq 0$, the production function can be specified as $\mathrm{F}(x)=\mathrm{Q}(q)$, so that the individual outputs can be aggregated into a single output index $\mathrm{Q}$. Using this specification, the production function can be estimated, or an aggregate price index can be constructed to estimate corresponding dual supply, revenue or cost functions. In the Machakos application an input-output separable revenue function is used.

\section{Crop failure}

An important occurrence in many CLS is crop failure. To incorporate crop failure into the economic simulation model, we estimate probit models as functions of farm characteristics and management variables, and then use these models to predict probabilities of crop failure. In the simulation model, we use these probabilities to compute expected returns adjusted for risk of crop failure.

\section{Non-essential inputs}

Some key agricultural inputs are non-essential, meaning that output can be produced with either zero or positive quantities of those inputs. As noted above, in (semi-) subsistence agriculture, many farmers do not use mineral fertilizers and pesticides on some crops, and may not employ hired labor or animal traction. Non-essential inputs raise the issue of modeling the discrete choice of input use/non-use, and the specification of primal or dual representations of the technology.

Production systems with non-essential inputs can be modelled using the estimation of revenue (or production) functions and input demand equations. The revenue function is used here because it is defined in terms of input quantities, thus avoiding the problem of specifying a profit or cost function that allows for corner solutions. We have developed two techniques for revenue function specification with non-essential inputs. The first technique is used in cases where input 
quantities are measured with so much error (e.g., when data are collected using surveys based on recall) that the quantities observed convey relatively little information, but the input use/non-use observation is likely to be accurate. In such cases, it is possible to approximate the production or revenue function by replacing the input quantity with a dummy variable for input use/non-use. The production function can then be approximated in a simulation using a linear interpolation between the output levels associated with zero and the average rate observed for users (Gray 2005).

When both input use/non-use and quantities are observed with reasonable accuracy, a non-essential input choice can be represented with a discrete-continuous choice model such as the Heckman model. However, a well-known limitation of the Heckman two-step estimator is the difficulty in identification of the use/non-use decision distinct from the continuous use (Fox, et al. 2009). It would be most efficient to estimate the system of input demand functions jointly, but in practice joint estimation is complicated by the fact that farmers use various combinations of non-essential inputs, so we use single-equation estimation. To specify constant-elasticity production or revenue functions that depend on non-essential input quantities, we apply the procedure proposed by Battese (1997). Accordingly, we define a dummy variable $d_{\mathrm{k}}=1$ if input $x_{\mathrm{k}}>0$ and otherwise $d_{\mathrm{k}}=0$, and the revenue function is specified with $\left(1-d_{\mathrm{k}}\right)$ and $\ln \left(x_{\mathrm{k}}+\left(1-d_{\mathrm{k}}\right)\right)$ (see equation 2 below). The coefficient on the dummy variable represents the shift in the intercept when the input is not used, and the coefficient on the term $\ln \left(x_{\mathrm{k}}+\left(1-d_{\mathrm{k}}\right)\right)$ is the production elasticity when the input is used. In the simulation, a probit model is used to predict the value of the dummy variable.

Another issue that arises with non-essential inputs is how to specify prices for observations where inputs are not used and thus input prices are not reported. Some researchers use the practice of replacing missing data with sample means. Note, however, that this practice would not be appropriate for non-essential inputs if the input is not used because the farmer faces a high effective opportunity cost, e.g., because of high transportation costs or other market imperfections. We apply this logic by assuming that non-users face a price at the upper end of the observed price distribution. 


\section{Biophysical heterogeneity}

Agricultural economists have devised a number of methods to capture the effects of soils, climate and crop characteristics in empirical economic models. Many econometric models have been estimated with farm-specific or region-specific dummy variables to capture spatial differences in productivity. Also, economists have included measurements of soil quality and climate in econometric production models. While these techniques may capture some of the effects of bio-physical characteristics of land on productivity and behavior, they fail to incorporate the systematic knowledge that farm decision makers have about the relationships between the physical environment at a site, the crop characteristics, and crop productivity. This knowledge has been embedded in modern crop growth models such as the Decision Support System for Agrotechnology Transfer (DSSAT) models (Jones et al. 2003).

We have developed a procedure to link bio-physical crop simulation models to econometric-process simulation models (Stoorvogel et al. 2004; Antle and Stoorvogel 2006). This procedure is based on the observation that farmers base management decisions, in part, on their site-specific knowledge of production potential. We interpret the outputs of bio-physical crop simulation models, simulated with site-specific soils and climate data for a typical technology with average or representative management inputs, as a site's inherent productivity. Inherent productivity variables are calculated with DSSAT crop growth simulation models as nitrogen limited yield. They are included in the econometric production model as exogenous predictors of farmer's crop management decision-making. Crop simulation models are designed primarily for single crops or simple intercrops, but they are not suited for complex intercrops. One way to overcome this issue is to use crop inherent productivities that best correlate with the outputs and inputs used in the intercrop.

In the case of Machakos, the economic model includes four cropping systems (inter-crop, maize, beans, vegetables). Associated with each system are a main product and a byproduct. In addition, Napier grass is grown for animal feed. The amount of land allocated to grass (Napier grass, mostly in higher elevation areas and natural pasture in lower areas) is treated as a parameter in this model that is varied in model scenarios along with herd size, to reflect the fact that it is associated with livestock production. Corresponding to these crop definitions, maize, bean and tomato crop models were parameterized using the DSSAT crop modeling system to produce inherent productivities (hereafter referred to as inprods). Maize and bean are important 
crops in the complex intercrop, so both maize and bean inprods were tested in the econometric models for the subsistence crop. The two inprods were highly correlated, but the bean inprod was found to provide the best results and was used in the model. The inprods were computed using site-specific soils data and climate data (Mora-Vallejo et al. 2012).

\section{Heterogeneity in farm households and decision makers}

Farm household and decision maker heterogeneity have been represented in models in various ways, including human capital (Huffman, 2001), risk attitudes and associated characteristics such as wealth and experience (Sunding and Zilberman, 2001), and through a non-separable household structure that introduces factors such as farm and family size and composition (Strauss and Thomas, 1995). All of these features could be incorporated into an econometric-process simulation model given suitable data. The choice of appropriate modeling strategy should depend on the properties of the system, the policy issues being addressed, and data availability (Holden, 2005, Flichman et al., 2012). We use a reduced form model that incorporates household characteristics. For the implementation of the simulation model, equations for all of the exogenous variables were estimated with village dummy variables and with selected interactions to represent logical inter-relationships. Equations for farm size and family size were specified as functions of village dummy variables, and equations for field size and livestock units were estimated as functions of village dummy variables and farm size, and family labor was specified as a function of village effects and family size. Equations for input and output prices were specified with village and seasonal effects. Risk aversion also could be incorporated into the model, although recent evidence suggests that heterogeneity is a more fundamental factor in crop choice and input use unless risk is a predominant factor in decision making (Valdivia, 2002; Lence, 2009; Suri, 2011; Antle, 2011).

\section{Economic Heterogeneity and Poverty}

Spatial price heterogeneity is represented by estimating and simulating a recursive system of price equations to represent price expectations of farmers. These equations incorporate observed spatial and seasonal patterns among prices and spatial correlations among prices.

The econometric-process model simulates the per capita income $m_{i}$ for the $\mathrm{i}^{\text {th }}$ farm, so with a poverty line $t$ we can calculate the headcount poverty index as $H=1 / N \sum_{i=1}^{N} I\left(m_{i}<t\right)$, 
where $\mathrm{N}$ is the total population and $I($.$) is an indicator function that is equal to 1$ if $\mathrm{m}_{\mathrm{i}}$ is less than the poverty line, and 0 otherwise (World Bank, 2005).

\subsubsection{Econometric Model Specification}

Econometric revenue and input demand models for complex intercrop, maize, beans, vegetables, and dairy production were specified in constant elasticity form. The output relationships were estimated as revenue functions with the dependent variable specified as the value of output, predetermined variables specified as output price, input quantities, and continuous and discrete exogenous variables (e.g., farm characteristics, inherent productivity). Following the discussion above, the output price for the complex intercrop was constructed as an output share-weighted index of the individual crop prices. Input demand functions were specified in conventional form as functions of input prices normalized by output price and other exogenous variables. Following the above discussion, the econometric models were specified in the following general form:

$$
p\left(y_{\mathrm{i}}\right)=\phi\left[\tau_{0}+\sum_{\mathrm{j}} \tau_{\mathrm{j}} x_{\mathrm{ji}}+\sum_{\mathrm{k}} \theta_{\mathrm{k}} c_{\mathrm{ki}}\right]
$$

where:

$$
\begin{aligned}
& p\left(y_{\mathrm{i}}\right)=\text { probability that } y_{\mathrm{i}}>r_{\mathrm{y}},\left(r_{y}=\text { threshold value for } y_{\mathrm{i}}\right) \\
& y_{\mathrm{i}}=\text { output value or input quantity } \\
& \mathrm{i}=1,2,3 \ldots \text { observation index } \\
& \mathrm{j}=1,2,3, \ldots \text { continuous exogenous variable index } \\
& \mathrm{k}=\text { discrete (dummy variable) exogenous variable index } \\
& x_{\mathrm{ji}}=\mathrm{j}^{\text {th }} \text { continuous exogenous variable } \\
& c_{\mathrm{ki}}=\mathrm{k}^{\text {th }} \text { discrete exogenous variable } \\
& \tau_{\mathrm{j},}, \theta_{\mathrm{k}}=\text { parameters. }
\end{aligned}
$$

For each dependent variable $y_{\mathrm{i}}$, a probit function (1) is estimated. When the dependent variable is revenue, the probit function determines the probability of crop failure defined as the probability of expected revenue falling below a threshold value $r_{y}$. In these models, the revenue threshold is selected to correspond to a minimal physical output. The threshold value $r_{y}$ is zero for inputs. 
Two stochastic specifications were considered for the econometric models (equation 2), additive and multiplicative error, with the choice based on goodness of fit and parameter sensitivity to collinearity.

$$
\begin{aligned}
& g\left[y_{\mathrm{i}}\right]=f\left[\beta_{0}+\sum_{\mathrm{j}} \beta_{\mathrm{j}}\left(1-d_{\mathrm{ji}}\right)+\gamma_{\mathrm{j}} \ln \left(\left(1-d_{\mathrm{ji}}\right)+x_{\mathrm{ji}}\right)+\sum_{\mathrm{k}} \delta_{\mathrm{k}} c_{\mathrm{ki}}\right] \\
& \text { where: } \quad g[z]=z, f[z]=\exp (z)+\varepsilon, \text { additive error specification } \\
& g[z]=\ln (z), f[z]=\ln (z)+\varepsilon, \text { multiplicative error specification } \\
& \varepsilon=\text { random error } \\
& \gamma_{\mathrm{j}}, \delta_{\mathrm{k}}=\text { parameters } \\
& d_{\mathrm{ji}}=1 \text { if } x_{\mathrm{ji}}>0, d_{\mathrm{ji}}=0 \text { if } x_{\mathrm{ji}}=0
\end{aligned}
$$

When the input quantities are positive, this is a conventional constant-elasticity model with either an additive or multiplicative error. When input quantities are zero, the model intercept is $\beta_{0}+\sum_{\mathrm{j} \in \mathrm{J}} \beta_{\mathrm{j}}$ where $\mathrm{j}$ indexes the exogenous variables that are zero. The models were estimated using the maximum likelihood estimation of the probit models and the application of least squares to the revenue and input demand equations. Because the use of the input is part of the farmer's decision problem, the estimation of the input demand equations could be affected by selection bias. We tested the models using ordinary least squares and a maximum likelihood estimator for Heckman's selectivity model. The results did not show evidence of selection bias for most models. Combined with the identification issue discussed above, we judged the least squares model estimates to be most reliable.

Following the standard procedures in the literature, for estimation of the revenue functions we assume that input quantities are predetermined relative to output. This assumption can be justified by observing that in CLS, most input quantities such as seed and manure are applied early in the season before most random production shocks (due to e.g., weather and pests) are observed by the farmer. One exception is that farmers may base planting and fertilization decisions on the amount of rainfall that occurs prior to the growing season. However, rainfall and other random events after planting also substantially impact crop output, so this bias should be limited. 


\section{Model Calibration}

The model was calibrated in several steps. First, the econometric models for the exogenous variables and for the revenue and factor demand equations were checked to ensure that simulated values were consistent with observations. Second, the model was calibrated to predict within-sample land allocations, using means of crop price distributions as calibration parameters, based on the idea that price expectations are not observed and may differ from the means of observed ex post price distributions. As Figure 3.2 shows, the correlation between the observed and simulated village-level crop land allocations is about 0.76 . Third, the model's behavior was checked for consistency with economic theory. Figure 3.3 shows the effects of varying the price of maize on the shares of land allocated to the four components of the production system (intercrop, maize, beans, vegetables). As economic theory predicts, the share of land allocated to maize varies positively with the maize price, while the other components vary negatively. Observe that the principal reallocation is between the two key components in the system, the intercrop and maize.

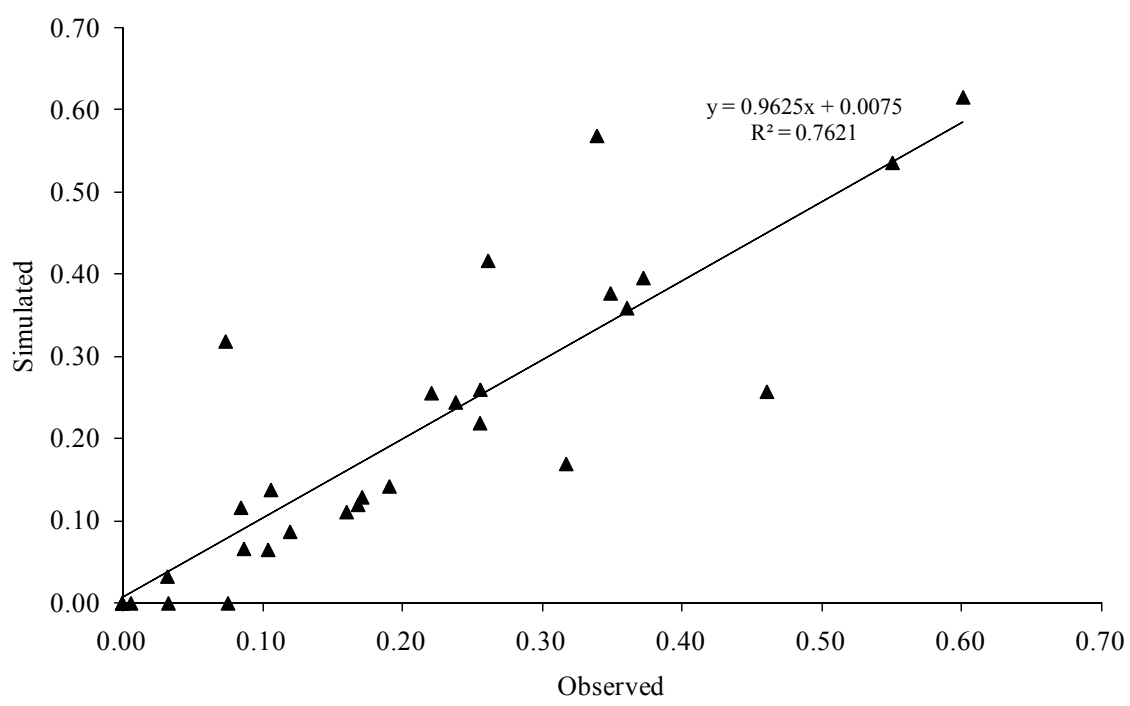

Figure 3.2 Observed versus simulated land allocation shares for the Machakos Model (farm data aggregated to village level) 


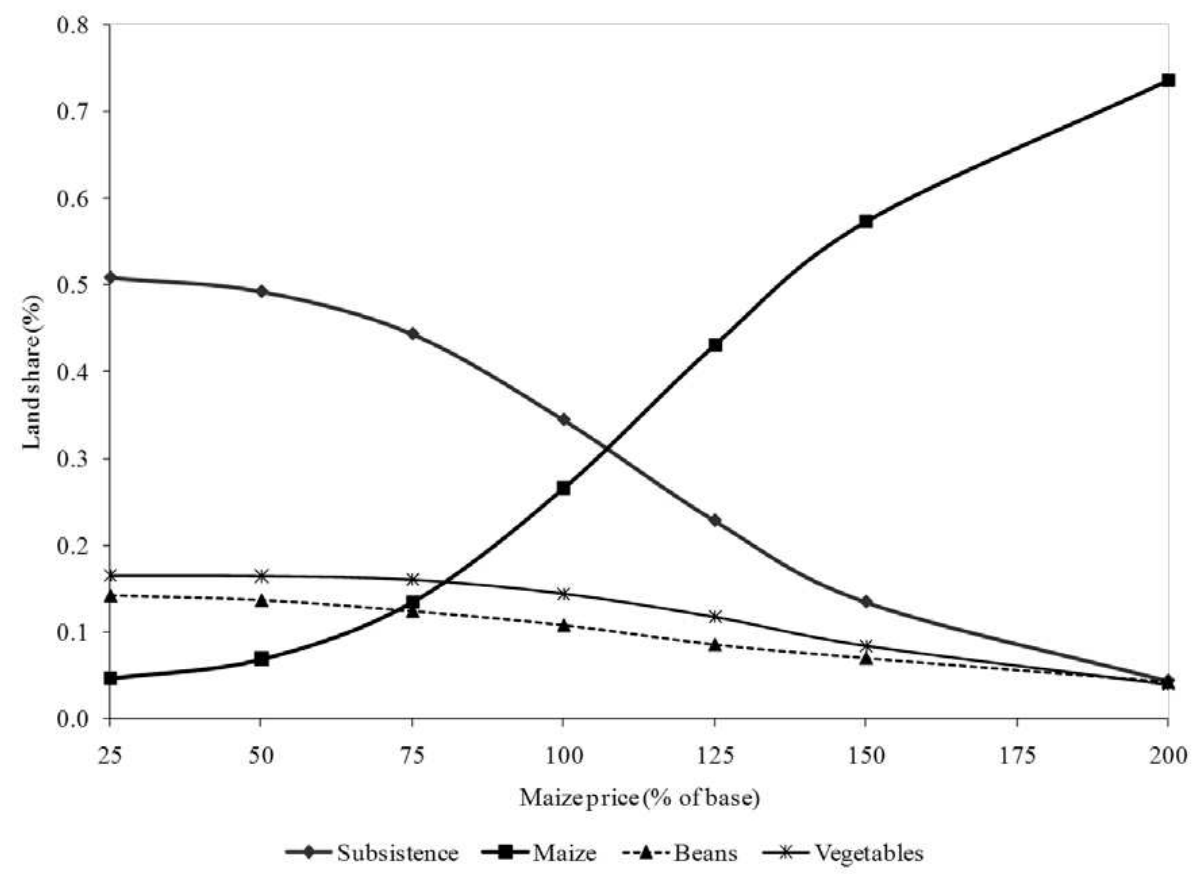

Figure 3.3. Response of simulated land allocation to changes in the mean maize price in the BAU scenario, Machakos, Kenya

\section{Aggregation, Indicators, Scenarios and Tradeoff Curves}

Policy decision makers typically are concerned about the well-being of populations rather than individuals. In the application of the TOA model, the simulations are executed for a sample of farms drawn from maps representing the distribution of bio-physical and economic conditions in the region. The resulting farm-level outcomes can be interpreted as the joint distribution in the population, and can be used to calculate population-level statistics including the poverty rate, the average rate of soil nutrient loss in the population, the risk of soil nutrient loss exceeding a threshold. These simulations can be executed to represent the current or base conditions of the system or to assess the impacts of policy or technology interventions. The impacts of these interventions will depend on current bio-physical and socio-economic conditions together with 
the trends of key elements of the system (e.g., regional market price of fertilizer) that we refer to as Representative Agricultural Pathways (RAP). RAPs are plausible qualitative narratives and quantitative trends that can be translated into model parameters (i.e., scenarios) for policy analysis and climate impact assessment (Rosenzweig et al., 2012; Antle et al., 2013; Valdivia et al. 2014). In this article we use RAPs to specify two development pathways to assess the impacts of proposed interventions of the GoK that have the main goals of reducing poverty and improving food security. We compare the impacts of these RAPs to a RAP that assumes no changes in current growth trends and no implementation of the proposed interventions. The relationships between economic and environmental indicators, which we refer to as "tradeoff curves," can be constructed for each scenario by replicating the simulations while varying one or more parameters in the model. In the analysis presented below, we construct tradeoff curves by varying a key price in the system, the price of maize, which is varied over a range of -75 percent to +100 percent of the mean base price for each RAP. In the design of the scenarios, we set prices parametrically to be consistent with the RAP and interpret them as the result of market equilibria along the development pathway.

\subsection{Assessing Sustainable Development Pathways for Machakos, Kenya}

The Kenyan government has developed a strategic plan (Kenya Vision, 2030) to transform the country into a "new industrialized country that provides a high quality of life to all citizens by 2030 in a clean and secure environment" (GoK, 2008, 2013). The Kenya Vision 2030 provides guidelines for policy and technology interventions in all sectors with the main goals of reducing poverty, increasing food security and protecting the environment. The agricultural sector is one of the pillars for the transformation plans of Kenya, and the Vision 2030 aims to deal with two key policy issues that have been studied in the Machakos region: the loss of soil nutrients and the resulting loss in crop productivity; and the increasing risk of poverty in a growing population dependent on small farms for their livelihoods (de Jager et al., 2001; GoK 2003, 2004, 2005; Alila and Atieno, 2006). In order to complement and implement the Vision 2030 interventions, the Machakos County recently published the "Machakos County Strategic Plan: Form Third Word to First World in One Generation" (Machakos County, 2012). The Machakos strategic plan was designed to help achieve the Vision 2030 goals and align county 
and national policies. The objectives of both the Vision 2030 and the Machakos Strategic Plans are in line with the goals and targets of the Millennium Development Goals (MDGs) and SDGs.

We define a Business as Usual RAP (BAU) as a continuation of current growth trends, the same crop-livestock production system characteristics (small farms, low or no purchased input use, etc.) and no implementation of the Vision 2030. Then we developed two RAPs to represent the GoK strategy and future trends (see Tables 3.3 and 3.4). Several scenarios were developed for each RAP to represent different ways that the Kenyan Vision 2030 and Machakos Strategic Plan could be implemented. We compared these scenarios by assessing the impacts of these policies on two indicators of the system's performance: the poverty rate (defined as the headcount poverty index with the poverty line set at $\$ 1$ per day), and the soil nutrient depletion rate (represented by soil nitrogen loss) derived from the NUTMON model. As noted above, maize is a key crop for rural households and policy makers, so tradeoff curves between these two indicators were constructed by varying the mean of the maize price distribution while holding all other parameters constant. 
Table 3.3. Trends of Key Indicators within each RAP and Scenarios for the Machakos region, Kenya: Direction and Magnitude Changes Respect to the BAU Scenario.

\begin{tabular}{|c|c|c|c|c|c|c|}
\hline & \multicolumn{3}{|c|}{ RAP 1} & \multicolumn{3}{|c|}{ RAP 2} \\
\hline Variable & 1.1 & 1.2 & 1.3 & 2.1 & 2.2 & 2.3 \\
\hline Farm size & & & & & & \\
\hline Household size & $\longrightarrow$ & & & & & \\
\hline $\begin{array}{l}\text { Farms using } \\
\text { mineral fertilize }\end{array}$ & & & & & & \\
\hline Fertilizer price & & & & & & \\
\hline $\begin{array}{l}\text { Quantity miner } \\
\text { fertilizer used }\end{array}$ & & & & & & \\
\hline $\begin{array}{l}\text { Land allocated } \\
\text { Napier Grass }\end{array}$ & & & & & & \\
\hline $\begin{array}{l}\text { Fertilizer applie } \\
\text { to Napier Grass }\end{array}$ & & & & & & \\
\hline Dairy Productiv & & & & & & \\
\hline $\begin{array}{l}\text { Manure } \\
\text { Productivity }\end{array}$ & & & & & & \\
\hline TLU ownership & & & & & & \\
\hline TLU Quantity & & $\longrightarrow$ & & & & \\
\hline $\begin{array}{l}\text { Off farm } \\
\text { employment } \\
\text { opportunities }\end{array}$ & & & & & & \\
\hline
\end{tabular}

\begin{tabular}{|l|l|l|l|l|l|l|l|}
\hline & $\begin{array}{l}\text { No } \\
\text { change }\end{array}$ & $\begin{array}{l}\text { Small } \\
\text { increase }\end{array}$ & $\begin{array}{l}\text { Moderate } \\
\text { increase }\end{array}$ & $\begin{array}{l}\text { Large } \\
\text { increase }\end{array}$ & $\begin{array}{l}\text { Small } \\
\text { decrease }\end{array}$ & $\begin{array}{l}\text { Moderate } \\
\text { decrease }\end{array}$ & $\begin{array}{l}\text { Large } \\
\text { decrease }\end{array}$ \\
\hline $\begin{array}{l}\text { Direction and } \\
\text { magnitude }\end{array}$ & $\longrightarrow$ & $\longrightarrow$ & $\nearrow$ & & $\longrightarrow$ & & \\
\hline
\end{tabular}


Table 3.4. Scenarios design for impact assessment of policy and technology interventions, Machakos, Kenya

\begin{tabular}{|c|c|c|c|c|c|c|c|}
\hline \multirow[b]{2}{*}{ Variable } & $\begin{array}{c}\text { Business as } \\
\text { Usual }\end{array}$ & \multicolumn{3}{|c|}{ RAP 1} & \multicolumn{3}{|c|}{ RAP 2} \\
\hline & Base & Scenario 1.1 & Scenario 1.2 & Scenario 1.3 & Scenario 2.1 & Scenario 2.2 & Scenario 3.2 \\
\hline Farm Size & 3.7 ha & Double & Double & Double & Double & $\begin{array}{c}\text { Increases to a } \\
\text { regional } \\
\text { average of } 11 \\
\text { ha }\end{array}$ & $\begin{array}{l}\text { Increases to a } \\
\text { regional average } \\
\text { of } 11 \text { ha }\end{array}$ \\
\hline Houhehold Size & 8 & reduced by $25 \%$ & $\begin{array}{c}\text { reduced by } \\
25 \%\end{array}$ & $\begin{array}{c}\text { reduced by } \\
25 \%\end{array}$ & $\begin{array}{l}\text { reduced by } \\
25 \%\end{array}$ & reduced by $25 \%$ & reduced by $25 \%$ \\
\hline $\begin{array}{l}\text { Farms using Mineral } \\
\text { fertilizer }\end{array}$ & $20 \%$ & $100 \%$ & $100 \%$ & $100 \%$ & $100 \%$ & $100 \%$ & $100 \%$ \\
\hline Fetilizer Price & $30 \mathrm{Khs} / \mathrm{Kg}$ & Reduced by $50 \%$ & $\begin{array}{c}\text { Reduced by } \\
50 \%\end{array}$ & $\begin{array}{c}\text { Reduced by } \\
75 \%\end{array}$ & $\begin{array}{c}\text { Reduced by } \\
75 \%\end{array}$ & $\begin{array}{c}\text { Reduced by } \\
75 \%\end{array}$ & Reduced by $75 \%$ \\
\hline $\begin{array}{l}\text { Quantity mineral fertilizer } \\
\text { used }\end{array}$ & $\begin{array}{l}\text { Estimated by } \\
\text { model }\end{array}$ & $\begin{array}{l}\text { Estimated by } \\
\text { model }\end{array}$ & Increased & Increased & Increased & Increased & Increased \\
\hline $\begin{array}{l}\text { Fertilizer applied to Napier } \\
\text { Grass }\end{array}$ & No & No & No & No & No & No & Yes \\
\hline Dairy Productivity & $\begin{array}{l}\text { Estimated by } \\
\text { model }\end{array}$ & No change & No change & No change & Small increase & $\begin{array}{l}\text { Moderate } \\
\text { increase }\end{array}$ & High increase \\
\hline Manure Productivity & $\begin{array}{l}\text { Estimated by } \\
\text { model }\end{array}$ & No change & No change & No change & $\begin{array}{l}\text { Moderate } \\
\text { increase }\end{array}$ & $\begin{array}{l}\text { Moderate } \\
\text { increase }\end{array}$ & $\begin{array}{l}\text { Moderate } \\
\text { increase }\end{array}$ \\
\hline TLU Ownership & $\begin{array}{l}\text { Estimated by } \\
\text { model }\end{array}$ & No change & No change & No change & $\begin{array}{l}\text { All farms have } \\
\text { TLUs }\end{array}$ & $\begin{array}{l}\text { All farms have } \\
\text { TLUs }\end{array}$ & $\begin{array}{l}\text { All farms have } \\
\text { TLUs }\end{array}$ \\
\hline Average TLU Quantity & 1.95 & No change & No change & No change & $\begin{array}{c}\text { All farms have } \\
\text { average TLU } \\
\text { quantity }\end{array}$ & $\begin{array}{c}\text { Increase by } \\
250 \% \text { on } \\
\text { average }\end{array}$ & $\begin{array}{c}\text { Increase by } \\
250 \% \text { on average }\end{array}$ \\
\hline
\end{tabular}


RAP 1: Implementing the Vision 2030 with continuation of current growth trends and current production systems. Under this pathway, the GoK implements two key sets of the proposed Vision 2030 policy interventions. The first set includes interventions that seek to reduce import tariffs and increase investments in market infrastructure with the objective of increasing fertilizer availability and reducing its farm-gate cost. The second set is composed of policies based on increasing non-agricultural industry and trade that would lead to improving off-farm employment opportunities and farm consolidation.

Scenario 1.1: This scenario is based on previous Kenyan strategic plans (GoK, 2004, 2005) and assumes that the mean fertilizer price would be reduced by 50 percent, which would induce all farmers to use a positive quantity of fertilizer, as determined by the fertilizer demand functions at the reduced price (note that the analysis of this scenario is only possible with a model that incorporates fertilizer as a non-essential input). In addition, for this scenario it is assumed that improved off-farm employment opportunities and farm consolidation would reduce household size by $25 \%$, from 8 to 6 persons, and double farm size from the regional average of 3 to 6 ha. Valdivia, Antle and Stoorvogel (2012) assessed the impacts of this combination of interventions on poverty and nutrient depletion rates for the same region.

Scenario 1.2: In addition to the assumptions made in scenario 1.1, we assume that farmers use higher quantities of mineral fertilizer as a consequence of increased technical assistance promoted by the government and county policies.

Scenario 1.3: This scenario incorporates the goal of the Machakos strategic plan to reduce the mineral fertilizer price by $75 \%$ using the same assumptions as scenario 1.2 .

RAP2: The GoK exhibits an improved capacity to facilitate economic development, including increased investment in infrastructure and implementation of programs to promote more livestock and dairy oriented production systems where feasible. Sustainable intensification interventions are developed and promoted.

Similar to RAP1, there is ongoing economic growth and the proposed GoK interventions to deal with poverty and soil degradation are implemented. However, there is more investment in infrastructure for the livestock and dairy sectors, and provides more technical assistance for adoption and management of improved livestock breeds. More off-farm employment opportunities exist and average household size is reduced, while livestock herd sizes increase. 
Scenario 2.1. Scenario 1.3 is modified so that the share of land allocated to grass increases from $20 \%$ to $49 \%$ on average, and Napier grass is cultivated for livestock feed. This scenario also assumes that all farms have livestock, which in turn increases dairy and manure production.

Scenario 2.2. This scenario assumes that all farms produce livestock and the average number of TLUs per farm is increased by $250 \%$. The GoK intervention also seek to increase livestock and dairy productivity through the promotion of improved breeds, increased land allocated to (improved) pastures and enhancing market opportunities for dairy products. These types of interventions are in line with what the East Africa Dairy Development Project (EADD) is promoting throughout several regions of Africa, including Kenya (EADD, 2013, 2014). Several studies also suggest that improving livestock productivity could potentially be a way to deal with the poverty trap (Thornton and Herrero, 2001; Herrero et al., 2009). In addition, we assume that improved off-farm employment opportunities and farm consolidation will increase farm size to a regional average of 11 hectares.

Scenario 2.3. The promotion of improved breeds leads to an increase in dairy productivity. Similar to the previous scenarios we assume that policy interventions reduce import tariffs and increase investment in market infrastructure designed to increase fertilizer availability and reduce its farm-gate cost. The GoK is buying fertilizer and making it available to farmers through their agencies. In addition, the government wants to eliminate the dependence on imports and reduce fertilizer prices, so a new fertilizer plant is currently being built. It is important to note that Napier grass used for livestock feed could actually be a soil-depleting crop if fertilization rates are not adequate. This scenario assumes that fertilizer is available to all farmers and that Napier grass is fertilized.

\subsection{Results}

To illustrate the econometric model's properties, we present selected results for the intercrop and maize, as well as the livestock models. Table 3.5 presents the revenue functions and crop failure equations for the complex intercrop and maize. The revenue functions are specified with the dependent variable as value of crop output. Note that because the revenue functions are specified as functions of input quantities, and given the discrete/continuous 
structure of the input demand models, the own-price parameters represent only part of the supply response. This partial output price response is positive but less for the intercrop than for maize, consistent with the fact that the subsistence crops within the intercrop are produced primarily for home consumption and thus are less price-responsive. The parameters also indicate a positive relationship between inherent productivity and output, but do not show a statistically significant effect on the probability of crop failure, suggesting that crop failure is associated primarily with management and weather events. Field size shows the typical negative relationship with productivity in this type of systems, and a positive association with crop failure, as might be expected if larger fields are managed less intensively, and the timing of key activities such as planting is more difficult to manage for larger fields. Farm size and family labor do not have strong effects on productivity, but are strongly and negatively associated with crop failure, indicating that larger farms are better able to manage risks such as climate variability. Inputs generally show positive marginal products, and increased input use generally reduces crop failure risk.

Table 3.5. Output Equations for Complex Intercrop and Maize for Machakos, Kenya

\begin{tabular}{lllll}
\hline Variable & Intercrop output & Intercrop failure & $\begin{array}{l}\text { Maize } \\
\text { grain }\end{array}$ & $\begin{array}{l}\text { Maize } \\
\text { failure }\end{array}$ \\
\hline Intercept & -4.283 & -0.525 & -4.749 & 1.333 \\
& $(3.179)$ & $(3.61)$ & $(3.262)$ & $(2.672)$ \\
Output price & 1.162 & - & 1.690 & - \\
Inprod & $(0.178)$ & & $(0.387)$ & \\
& 0.830 & .358 & 0.431 & 0.224 \\
Area & $(0.389)$ & $(0.515)$ & $(0.385)$ & $(0.342)$ \\
Farm size & -0.515 & 0.621 & -0.674 & 0.617 \\
& $(0.169)$ & $(0.182)$ & $(0.114)$ & $(0.148)$ \\
Family labor & -0.080 & -0.781 & 0.381 & -0.437 \\
Education & $(0.167)$ & $(0.194)$ & $(0.123)$ & $(0.146)$ \\
& 0.176 & -0.674 & 0.362 & -0.578 \\
Occupation & $(0.140)$ & $(0.115)$ & $(0.082)$ & $(0.118)$ \\
& 0.853 & 0.358 & 0.858 & -0.283 \\
Off-farm income & $(0.523)$ & $(0.455)$ & $(0.207)$ & $(0.211)$ \\
Season & 0.098 & 0.524 & 0.473 & -0.352 \\
& $(0.122)$ & $(0.255)$ & $(0.170)$ & $(0.175)$ \\
Manure intercept & - & -0.021 & - & -0.101 \\
& & $(0.231)$ & & $(0.157)$ \\
& 0.495 & 0.769 & 0.248 & -0.155 \\
& $(0.132)$ & $(0.240)$ & $(0.148)$ & $(0.159)$ \\
& 0.684 & -0.046 & 0.847 & -0.313
\end{tabular}




\begin{tabular}{|c|c|c|c|c|}
\hline Variable & Intercrop output & Intercrop failure & $\begin{array}{l}\text { Maize } \\
\text { grain }\end{array}$ & $\begin{array}{l}\text { Maize } \\
\text { failure }\end{array}$ \\
\hline & $(0.519)$ & $(0.266)$ & $(0.505)$ & $(0.161)$ \\
\hline Manure quantity & $\begin{array}{l}0.140 \\
(0.077)\end{array}$ & - & $\begin{array}{l}0.181 \\
(0.076)\end{array}$ & - \\
\hline Hired labor intercept & - & $\begin{array}{l}-0.204 \\
(0.278)\end{array}$ & - & $\begin{array}{l}-0.028 \\
(0.178)\end{array}$ \\
\hline Hired labor & $\begin{array}{l}0.253 \\
(0.186)\end{array}$ & - & $\begin{array}{l}0.090 \\
(0.187)\end{array}$ & - \\
\hline Mineral fert intercept & $\begin{array}{l}1.543 \\
(1.265)\end{array}$ & $\begin{array}{l}-0.172 \\
(0.400)\end{array}$ & $\begin{array}{l}1.014 \\
(0.499)\end{array}$ & $\begin{array}{l}-0.310 \\
(0.211)\end{array}$ \\
\hline Mineral fert quantity & $\begin{array}{l}0.331 \\
(0.292)\end{array}$ & - & $\begin{array}{l}0.324 \\
(0.128)\end{array}$ & - \\
\hline Seed intercept & $\begin{array}{l}-0.081 \\
(0.177)\end{array}$ & $\begin{array}{l}-0.684 \\
(0.242)\end{array}$ & $\begin{array}{l}0.609 \\
(0.220)\end{array}$ & $\begin{array}{l}-0.320 \\
(0.209)\end{array}$ \\
\hline Pesticide intercept & $\begin{array}{l}0.522 \\
(0.126)\end{array}$ & - & $\begin{array}{l}0.077 \\
(0.249)\end{array}$ & - \\
\hline Irrigation intercept & - & - & $\begin{array}{l}0.482 \\
(0.148)\end{array}$ & - \\
\hline $\mathrm{R}^{2}$ & 0.459 & 0.855 & 0.303 & 0.744 \\
\hline $\mathrm{N}$ & 155 & 235 & 384 & 429 \\
\hline
\end{tabular}

Note: standard errors in parentheses.

Table 3.6 shows that there is a strong positive effect of farm size on the number of livestock and on dairy production. Larger farms have more livestock and produce more dairy products and manure. As expected, increased feed input has a positive impact on dairy and manure production. Full-time farmers are more likely to be dairy producers and achieve higher dairy productivity; larger family size is associated with substantially more livestock per hectare, perhaps because of their ability to manage more animals. Off-farm income is strongly associated with dairy production. Some analysts argue that off-farm income provides the ability to selffinance feed purchases, for example, but this positive association could be a spurious correlation due to proximity to markets for dairy and labor market opportunities for family labor. The data also show strong spatial differences in all of these relationships. 
Table 3.6. Livestock Equations for Machakos, Kenya

\begin{tabular}{|c|c|c|c|c|c|}
\hline Variable & Livestock use & Livestock units & $\begin{array}{l}\text { Dairy } \\
\text { use }\end{array}$ & $\begin{array}{l}\text { Dairy } \\
\text { production }\end{array}$ & $\begin{array}{l}\text { Manure } \\
\text { production }\end{array}$ \\
\hline Intercept & $\begin{array}{l}2.400 \\
(0.526)\end{array}$ & $\begin{array}{l}-1.947 \\
(0.543)\end{array}$ & $\begin{array}{l}-3.050 \\
(0.303)\end{array}$ & $\begin{array}{l}1.956 \\
(0.334)\end{array}$ & $\begin{array}{l}4.688 \\
(0.141)\end{array}$ \\
\hline Farm size & $\begin{array}{l}-0.016 \\
(0.027)\end{array}$ & $\begin{array}{l}-0.710 \\
(0.107)\end{array}$ & $\begin{array}{l}0.739 \\
(0.084)\end{array}$ & $\begin{array}{l}-0.257 \\
(0.093)\end{array}$ & $\begin{array}{l}-0.102 \\
(0.038)\end{array}$ \\
\hline Milk price & & & & $\begin{array}{l}0.100 \\
(0.000)\end{array}$ & \\
\hline Feed & & & & $\begin{array}{l}0.142 \\
(0.041)\end{array}$ & $\begin{array}{l}0.397 \\
(0.021)\end{array}$ \\
\hline Literacy & $\begin{array}{l}-0.591 \\
(0.292)\end{array}$ & $\begin{array}{l}0.409 \\
(0.230)\end{array}$ & $\begin{array}{l}0.176 \\
(0.039)\end{array}$ & $\begin{array}{l}0.054 \\
(0.033)\end{array}$ & $\begin{array}{l}0.029 \\
(0.016)\end{array}$ \\
\hline Occupation & $\begin{array}{l}-0.233 \\
(0.224)\end{array}$ & $\begin{array}{l}-0.310 \\
(0.149)\end{array}$ & $\begin{array}{l}0.518 \\
(0.114)\end{array}$ & $\begin{array}{l}0.473 \\
(0.126)\end{array}$ & $\begin{array}{l}0.112 \\
(0.051)\end{array}$ \\
\hline Family size & $\begin{array}{l}0.020 \\
(0.031)\end{array}$ & $\begin{array}{l}0.715 \\
(0.181)\end{array}$ & $\begin{array}{l}0.043 \\
(0.115)\end{array}$ & $\begin{array}{l}-0.324 \\
(0.118)\end{array}$ & $\begin{array}{l}-0.064 \\
(0.054)\end{array}$ \\
\hline Off-farm income & $\begin{array}{l}0.237 \\
(0.197)\end{array}$ & $\begin{array}{l}-0.334 \\
(0.131)\end{array}$ & $\begin{array}{l}0.453 \\
(0.107)\end{array}$ & $\begin{array}{l}0.868 \\
(0.108)\end{array}$ & $\begin{array}{l}0.081 \\
(0.046)\end{array}$ \\
\hline Livestock units & & & $\begin{array}{l}0.489 \\
(0.054)\end{array}$ & $\begin{array}{l}-0.464 \\
(0.064)\end{array}$ & $\begin{array}{l}-0.191 \\
(0.018)\end{array}$ \\
\hline Dairy farm & & & & & $\begin{array}{l}0.144 \\
(0.052)\end{array}$ \\
\hline Season & & & $\begin{array}{l}0.031 \\
(0.104)\end{array}$ & $\begin{array}{l}-0.005 \\
(0.119)\end{array}$ & $\begin{array}{l}0.087 \\
(0.048)\end{array}$ \\
\hline Kionyweni & $\begin{array}{l}-1.768 \\
(0.367)\end{array}$ & $\begin{array}{l}0.740 \\
(0.271)\end{array}$ & $\begin{array}{l}-0.180 \\
(0.181)\end{array}$ & $\begin{array}{l}1.293 \\
(0.263)\end{array}$ & $\begin{array}{l}-0.326 \\
(0.079)\end{array}$ \\
\hline Kasikeu & $\begin{array}{l}-1.798 \\
(0.372)\end{array}$ & $\begin{array}{l}0.998 \\
(0.299)\end{array}$ & $\begin{array}{l}0.994 \\
(0.147)\end{array}$ & $\begin{array}{l}-0.209 \\
(0.180)\end{array}$ & $\begin{array}{l}-0.484 \\
(0.071)\end{array}$ \\
\hline Kiomo & $\begin{array}{l}-1.060 \\
(0.448)\end{array}$ & $\begin{array}{l}0.546 \\
(0.504)\end{array}$ & $\begin{array}{l}0.816 \\
(0.167)\end{array}$ & $\begin{array}{l}-1.102 \\
(0.225)\end{array}$ & $\begin{array}{l}0.083 \\
(0.079)\end{array}$ \\
\hline Matuu & $\begin{array}{l}-0.081 \\
(0.452)\end{array}$ & $\begin{array}{l}1.043 \\
(0.245)\end{array}$ & $\begin{array}{l}1.841 \\
(0.146)\end{array}$ & $\begin{array}{l}0.328 \\
(0.173)\end{array}$ & $\begin{array}{l}0.721 \\
(0.076)\end{array}$ \\
\hline Kibwezi & $\begin{array}{l}-2.390 \\
(0.394)\end{array}$ & $\begin{array}{l}0.702 \\
(0.420)\end{array}$ & $\begin{array}{l}1.757 \\
(0.211)\end{array}$ & $\begin{array}{l}-0.213 \\
(0.238)\end{array}$ & $\begin{array}{l}0.184 \\
(0.110)\end{array}$ \\
\hline $\mathrm{R}^{2}$ & 0.78 & 0.34 & 0.80 & 0.44 & 0.56 \\
\hline $\mathrm{N}$ & 295 & 221 & 1163 & 356 & 934 \\
\hline
\end{tabular}

Note: Standard errors in parentheses; livestock use and dairy use are probit equations; $\mathrm{R}^{2}$ for probit equations is proportion of correct predictions, livestock units $=$ tropical livestock units per ha; occupation $=$ dummy for full time farmer; dairy production $=\mathrm{kg}$ /livestock unit; manure production $=\mathrm{kg} /$ livestock unit. 
Table 3.7 presents the selected input demand equations for the subsistence and maize systems. We assume that the application of manure is determined largely by the amount of livestock on the farm, so manure use is an explanatory variable in other input use and quantity equations. Cross-price effects were generally not large or significant, so they are not presented. The input demand equations show that inherent productivity generally has strong and statistically significant effects on the decision to use an input and on the quantity applied when an input is used. For example, inherent productivity has a large and positive effect on manure use in both the intercrop and maize, and on fertilizer use in maize, indicating a complementary effect of favorable soil and climate conditions on use of organic amendments and mineral fertilizer, consistent with the findings of Marenya and Barrett (2009). The results also show that both input use/non-use and application rates generally are responsive to input prices. As expected, livestock presence on the farm has a strong positive effect on manure use and application rates. Other exogenous variables (field size, farm size, family labor, etc.) have mixed effects on inputs. For example, farm size has a positive effect on labor use in maize and a negative effect on labor use in the intercrop, suggesting a bias in larger farms towards the cash crop maize. 


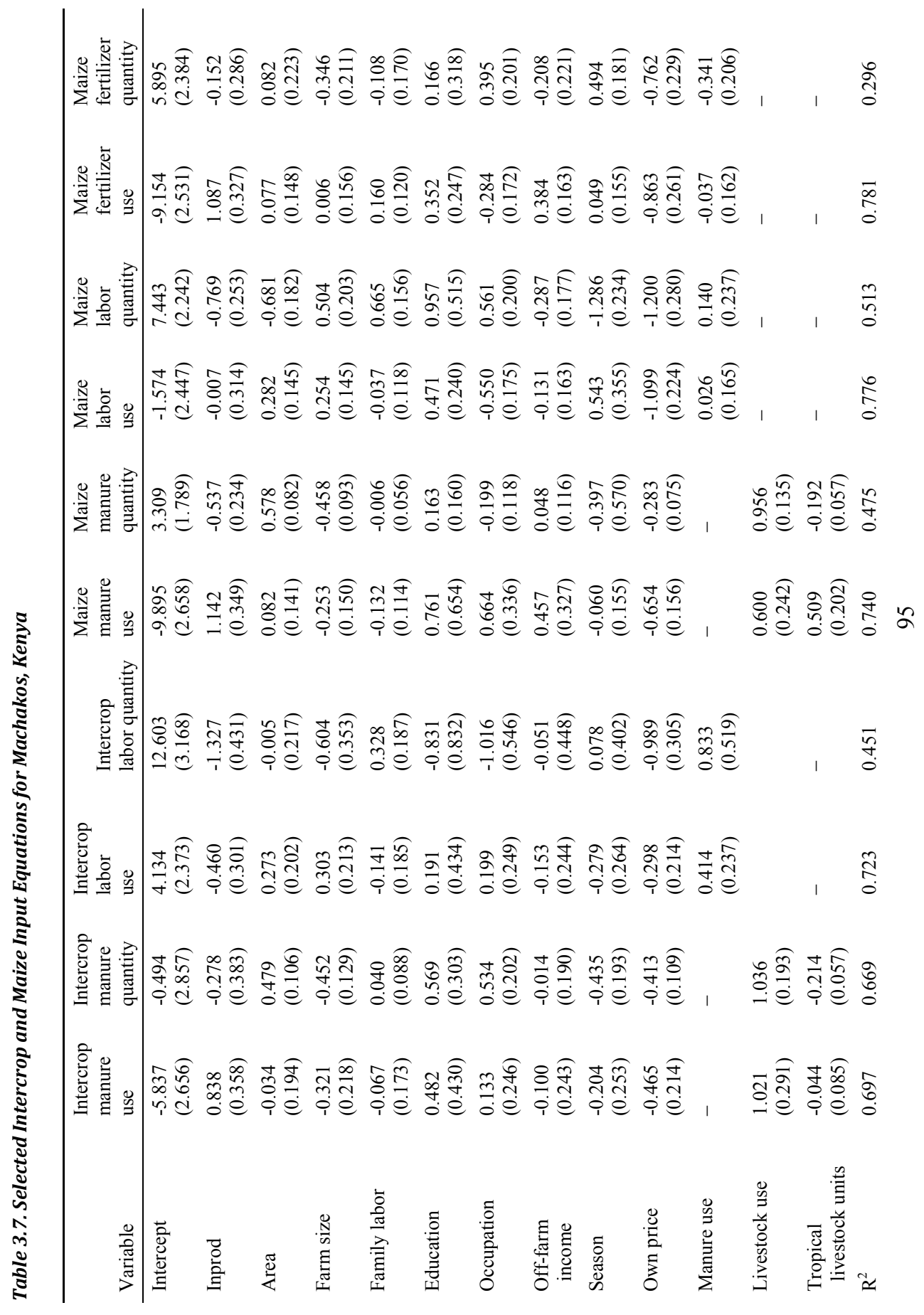




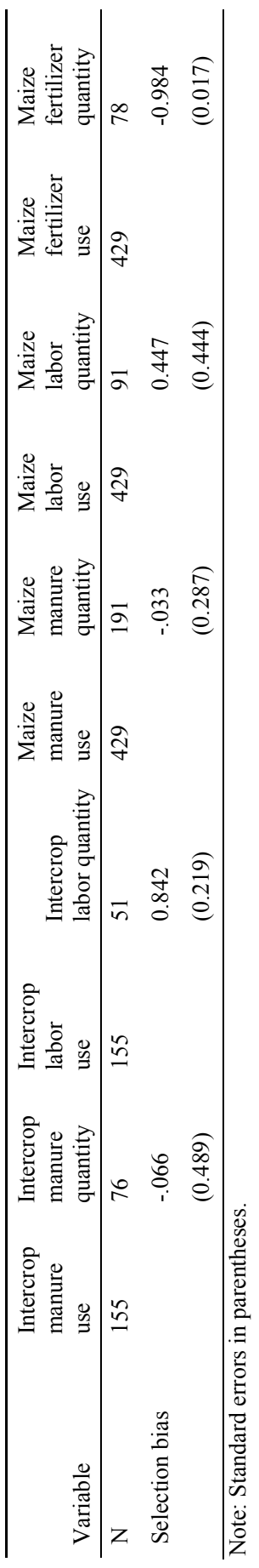


Two key assumptions in the scenarios described above are the increased availability and price reduction of mineral fertilizer. In order to better understand the effects of these assumptions we compare the BAU scenario to a case where all farms use fertilizer and mineral fertilizer price is reduced by $50 \%$, while holding other parameters constant. Figure 3.4 illustrates the simulated distributions of mineral fertilizer applied under the BAU scenario and the effects of fertilizer availability. This figure demonstrates the ability of the discrete-choice structure of the model to represent non-essential input use and policies designed to increase fertilizer use. In the BAU case, about 75 percent of farmers do not use mineral fertilizer, consistent with the observed data (Table 3.2). When fertilizer is made available, this spike at zero is eliminated and the distribution is spread across a wide range, with a substantial number of farmers still using relatively small quantities, but the majority of farmers using much larger quantities than in the BAU case. However, the efficiency (i.e., positive effect on soil nutrients and crop yields) of the increased use of fertilizer depends largely on the soil conditions (e.g., $\mathrm{N}$ stock) and the level of intensification as discussed below. 


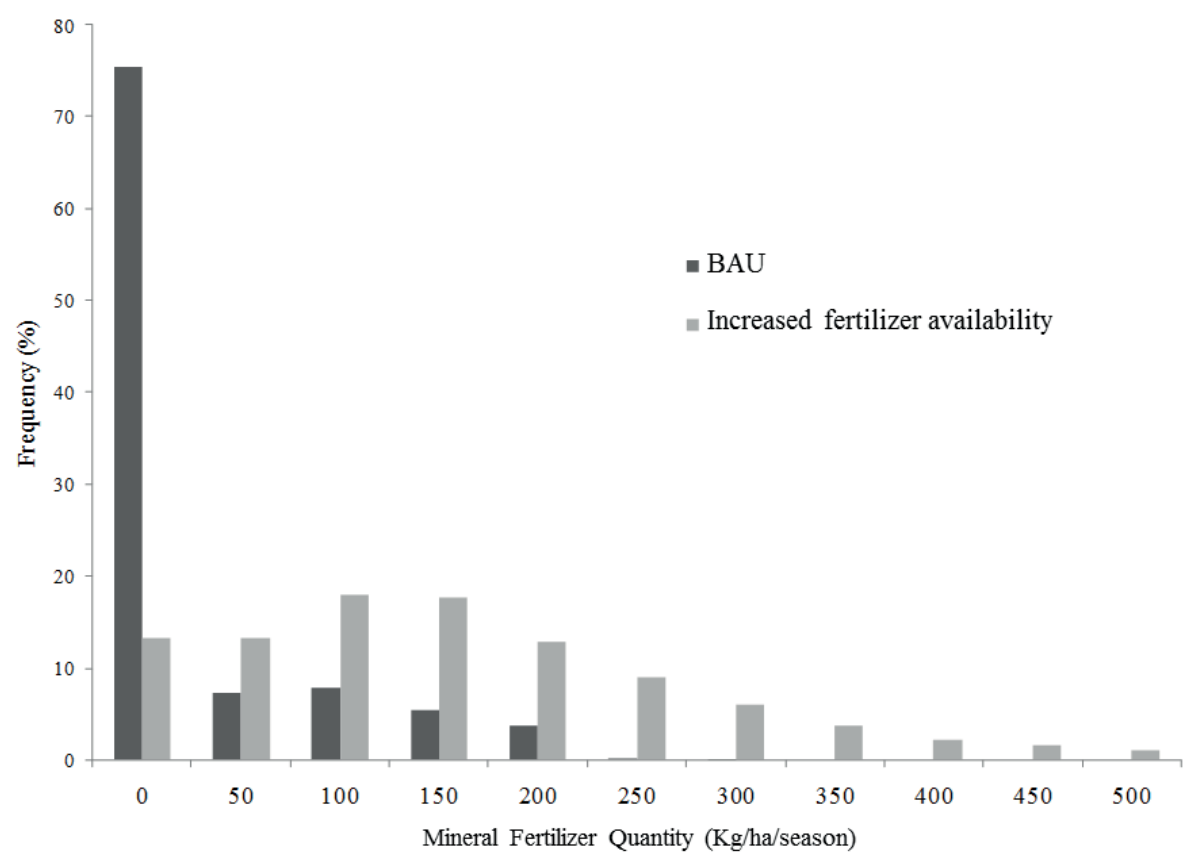

Figure 3.4. Distribution of mineral fertilizer applications under the BAU scenario compared to the case where mineral fertilizer availability is increased (price of mineral fertilizer is reduced by $50 \%$ and all farms use a positive amount) for Machakos, Kenya.

Figure 3.5 shows the poverty-nutrient depletion tradeoffs for the Machakos region, for the BAU scenario and the three scenarios under each RAP described above. These tradeoff curves represent all the scenarios generated by varying the mean of the maize price distribution as in figure 3.3. The BAU scenario tradeoff curve shows that at the base maize price (the midpoint on the tradeoff curve), the headcount poverty rate is about $76 \%$, a value similar to the rural poverty rate found by recent studies based on Government of Kenya statistics (GoK, 2003). The nutrient depletion variable has a regional mean value of about $30 \mathrm{~kg} / \mathrm{ha}$ of $\mathrm{N}$. As the maize price is varied we see a negative relationship between poverty and nutrient loss. Note that this loss indicates the system is not sustainable; eventually productivity of the system will decline to a low-level equilibrium and the rate of loss will decline to zero. As the maize price increases, poverty is reduced as farm income increases, and vice versa, as expected, for all scenarios. 
Scenario 1.1 has relatively large impacts on nutrient depletion and small impacts on poverty at low maize prices, and opposite effects at higher maize prices, showing that there is an important interaction between maize and fertilizer prices and availability (see Table 3.8). The results discussed below are at the base maize price (middle point of the tradeoff curve), unless noted. The results suggest that the increase in farm size in scenario 1.1 increases livestock use and thus the availability of manure. In addition, the use of mineral fertilizer increases. The greater reduction in poverty is caused by the higher per capita incomes associated with the larger farm size and the smaller family size in the scenario. Figure 3.5 shows that increasing fertilizer use as in scenario 1.2 , results in a further reduction in nutrient depletion and an improvement in poverty rates compared to scenario 1.1 (from point $B$ to $C$ ). Average soil nutrient losses decline to very low rates while poverty rates decrease by about $40 \%$ at low maize prices and by $86 \%$ at high maize prices. These results suggest that adding more nutrients to the system is a key factor to improve the sustainability of the system. This hypothesis is confirmed with the results of scenario 1.3, where fertilizer price has been reduced by $75 \%$ making it more affordable for farmers and therefore increasing its use. Our results indicate that on average, fertilizer use ( $\mathrm{kg} /$ farm/season) increased by $60 \%$ in scenario 1.3 compared to scenario 1.2 (point $D$ ). Soil N losses are negative (i.e., there are gains of soil nutrients to the system) at any maize price. Increasing fertilizer use also increases maize productivity, which leads to an increase on average farm income and to a reduction in poverty rates. 


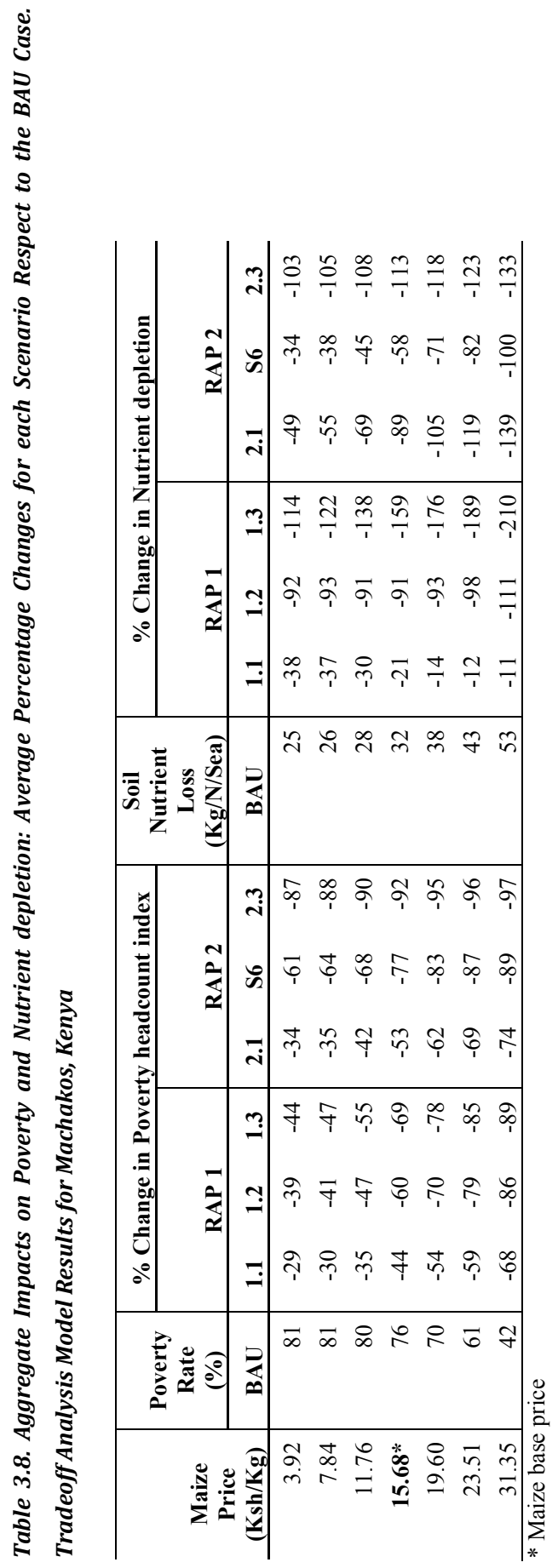




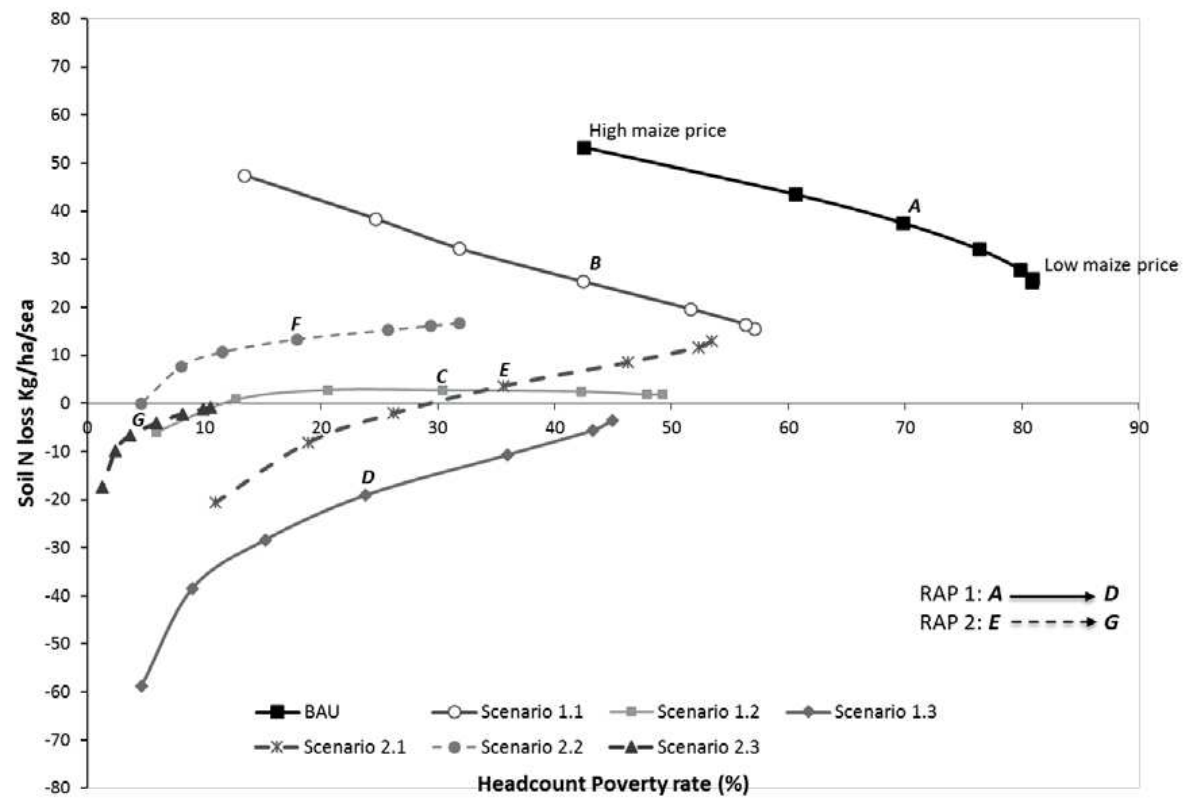

Figure 3.5. Poverty-nutrient depletion tradeoffs Machakos region: Pathway from tradeoffs to win-win outcomes as intervention and strategies are implemented (RAP1: A to D and RAP2: E to G). Tradeoffs generated by changes in the mean maize price (maize price increases from right to left, mid-point is base price).

The scenarios under RAP 2 are based on switching part of the production system to livestock. Scenarios 2.1 to 2.3 represent policies that promote livestock and dairy production. Scenario 2.1 shows the case of increasing the land allocated to Napier grass and having all farms own livestock while keeping the other assumptions of scenario 1.3. The results show that soil nutrient losses and poverty rates are higher than those obtained under scenario 1.3 (see point $E$ in figure 3.5), due to the increase of non-fertilized Napier grass area and the requirement that all farms have livestock. Scenario 2.2 results show the effects of farm consolidation (i.e., larger farm size) and the increase of livestock on the farm. These two factors have a large positive effect on poverty rates, but as expected soil 
nutrient losses increase with respect to scenario 2.1 (point $F$ ). It is important to note that in these two scenarios 2.1 and 2.2, the improvement in soil degradation and poverty rates with respect to the BAU scenario is considerable, in particular at high maize prices.

Scenario 2.3 represents a more complete implementation of the Vision 2030 and investments that aim to increase livestock productivity. The results show that both poverty rates and soil nutrient losses are at levels that would guarantee the sustainability of the system (point $G$ ). In this scenario, Napier grass is fertilized at recommended rates and dairy productivity is increased due to the adoption of improved breeds that yield higher milk productivity. This scenario provides a win-win (environmental-economic) situation at any maize price. Figure 3.5 shows the overall pathway from tradeoffs to synergies as interventions and strategies are implemented in the Machakos region. RAP 1 scenarios follow the pathway from $A$ to $D$ while implementation of RAP 2 scenarios continue the path from $E$ to $G$. Although the aggregate figure shows this transition from tradeoffs to win-win outcomes, some villages may respond differently to the proposed interventions due to the systems heterogeneity that characterizes this region as we discuss below.

The aggregated results discussed above show the regional impacts of these interventions. However, it is also important to recognize that the impacts can vary considerably across a heterogeneous region such as Machakos. Figure 3.6 and Table 3.9 show the importance of heterogeneity across Machakos, in terms of the levels of poverty and nutrient depletion in response to change in maize prices and RAPs. Figure 6 shows that there are substantially different sub-regional responses of poverty and nutrient depletion to the maize price and to the policy interventions under the two RAPs and corresponding scenarios. In Kiomo where subsistence crops play a large role in the farming system and maize responds poorly to nutrient inputs due to poor soils and low rainfall, an increase in maize prices raises incomes but induces little increase in nutrient inputs; in contrast, in Matuu where irrigated vegetables are an important crop in the system and farmers have better access to markets, maize prices have relatively little impact on poverty but induce substantial increases in nutrient use. 

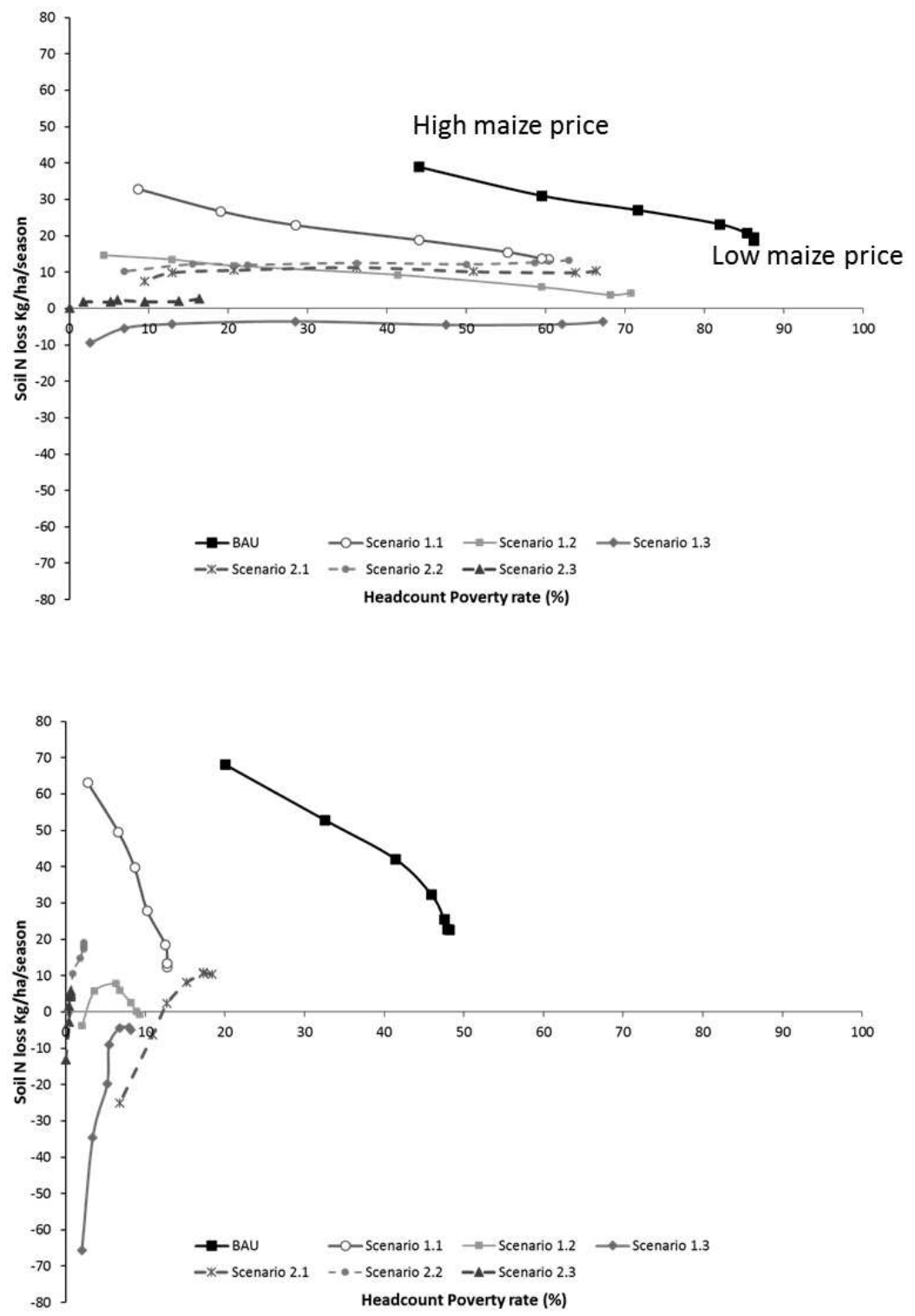

Figure 3.6. Response of Poverty-nutrient depletion tradeoffs to maize price and importance of system heterogeneity: rainfed maize based subsistence system (Kiomo, top) versus irrigated vegetables and better market access systems (Matuu, bottom). Tradeoffs generated by changes in the mean maize price (maize price increases from right to left, mid-point is base price) for all the scenarios under each RAP. 
Table 3.9. Impacts on Poverty and Nutrient depletion: Changes by Village and Scenario for Low, Base and High Maize Prices. Tradeoff Analysis Model Results for Machakos, Kenya

\begin{tabular}{|c|c|c|c|c|c|c|c|}
\hline \multirow[b]{2}{*}{ Village } & \multirow[b]{2}{*}{ Scenario } & \multicolumn{3}{|c|}{ Headcount Poverty Rate (\%) } & \multicolumn{3}{|c|}{$\begin{array}{l}\text { Soil Nutrient Loss } \\
\text { (Kg N/Ha/season) }\end{array}$} \\
\hline & & $\begin{array}{c}\text { Low } \\
\text { Maize } \\
\text { Price }\end{array}$ & $\begin{array}{c}\text { Base } \\
\text { Maize } \\
\text { Price }\end{array}$ & $\begin{array}{c}\text { High } \\
\text { maize } \\
\text { Price }\end{array}$ & $\begin{array}{c}\text { Low } \\
\text { Maize } \\
\text { Price }\end{array}$ & $\begin{array}{c}\text { Base } \\
\text { Maize } \\
\text { Price }\end{array}$ & $\begin{array}{c}\text { High } \\
\text { maize } \\
\text { Price }\end{array}$ \\
\hline \multirow{7}{*}{ Machakos } & BAU & 90.7 & 88.2 & 41.9 & 31.4 & 36.6 & 58.2 \\
\hline & 1.1 & 68.6 & 55.9 & 17.2 & 20.1 & 29.4 & 54.3 \\
\hline & 1.2 & 53.5 & 43.0 & 10.8 & 12.3 & 20.0 & 27.5 \\
\hline & 1.3 & 47.7 & 34.4 & 7.5 & 8.6 & 5.3 & -6.4 \\
\hline & 2.1 & 54.7 & 40.9 & 14.0 & 26.0 & 23.2 & 17.4 \\
\hline & 2.2 & 29.1 & 17.2 & 2.2 & 25.2 & 28.7 & 29.0 \\
\hline & 2.3 & 20.9 & 10.8 & 0.0 & 0.6 & 3.7 & 3.9 \\
\hline \multirow{7}{*}{ Kionyweni } & BAU & 92.8 & 89.6 & 65.5 & 31.3 & 34.8 & 47.9 \\
\hline & 1.1 & 75.0 & 64.1 & 24.8 & 19.9 & 26.1 & 43.5 \\
\hline & 1.2 & 59.7 & 47.7 & 7.9 & -3.9 & -3.6 & -8.3 \\
\hline & 1.3 & 52.8 & 36.3 & 5.1 & -11.6 & -27.9 & -61.2 \\
\hline & 2.1 & 61.6 & 48.4 & 12.3 & 14.7 & 5.0 & -15.8 \\
\hline & 2.2 & 33.8 & 22.9 & 5.6 & 20.0 & 18.2 & 9.0 \\
\hline & 2.3 & 18.5 & 11.1 & 2.5 & -10.2 & -11.8 & -20.7 \\
\hline \multirow{7}{*}{ Kasikeu } & BAU & 90.3 & 83.8 & 44.5 & 24.1 & 31.6 & 47.7 \\
\hline & 1.1 & 72.3 & 48.0 & 13.6 & 15.5 & 24.4 & 40.3 \\
\hline & 1.2 & 65.3 & 32.6 & 6.8 & 5.1 & 0.6 & -13.6 \\
\hline & 1.3 & 60.6 & 26.6 & 5.9 & -0.2 & -26.4 & -66.5 \\
\hline & 2.1 & 67.4 & 39.4 & 12.0 & 13.3 & -2.4 & -27.7 \\
\hline & 2.2 & 36.1 & 17.8 & 4.8 & 15.4 & 7.9 & -6.9 \\
\hline & 2.3 & 9.3 & 4.6 & 1.4 & 0.3 & -7.3 & -21.9 \\
\hline \multirow{7}{*}{ Kiomo } & BAU & 86.2 & 81.9 & 44.0 & 18.8 & 23.2 & 39.0 \\
\hline & 1.1 & 60.3 & 44.0 & 8.6 & 13.6 & 18.9 & 32.9 \\
\hline & 1.2 & 70.7 & 41.4 & 4.3 & 4.3 & 9.3 & 14.7 \\
\hline & 1.3 & 67.2 & 28.4 & 2.6 & -3.7 & -3.5 & -9.5 \\
\hline & 2.1 & 66.4 & 36.2 & 9.5 & 10.4 & 11.3 & 7.6 \\
\hline & 2.2 & 62.9 & 36.2 & 6.9 & 13.3 & 12.5 & 10.1 \\
\hline & 2.3 & 16.4 & 6.0 & 0.0 & 2.7 & 2.4 & 0.1 \\
\hline \multirow{5}{*}{ Matuu } & BAU & 48.2 & 45.9 & 20.0 & 22.7 & 32.3 & 68.1 \\
\hline & 1.1 & 12.7 & 10.2 & 2.7 & 12.5 & 28.0 & 63.3 \\
\hline & 1.2 & 9.3 & 6.8 & 2.0 & -0.7 & 6.0 & -3.8 \\
\hline & 1.3 & 8.2 & 5.5 & 2.0 & -4.9 & -9.1 & -65.7 \\
\hline & 2.1 & 18.4 & 15.2 & 6.8 & 10.3 & 8.1 & -25.0 \\
\hline
\end{tabular}




\begin{tabular}{|r|r|rrr|rrr|} 
& 2.2 & 2.3 & 2.3 & 0.5 & 17.4 & 18.2 & 0.1 \\
& 2.3 & 0.7 & 0.7 & 0.0 & 4.2 & 5.0 & -13.1 \\
\hline \multirow{6}{*}{ Kibwezi } & BAU & 81.7 & 75.8 & 27.5 & 23.1 & 29.1 & 65.4 \\
& 1.1 & 42.5 & 33.3 & 11.7 & 10.5 & 23.0 & 61.1 \\
& 1.2 & 26.7 & 19.2 & 5.8 & 1.1 & 8.8 & 1.3 \\
& 1.3 & 23.3 & 15.0 & 4.2 & -1.7 & -9.1 & -60.6 \\
& 2.1 & 45.8 & 35.0 & 13.3 & 5.8 & 0.3 & -32.0 \\
& 2.2 & 34.2 & 25.0 & 7.5 & 8.1 & 4.1 & -19.2 \\
& 2.3 & 14.2 & 11.7 & 3.3 & 2.7 & -1.1 & -24.4 \\
\hline
\end{tabular}

Table 3.9 shows that at the base maize price, poverty rates range from 45 to 90 percent across the villages in the BAU case, whereas nutrient depletion ranges from 23 to $37 \mathrm{~kg} \mathrm{~N} / \mathrm{ha} /$ season. Scenario 1.1 substantially improves both poverty and nutrient depletion in all areas, and reduces the poverty rate at base prices in the poorest areas by more than 50 percent, although the poverty rates and nutrient losses remain high. In contrast, poverty is almost eliminated in the richest area, although nutrient losses remain relatively high at nearly $30 \mathrm{~kg} / \mathrm{ha} /$ season. The proposed policy interventions under scenario 1.1 are likely to increase the use of fertilizer with the goals of increasing maize productivity and offsetting soil nutrient loss, however the analysis suggests that when maize prices increase, soil nutrient depletion increases due to the increase in maize production (i.e., more land is allocated to maize), and also because at higher maize prices the amount of fertilizer applied per kilogram of maize (i.e., kg of fertilizer applied per farm/total maize proportion $\mathrm{kg}$ per farm) decreases. When maize prices are low, land allocated to maize decreases (i.e., maize production is lower) therefore the increased availability of fertilizer helps to offset soil nutrient losses. These results produce the typical tradeoffs between economic and environmental outcomes as shown in figures 3.5 and 3.6. The scenarios that increase the availability and use of fertilizer eliminate this tradeoff, but responses across villages are different. For example, under scenario 2.2 in the Machakos village, poverty rates range between 2 to $30 \%$ and soil $\mathrm{N}$ losses range between 25 to $29 \mathrm{~kg} / \mathrm{ha} /$ season. The same scenario for the Matuu village produces poverty rates between 0 to $2 \%$ and soil $\mathrm{N}$ losses between 0 to $18 \mathrm{~kg} / \mathrm{ha} / \mathrm{season}$. Thus, the analysis suggests that these interventions may actually benefit most the areas with better 
initial endowments of soils and climate, a finding consistent with Marenya and Barrett's (2009) analysis of the effects of soil organic matter on fertilizer use.

\subsection{Moving along a Sustainable Agricultural Development Pathway}

The results discussed above show the possibility of a transition towards a sustainable system where tradeoffs between economic and environmental outcomes are eliminated. One of the key implications of the analysis is that getting enough nutrients into the system (e.g., increasing fertilizer use), can make the system respond positively (i.e., decreasing poverty rate and soil nutrient losses) to economic incentives. Furthermore, the analysis presented above suggests that under these scenarios and with the right infrastructure in place and good market conditions, an increase in maize prices could solve the poverty-productivity-sustainability puzzle. However, this result also implies that these interventions need to be accompanied by a set of policies, investments and structural reforms that lead to positive development pathways. The improvement of the system and the consequent change to win-win outcomes takes place as a joint combination of interventions (e.g., sustainable intensification) and drivers that affect the systems and that are embedded into the RAPs.

The evaluation of this development pathway could be affected importantly by consideration of other sustainability indicators. For example, in this article most of the scenarios lead to an increase in herd size and in dairy and manure production. Livestock production systems can produce significant amounts of greenhouse gas (GHG) emissions, according to FAO (2006) livestock contributes to $18 \%$ of global anthropogenic GHG emissions, being methane, carbon dioxide $\left(\mathrm{CO}_{2}\right)$ and nitrous oxide $\left(\mathrm{N}_{2} \mathrm{O}\right)$ the main GHGs sources. However, there are options to reduce and mitigate GHS emissions from livestock, for example it is possible to reduce methane emissions by better diets for ruminants and using improved breeds. Better management of manure can reduce $\mathrm{N} 2 \mathrm{O}$ emissions (Herrero and Thornton, 2009). Sustainable Intensification technologies based on better feeding strategies, improved breeds that reduce GHS from livestock are being investigated and promoted by ILRI as part of one of their global research challenges. Similarly, the possible increased leaching or runoff of nutrients due to the higher fertilizer 
application rates. This can also increase $\mathrm{NH}_{3}$ losses and $\mathrm{N}_{2} \mathrm{O}$ emissions and may also contaminate underground and surface waters. FAO and other institutions like IFDC and USAID are promoting the use of controlled or slow-release fertilizers to deal with this issue.

Another dimension not included in the analysis that could potentially change the development pathway is climate change. Valdivia, Stoorvogel and Antle (2012) assessed the impacts of climate change on this type of crop-livestock production system and compared them to the impacts under a development scenario (similar to scenario 1.1. above). They concluded that socio-economic scenarios are important when assessing the economic and environmental impacts of climate change to complement the bio-physical changes due to climate change. An interesting extension to this article would be to assess the impacts of climate change on economic and environmental outcomes (i.e., poverty and nutrient depletion) under the different scenarios and RAPs presented in the analysis above.

The analysis presented in this article suggests that the Vision 2030 of the Kenyan government is the basis for a sustainable development pathway that could solve the poverty-productivity-sustainability puzzle and achieve not only the MDGs but also the proposed SDGs.

\subsection{Conclusions}

Modeling semi-subsistence crop-livestock systems (CLS) for policy analysis poses many challenges. In this article we demonstrate that the complex behavior of these systems has important implications for the effectiveness of policy interventions. Furthermore, we demonstrate that the use of a simulation model linked to agricultural development pathways can be a useful tool to assess the impacts of policy interventions aimed to move agricultural systems towards meeting sustainable development goals.

We adapted the spatially-explicit econometric-process simulation models developed by Antle and Capalbo (2001) to conditions encountered in semi-subsistence mixed systems, including spatial heterogeneity, complex intercrops, non-essential inputs, and dynamic crop-livestock interactions. We presented methods to deal with these issues using an integrated modeling approach. In order to illustrate how the econometric-process 
simulation model can be implemented for a CLS we applied it to the agricultural systems in the Machakos region of Kenya. This application illustrates how the model can be used to quantify key indicators for policy analysis, such as poverty indexes and measures of sustainability, and how the model can be linked to Representative Agricultural Pathways to represent different future socio-economic scenarios. The Machakos analysis provides important findings regarding the implementation and effectiveness of policy interventions addressing poverty and sustainability in Africa and other parts of the developing world. As we have shown in the analysis, policy interventions tend to result in much larger benefits for better-endowed farms, implying that farm heterogeneity farms results in differential policy impacts. This finding is also consistent with the conclusions in Antle, Stoorvogel and Valdivia (2006), that resilience of agricultural systems is likely to be highly variable and strongly associated with heterogeneity in bio-physical and economic conditions.

CLS are complex systems influenced by site-specific bio-physical conditions as well as the larger economic environment. The soil nutrient depletion rates observed in many parts of Sub-Saharan Africa appear to be caused by many factors, including extremely small farm size and associated extreme poverty that make sustainable management practices difficult to maintain, particularly in an environment of distorted input and output markets. Our results are consistent with recent findings by Harris and Orr (2014). They argue that small farms with limited access to markets are not likely to benefit enough from improved technologies to climb out of poverty because returns to these technologies are generally too low. Policy interventions aimed to deal with poverty and sustainability can have unintended consequences if they are not accompanied by a set of policy strategies and investments. For example, as we have shown in the analysis above, increasing the maize price can result in substitution from subsistence crops to maize, without much increase in nutrient inputs, thus increasing soil nutrient losses (scenario 1.1). The analysis presented here shows that improving soil nutrient balances by increasing fertilizer and manure use is critically important, but is not enough to move the system to a sustainable path. There is no one factor that can reverse the negative nutrient balances and move the system towards sustainability. Rather, a broad-based strategy is required that stimulates rural development, increases farm size to a sustainable level, and 
also reduces distortions and inefficiencies in input and output markets that tend to discourage the use of sustainable practices. The Machakos case shows that a combination of these interventions and strategies, based on the GoK Vision 2030 and the Machakos County plans, could solve the poverty-productivity-sustainability puzzle in this region. The pathway from tradeoffs to synergies (win-win) seem to be feasible if these interventions and strategies are implemented, however further research is needed to assess the potential adoption of these systems and their corresponding impacts on economic and environmental outcomes as discussed by Antle, Stoorvogel and Valdivia (2014).

An important issue not addressed in this study is the possible endogeneity of prices. The analysis shows that prices (e.g., price of maize) play a key role in the assessment of policy interventions; for the linkage of this type of model to a market equilibrium model, see Valdivia, Antle and Stoorvogel (2012). Additional extensions to this article could include assessing the impacts of more livestock-oriented systems (e.g., scenarios 2.1-2.3) on GHGs emissions and their mitigation strategies, and the impacts of climate change on vulnerability and adaptation.

An important feature of CLS is the interactions and dynamic feedbacks between crops, livestock and the environment. In the Machakos model presented in this article interactions between crops and livestock components are closely coupled (i.e., components interact dynamically). This allows the model to capture the effects of soil nutrients being cycled through the system: crop residues are harvested and used as livestock feed, and manure and other organic amendments are accumulated and used on crops in subsequent seasons. However, the model is loosely coupled to the bio-physical crop models, in the sense that there are no feedbacks from the economic models to the crop models. Thus, the crop models provide the basis for predicting the spatial patterns of productivity implied by the baseline soils and climate data, but the model does not feedback changes in soil organic matter or soil fertility to management decisions in the crop models. Likewise, the analysis of nutrient balances provided by the NUTMON model is a static accounting of nutrient flows and is not able to predict the dynamic changes in soil nutrients in response to changes in land use and management. To achieve a more dynamic analysis of soil nutrient management, better models of nutrient dynamics 
are needed, and could be closely coupled to the economic decision model. In addition, the focus of this study is on soil $\mathrm{N}$ losses, because we argue that $\mathrm{N}$ is a limiting factor considering the low yields and low fertilizer use in the region. However, it is important to acknowledge that there are other factors that may affect soil degradation (e.g., SOM content) and that these factors are site-specific.

Another important methodological issue is the large amount of farm survey data needed to implement the type of econometric-process model presented here. For an alternative parsimonious approach see Antle (2011) and Antle, Stoorvogel and Valdivia (2014). Antle et al. (2010) show that a parsimonious approach may provide a good approximation to more elaborate models, at least for analysis of certain kinds of policy analysis such as ecosystem service supply. Further research is needed to assess the pros and cons of alternative approaches for more general policy analysis.

Reducing poverty, improving food security and human health, and reducing environmental damage is a priority on the international research agenda. The agricultural scientific community faces the significant challenge of developing a new generation of data, tools and approaches that capture all the complexities of agricultural production systems to adequately assess the distributional impacts of policy and technological interventions, climate change adaptation and mitigation. Clearly, a coordinated multidisciplinary effort is needed to deal with the complex multi-dimensional challenges of the agricultural sustainable development of the $21^{\text {st }}$ century. 


\title{
CHAPTER 4
}

\section{Coupling the Tradeoff Analysis Model with a}

\author{
market equilibrium model to analyze economic
}

and environmental outcomes of agricultural

\author{
production systems
}

Analysis of the economic and environmental outcomes of agricultural systems requires a bottom-up linkage from the farm to market, as well as a top-down linkage from market to farm. This study develops this two-way linkage between the Tradeoff Analysis model of agricultural systems and a partial equilibrium market model. The resulting model can determine the effects of technology and policy interventions on the spatial distribution of environmental and economic outcomes at market equilibrium quantities and prices. The approach is demonstrated with a case study of tradeoffs between poverty and nutrient depletion in a semi-subsistence agricultural system (Machakos, Kenya). The results suggest that the linkage of market equilibrium analysis to farm level integrated assessment models can be important in the analysis of agriculture-environment interactions.

Based on: Valdivia, R.O., J.M. Antle, and J.J. Stoorvogel. 2012. Coupling the Tradeoff Analysis Model with a market equilibrium model to analyze economic and environmental outcomes of agricultural production systems. Agricultural Systems 110: 17-29 


\subsection{Introduction}

Integrated Assessment Models (IAMs) are used in agricultural research to assess policy impacts on economic and environmental sustainability of agricultural production systems. Assessing the spatial distribution of economic outcomes (e.g., poverty), and environmental impacts (e.g., nutrient depletion) requires the use of spatially explicit data and models. Some farm-level IAMs have been developed to represent the heterogeneity of the physical environment and economic behavior of farmers by integrating sitespecific biophysical and economic models. These models typically use spatially-explicit data to model agriculture-environment interactions but treat prices as exogenous (see Goddard et al., 1996; Fleming and Adams, 1997; Brown, 2000; Antle and Capalbo, 2001; Mathur, 2003; Oxley and ApSimon, 2007; Uthes et al., 2010). However, when a policy or a technological change affects many farms, the aggregate responses may impact market equilibrium agricultural prices. Consequently, farm-level IAMs may need to be coupled to market equilibrium models to account for price endogeneity and market interactions in the assessment of agricultural production systems (Kayser, 1999; Verburg and Veldkamp, 2004; Perez Dominguez, et al., 2009).

The goal of this study is to link the Tradeoff Analysis (TOA) Model (Antle et al.,1998; Stoorvogel et al., 2004), to a price-endogenous (partial) market equilibrium (ME) model. The TOA model is an IAM that links site-specific bio-physical process models and economic decision models, and aggregates economic and environmental outcomes to a regional scale, but treats prices as exogenous. The linkage between the TOA model and the ME model allows the effects of site-specific interactions at the farm scale to be aggregated and used to determine market equilibrium. The resulting market equilibrium in turn can be used in the TOA model to determine spatially explicit economic and environmental outcomes. The linkage is illustrated in a case study of the semi-subsistence agricultural production system of the Machakos region in Kenya. Poverty and sustainability issues are critical in this region where technology or policy interventions are likely to affect the market for maize, a key commodity in Machakos. The case study illustrates the differences in the analysis with and without market equilibrium and the importance of feedbacks in the assessment of tradeoffs between nutrient depletion and poverty in the semi-subsistence agricultural system of Machakos, 
Kenya. The next section presents the linkage between the TOA model and the ME model. The third section presents the application of the linked models for Machakos, Kenya. The results are discussed in section four followed by general conclusions in the last section

\subsection{Coupling the TOA and ME model}

\subsubsection{The Tradeoff Analysis model}

The TOA model (Figure 4.1) incorporates crop models to assess land quality and economic models to simulate land management decisions. Subsequently, those decisions are input in environmental process models to simulate the associated environmental outcomes. These simulations are executed for a statistically representative sample of the farmer population in a region. The site-specific economic and environmental outcomes can then be aggregated to the regional level to create economic and environmental indicators of interest to stakeholders. The simulations can be repeated for alternative parameter settings to quantify the inter-relationships (i.e., tradeoffs) among the indicators. 


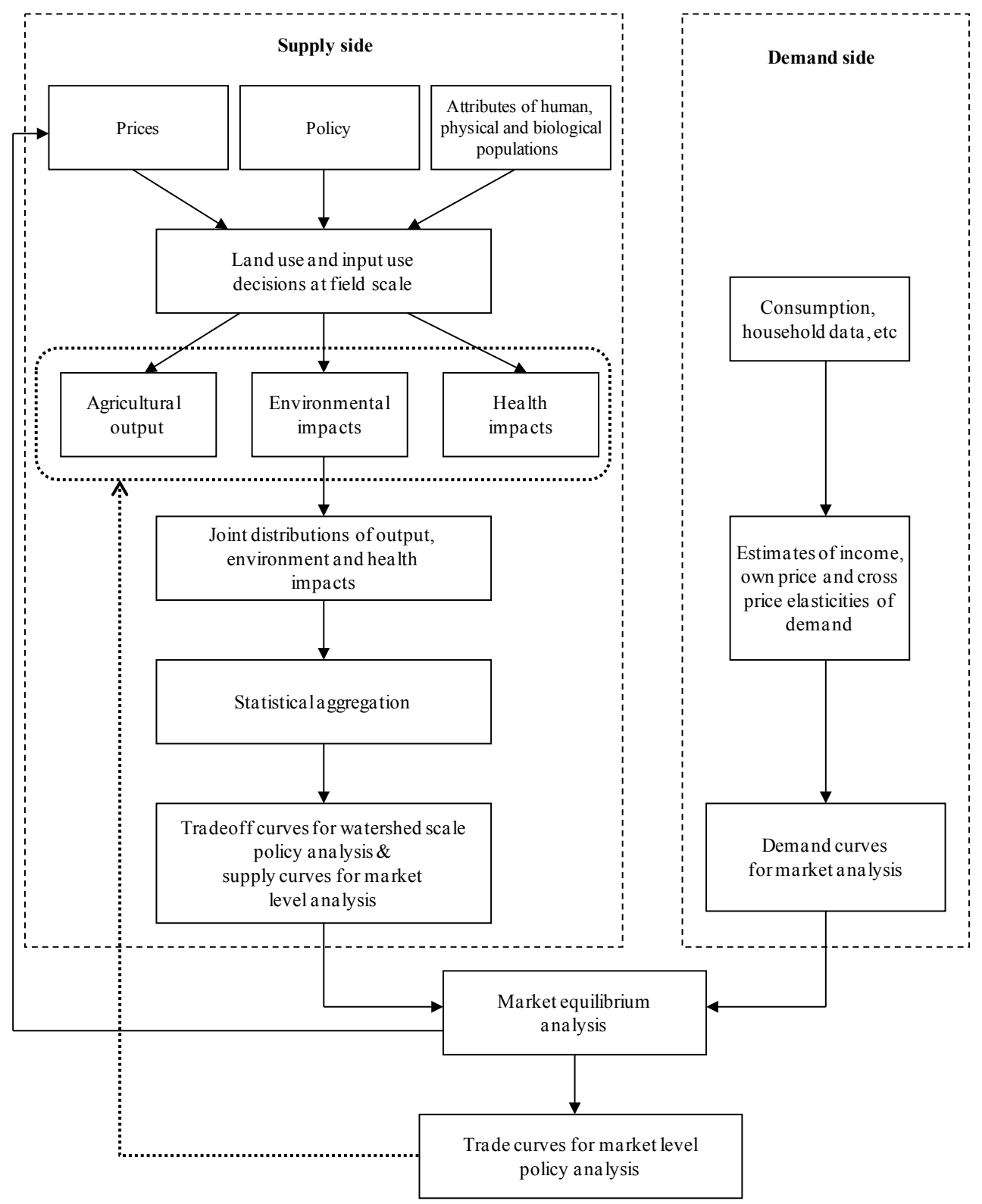

Figure 4.1. Conceptual framework for disciplinary integration and policy analysis that include market level linkage (Adapted from Antle, Capalbo and Crissman, 1998). 
At the farm level, the effects of site-specific soil and climate conditions on productivity potential, or inherent productivity (estimated as nutrient limited crop yields), are estimated using crop simulation models with average or representative management inputs. Then an econometric-process model (an empirical econometric production model developed by Antle and Capalbo, 2001 and later adapted by Antle et al., 2010a) simulates site-specific land management decisions using econometric production models (input demand and output supply) that are functions of inherent productivity prices, farm characteristics, and policy parameters (See chapter 3 in this thesis).

Environmental impacts of these management decisions are then simulated using environmental process models. As a result, management decisions and resulting environmental outcomes on each unit of land in production are functions of site-specific environmental conditions, prices, policies, technology and other farm-specific variables. The distributions of these site-specific and farm-specific characteristics in the population generate a joint distribution of economic and environmental outcomes in the population that are functions of the underlying environmental and economic parameters.

With this joint distribution the outcomes can be statistically aggregated into economic and environmental indicators that represent the population. By varying model parameters, such as prices, different environmental and economic outcomes are generated. The aggregate relationships between economic and environmental indicators generated in this way are referred to as tradeoff curves. Thus, tradeoff curves represent the supply side of the agricultural system. Here we use the fact that when tradeoff curves are generated by varying output or input prices, they represent the output supply and input demand behavior of farms (Stoorvogel et al., 2004, See also Chapter 2 in this thesis).

Figure 4.2 shows graphically how price-based tradeoff curves can be constructed by aggregating farm-level outcomes. Suppose that the simulated farm-level outcomes (e.g., soil quality and crop production) associated with a given set of crop and input prices, is point A in figure 4.2a. Repeating this simulation for a statistically representative sample of farms in a region generates a distribution of points representing the population of farms in the region as in figure 4.2b. Different distributions of outcomes can be generated by changing a parameter, such as the mean of the distribution of a crop price 
(see figure 4.2c). The data can then be aggregated to obtain a tradeoff curve (see figure 4.2d). When the tradeoff curve is generated by varying a price, it can be interpreted as a set of possible equilibrium points associated with these prices. Each point along the tradeoff curve are referred to as tradeoff points.
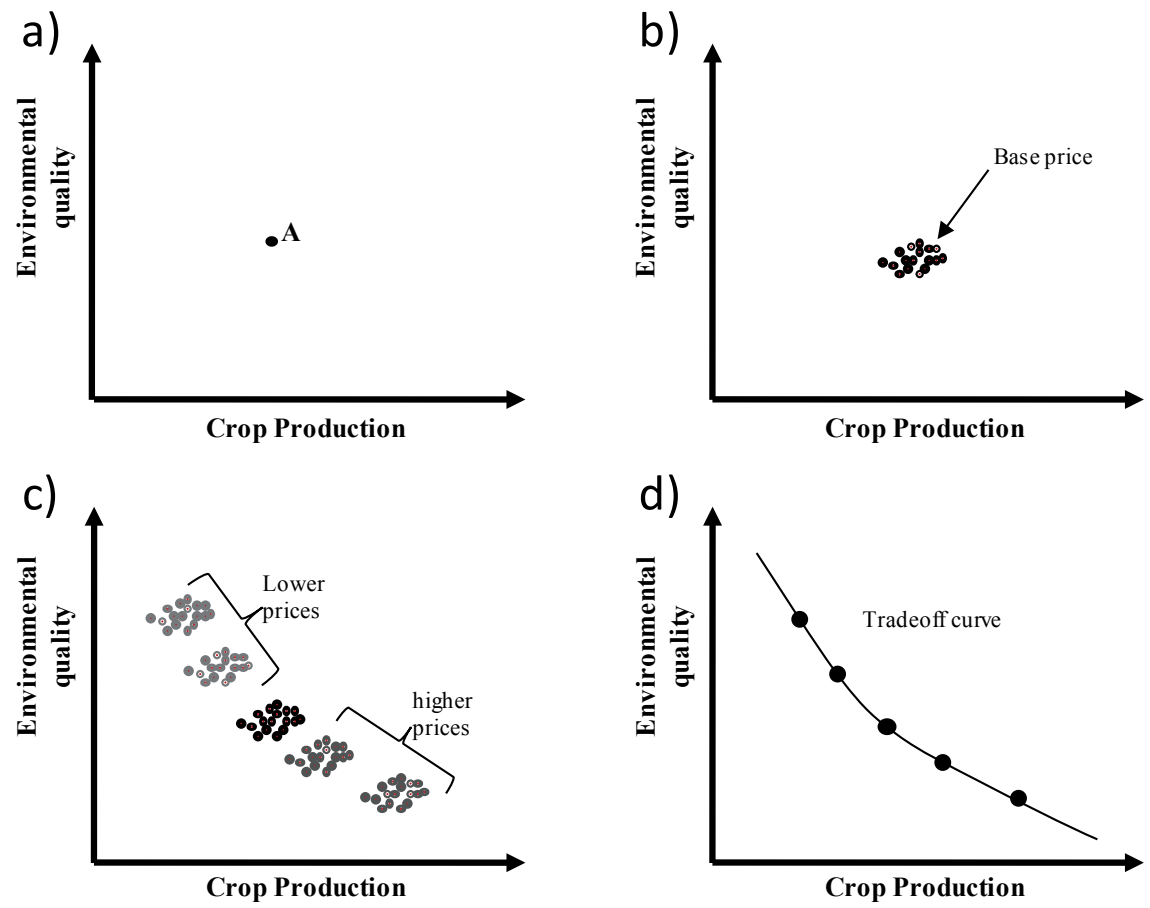

Figure 4.2. Derivation of the tradeoff curves of two environmental and economic indicators (e.g., environmental quality and crop production) by changing the mean of the distribution of crop prices.

\subsubsection{Linking the TOA model to a market model}

The tradeoff curve derived in Figure 4.2 illustrates, besides the relation between environmental quality and crop production, the relationship between the market price and the aggregate quantity of an output. The latter is relationship is the supply curve for the population. This forms the basis for linking a tradeoff analysis to a market equilibrium 
analysis. This linkage is portrayed in Figure 4.3 which shows a tradeoff between an environmental quality indicator $\boldsymbol{E}$ (e.g., an indicator of sustainability such as nutrient depletion) and aggregate output $\boldsymbol{Q}$ represented by the curve $\boldsymbol{T}$. That tradeoff curve is generated by varying a price $\boldsymbol{P}$ (e.g., price of $\boldsymbol{Q}$ or an input price). Each point along $\boldsymbol{T}$ is a possible equilibrium, and corresponds to a point on the supply curve $\boldsymbol{S}$. If we add to this system a demand curve such as $\boldsymbol{D}_{\boldsymbol{0}}$, we obtain a market equilibrium point $\boldsymbol{a}$ which in turn defines the point $\boldsymbol{b}$ on the tradeoff curve as the equilibrium. Since point $\boldsymbol{b}$ is associated with a specific spatial distribution, the correspondence between points $\boldsymbol{a}$ and $\boldsymbol{b}$ allows the market equilibrium to be linked to the associated spatial distribution of outcomes ( map $_{0}$ in the figure). If market conditions change (e.g., a shift in the demand curve due to a policy intervention) then a new market equilibrium point $\boldsymbol{a}^{\prime}$ is attained. Point $\boldsymbol{a}^{\text {' }}$ corresponds to a different equilibrium crop price, so producers respond by changing production decisions, resulting in a different spatial distribution of economic and environmental outcomes $\left(\mathrm{map}_{1}\right)$ associated with the corresponding equilibrium point $\boldsymbol{b}$ ' in the tradeoff curve. Thus, the linkage between the TOA analysis and market equilibrium analysis allows us to associate the spatial distribution of economic and environmental outcomes with each possible market equilibrium. 


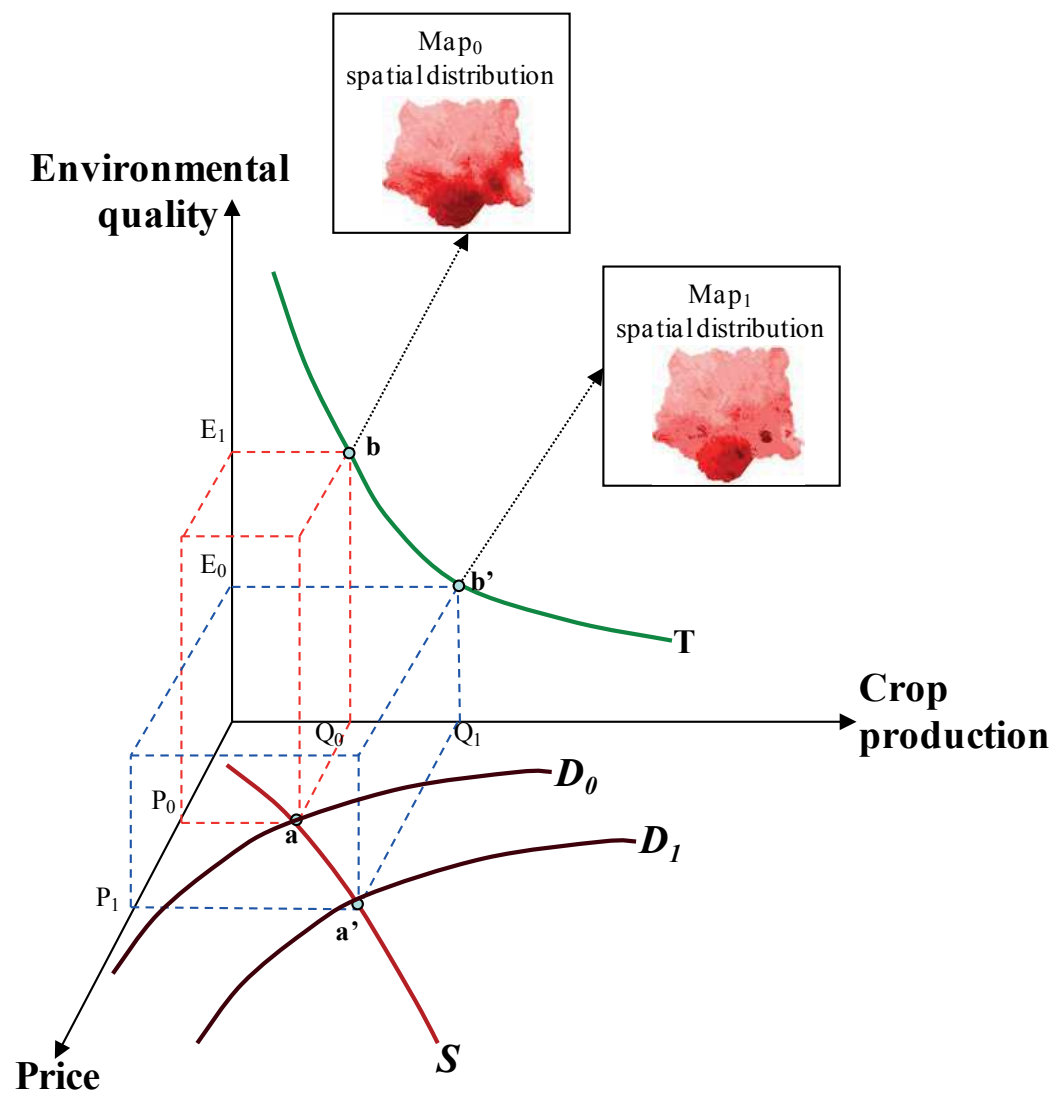

Figure 4.3. Theoretical framework to link environmental and economic outcomes, market equilibrium and underlying spatial distributions.

Market equilibrium can change in response to factors affecting market demand, as in Figure 4.3, as well as changes in the factors determining market supply. As the discussion above showed, the market supply of a crop is derived by aggregating the individual quantities produced at each price. Consequently, a change in any of the factors that determine this farm-level supply decision will shift the market supply curve. To illustrate this point, let the market supply be defined as $S=f(P, \theta)$ where $P$ is a crop price and $\theta$ is a vector that defines the distribution of individual farm characteristics in the population, including other output and input prices, and farm characteristics such as farm 
size and technologies in use. The market demand is defined as $\mathrm{D}=\mathrm{f}(\mathrm{P}, \psi)$ where $\psi$ is a vector that defines parameters that may influence the demand such as aggregate income or the distribution of income and household characteristics. Figure 4.4a shows the supply $\mathrm{S}^{0}(\mathrm{P}, \theta)$ and demand $\mathrm{D}^{0}(\mathrm{P}, \psi)$ schedules of a crop in the market and $\mathrm{A}\left(\mathrm{P}_{0}, \mathrm{Q}_{0} \mid \theta, \psi\right)$ is the initial equilibrium point implying that $\mathrm{P}_{0}$ is the initial price equilibrium and $\mathrm{Q}_{0}$ the initial equilibrium quantity of the system given the parameters $\theta, \psi$.

a)

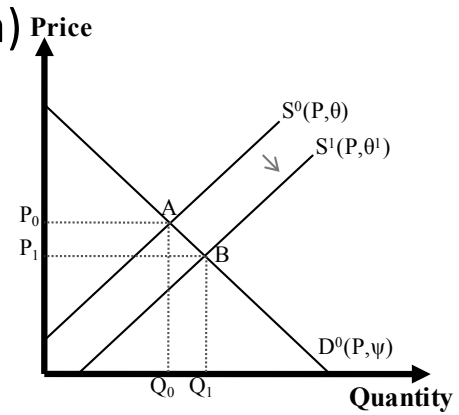

c)

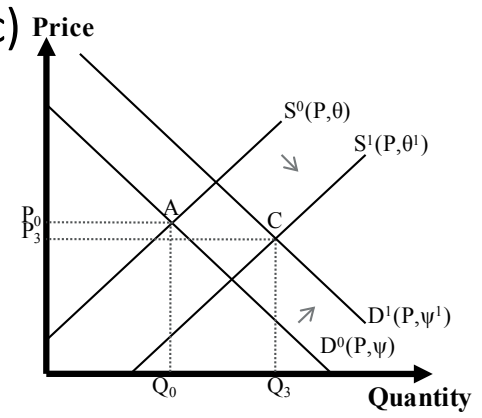

b) Price

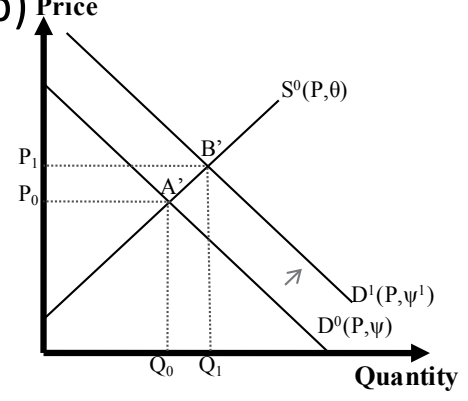

d)

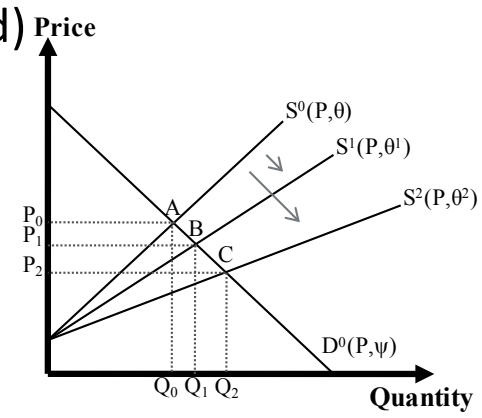

Figure 4.4. Market Equilibrium: Shifts on Supply and Demand schedules due to changes on their parameters

Changes in factors determining either demand or supply result in a change in market equilibrium price, and thus will lead to a different spatial distribution of economic and environmental outcomes. For example, a reduction in production costs will result in a rightward shift in the supply curve from $S^{0}(P, \theta)$ to $S^{1}\left(P, \theta^{1}\right)$. Given that the demand curve has a negative slope, the market equilibrium point moves to point $B\left(P_{1}, Q_{1} \mid \theta^{1}, \psi\right)$. Consumers benefit from the increased consumption (from $\mathrm{Q}_{0}$ to $\mathrm{Q}_{1}$ ) at a reduced price 
(from $\mathrm{P}_{0}$ to $\mathrm{P}_{1}$ ). In contrast, if there is a change in demand, caused for example by an increase in consumer income leading to a new value $\psi^{1}$, then the demand curve shifts to the right (figure $4.4 \mathrm{~b})$. In this case, the equilibrium point moves from point $\mathrm{A}^{\prime}\left(\mathrm{P}_{0}, \mathrm{Q}_{0} \mid \theta\right.$, $\psi)$ to $\mathrm{B}^{\prime}\left(\mathrm{P}_{1}, \mathrm{Q}_{1} \mid \theta, \psi^{1}\right)$. As in the previous case, the equilibrium quantity changes from $\mathrm{Q}_{0}$ to $\mathrm{Q}_{1}$, but this time there is an increase on the price from $\mathrm{P}_{0}$ to $\mathrm{P}_{1}$. Alternatively, there is the case when both market supply and market demand shift. Figure $4.4 \mathrm{c}$ shows a shift of the demand curve to the right, from $\mathrm{D}_{0}(\mathrm{P}, \psi)$ to $\mathrm{D}_{1}\left(\mathrm{P}, \psi^{1}\right)$ and a shift of the supply curve from $S^{0}(P, \theta)$ to $S^{1}\left(P, \theta^{1}\right)$. The new equilibrium point $C\left(P_{3}, Q_{3} \mid \theta^{1}, \psi^{1}\right)$ implies a decrease in the equilibrium price from $\mathrm{P}_{0}$ to $\mathrm{P}_{3}$ and a new equilibrium quantity $\mathrm{Q}_{3}$ given the conditions $\theta^{1}, \psi^{1}$. Any change in market demand or supply results in a change in market equilibrium price. The change moves the system to a different point along the tradeoff curve shown in Figure 4.3 associated with a different spatial distribution of economic and environmental outcomes. It is important to note that changes in the structure of the farm or changes induced by a technological change or policy (e.g., a change of $\theta$ on the supply side) could lead to different price responsiveness (elasticities). The latter will influence the magnitude of shifts in supply/demand on the equilibrium price and quantity in the market. For example, figure $4.4 \mathrm{~d}$ shows the effects of a shift from the supply curve $S^{0}$ to a new supply curve $S^{1}$ and to another more elastic supply curve $S^{2}$ Although the new equilibrium values obtained from the shift of the supply curve to $S^{1}$ and $S^{2}$ both have the same effect (e.g., consumers benefit from an increased consumption and lower prices in both cases) the magnitude of the effect is larger $\left(\mathrm{Q}_{0} \mathrm{Q}_{2}>\mathrm{Q}_{0} \mathrm{Q}_{1}\right.$ and $\left.\mathrm{P}_{0} \mathrm{P}_{2}>\mathrm{P}_{0} \mathrm{P}_{1}\right)$ when a supply curve such as $\mathrm{S}^{2}$ is more elastic. The market analysis shown above can be done in a similar manner in terms of input demand and supply.

\subsubsection{Implementation: The TOA-ME}

The linkage of the TOA model with a market equilibrium model has been implemented in the TOA software (Stoorvogel et al., 2004). The TOA software integrates spatially explicit GIS-based soils and climate data with the DSSAT crop growth simulation models (Tsuji et al., 1994; Jones et al., 2003), econometric-process simulation models of land use and management decisions (Antle and Capalbo 2001), and a suite of environmental process models. The software can be used to create two-dimensional 
tradeoff graphs, such as illustrated in Figure 4.2, as well as maps of the spatial distributions of outcomes illustrated in Figure 4.3. The TOA software and documentation are publicly available at www.tradeoffs.nl.

In order to link the TOA model to a market equilibrium model, an additional module was created within the TOA software (Figure 4.5). The TOA-ME module reads the output data from the TOA simulation. As noted above, either output supply functions or input demand functions can be derived from the TOA analysis. Here we discuss the case of output supply. The user chooses a functional form for the output supply function (e.g., the supply function for maize) and the program estimates the corresponding parameters using ordinary least squares. It is assumed that the initial market equilibrium is at the base prices, so the program reads the user-defined demand parameters (price elasticity or slope) to calibrate the demand function's intercept corresponding to the initial equilibrium. Once the parameters are estimated and calibrated, the program solves the equations simultaneously for the equilibrium price and supply. The resulting market equilibrium price and supply represent the tradeoff point associated with the equilibrium values. The user can then re-run the TOA model using the equilibrium values and generate the spatial distribution of outcomes associated with this equilibrium point. This process can be repeated for different policy or technology scenarios to get the new equilibrium values and measure the effects of these policies on the underlying spatial distributions of the economic and environmental indicators. 


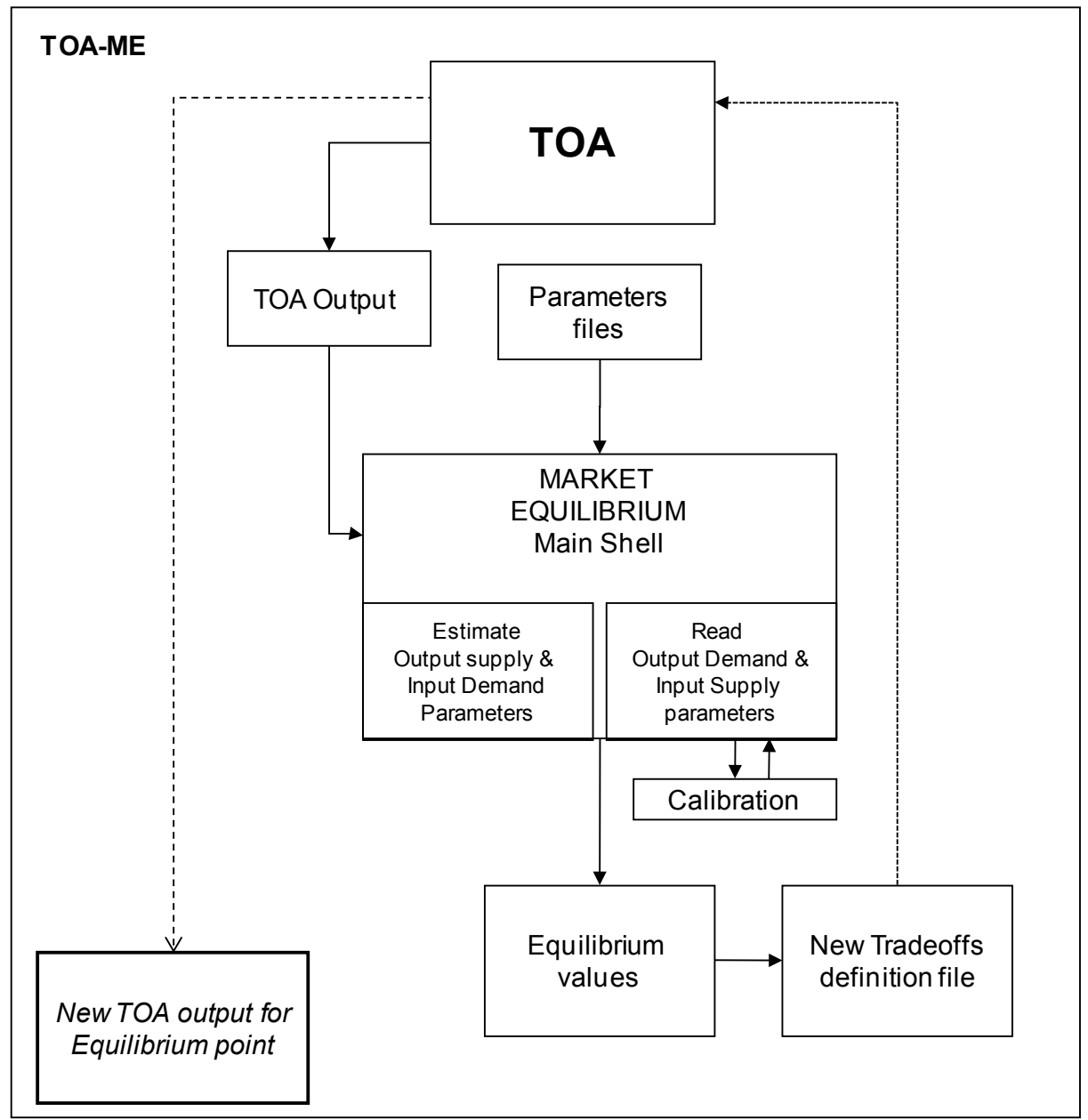

Figure 4.5. General structure of the TOA-ME

For the single market setting, the aggregate output supply function for a specific crop can be defined as:

$$
Q^{s}=\alpha_{0} P^{\alpha_{1}}
$$

The output supply parameters $\left(\alpha_{0}\right.$ and $\left.\alpha_{1}\right)$ are estimated using ordinary least squares. A constant elasticity demand curve for the same crop is specified as:

$$
Q^{d}=\beta_{0} P^{\beta_{1}}
$$

The condition for market equilibrium is then defined as: 


$$
Q^{s}=Q^{d}
$$

Equations 1, 2 and 3 are solved simultaneously in order to obtain the equilibrium quantity and price $Q^{*}$ and $P^{*}$. The equilibrium price is then used to define a new tradeoff point by setting the mean of the price distribution of the corresponding crop to the equilibrium value. The econometric production model and the environmental process models are run again using this price. The results from this process will show the tradeoffs between environmental outcomes and economic outcomes at the equilibrium price. Different technology or policy scenarios can be run in order to measure their effects under a market equilibrium condition.

As noted above, the TOA-ME can estimate equilibrium for input markets in a similar manner. Input demand equations (e.g., for fertilizer) can be derived from the TOA output, and together with a corresponding input supply equation, the TOA-ME can solve for input market equilibrium.

In order to specify the market output demand or input supply functions we can follow two approaches. One is to use data to estimate statistically the needed demand or supply function parameters. Alternatively, parameters from the literature can be used. Sensitivity analysis of these parameters can be used to assess the effects of parameters on the model. The TOA-ME is also capable of conducting multiple market analysis (two or more outputs or two or more inputs or a combination of outputs and inputs). However, there are some additional issues that must be addressed in the multiple market case such as how the multiple prices are jointly varied for parameter estimation.

\subsection{TOA-ME Application for Semi-subsistence Agricultural System}

In this section we consider a case study of the semi-subsistence agricultural system in Machakos, where maize is an important part of the system. We use this example to illustrate the differences of the analysis with and without considering market equilibrium analysis in the assessment of policies designed to reduce poverty and soil degradation. 


\subsubsection{Study area}

Kenya is one of the world's poorest countries with about half of the population living on an income of less than US\$1 per day. Agriculture in Kenya is the most important sector in the economy, representing about 30\% of the GDP (Karanja et al., 2002). Most of the agriculture is semi-subsistence where intercropping, small farm size ( $<2.5$ ha), high rates of crop failure ( $>50 \%$ during dry years) and lack of an established capital market are typical (Kamau, 2000; Antle et al., 2010a). In many regions of Kenya, rapid population growth and limited access to land has led to farm sizes so small that it is difficult for farmers to climb out of poverty by relying solely on growth in farm productivity. All these conditions plus the highly variable and changing climate make farms in this region highly vulnerable. Thus, investment in the rural non-farm sector that creates opportunities for non-farm employment, and investment in education and training programs in addition to investment in market infrastructure, would be necessary to increase rural income growth (Marenya et al., 2003). These issues are the core of the policy scenarios analyzed in this study, which are in line with proposed policy interventions set by the Government of Kenya (Government of Kenya, 2004).

The Machakos region is located southeast of Nairobi between $0^{\circ} 70^{\prime}$ and $3^{\circ} 00^{\prime}$ southern latitude and between $36^{\circ} 87^{\prime}$ ' and $38^{\circ} 51^{\prime}$ ' eastern latitude. The area of the region is approximately $14,000 \mathrm{~km}^{2}$ with an altitude range between 340 and $1710 \mathrm{~m}$.a.s.l. The main crops grown in the Machakos region are maize, pigeon pea, sorghum, beans, horticultural crops and fruit trees. Maize production is an important subsistence crop and a cash crop for larger farms. Despite several efforts of the government and research programs to increase maize yields, average yields are far below the potential contributing to serious food deficits in many regions of Kenya. Soil nutrient depletion is one of the major constraints to increasing crop productivity. In order to reverse the declining trends in per capita food production and negative nutrient balances, soil fertility management on farms must be improved (e.g., Donovan and Casey, 1998). Despite research showing that fertilizer could be a profitable option to increase yields and income, fertilizer use in SubSaharan Africa is low, and it is even lower in semi-arid areas. According to the UNDP (2001), average consumption of fertilizer in 1998 was $13.8 \mathrm{~kg}$ of nutrients per hectare of arable and permanently cropped land. The low use of fertilizer has been attributed to high 
prices caused by high transport costs and import tariffs, high levels of risk associated with low and highly variable rainfall patterns, inefficient input distribution and availability, financial constraints and difficulty of farmers in assessing returns to fertilizer (Freeman and Omiti, 2003). Marenya and Barrett (2009) show that low rates of fertilizer use in Kenya are also associated with low soil fertility due to severe nutrient depletion that results in low fertilizer response.

\subsubsection{Data}

This study uses data from two farm-level surveys from 6 villages in Machakos and Makueni District carried out between 1997 and 2001, (De Jager et al., 1998, see Chapters 1 and 3 for more details). Table 4.1 shows summary statistics for the six villages. The main cropping systems in the region can be grouped as:

- maize and beans grown as monocrop or intercrop and sold in the market or used for home consumption;

- complex intercrop systems which are mostly used for home consumption. A large number of crops are planted together and frequently diverse combinations and proportions are found in different farms;

- vegetables are primarily cash crops but are limited to the areas that have access to irrigation; and

- grass used for livestock feeding. 
Table 4.1. Summary Statistics by Village, Machakos NUTMON Data

\begin{tabular}{llllll}
\hline Variable & Machakos & Kionyweni & Kasikeu & Kiomo & Matuu \\
\hline Output price, complex intercrop (ksh/kg) & 9.26 & 8.06 & 16.45 & 12.24 & 14.28 \\
& $(7.63)$ & $(7.17)$ & $(8.87)$ & $(8.81)$ & $(11.00)$ \\
Maize price (ksh/kg) & 12.64 & 15.61 & 16.47 & 14.93 & 15.18 \\
& $(4.89)$ & $(1.02)$ & $(2.40)$ & $(2.14)$ & $(1.42)$ \\
Bean price (ksh/kg) & 32.22 & - & 28.78 & 25.00 & 29.95 \\
& $(2.82)$ & & $(0.94)$ & $(0.01)$ & $(0.46)$ \\
Vegetable price (ksh/kg) & 10.23 & - & 9.52 & - & 24.29 \\
& $(7.44)$ & & $(2.24)$ & & $(16.00)$ \\
Complex intercrop (\%) & 26.16 & 60.12 & 34.91 & 46.09 & 19.10 \\
& $(44)$ & $(49)$ & $(48)$ & $(50)$ & $(39)$ \\
Maize (\%) & 25.58 & 22.11 & 37.26 & 36.09 & 31.74 \\
& $(44)$ & $(42)$ & $(48)$ & $(48)$ & $(47)$ \\
Beans (\%) & 16.86 & 0.62 & 8.49 & 7.39 & 12.00 \\
Vegetables (\%) & $(37)$ & $(7.86)$ & $(28)$ & $(26)$ & $(33)$ \\
& 7.56 & - & 3.30 & - & 33.94 \\
Grass (\%) & $(26)$ & & $(18)$ & & $(47)$ \\
Farm size (ha) & 23.84 & 17.15 & 16.04 & 10.43 & 3.23 \\
& $(43)$ & $(38)$ & $(37)$ & $(31)$ & $(18)$ \\
Family size & 2.78 & 3.14 & 3.08 & 7.84 & 1.55 \\
& $(1.43)$ & $(3.24)$ & $(2.06)$ & $(7.10)$ & $(0.74)$ \\
Mineral fertilizer price (ksh/kg) & 8.68 & 8.17 & 7.25 & 7.33 & 8.92 \\
Mineral fertilizer use (\%) & $(3.16)$ & $(2.90)$ & $(3.99)$ & $(2.19)$ & $(2.93)$ \\
& 28.19 & 29.87 & 25.56 & - & 32.34 \\
& $(6.08)$ & $(2.38)$ & $(4.09)$ & & $(22.00)$ \\
No: & 25.19 & 3.10 & 23.11 & - & 17.29 \\
& $(43.45)$ & $(17.35)$ & $(42.25)$ & & $(37.84)$ \\
& & & &
\end{tabular}

Note: Means with standard deviations in parentheses. Source: Antle et al, 2010. 
The data show that farm size varies across the region but most farms are very small relative to the average household size of about 8 persons.

Data for the demand side of the analysis were obtained from the literature. There are few studies that have actually estimated the price elasticities of demand for maize and other crops in Kenya. Nzuma and Sarker (2008) estimated that the short-run own price elasticity of demand for maize is about -0.53 while the long-run own price elasticity of maize was about -0.80 . Other studies surveyed by Nzuma and Sarker reported elasticities of demand for maize ranging from -0.45 to -0.90 (See Table 4.2). In the present study we use an own price elasticity of demand for maize of -0.50 .

Table 4.2. Demand Elasticities for maize, Kenya.

\begin{tabular}{lll}
\hline Source & $\begin{array}{l}\text { Period of } \\
\text { Analysis }\end{array}$ & $\begin{array}{l}\text { Own Price } \\
\text { Elasticity }\end{array}$ \\
\hline Nzuma and Sarker (2008) & $1963-2005$ & -0.53 \\
Waliweta et al. (2003) & 2003 & -0.90 \\
Seale et al. (2003) & $1993-1996$ & -0.46 \\
Munyi, (2000) & 1999 & -0.45 \\
Benzuneh et al. (1988) & $1983-1984$ & -1.19 to $-1.75^{*}$ \\
\hline$*$ Maize and beans were treated as the same group, so the elasticity is for both \\
maize and beans.
\end{tabular}

\subsubsection{The TOA model application for Machakos and scenarios}

In the application of the TOA model for Machakos, Antle et al. (2010a) defined the farm according to its characteristics (location, size, number of family members, age and education of household head, availability of off-farm income, number of Tropical Livestock Units (TLUs), and family labor) (Figure 4.6). For each growing season the model simulates milk and manure production as functions of feed availability. Manure and organic fertilizer as well as crop residues accumulated in a previous season become inputs available for crop and livestock production in the current season. Cost of production, expected revenue and expected returns of each activity for each field on the farm are computed by simulating crop input use and input demand functions, crop failure probabilities and crop and byproduct equations. The model assumes that farmers maximize returns by choosing the activity with the highest expected returns in each field. 
These crop-specific outputs, inputs and returns at the field level are aggregated to the farm level.

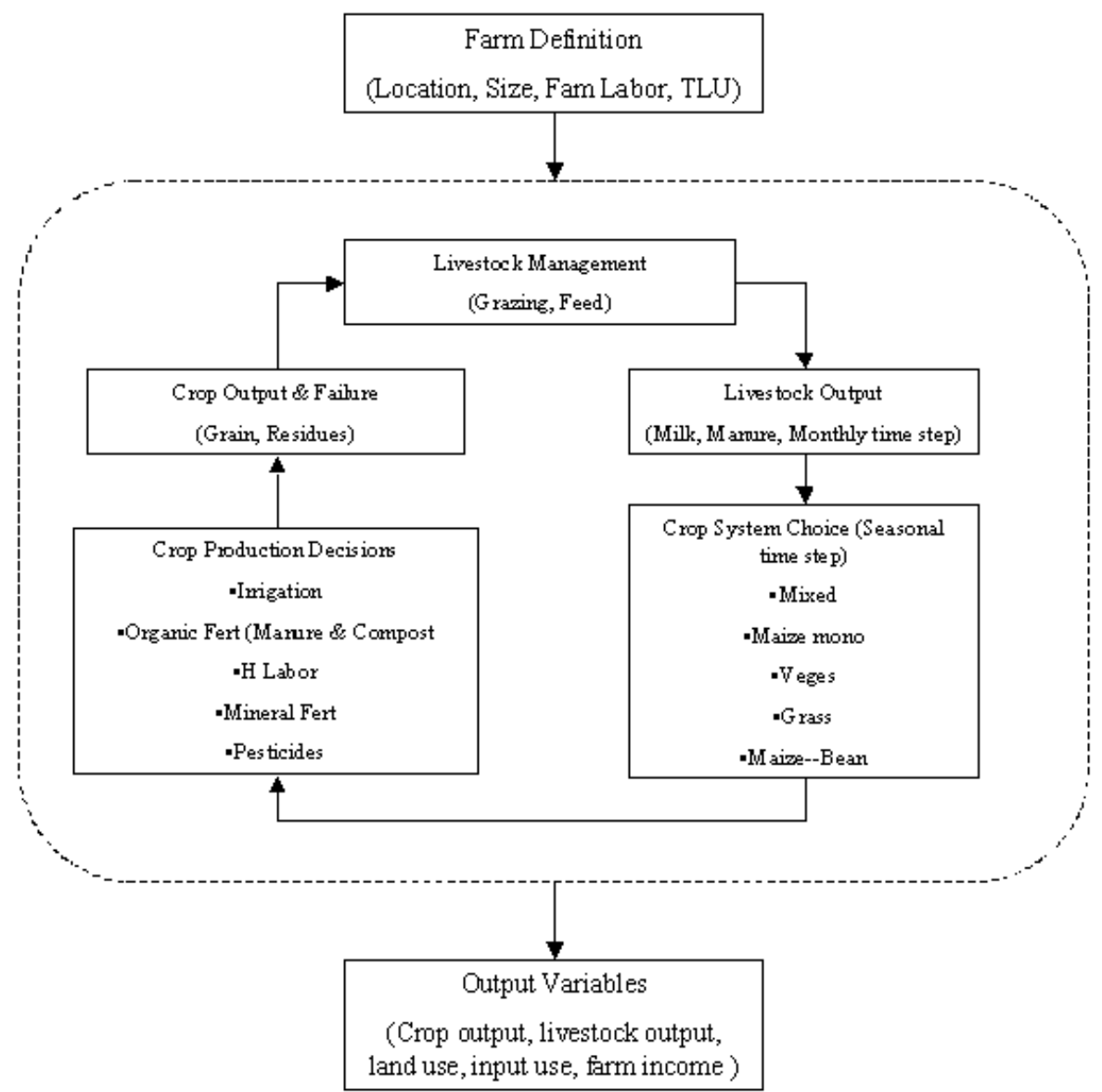

Figure 4.6. Structure of the Whole-Farm Econometric-Process Simulation Model for Machakos, Kenya. (Antle et al., 2010a)

Antle et al. (2010a) analyzed two policy issues: the loss of soil nutrients with the resulting loss in crop productivity, and the increasing dependence of a growing population on small farms for their livelihoods. To deal with these two policy issues, Antle et al. (2010a) constructed three scenarios to be analyzed. The first scenario assumes 
that there is an increase in fertilizer availability due to investments in market infrastructure and reductions in import tariffs which lower farm-gate cost of fertilizer. This fertilizer scenario assumes that these interventions reduce the price of fertilizer by $50 \%$ and assumes all farmers use fertilizer (the quantity is estimated by the fertilizer demand at those lower prices). The second scenario, called rural development, represents the consequences of a policy that stimulates investments in the rural sector, which in turn increases off-farm employment opportunities and farm consolidation. This scenario assumes that household size is reduced by $25 \%$ and farm size is increased from the regional average of about 3 ha to 6 ha. A third scenario is a combination of the fertilizer and the rural development scenarios.

These three policy scenarios are compared to the base scenario. The indicators used to analyze the system are the poverty rate (headcount poverty index, HPI with a poverty line equals to $\$ 1 /$ day), and the average soil nutrient depletion rate (nitrogen loss), estimated by incorporating the NUTMON model into the TOA analysis. As mentioned before, maize is an important food crop in Kenya, making the price of maize a key variable for policymakers. For this reason, the mean of the maize price distribution was varied in order to construct the tradeoffs between poverty and nutrient depletion indicators.

\subsubsection{Results}

\section{Results from TOA}

Figure 4.7 shows the tradeoff curves between the poverty and sustainability indicators for the base scenario and for the three policy scenarios. For the base scenario, at the base maize price, $\mathrm{P}_{\mathrm{b}}{ }^{\mathrm{B}}$, the results show that the poverty rate is about $76 \%$ and the soil nitrogen depletion averages about $32 \mathrm{~kg} / \mathrm{ha}$. The rural development scenario shows a reduction in poverty from the base value of $76 \%$ to an average of $51 \%$ (point $\mathrm{P}_{b}{ }^{\mathrm{RD}}$ in the figure), and a reduction in the nitrogen depletion rate to $27 \mathrm{~kg} / \mathrm{ha}$ from the $32 \mathrm{~kg} / \mathrm{ha}$ of the base scenario. The fertilizer scenario shows that at the base price $\mathrm{P}_{\mathrm{b}}{ }^{\mathrm{F}}$ the soil nitrogen depletion is about $29 \mathrm{~kg} /$ ha and the headcount poverty rate is about $68 \%$. The combined rural development and fertilizer scenarios yielded the largest changes in poverty rate and 
nutrient depletion, with a headcount poverty rate at the base price $\mathrm{P}_{\mathrm{b}}{ }^{\mathrm{R}+\mathrm{F}}$ of about $42 \%$, and an average nitrogen depletion rate of about $25 \mathrm{~kg} / \mathrm{ha}$. In all cases there is a negative relationship between poverty and nitrogen depletion as the price of maize is varied. As expected, an increase in maize price leads to an increase in farm income and a reduction in poverty. Note that the poverty measure in this analysis is income based, therefore it does not take into account changes in consumption (e.g., the effects of maize price changes on consumption). Conversely, an increase in maize price causes an increase in soil nutrient depletion. Figure 6 shows that the alternative scenarios shift the tradeoff curve inwards relative to the base scenario. In this case, an inward shifting of the tradeoff curve is good because both poverty and nutrient depletion are reduced. The effect of maize price on soil nutrient losses is explained by the fact that farmers increase the amount of land allocated to maize as the maize price increases, but do not increase fertilizer use enough to prevent a net loss of nutrients in the harvested grain.

\section{Results from TOA-ME}

The TOA analysis presented above is the first step in the market equilibrium analysis, as indicated in Figure 4.5. Using these simulation outputs, the maize supply elasticities were estimated, assuming a constant-elasticity supply function (Table 4.3). These elasticities for Machakos are larger than some reported in the literature (see for example, Lubulwa et al., 1995; Thorne et al., 2002; Karanja, 2003; and Mghenyi, 2006). This difference may be explained by the explicit representation of the discrete land use decision embedded in the econometric-process model described in section 4.2.1, which can produce a more price-responsive supply function than estimates based on aggregated data (for more details see Antle and Capalbo, 2001). On the demand side, the intercept of the constant elasticity demand function was calibrated using the base price of maize $(15.7 \mathrm{KSh} / \mathrm{kg})$ as the initial equilibrium price. The supply and demand parameters are used to determine the market equilibrium price and quantity which allow us to identify the point on the tradeoff curve associated to those equilibrium values for the three scenarios. 


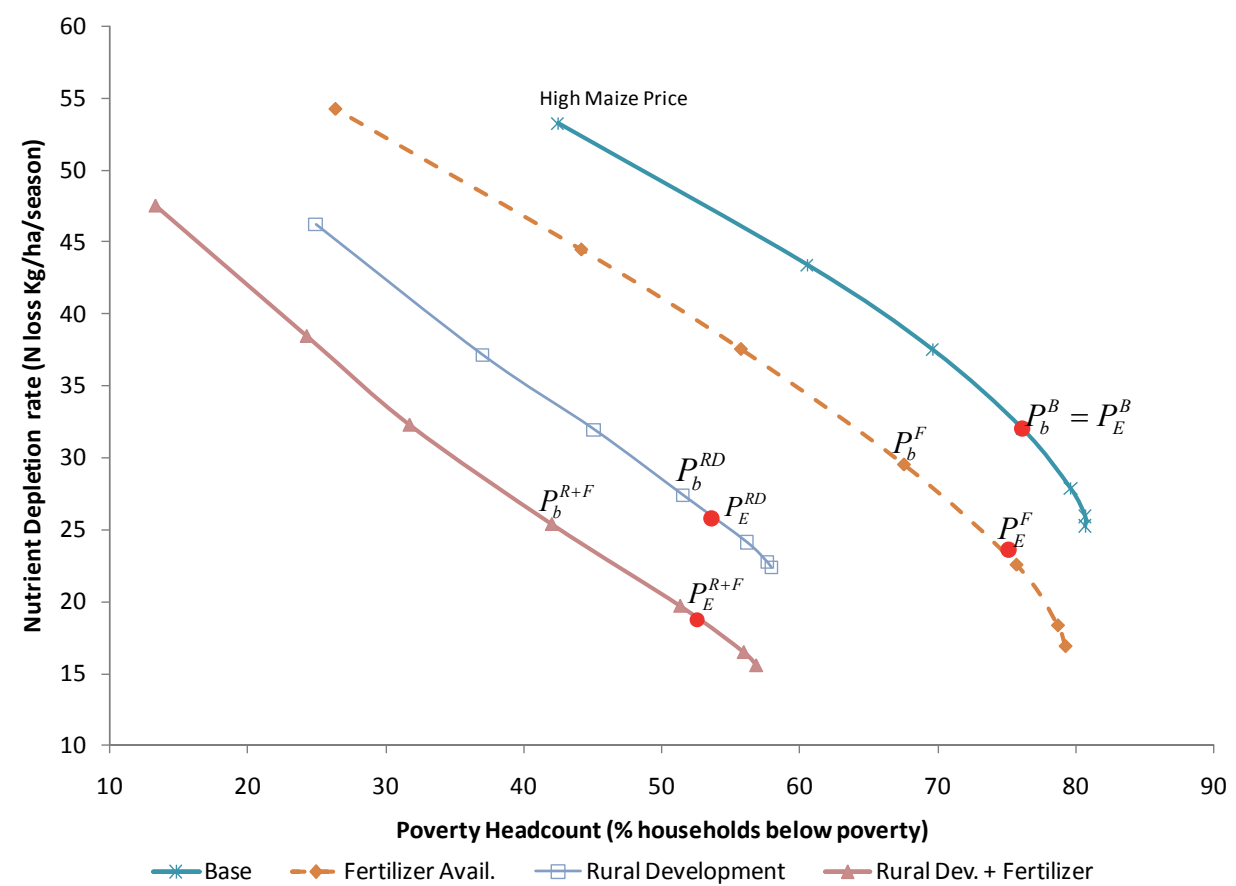

Figure 4.7. Poverty and nutrient depletion tradeoff curves constructed by varying the mean price of maize ( $P_{b}=b a s e$ price) under different scenarios and the effects of these scenarios on poverty and nutrient depletion compared to the base scenario using the models with and

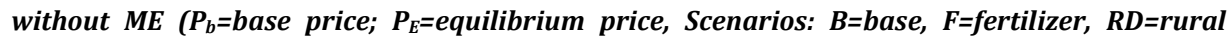
development, and $R+F=$ combined rural development and fertilizer). Machakos, Kenya.

Table 4.3. Output supply parameter estimates for Machakos Kenya

\begin{tabular}{lll}
\hline & \multicolumn{2}{c}{ Coefficients } \\
\cline { 2 - 3 } Scenario & $\begin{array}{l}\text { Output } \\
\text { Supply } \\
\text { Elasticity }\end{array}$ \\
\hline Base & 7.22 & 2.6 \\
Rural Development & $(0.37)$ & $(0.37)$ \\
Fertilizer Availability & 7.7 & 2.56 \\
& $(0.37)$ & $(0.37)$ \\
Rural Dev. + Fertilizer & 8.75 & 2.29 \\
& $(0.37)$ & $(0.37)$ \\
& 8.93 & 2.36 \\
& $(0.37)$ & $(0.37)$ \\
\hline
\end{tabular}

* Standard deviations in parenthesis 
Figure 4.8 shows the relationship between poverty and output quantity (maize production) and the link to the market supply and demand curve. The poverty-maize production tradeoff curve is, as mentioned before, a set of possible equilibrium points associated with different prices. The implied supply curve $S_{B}$ for the base scenario is drawn in the bottom part of the figure. The demand schedule D results in a market equilibrium point $E_{B}$ which in turn defines the point $T_{B}$ on the tradeoff curve. Using this point we can map the spatial distribution of the outcomes (e.g., poverty) as it is shown in the figure $\left(\operatorname{map}_{0}\right)$.

Each scenario generates a different tradeoff curve and a new supply curve. Consequently, new equilibrium points are estimated for each scenario. In this presentation the demand curve is fixed. We assume that the income that drives the demand is more than just farm income (e.g., farmers have other sources of income such as off-farm income, remittances, etc.). Consequently, changes in farm income due to changes in the price of maize are not large enough to shift the demand. However, demand effects could also be estimated and incorporated into the market equilibrium analysis. More generally, demand may also respond to policies that increase crop production or stimulate rural development and thus raise incomes. Figure 8 also shows the tradeoff curve for the combined scenario of rural development and fertilizer availability, the derived supply curve $\left(\mathrm{S}_{\mathrm{R}+\mathrm{F}}\right)$ and the equilibrium point $\left(\mathrm{E}_{\mathrm{R}+\mathrm{F}}\right)$ at the equilibrium price $\left(\mathrm{P}_{\mathrm{E}}^{\mathrm{R}+\mathrm{F}}\right)$ which determines the point $\left(\mathrm{T}_{\mathrm{R}+\mathrm{F}}\right)$ along the tradeoff curve. This point allows us to determine the spatial distribution of impacts on the disaggregate outcomes. In the figure a new map of the distribution of poverty for the district of Machakos is obtained (see map $_{1}$ in figure 4.8). 


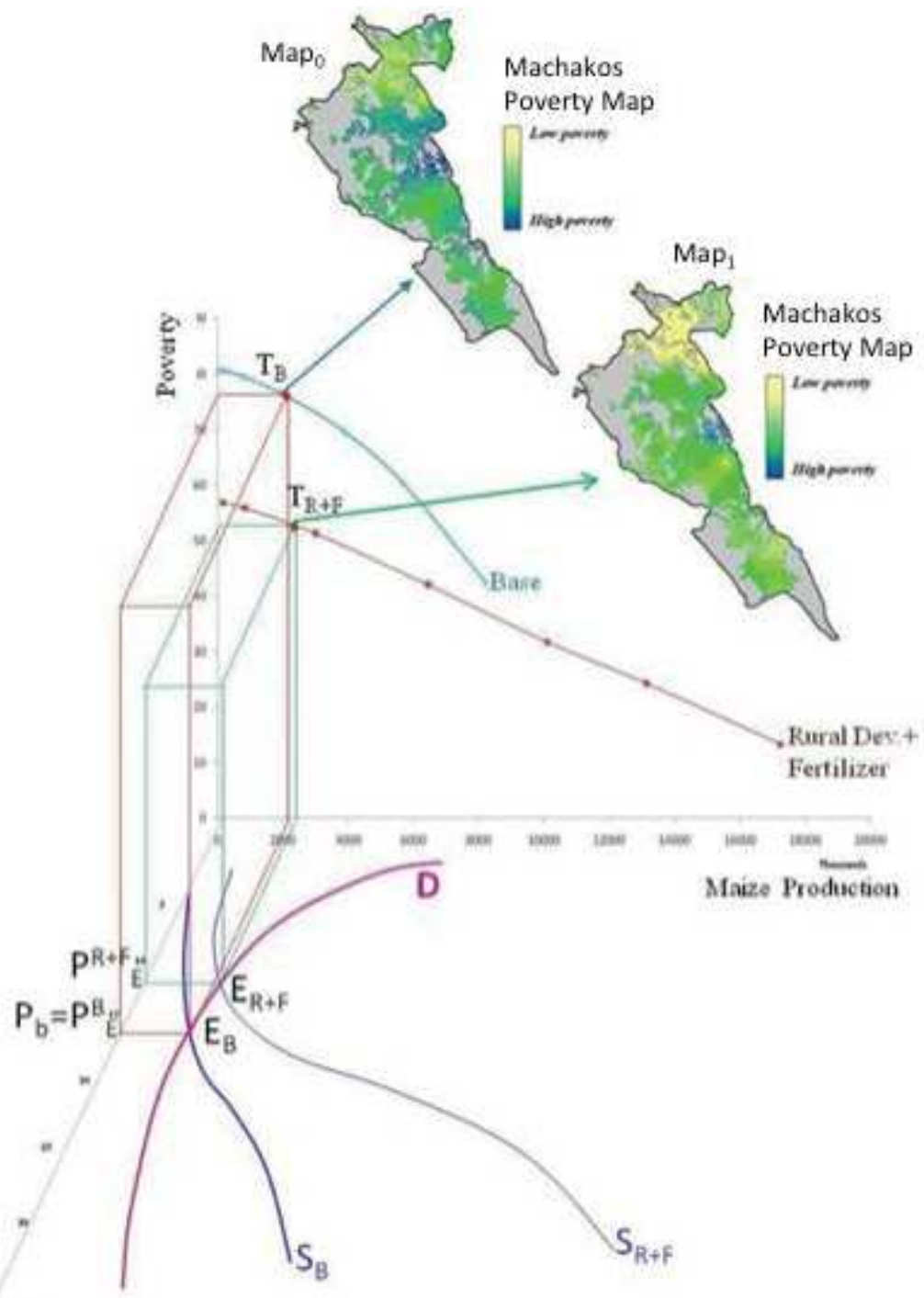

Price

Figure 4.8. Results of the TOA-ME for the base scenario (B) and the combined rural development and fertilizer availability scenario ( $R+F)$ : Derivation of the Tradeoff curves (poverty vs. maize production), link to the ME model (supply and demand curves) and linkage back to the point (T) on the tradeoff curve and the corresponding spatial distribution of outcomes (e.g., poverty maps) 
The goal of this analysis is to estimate the effect of policy scenarios in moving along the tradeoff curve. Without the ME analysis, an analyst would not know the impact of the scenario on the market equilibrium price, so the analyst might compare the simulation results at the base prices. To illustrate how the results of a tradeoff analysis could be impacted by not incorporating a ME analysis, Figure 4.9 shows how the distribution of poverty changes due to the effects of the combined rural and fertilizer scenario in relation to the base scenario. When market equilibrium is considered, the effects of the combined rural development and fertilizer policies on poverty are less than the impacts measured at the base prices, due to the effect that the higher maize price has in reducing poverty. Table 4.4 shows the average (and standard deviation) poverty and nitrogen depletion disaggregated by village, as well as the percent change of poverty and nitrogen depletion for the combined rural development and fertilizer scenario at base prices and at the market equilibrium prices. At market equilibrium prices, the effects of the policy on poverty are smaller in all the villages and consequently smaller in the aggregate. Conversely, the impact on nutrient depletion is much larger at the market equilibrium price in all villages. Table 4.4 shows that the spatial distribution of outcomes is different at the base prices and at the market equilibrium prices. 


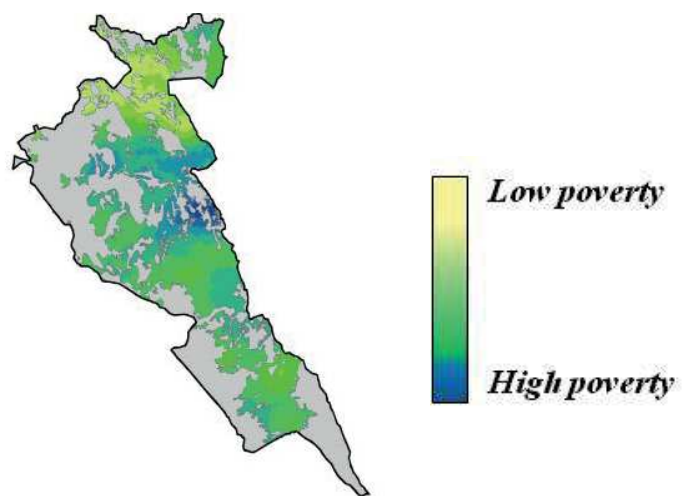

Base scenario

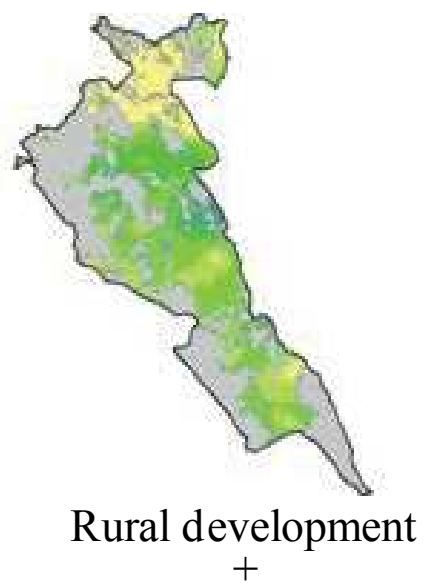

fertilizer at the base price

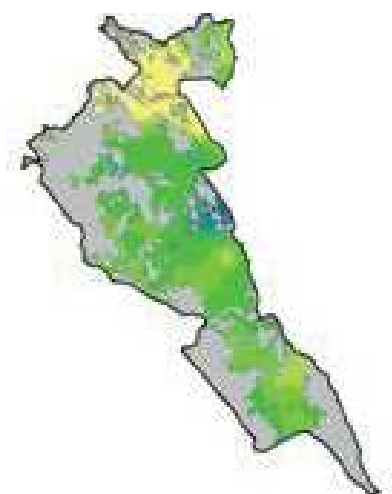

Rural development $+$ fertilizer at market equilibrium price

Figure 4.9. Distribution of spatial effects on poverty for the base scenario and combined rural development and fertilizer scenario, at the base and market prices for Machakos, Kenya (excludes non-agricultural area). 


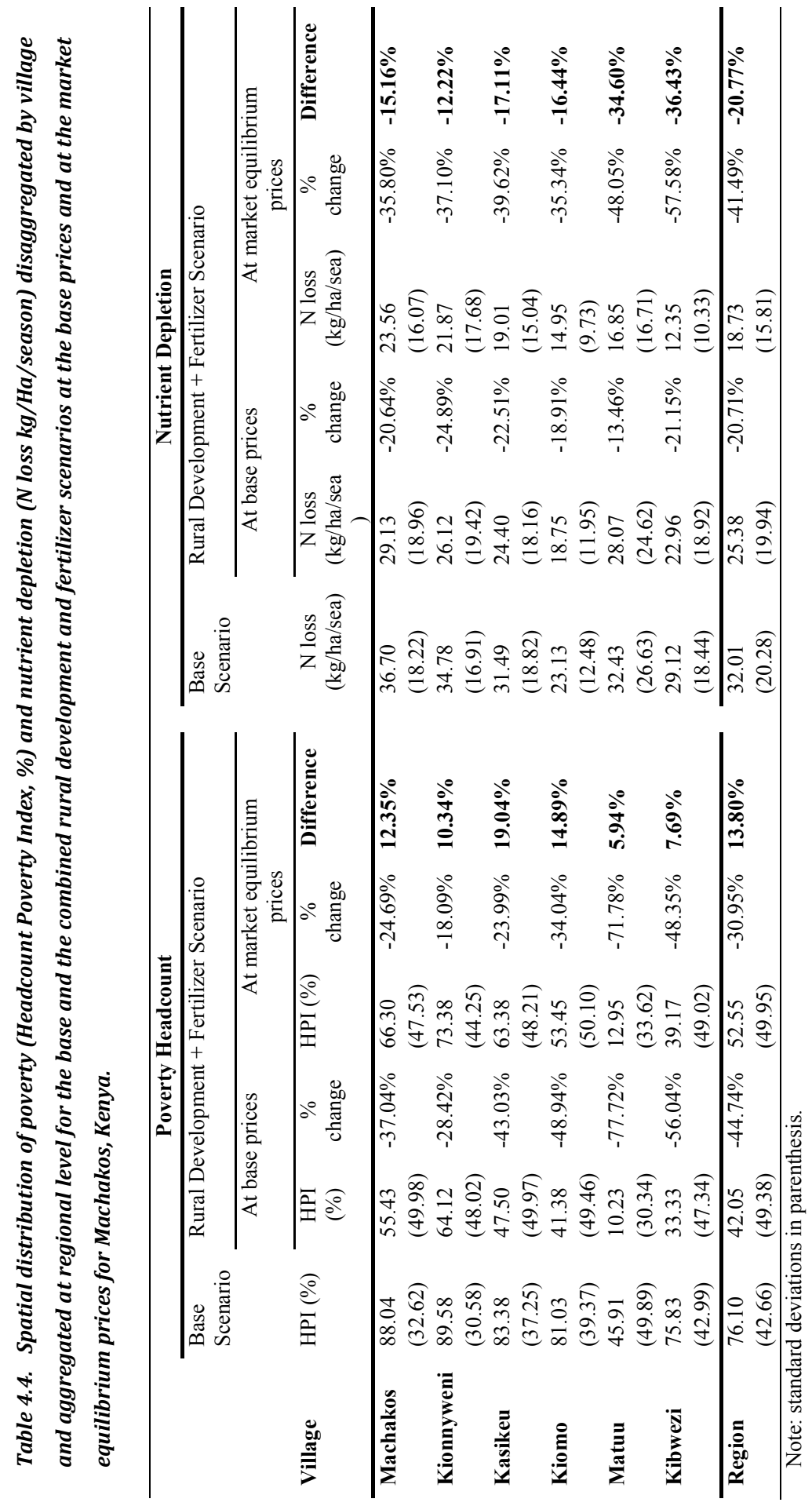

$n$ 
The effects of market equilibrium on aggregate outcomes are presented in Figure 4.7. The market equilibrium points estimated for each scenario are labeled as $P_{E}^{B}$ for the base scenario, $P_{E}^{F}$ for the fertilizer scenario, $P_{E}^{R D}$ for the rural development scenario, and $P_{E}^{R+F}$ for the combined rural and fertilizer scenario. The figure shows that the market equilibrium points are different than the base prices for each scenario. To illustrate the implications of not considering a ME analysis, we analyze the effects of the combined rural development and fertilizer scenarios. The results suggest that at the base price this policy would decrease the poverty rate from $76 \%$ to $42 \%$ (which implies a $45 \%$ reduction in the poverty). However, the results at the market equilibrium prices suggest that the poverty rate is reduced to about $53 \%$ (implying a $31 \%$ reduction in poverty). This means that the difference between the results at the base and market prices is about $14 \%$.

Likewise, the model suggests that at the base price this policy reduces the nitrogen depletion rate from $32 \mathrm{~kg} /$ ha to about $25 \mathrm{~kg} /$ ha. The model shows that at the market equilibrium price this policy would reduce the nitrogen depletion to about $19 \mathrm{~kg} / \mathrm{ha}$, implying that the difference between the two models is about $21 \%$. The difference between the impacts on poverty and nitrogen depletion measured at the base price and at the market equilibrium price may be explained by the fact that the policy intervention leads to new socio-economic conditions in the population (larger farm size, smaller household size and fertilizer availability). These changed conditions in turn, cause an outward shift of the maize supply curve (i.e., the supply curve shifts to the right) resulting in a lower (equilibrium) price of maize (this is equivalent to the shift of the supply curve shown in Figure 4.4a. Figure 4.8 also provides a graphical illustration of the impacts on poverty and nitrogen depletion measured at the base and equilibrium prices). As result, land allocated to maize is reduced (recall from above that price of maize drives land use decisions) and farm income is decreased. Thus, compared to the base price, the impacts on poverty are smaller at the market equilibrium and the impacts on nitrogen depletion are larger.

Table 4.5 shows a comparison of the aggregate results for both cases, at the base and market prices, in terms of the changes on poverty and nutrient depletion due to the policy interventions (the three scenarios under analysis). In conclusion, Tables 4.4 and 
4.5 show that linking an ME analysis to the TOA has quantitatively important effects on the assessment of agriculture-environment interactions and policy making in cases where market conditions determine prices (i.e., existence of local or regional markets). 


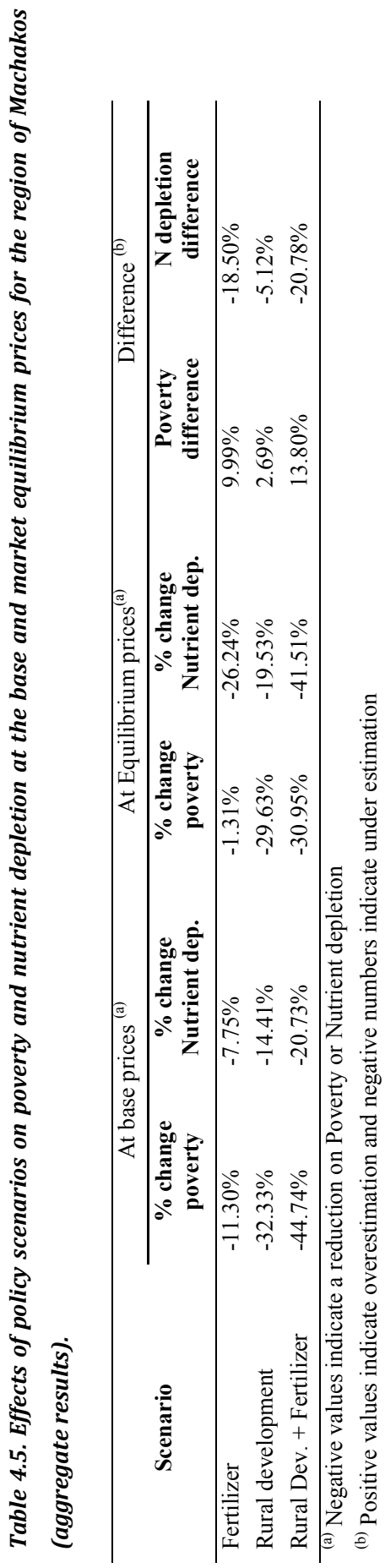




\subsection{Discussion}

Market equilibrium is likely to be important in the analysis of agricultural systems in developing countries where product and input markets are not well integrated, and therefore, local supply determines local prices (e.g., high transport costs may cause farmgate prices be set locally). Also, changes in the market supply schedules are driven not only by prices but also by changes in farm characteristics in response to policy changes, environmental conditions or socio-economic conditions. For example, in developing countries, urban and rural development policies such as infrastructure investment can affect rural-urban migration and off-farm employment, and thus change farm characteristics such as farm size, household composition, and farm family members' health and education (Reardon et al., 1998). These policy-induced changes in the distribution of farm characteristics affect market supply, which together with market demand determines the equilibrium market price. This equilibrium price in turn determines farm-level land management decisions and thus determines the spatial distribution of economic and environmental outcomes as shown in Figure 4.3. Linking the ME results back to the spatial distribution of economic and environmental impacts (e.g., poverty, land quality, etc.) allows us to understand the magnitude of these impacts at the disaggregate level (i.e., site-specific economic and environmental outcomes). The fact that the TOA model is a spatially explicit model that incorporate the effects of farm characteristics on land use and management decisions, provides an opportunity to fill that gap by linking spatially explicit production systems to ME models.

The model allows us to assess the interaction between socio-economic and environmental indicators and the effects at the market level and vice versa (i.e., interaction across scales). In fact, several studies have recognized the need to link farmlevel agricultural systems models to the aggregate, regional scales that are the principal concern of policy makers (Easterling, 1997; Ewert et al., 2006; Van Ittersum et al., 2008). Most methods and modeling tools that link micro and macro scales use either a bottom-up or a top-down approach. The gap between micro-level (e.g., field or farm) and macro level (e.g., region or market) and their interactions has barely been bridged by the few 
models designed for multi-scale assessments (Laborte et al., 2007). The TOA-ME described in this paper achieves the micro-macro linkage using a multi-scale approach that includes both bottom-up (e.g., farm to market) and top-down (e.g., market to farm) analyses.

Another example of a multi-scale model is the System for Environmental and Agricultural Modelling; Linking European Science and Society - Integrated Framework (SEAMLESS-IF, Van Ittersum et al., 2008). The SEAMLESS-IF couples bio-physical models (e.g., APES), bio-economic farm-level models (e.g., FSSIM) and market level models (e.g., SEAMCAP, CAPRI). The SEAMLESS-IF is based on simulation of representative farm types derived from the EU's Farm Accountancy Data Network (FADN). Land-based differences in agricultural production systems are defined in land capability classes. A statistical procedure is used to allocate non-spatial farm types to land capability classes (polygons). These results are up-scaled to the regional scale based on area-weighted aggregation or further aggregated to the whole EU (Uthes et al., 2010).

SEAMLESS-IF has a coarse representation of farm-level decision-making and which scope of analysis is the whole EU or its NUTS (EU nomenclature of territorial Units for Statistics). In contrast, the TOA-ME uses spatially-explicit data that represents the heterogeneity of the farm population, which enables the assessment of distributional impacts of policy or technology interventions. While the TOA-ME's scope of analysis is a region such a watershed, a key feature is that the TOA-ME provides a transparent framework that can be applied to any system in any region of the world. However, a frequent limitation for the application of the TOA-ME, particularly in developing countries, is the availability of data. Spatially-explicit IAM, such as the TOA, require highly detailed data that are generally available only from special purpose surveys. In order to deal with this limitation, Antle and Valdivia (2006) developed a minimum-data (MD) approach to agricultural system modeling which can be implemented using data that are usually available from secondary sources (e.g., previous studies, census, etc.) to characterize the distribution of returns for competing land use and management activities in the farm population. They applied the MD approach to the analysis of ecosystem service supply, and concluded that this approach could provide information to policy makers within the degree of accuracy necessary for policy making. The MD has been 
applied to the analysis of ecosystem services supply, technology adoption and technology impact assessment (see Antle and Stoorvogel, 2006; Immerzeel et al., 2008; Claessens et al., 2009; Antle et al., 2010b). A challenge for future research is to link the MD approach to a ME model. The methods and concepts discussed in this paper could be used as the starting point to develop methods for coupling the MD approach to a ME.

\subsection{Conclusions}

This paper describes the linkage of the TOA model to a ME model. The TOA-ME allows us to use site-specific data to capture the heterogeneity in the population and generate tradeoffs between environmental and economic indicators. This analysis can be coupled to a market equilibrium model and the results can be linked back to the underlying spatial distributions in order to measure their effects.

We illustrated the implementation of the TOA-ME using a case study of a semisubsistence agricultural system in Machakos, Kenya. We analyzed different policy scenarios aimed at reducing poverty rates and nutrient depletion in the region. Without a ME model, analysts can compare the effects of the policy scenarios on poverty levels and nutrient depletion over a range of plausible prices (e.g., at base prices and at selected prices above or below the base prices), but cannot determine which equilibrium prices are likely to result from the technology or policy intervention. The coupling of the TOA analysis to a ME model allows the analyst to determine the equilibrium prices of the system and thus to identify the point on a tradeoff curve that is associated to that equilibrium price, and consequently identify how the change in market prices affects the spatial distribution of economic and environmental outcomes in the region. The example presented shows that the market equilibrium price with a policy intervention could be substantially different than the prices observed without the market equilibrium analysis, and therefore could play an important role in evaluating the impacts of the policy intervention. 


\title{
CHAPTER 5
}

\section{Economic and Environmental Impacts of}

\author{
Climate Change and Socio-Economic
}

\section{Scenarios: A case study on a Semi-Subsistence Agricultural Production System}

In this study we use a spatially-explicit integrated assessment model, TOA-ME, to evaluate the economic (income, poverty) and environmental (soil nutrient depletion) impacts of climate change and socio-economic scenarios in a case study of the semisubsistence agricultural production systems of Machakos (Kenya). This model provides a unique capability to assess distributional effects of climate change on economic and environmental outcomes while also accounting for market-level impacts on prices. We use this framework to examine how a socio-economic scenario based on policy and technology interventions can offset the likely negative effects of climate change. In order to conduct this analysis we propose a three-step methodology: i) analysis of climate change scenarios generated by GCMs, ii) use of GCMs output to estimate crop responses, and iii) modeling the land use decisions and economics of the farming systems. Output data from 5 commonly used GCMs and 3 emission scenarios were used. Outputs from GCMs and emission scenarios corresponding to the Machakos region are highly variable but present a similar trend of higher temperatures and decreasing precipitation. As a result, crop production decreases with the effects varying by location. Farmers are likely to adapt to the new climate conditions through changes in land use; however the effects on poverty and soil nutrient depletion rates are small. In contrast, the analysis shows that an effective policy and technology intervention that leads to different socio-economic conditions could offset the negative effects of climate change and reduce this region's vulnerability. The results also imply that ignoring new market conditions could lead to incorrect information for policy making.

Based on: Valdivia, R.O.; J.J. Stoorvogel and J.M. Antle. 2012. Economic and Environmental Impacts of Climate Change and Socio-economic Scenarios: A Case Study on a Semi-subsistence Agricultural Production System. The International Journal of Climate Change: Impacts and Responses. 3: 157- 176. 


\subsection{Introduction}

There is a scientific consensus that climate change poses a long-term threat for rural households in vulnerable regions like Sub-Saharan Africa (SSA) (Fischer et al., 2005; IPCC, 2007; FAO, 2008). Accordingly, the assessment of economic (e.g., poverty) and environmental impacts (e.g., nutrient depletion) of climate change are on the agendas of policy makers and researchers. Projected climate data from global circulation models (GCMs) are available and tools to analyze the impacts of climate change on a broad range of situations are being constructed. At the same time there are efforts to create and analyze future socio-economic scenarios based on possible adaptation strategies, rural development policies and technology change (Nelson et al., 2010; Rosenzweig et al., 2011).

In this study the analysis of climate change impacts on agricultural production systems, and possible responses to those impacts (e.g., farmers' adaptation, rural development policies) is implemented in three steps. The first step deals with the analysis of climate change scenarios generated by general circulation models (GCM). The second step uses the projected climate data from GCMs to estimate crop yield responses for the climate scenarios. These crop yield responses can be obtained by simulating statistical models based on historical data, or from process-based simulation models. Statistical methods relate historical yields to observed climatic variation (Thompson, 1969; Lobell and Field, 2007; McCarl et al., 2008; Feng et al., 2010; Liu et al., 2010; Schlenker and Lobell, 2010) or spatial patterns of yields to climate variability (Wigley and Qipu, 1983; Wood et al., 2004; Basso et al., 2007). Crop simulation models are implemented for climate impact assessment by combining genetic parameters from experiments with representative management data, soils data, and weather data generated by climate models (e.g., Jones and Thornton, 2003; Stöckle et al., 2003; Iglesias, 2006).

The third step involves an economic analysis of the possible adaptation strategies at the farm level as well as changes in markets for farm products (autonomous or planned). Autonomous adaptation is triggered by ecological changes in the natural system and by market or welfare changes in human systems (IPCC, 2001). At the farm level, individual producers choose the crop or crop mix that is most profitable. Given a change in climate conditions, that crop or crop mix may not be the most profitable; therefore 
producers may select another set of crops and corresponding management (i.e., adapt to the new conditions). If other producers take similar action and switch from one set of crops to a different set, then the aggregate supply of marketed commodities will likely be affected. Similarly, changes in income or population also may shift the demand, resulting in changes in the market equilibrium prices.

Planned adaptation is implemented through policies designed to reduce adverse impacts of climate change. Due to the uncertainty in future climate and economic conditions, climate change policy studies are using a range of plausible future socioeconomic conditions, referred to as agricultural pathways or adaptation pathways (Rosenzweig et al., 2011).

Integrated assessment models (IAM) have been developed to deal with the complexity of the analysis and the relationships of the elements involved within and between steps 2 and 3 (assessment of productivity impacts and adaptation) (e.g., Dowlatabadi and Morgan, 1993; Nordhaus 1991, 1994; Manne et al., 1993, 1995). The Tradeoff Analysis Model (TOA) (Stoorvogel et al., 2004) is an integrated assessment model of agricultural production systems that integrates site-specific bio-physical processes and farmers' economic decision making.

The TOA uses the Decision Support System for Agrotechnology Transfer (DSSAT; Jones et al., 2003) to simulate the spatial (and temporal) variability in productivity. The simulated crop productions are used to estimate econometric production models for site-specific input use and output supply decisions of farmers. These models are the basis for a spatially-explicit econometric-process simulation model that simulates land use and management decisions under different economic, technological or climate scenarios. Results from the TOA can be statistically aggregated to a level that is relevant for policymaking (See chapters 2 and 3 in this thesis).

In Chapter 4 of this thesis, we coupled the TOA to the partial market equilibrium (TOA-ME) model to analyze the effects of policy and technology interventions on the spatial distribution of environmental and economic outcomes at the market equilibrium prices. The results suggest that the linkage of market equilibrium analysis to farm level integrated assessment models can be important in the analysis of agriculture-environment 
interactions. Steps two and three mentioned above can be accomplished by using the TOA-ME. Furthermore, the TOA-ME can: a) capture farm-level decision making, b) be used to represent any policy or technology intervention scenarios as well as incorporate climate change scenarios c) incorporate market conditions, and d) uses spatially-explicit data which allows the assessment of distributional impacts. All these characteristics of the TOA-ME make it a well suited IAM model for climate change and policy analysis.

The objective of this paper therefore is to assess the economic and environmental impacts of climate change and the effectiveness of rural socio-economic scenarios using the TOA-ME as applied to the semi-subsistence agricultural production system of Machakos, Kenya. In particular, we analyze the impacts of climate change on poverty and nutrient depletion. We then analyze the effects of a policy and technology intervention aimed to reduce poverty and decrease nutrient soil depletion within the climate change context. In addition we discuss the importance of including a market equilibrium analysis. We conclude with a discussion of the findings and limitations of the study.

\subsection{Materials and Methods}

\subsubsection{Study Area}

The Machakos region, which includes the districts of Machakos, Makueni and Mwingi, is located in the Eastern Province of Kenya, southeast of Nairobi between $0^{\circ} 70^{\prime}$ and $3^{\circ} 00^{\prime}$ southern latitude and between $36^{\circ} 87^{\prime}$ and $38^{\circ} 51^{\prime}$ eastern latitude. The study area is approximately $14,000 \mathrm{~km}^{2}$ with an altitude range between 340 and 1710 meters above sea level. The climate is semi-arid with an average annual rainfall that ranges between 500 to $1300 \mathrm{~mm}$. Rainfall patterns are highly variable and distributed in two rainy seasons. The short season occurs from November to January and the long season from March to June. Severe droughts are frequent and usually last two or more seasons hurting crop production and food security (Tiffen et al., 1994). Mean annual temperature ranges from $15^{\circ} \mathrm{C}$ to $25^{\circ} \mathrm{C}$. About half of the area in the Machakos region is under agricultural use. Most agriculture is semi-subsistence characterized by complex intercropping, small field size, low yields, high rates of crop failure, and lacking an 
established capital market. Agricultural production systems include both crop and livestock activities. Maize is grown as the main staple crop but other crops (e.g., beans), vegetables (e.g., tomatoes) and fruit trees (e.g., mangoes) are also cultivated. Livestock, which is mostly managed as zero-grazing with some free-grazing in the lower areas, is also an important activity in the region. Farm households face deteriorating price relations between farm outputs and inputs and increased land pressure which lead to a severe exploitation of soil nutrients (de Jager et al., 1998). Soil nutrient depletion is one of the major constraints to a sustainable agricultural development in the Machakos region.

Several studies showed that soil nutrient balances in Machakos are often negative with annual losses of about $55 \mathrm{~kg} \mathrm{~N} / \mathrm{ha} / \mathrm{yr}$ (Nandwa et al., 2000). Average crop yields are low, about $399 \mathrm{~kg} / \mathrm{ha}$ for maize and $687 \mathrm{~kg} / \mathrm{ha}$ for beans (de Jager, 2001). Despite several efforts of the government and research programs to increase maize yields, average yields remain far below their potential creating serious food deficits in many regions of Kenya where maize is a primary staple. Donovan and Casey (1998), Sanchez et al. (1997), Bationo, Lamers and Lehman, (2015) among others, recognize that in order to reverse the declining trends in per capita food production and negative nutrient balances, soil fertility management on farms must be improved. Increasing crop productivity is clearly a key element to improve living standards and to reduce poverty levels. The question is then how climate change will affect crop productivity and land use, and how policies can be structured to deal with nutrient depletion and poverty under new (and possible negative) climatic conditions.

\subsubsection{Step 1: Climate Change Projections}

Emission scenarios developed by the Inter-governmental Panel on Climate Change (IPCC) are widely used for climate change analysis. These scenarios describe greenhouse gas emissions related to economic growth and energy use. The emissions rates are used as input to the Global Circulation Models (GCM) to project climate change. For this study we used the following emission scenarios developed by the IPCC (IPCC SRES, 2000): 
A1B: This scenario is of a more integrated world of very rapid economic growth, global population that peaks in mid-century and declines thereafter, and rapid introduction of new and more efficient technologies, with the development balanced across energy sources.

A2: This scenario is of a more divided world and is characterized by being heterogeneous with continuously increasing global population and regionally oriented economic growth that is more fragmented and slower than in other scenarios.

B1: This scenario is of a world more integrated, and more ecologically friendly and is characterized by being a world with the same global population as in the A1B scenario but with rapid changes in economic structures toward a service and information economy, with reductions in material intensity, and the introduction of clean and resource-efficient technologies.

General Circulation Models (GCMs) are large-scale mathematical models that simulate the physical processes that affect climate. GCMs use transient climate simulations to project future climate changes under various scenarios. While the accuracy of GCMs output is under debate, there is a scientific consensus that they are suitable to project future climate change (Grassl, 2000; IPCC, 2001). For this study we use the output of 5 commonly used GCMs:

- CGCM3 (T47 resolution) developed by the Canadian Center for Climate Modelling Analysis, Canada.

- ECHAM5-OM developed by the Max-Planck-Institute for Meteorology, Germany.

- HadCM3 developed by the UK Meteorology Office, UK.

- MIROC 3.2 medres, developed by the National Institute for Environmental Studies, Japan.

- MK 3.0, developed by the Australia's Commonwealth Scientific and Industrial Research Organization, Australia.

Output data from each model for the emission scenarios mentioned above were downloaded from the IPCC Data Distribution Centre website (IPCC-DDC, 2009). The results for each combination of GCM and emission scenario contain information on climatic conditions (i.e., temperature, precipitation and solar radiation) over a specific time span. We used a 10-year average to calculate climate change with a projection of 50 
years. Thus, climate change was calculated as the difference between the average of the first ten years and the average of the last 10 years of a 60 -year period. Climate change data in terms of changes in monthly temperature, rainfall and radiation for the grid cells covering the Machakos region were extracted.

The spatial resolution of the GCMs varies between 3 and 9 degrees. Climate change projections for the weather stations in the Machakos region were calculated by interpolating the data from the surrounding grid cells using a weighted average based on the distance from the centre of the grid cell to the location of the weather stations.

\subsubsection{Step 2: Productivity Effects of Climate Change}

The agricultural production system in the Machakos region is characterized by a highly complex intercropping system that involves a diverse mix of crops and is mostly used for home consumption. Maize and beans are grown as monocrop or as intercrop and used for both home consumption and sold for cash. Vegetables are primarily cash crops but are limited to the areas that have access to irrigation. Accordingly, expected crop productivities for maize, beans and tomatoes (as a proxy for vegetables) were calculated using the respective crop models from DSSAT. The estimates of the bio-physical crop simulation models are interpreted as an index of productivity potential rather than a prediction of actual yield. We refer to this index as the site's inherent productivity estimated with average management and site-specific soil and climate data. It is important to note that there are two villages that have access to irrigation where irrigated vegetables are produced. Therefore, irrigated and rainfed tomato inherent productivities where estimated as a proxy for vegetables. The crop models use daily weather data and the key parameters are maximum and minimum temperature, precipitation and solar radiation. These parameters were modified to incorporate the effects of climate change produced by the GCMs. The IPCC data are monthly climate change data. Therefore, we perturbed the observed weather data by changing the monthly means as described in step 1. Inherent productivities were obtained for the current climatic conditions using observed weather data and for future climatic conditions using the perturbed weather data. It is important to note that, although more extreme weather conditions are predicted, 
the distributions of the parameters were not changed as quantitative information on these changes is lacking. The effects of $\mathrm{CO}_{2}$ fertilization on crop production are still highly uncertain and models are not calibrated to model these effects. Therefore, $\mathrm{CO}_{2}$ concentrations were kept constant in the analysis.

\subsubsection{Step 3: Economic Analysis}

\section{The TOA-ME}

The TOA integrates bio-physical and econometric process models. These models need to be calibrated and estimated for the specific conditions of the area under analysis. The calibration and estimation of these models for specific conditions requires spatiallyexplicit data including environmental data (site-specific soil and climate data) and farm survey data (site-specific production, input and price data). Inherent productivities are estimated for each farm in the survey using DSSAT as described in the previous section. Then an econometric-process model simulates site-specific land management decisions using econometric production models (input demand and output supply) that are functions of inherent productivity, prices, farm characteristics, and policy parameters.

Environmental impacts of these management decisions are then simulated using environmental process models. As a result, management decisions and resulting environmental outcomes on each unit of land in production are functions of site-specific environmental conditions, prices, policies, technology and other farm-specific variables. The distributions of these site-specific and farm-specific characteristics in the population generate a joint distribution of economic and environmental outcomes in the population that are functions of the underlying environmental and economic parameters. With this joint distribution the outcomes can be statistically aggregated into economic and environmental indicators that represent the population. Different environmental and economic outcomes can be generated by varying key model parameters such as prices (e.g., maize price). Consequently, the aggregate relationships between economic and environmental indicators generated in this way are referred to as tradeoff curves. Thus, tradeoff curves represent the supply side of the agricultural system. Here we use the fact that when tradeoff curves are generated by varying output or input prices, they represent 
the input demand and output supply behavior of farms (Valdivia et al., 2012, See Chapter 2 in this thesis for more details).

Different scenarios can also be simulated by varying other model parameters. Changes in a commodity price (e.g., maize price) or a change in the scenario (e.g., a climate change scenario) may change the model outcomes, for example it may change land use patterns, and consequently may have impacts on market equilibrium prices. Using data to characterize the output demand (e.g., output demand price elasticity) for a specific commodity in the system, the TOA linked to a market equilibrium model (i.e., TOA-ME) can estimate the equilibrium price and quantity. Economic and environmental indicators can be estimated at the equilibrium point by executing the simulation using the estimated equilibrium price (see Valdivia et al., 2012 for more details about coupling the TOA to a market equilibrium model).

\section{Data}

In this study we used data from two farm-level surveys carried out in the Machakos region. These surveys were carried out by the projects LEINUTS (1997 to 1999) and NUTSAL (1999 to 2001) covering six villages in total. The LEINUTS data covers 4 growing seasons while the NUTSAL data covers 2 to 3 growing seasons. Both projects have used the Nutrient Monitoring (NUTMON) approach.

NUTMON is a multi-disciplinary and multi-scale approach to address the problem of soil nutrient depletion (De Jager et al., 1998b). The NUTMON approach includes standardized survey instruments and quantifies soil nutrient balances using a comprehensive accounting of inputs and outputs of the farm and household system. Table 5.1 shows summary statistics for key variables of the study area. The survey data shows that, as mentioned before, the principal crop systems are: the diverse intercrop which is primarily used for home consumption. Maize and beans are grown as monocrop or as a single intercrop and used for both home consumption and sold for cash. Vegetables are primarily cash crops but are limited to the areas that have access to irrigation. There is also land used for grass to feed livestock. Although the average farm size in the area is about 3 ha, its distribution is highly skewed with a range between 2 to about 8 ha (see Antle et al., 2011 for more details). 
Table 5.1: Summary Statistics from NUTMON Data for the Machakos Region, Kenya

\begin{tabular}{lcc}
\hline Variable & Mean & Standard deviation \\
\hline Output price, complex intercrop (ksh/kg) & 10.7 & $(8.8)$ \\
Maize price $(\mathrm{ksh} / \mathrm{kg})$ & 15.0 & $(2.7)$ \\
Bean price $(\mathrm{ksh} / \mathrm{kg})$ & 30.4 & $(2.7)$ \\
Vegetable price (ksh/kg) & 19.0 & $(14.00)$ \\
Complex intercrop land share (\%) & 33.3 & $(47.1)$ \\
Maize land share (\%) & 27.6 & $(44.7)$ \\
Beans land share (\%) & 9.0 & $(28.6)$ \\
Vegetables land share (\%) & 17.5 & $(37.9)$ \\
Grass land share (\%) & 12.8 & $(33.3)$ \\
Farm size (ha) & 3.1 & $(3.5)$ \\
Family size (persons) & 8.0 & $(3.0)$
\end{tabular}

Data for the demand side of the analysis in the market equilibrium model were obtained from the literature. There are few studies that have actually estimated the price elasticities of demand for maize and other crops in Kenya. Nzuma and Sarker (2008) estimated that the short-run own price elasticity of demand for maize is about -0.53 while the long-run own price elasticity of maize was about -0.80 . Other studies surveyed by Nzuma and Sarker reported elasticities of demand for maize ranging from -0.45 to -0.90 . In the present study we use an own price elasticity of demand for maize of -0.50 . We assume in this application that the income that drives the demand is more than just farm income (e.g., farmers have other sources of income such as off-farm income, remittances, etc.). Consequently, changes in farm income due to changes in the price of maize are not large enough to shift the demand. However, demand effects could also be estimated and incorporated into the market equilibrium analysis. More generally, demand may also respond to policies that increase crop production or stimulate rural development and thus raise incomes. In addition, population increase corresponding to the time period of analysis could also shift the demand. 


\section{Simulation}

The TOA-ME model is based on the whole-farm model for the Machakos region constructed by Antle et al. (2011). This model utilizes econometric models (revenue and input demand equations) for complex intercrop, maize, beans, vegetables and dairy production that are functions of inherent productivities for maize, beans and tomatoes. For the case of the complex intercrop, both maize and beans are important crops in the mix. Antle et al. (2011) tested both inherent productivities in the econometric models and found that the bean's inherent productivity provided better results, so it was used in the model. The econometric models were estimated using the survey data, the inherent productivities and livestock data. The output of the econometric models is then used as input to an econometric process simulation model. It is important to mention that land share allocated to grass is kept fixed in the model (about 14\%).

In the TOA model for Machakos, Antle et al. (2011) defined the farm according to its characteristics (location, size, number of family members, age and education of household head, availability of off-farm income, number of Tropical Livestock Units (TLUs), and family labor). For each growing season the model simulates milk and manure production as functions of feed availability. Manure and organic fertilizer as well as crop residues accumulated from the previous season become inputs available for crop and livestock production in the current season. Cost of production, expected revenue and expected returns of each activity for each field on the farm are computed by simulating crop input use and input demand functions, crop failure probabilities and crop and byproduct equations. The model assumes that farmers maximize returns by choosing the activity with the highest expected returns in each field. These crop-specific outputs, inputs and returns at the field level are saved for aggregation to the farm level.

The simulation is executed for a sample of farms that represent the distribution of bio-physical and economic conditions of the region. Inherent productivities play a key role in the process as they capture bio-physical (soil and climate) conditions and its spatial variability. Thus, the simulation of inherent productivities for all the climate change scenarios described above are used in the simulation to estimate the effects of climate change on the model's outcomes. The outcomes of the simulation are used to calculate population-level indicators such as the population's poverty rate and the 
average rate of soil nutrient loss in the population. The poverty rate is calculated as the headcount poverty index with a poverty line of $\$ 1 /$ day/person. The soil nutrient loss rate is calculated using NUTMON. Tradeoff curves between these two indicators were constructed by varying the mean of the maize price distribution. Each scenario was replicated by varying the maize of price over a range of $-75 \%$ to $125 \%$ of the base price while prices of other inputs and crops were held constant. The output from the TOA is then used in the market equilibrium model to estimate the output supply parameters for maize. The market equilibrium model uses output supply parameters and the demand parameters to estimate the equilibrium price and quantity. The TOA is executed again with the equilibrium values to estimate the spatial distribution of the outcomes (e.g., poverty or nutrient depletion) at the equilibrium points.

\section{Scenarios}

The simulation is run for three scenarios which are combinations of socioeconomic and climate change scenarios:

Baseline scenario. This scenario represents current socio-economic and climate conditions.

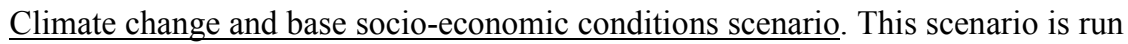
for future climate change conditions and assumes no policy or technology intervention.

Climate change and changed socio-economic conditions scenario. This scenario is run for climate change and new socio-economic conditions which are a consequence of rural development policies. This scenario deals with two policy issues that have been identified as the major constrains to the sustainability of agricultural production systems, food security and poverty in Kenya (Government of Kenya, 2004). These issues are the loss of soil nutrients with the resulting loss in crop productivity, and the increasing dependence of a growing population on small farms for their livelihoods. Consequently, this scenario is based on a policy intervention and technology change. The policy intervention represents the consequences of a policy that stimulates investments in the rural sector, which in turn increases off-farm employment opportunities and farm consolidation. To investigate the kinds of effects that rural development could have, we utilized the observed historical patterns of agricultural development, in which economic 
growth leads to larger farms and smaller household sizes (see for example Deininger and Jin, 2008). Accordingly, we assume that the average household size is reduced by $25 \%$ and average farm size is increased from the regional average of about 3 ha to 6 ha. The technology intervention part of the scenario assumes that there is an increase in fertilizer availability due to investments in market infrastructure and reductions in import tariffs which lower farm-gate cost of fertilizer. The scenario assumes that these interventions reduce the price of fertilizer by $50 \%$ and assumes all farmers use fertilizer (the quantity is estimated by the fertilizer demand at those lower prices).

We compare the outcomes of the baseline scenario to the outcomes of the second and third scenarios. The comparison is made in terms of changes in poverty rates and soil nutrient depletion rates. The results are presented with and without market equilibrium analysis.

\subsection{Results and Discussion}

\subsubsection{Step 1: Changes in Temperature, Precipitation, and Solar Radiation}

Results from the different emission scenarios and GCMs are summarized in table 2. The multi-year average of climate change data for the selected GCMs shows an increase in temperature which is consistent across the different emission scenarios. However, it is important to note that there is a significant variation across the different GCMs. The prediction for precipitation is highly variable across scenarios and across GCMs. On average, the emission scenarios suggest changes on rainfall that range from a small increase of $0.02 \mathrm{~mm} /$ day to a more significant decrease of about $-0.2 \mathrm{~mm} /$ day. Although these changes may seem low, in marginal areas where current annual precipitation is already low these results may have an important effect. For example, in some areas in Machakos where the annual average rainfall is about $500 \mathrm{~mm} /$ year, the most extreme prediction (scenario B1 shown in table 5.2) would mean a reduction of about $15 \%$ in annual rainfall, while in areas where the annual average rainfall is about $1300 \mathrm{~mm} /$ year, the same change in precipitation would cause a decrease in the average 
annual rainfall of about $5 \%$. This shows that the changes in weather can have different degree of impacts in a region with heterogeneous micro environmental conditions (i.e., heterogeneous landscapes).

Table 5.2: Climate Change Data for Machakos Region, Kenya: Average Change on Temperature, Precipitation and Solar Radiation for the Selected Emission Scenarios. Standard Deviations Estimated Over the GCMs are in Parentheses

\begin{tabular}{lcccccc}
\hline $\begin{array}{l}\text { Emission } \\
\text { Scenario }\end{array}$ & \multicolumn{2}{c}{$\begin{array}{c}\text { Temperature }{ }^{\circ} \mathbf{C} \\
\text { monthly average }\end{array}$} & \multicolumn{2}{c}{$\begin{array}{c}\text { Precipitation } \\
\text { mm/day }\end{array}$} & \multicolumn{2}{c}{$\begin{array}{c}\text { Solar Radiation } \\
\text { MJ/m2/day }\end{array}$} \\
\hline A1B & 0.56 & $(0.79)$ & 0.02 & $(0.30)$ & 0.29 & $(2.98)$ \\
A2 & 0.85 & $(0.66)$ & -0.08 & $(0.30)$ & 2.01 & $(2.26)$ \\
B1 & 0.68 & $(0.58)$ & -0.18 & $(0.20)$ & 1.79 & $(3.59)$
\end{tabular}

\subsubsection{Step 2. Effects of Climate Change on Inherent Productivities}

Table 5.3 shows that the aggregate effects of climate change result in a reduction of inherent productivities. These results are in line with several studies that suggest that climate change will have negative effects on crop yields in Sub-Saharan Africa (e.g., Thornton et al., 2006; IPCC, 2007). The response of crop yields to the increasing temperatures and the general decrease in rainfall varies by crop. The results show a large amount of variability across the GCMs. The impact of climate change will be different for different plant functional types due to the different metabolic pathways for carbon fixation in photosynthesis. In general, a C4-crop like maize is more tolerant to higher temperatures than a C3-crop like beans (Jones and Thornton, 2003). Thornton et al. (2008), suggest that the variability they found in the response of maize and beans yields to climate change, can be explained by temperature effects. 
Table 5.3: Effects of Climate Change on Inherent Productivities in the Machakos Region, Kenya Estimated Using DSSAT: Average Absolute Change of Inherent Productivities Simulated Under the Selected Emission Scenarios Respect to Inherent Productivities Simulated Under Current Climate Conditions (Baseline, First Row). Standard Deviations Estimated over the GCMs are in Parentheses

\begin{tabular}{|c|c|c|c|c|c|c|c|c|}
\hline $\begin{array}{l}\text { Emission } \\
\text { Scenario }\end{array}$ & \multicolumn{2}{|c|}{$\begin{array}{c}\text { Maize } \\
\text { (Kg/ha) }\end{array}$} & \multicolumn{2}{|c|}{$\begin{array}{c}\text { Beans } \\
(\mathrm{Kg} / \mathrm{ha})\end{array}$} & \multicolumn{2}{|c|}{$\begin{array}{c}\text { Rainfed Tomato } \\
\text { (Kg/ha) }\end{array}$} & \multicolumn{2}{|c|}{$\begin{array}{c}\text { Irrigated } \\
\text { Tomato (Kg/ha) }\end{array}$} \\
\hline Baseline & 2234 & & 1005 & & 1923 & & 8546 & \\
\hline A1B & -221 & (611) & -237 & (380) & -96 & (108) & -314 & (1464) \\
\hline A2 & -328 & (433) & -67 & (602) & -92 & (110) & -724 & (1048) \\
\hline B1 & -310 & (449) & -210 & (381) & -140 & (64) & -546 & (1035) \\
\hline
\end{tabular}

In the case of beans Thornton et al. (2009) suggest that yield increases will occur up to a temperature of about $20-22^{\circ} \mathrm{C}$. If temperatures pass this threshold, bean yields will start to decline. Maize, on the other hand, would benefit from an increase in temperature at higher altitudes; however at lower altitudes higher temperature and limited water availability would cause yields to decline. This shows that crop productivity may be affected differently depending on where crops are grown and how weather is affected by climate change on those specific locations.

It is important to note that in this study we are dealing with monthly data, and extreme events are not taken into consideration. In addition, other effects such as possible changes in growing season length are not included. Warmer temperatures and lower rainfall are likely to change the length and conditions of growing seasons. Drier growing seasons, and possible more frequent drought would impact crop yields and livestock productivity (Huq et al., 2005). We should also mention that pest and crop diseases are likely to affect crop (and livestock) production. These effects are not included in the present analysis. 


\subsubsection{Step 3. Effects of Climate Change on Land use, Nutrient Depletion and Poverty}

Table 5.4 shows the effects of climate change on the shares of land allocated to the crops of the production system. These results are presented at the maize market equilibrium price and represent the average share of land allocation for each emission scenario. The principal land reallocation occurs between maize and intercrops, the two the main crops in the system. As noted above, main crops in the intercrop system are maize and beans, however only beans' inherent productivity was used in the econometric models. The decrease in land allocated to intercrops can be explained by the fairly larger negative effects of climate change on the beans' inherent productivities as shown in table 5.3. Although the results show an increase of land allocated to maize, these changes are relatively small. Recall from the simulation section that the model assumes that farmers maximize returns by choosing the activity with the highest expected returns in each field.

Table 5.4: Effects of Climate Change on Land Allocation (i.e., Percent of Land Allocated to Each Crop) in the Machakos Region, Kenya: Simulated Land Allocation for the Crops in the System Under the Selected Emission Scenarios Compared to the Baseline (Current Climate Conditions, no Intervention. See first row). Standard Deviations Estimated over the GCMs are in Parentheses

\begin{tabular}{lcccccccc}
\hline $\begin{array}{l}\text { Emission } \\
\text { Scenario }\end{array}$ & \multicolumn{2}{c}{$\begin{array}{c}\text { Complex } \\
\text { Intercrop (\%) }\end{array}$} & & $\begin{array}{c}\text { Maize } \\
(\%)\end{array}$ & $\begin{array}{c}\text { Beans } \\
(\%)\end{array}$ & \multicolumn{2}{c}{$\begin{array}{c}\text { Vegetables } \\
\mathbf{( \% )}\end{array}$} \\
\hline Baseline & 0.35 & & 0.27 & & 0.10 & & 0.15 & \\
A1B & 0.29 & $(0.12)$ & 0.30 & $(0.08)$ & 0.11 & $(0.02)$ & 0.16 & $(0.03)$ \\
A2 & 0.31 & $(0.15)$ & 0.30 & $(0.09)$ & 0.10 & $(0.03)$ & 0.15 & $(0.04)$ \\
B1 & 0.29 & $(0.14)$ & 0.31 & $(0.09)$ & 0.11 & $(0.02)$ & 0.15 & $(0.03)$
\end{tabular}

Note: As noted in the text, land allocated to grass was held constant at $14 \%$.

The climate change results suggest that the relative changes in the expected returns to each crop compared to the baseline are small. Consequently, land reallocation is minimal. Table 5.4 also shows that in the case of land allocated to vegetables there is almost no change. This is due in part to the fact that the most important production of vegetables is located in only two of the villages that have access to irrigation. It is important to note that there are no major differences in results across emission scenarios; however there is a high variability across the different GCMs. 
The results of simulations to estimate the impacts of climate change and the socio-economic scenarios on nutrient depletion and poverty for the selected GCMs and emission scenarios are summarized in Table 5.5. This table shows the percentage change in poverty and nutrient depletion rates in the Machakos region for the scenarios under climate change: a) base socio-economic conditions and, b) changed socio-economic conditions with respect to the baseline scenario based on rural development policy and technology intervention.

Table 5.5: Climate Change Effects on Poverty and Nutrient Depletion for the Machakos Region, Kenya: Average Percentage Changes for the Selected Emission Scenarios. Changes are Presented for the Climate Change, Base Socio-economic Conditions Scenario and for Climate Change, Changed Socio-economic Conditions Scenario Respect to the Baseline (No Intervention, Current Climate). Results for Socio-economic Scenarios based on Policy and Technology Intervention are Presented with and without Market Equilibrium Analysis. Standard Deviations Estimated over the GCMs are in Parentheses

\begin{tabular}{|c|c|c|c|c|c|c|}
\hline \multirow[b]{3}{*}{$\begin{array}{l}\text { Emission } \\
\text { Scenario }\end{array}$} & \multirow{2}{*}{\multicolumn{2}{|c|}{$\begin{array}{c}\text { Base socio-economic } \\
\text { scenario }\end{array}$}} & \multicolumn{4}{|c|}{$\begin{array}{c}\text { Changed Socio-economic Scenario (based on policy and } \\
\text { technology intervention) }\end{array}$} \\
\hline & & & \multicolumn{2}{|c|}{$\begin{array}{c}\text { without Market } \\
\text { Equilibrium (at maize base } \\
\text { price) }\end{array}$} & \multicolumn{2}{|c|}{$\begin{array}{l}\text { with Market Equilibrium } \\
\text { (maize equilibrium price) }\end{array}$} \\
\hline & $\begin{array}{l}\text { Change in } \\
\text { Poverty }\end{array}$ & $\begin{array}{l}\text { Change in } \\
\text { Nutrient } \\
\text { Depletion }\end{array}$ & $\begin{array}{l}\text { Change in } \\
\text { Poverty }\end{array}$ & $\begin{array}{l}\text { Change in } \\
\text { Nutrient } \\
\text { Depletion }\end{array}$ & $\begin{array}{l}\text { Change in } \\
\text { Poverty }\end{array}$ & $\begin{array}{l}\text { Change in } \\
\text { Nutrient } \\
\text { Depletion }\end{array}$ \\
\hline \multirow[t]{2}{*}{ A1B } & $2.40 \%$ & $-7.83 \%$ & $-41.69 \%$ & $-23.07 \%$ & $-25.95 \%$ & $-45.86 \%$ \\
\hline & (3.77) & (13.12) & $(5.70)$ & (7.65) & (8.62) & $(7.90)$ \\
\hline \multirow[t]{2}{*}{ A2 } & $1.23 \%$ & $-2.38 \%$ & $-42.91 \%$ & $-21.67 \%$ & $-28.16 \%$ & $-41.87 \%$ \\
\hline & $(5.83)$ & (19.62) & (7.24) & $(9.01)$ & (11.15) & (12.67) \\
\hline \multirow[t]{2}{*}{ B1 } & $3.37 \%$ & $-7.09 \%$ & $-40.84 \%$ & $-23.96 \%$ & $-25.29 \%$ & $-45.65 \%$ \\
\hline & $(4.71)$ & (14.11) & $(7.56)$ & $(9.26)$ & $(9.84)$ & (8.89) \\
\hline
\end{tabular}

Market equilibrium results for the climate change and base socio-economic conditions were not significantly different from the analysis without ME, therefore the results presented in table 5.5 for this scenario are at the maize market equilibrium price. In contrast, results for the rural development scenario were considerably different with and without ME. In consequence both results are presented in table 5.5. 
The climate change and base socio-economic conditions scenario shows that on average, the poverty rate is slightly increased while nutrient depletion decreases. The increase in poverty rates may be explained by the decrease in productivity as a consequence of new climate conditions (see Table 5.3). As maize and beans productivity decreases, farm income decreases therefore poverty rates increase. The reason why this increase in poverty rate is small may be explained by the fact that more land is being allocated to maize which offsets in part the negative effect of the productivity reduction. In the case of nutrient depletion, the reduction on maize and beans productivity combined with the reduction on land allocated to complex intercrops leads to a small reduction on nutrient depletion.

The impacts of the climate change and changed socio-economic conditions scenario on poverty are considerably larger at the base prices (i.e., no market equilibrium analysis). Poverty rates are decreased between 40-43\%. On the other hand, impacts on nutrient depletion rates are decreased between $21-24 \%$. The larger decrease in poverty rates compared to the climate change and base socio-economic conditions scenario is in part due to the consolidation of the farms (large farm size and smaller household size) which creates higher per capita income. On the other hand, the decrease in nutrient depletion rates as shown in Table 5.5 can be explained by the increase in fertilizer use due to the price reduction and availability of fertilizer assumed in this socio-economic scenario. However, the market equilibrium analysis show that the impacts on poverty were overestimated by about $15 \%$ and the impacts on nutrient depletion were underestimated by about $21 \%$. The market equilibrium analysis predicts a decrease in poverty between 25 and $28 \%$ and a decrease in nutrient depletion rates between $41-45 \%$.

The changed socio-economic conditions scenario (larger farm size, smaller household size and fertilizer availability) shifts the maize supply curve to the right, causing the price of maize to fall. As result, land allocated to maize is reduced (recall from above that price of maize drives land use decisions) and farm income is decreased. Thus, compared to the base price, the impacts on poverty are smaller at the market equilibrium and the impacts on nutrient depletion are larger (see Table 5.5). The results in table 5.5 show little variation across the emission scenarios, but as in the other results showed above there is a high variability across GCMs. 


\subsection{Discussion}

Methods and models to analyze the impacts of climate change on agriculture have been the focus of attention of the scientific community for several years. Climate change impact assessment studies on agriculture initially were mostly focused on the first-order bio-physical impacts (crop yield changes), (Iglesias and Minguez, 1995). These first studies used simulated weather data from the GCMs and used crop simulation models (process based or statistical) to predict the impacts and variations of yields in response to different climate scenarios. Most of the studies, however, failed to analyze the resulting effects on the environment and on socio-economic conditions, and the implications of autonomous or proactive (planned) adaptation strategies. The IPCC Third Assessment Report on Climate Change pointed out the need for developing methods and models (tools) that include these impacts and adaptation issues in the analysis:

...However, progress to date, particularly with regard to integrated modeling, has focused largely on mitigation issues at the global or regional scale and only secondarily on issues of impacts, vulnerability, and adaptation. Greater emphasis on the development of methods for assessing vulnerability is required, especially at national and sub national scales where impacts of climate change are felt and responses are implemented. Methods designed to include adaptation and adaptive capacity explicitly in specific applications must be developed. IPCC (2001).

A more comprehensive analysis of climate change impacts has evolved since then, and the analysis of future climate conditions associated to likely socio-economic conditions is increasingly gaining more attention. Given the uncertainty of future conditions, the use of scenarios (or scenario approach) is becoming important in climate change analysis. As a consequence, many studies use IAMs that enable the analysis of different climate change scenarios and their potential bio-physical, environmental and socio-economic impacts.

Still, some IAMs used for climate change analysis fall short of adequately incorporating adaptation in the analysis, they also fall short of adequately assessing distributional economic and environmental impacts. Similarly, climate change is likely to change patterns of supply and demand of commodities with a consequent change in prices that could play an important role in designing policies at regional, national and 
international levels. Therefore, a market equilibrium model should also be incorporated in the analysis to assess how markets react to changing prices due to shifts in supply and demand of commodities.

This study analyzes the impacts of climate change and socio-economic scenarios on agricultural production systems and the consequences on poverty and nutrient depletion. We depicted three main steps to follow on the assessment of climate change impacts: 1. Climate change projections; 2. productivity effects and climate change; and 3. Land use change and impacts on poverty and nutrient depletion at the market equilibrium. These steps are a logical sequence for economic and environmental impacts of climate change studies. However, there are several issues that need further attention in order to do impact assessments of climate change. These issues also constitute a limitation associated to the application presented in this study:

Climate (e.g., temperature, rain, solar radiation) is a key driver for agricultural production and contributes to determine what, when and how to grow a crop (or animal) at a specific-site. In other words, site-specific climate conditions are a key element for farmers' decision making. The different GCMs and emission scenarios and the coarse resolution of their output generate substantial uncertainty, especially when the analysis is applied at finer resolutions (e.g., local or regional) where the adaptation process really takes place. In addition, climate variability and extreme events are two aspects that climate models can't simulate at the spatial and temporal resolution that corresponds to specific agricultural production systems and agricultural seasons. As we discussed earlier, climate change may have different effects depending on the crop, location and time. Methods and models for downscaling climate change data to deal with the spatial variability and heterogeneity that is frequently found at finer scales are being developed by scientists and they need to be incorporated to integrated assessment models.

In addition, output from crop models (e.g., yields) can capture the effects of climate conditions as well as other site-specific conditions (e.g., soil). This allows us to represent the yield variability in a region. However, when one tries to represent farmers' adaptation in the form of management, then representing spatial yield variability that accounts for site-specific management is a complex issue (Antle and Stoorvogel, 2006; Rosenzweig et al., 2011). Another issue, related to the previous point, that has been 
largely ignored in assessing climate change impacts is adaptation costs and the variability associated to the capability to adapt (adaptive capacity) to new conditions (Antle and Capalbo, 2010). Ignoring adaptation costs is likely to over-estimate adaptation, consequently analysis of distributional economic or environmental impacts (e.g., poverty, soil nutrient depletion) or markets effects (changes on prices) might be biased. It is important to note that, if available, adaptation costs can be incorporated into the TOAME.

As discussed above, markets are likely to be affected by different sources: for example, changes on supply and demand due to new adaptation strategies (e.g., different land use, new crops, etc.) which are likely to cause prices to change. Changes on income levels or demographic pressure over the time of analysis of climate change are also likely to affect markets. These changes can occur (or can be measured) at the regional, national or international levels, and most of the studies that consider market analysis utilize global or general market equilibrium models and use aggregate data. However, these models in general can't assess distributional effects.

In contrast, the TOA-ME can not only assess distributional effects, but also reduce the level of uncertainty of key parameters by doing sensitivity analysis (e.g., changes on demand elasticity for maize). The application of the TOA-ME presented in this study, shows how this integrated assessment model is well suited and is able to overcome several of the limitations of models used to assess economic and environmental impacts of climate change on agricultural production systems.

\subsection{Conclusions}

This study presented a case study to assess the economic and environmental impacts of climate change on agricultural production systems. The methodology consists of three steps that link climate change projections to changes in crop productivity and economic impacts in a transparent way. This paper shows that in order to be able to assess the economic and environmental impacts of climate change, it is important to include future socio-economic scenarios to complement the bio-physical effects (steps 1 and 2). Furthermore, economic analysis (step 3) should include adaptation and the effects 
on land use and market prices. It is also important to use an appropriate model (tool) capable of linking these steps to represent distributional effects (e.g., poverty, soil nutrient depletion, etc.) of climate change.

This study follows these steps for assessing the effects of climate change on poverty and nutrient depletion in the context of a semi-subsistence agricultural production system. We analyzed the effects of climate change with and without a policy and technology intervention. We depicted three main steps to follow on the assessment of climate change effects using the TOA-ME: 1 . Climate change projections; 2. Productivity effects and climate change; and 3. Land use change and impacts on poverty and nutrient depletion.

The results show that in this particular case, the changes on precipitation, temperature and solar radiation do not show a significant difference among the selected emission scenarios. On the contrary, the variability is significant across GCMs. The effects of climate change on crop productivity are negative on average. Changes in crop productivity lead to changes in land use as farmers maximize profits. These results show that in this particular case, policy and technology interventions are needed to reduce this region's vulnerability. This study has shown that the socio-economic scenario based on policy and technology interventions presented in the case study would be effective across a range of possible climate outcomes represented by different GCMs and the negative effect of climate change on crop production. Finally, the results show that ignoring market equilibrium analysis can lead to biased results and incorrect information for policy making. 
CHAPTER 6

Synthesis 


\subsection{Introduction}

The Millennium Declaration set the year 2015 as a target to achieve most of the development goals (MDG) with the objective of halving poverty in all of its forms. However, many developing countries are still far from achieving these goals. The Millennium Development Goals Report (MDGR, 2015) indicates that globally the MDG target has been met, but 1.2 billion people still live in extreme poverty. The MDGR 2015 states that the majority of people living on less that $\$ 1.25$ a day belong to Sub-Saharan Africa (SSA) and South Asia (SA). In SSA, 41 percent of the people live on less than $\$ 1.25$ a day respectively (see Figure 6.1). Rural poverty in this region is much higher where four out five people live in extreme poverty. The MDGs expired in 2015 and based on the global results, the international community has initiated the debate about the post2015 development agenda, which is centered in the new proposed Sustainable Development Goals (SDGs). The SGDs are a set of universally applicable goals (still under construction) that balances the three dimensions of sustainable development: environmental, social and economic. Like the MDGs, there many questions about what policies will be needed to accomplish the SDGs by 2030 and 2050, particularly in rural regions where most households are dependent on agriculture and where poverty rates are still high (e.g., in SSA).

Wright et al, 2011 estimates that two thirds of the global rural population lives in mixed crop-livestock systems (CLS) where interactions between crops and livestock activities are important for the subsistence of smallholders. CLS are characterized by high degree of biophysical and economic heterogeneity, complex and diversified production system that frequently involves a combination of several subsistence and cash crops and livestock. Increasing crop productivity is clearly a key element to improve living standards and to take these people out of poverty. However, agricultural productivity in regions like SSA has been stagnant or increased slowly (IFPRI, 2013). 


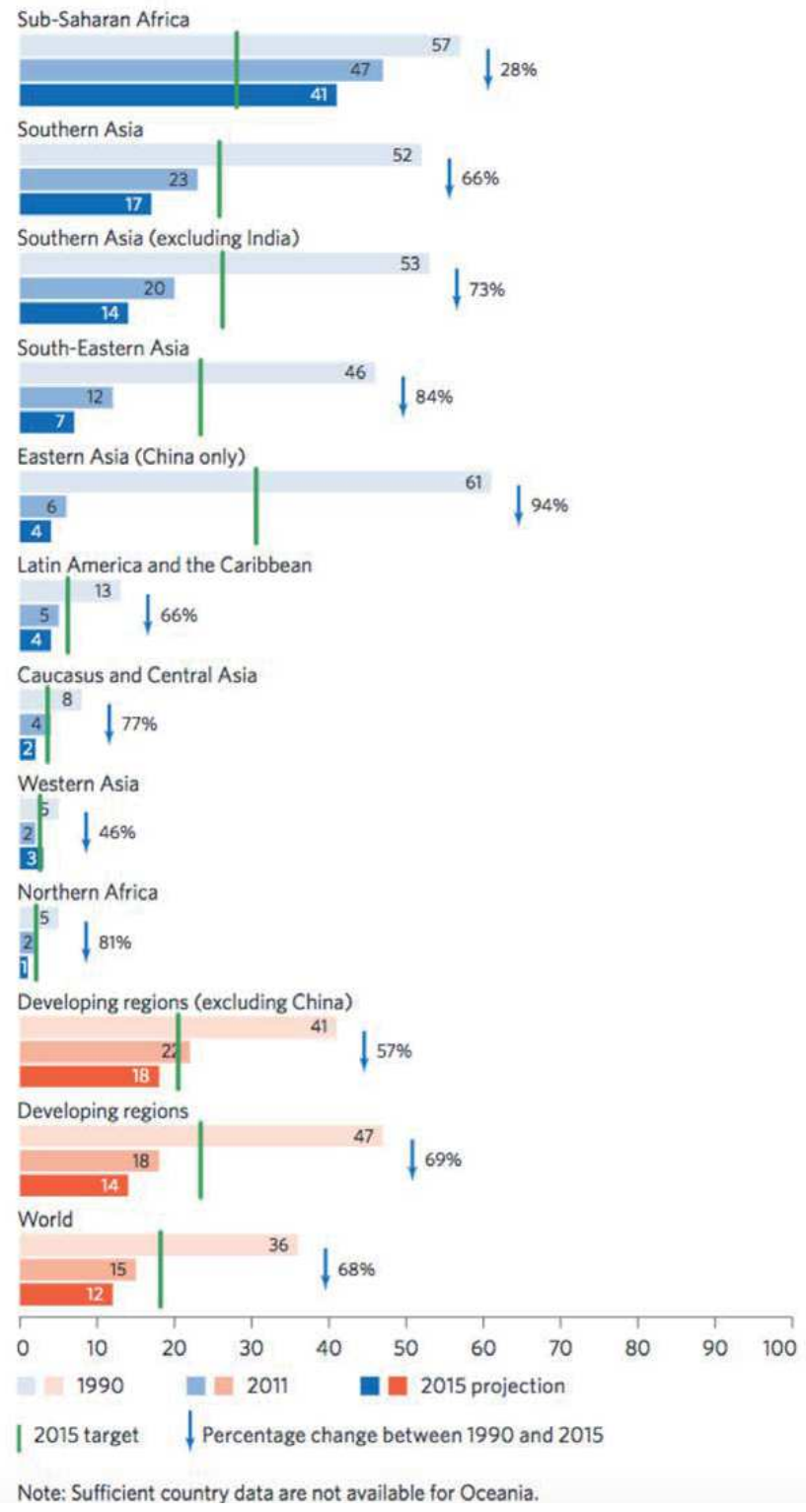

Figure 6.1. Proportion of people living on less than \$1.25 a day, 1990, 2011 and 2015 (percentage) and the MDG target by 2015. The Millennium Development Goals Report, 2015. 
Cereal yields have not significantly increased and per-capita food production has declined in the last 25 years and (Muchena et al., 2005, Herrick and Beh, 2015). Sanchez et al., 1997 and more recently Bationo, Lamers and Lehman, 2015 argue that land degradation and soil fertility depletion are the fundamental biophysical cause for the decline in per-capita food production. In Kenya for example, $65 \%$ of the population lives in rural areas where land degradation, inefficient agricultural practices, rapid population growth, land fragmentation and limited access to markets contribute to the high poverty levels in this region.

There have been considerable efforts in terms of research and rural development activities aimed to improve soil fertility, increase productivity and reduce poverty in the SSA (Pingali 2012; Pingali, Schneider and Zurek 2014). Yet evidence suggests that this region has continued the downward spiral of poverty and land degradation and the associated problems of food insecurity, and population pressure. But why decades of large investments in research and development, several policy and technology interventions have not produced the expected results in many regions of SSA is a key question that policy makers and researchers are facing.

I argue in this thesis that there is the need to have a better understanding of the complex agricultural systems typical of the SSA and of the linkages between poverty, land degradation and agricultural productivity in order to appropriately propose and implement policy and technology interventions that will lead to a sustainable path for these systems. But given the conditions mentioned above, is sustainable development of semi-subsistence mixed crop-livestock systems possible?

I also argue that, in addition to a better understanding of the complex relationships of these agricultural production systems, there is a need for modeling tools and data that appropriately capture these complexities to adequately conduct ex-ante impact assessment of policy and technology interventions.

This thesis develops and applies a modeling framework for integrated assessment of semi-subsistence mixed crop-livestock systems that takes into account key features of these complex agricultural production systems and key elements of the poverty-land degradation-agricultural productivity linkages shown in Figure 6.1 (e.g., market equilibrium, policy and technology interventions, socio-economic scenarios and climate 
change). The goal of the empirical applications is to test the modeling methods and to assess the impacts of policy and technology interventions and climate change under different socio-economic scenarios. The case of the semi-subsistence agricultural production system of Machakos, Kenya was used to assess how different degrees of implementation of the Vision 2030 could lead to a sustainable development pathway and be used as adaptation strategies to deal with climate change.

\subsection{Poverty, land degradation and agricultural productivity linkages}

The relationship between poverty, land degradation and agricultural productivity has been extensively studied in the literature. In particular, rapid population growth in regions such as SSA has led to the hypothesis of a downward spiral of mutually reinforcing linkages between these factors (Nkonya et al., 2008). The general idea of this hypothesis is based on the assumption that land degradation causes low agricultural productivity, which in turn worsens poverty levels. There are factors that may influence these relationships in a positive or negative way. Figure 6.2 shows linkages between land degradation, poverty, agricultural productivity and land management and the linkages to other factors that may affect these relationships.

Land degradation causes a negative impact on agricultural production but it can also affect poverty directly by reducing availability of goods and services to households. In particular, a completely degraded land may decrease the amount of crops produced for self-consumption. Land management technologies and land policies will also affect the level of land degradation and therefore have an effect on poverty. 


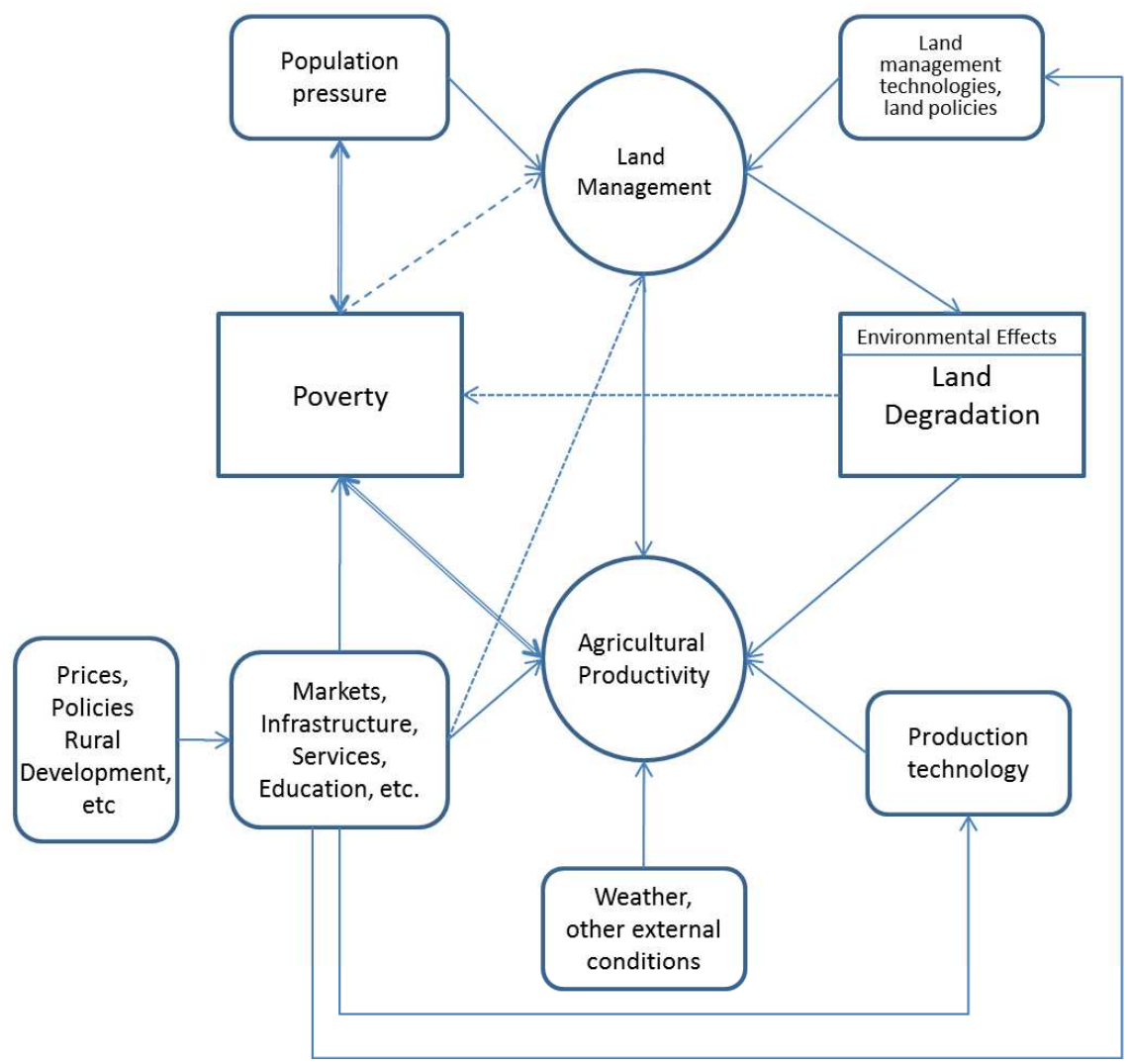

Figure 6.2. Poverty, land degradation and agricultural productivity linkages: Multi-scale framework to assess sustainability of agricultural production systems (Adapted from Nkoya et al, 2008)

The linkage between poverty and agricultural productivity is a linkage that goes in both directions. Poverty could be a factor for low productivity due to the constraints poor households face to use (obtain) productive inputs (e.g., purchased fertilizers). On the other hand, low agricultural productivity also means low incomes. Production technology also plays an important role by affecting directly agricultural productivity and thus affecting poverty. Another component that also affects agricultural productivity is weather. In vulnerable regions where conditions are less favorable for crop production 
due to frosts or droughts, weather may play an important role, especially in the context of climate change analysis.

Another element that has been the focus of many studies is population growth and land fragmentation. Rapid population growth in SSA has led to small farm sizes that are not economically or environmentally sustainable (Antle, Stoorvogel and Valdivia, 2014). The limited access to land, the needs to reduce fallow periods, or the inclusion of new agricultural land where soils are too fragile are increasing the rates of land degradation. Income per capita could be reduced as family size grows which may also constrain the ability to purchase inputs (e.g., fertilizers) leading to low crop yields and soil nutrient losses. The Machakos analysis presented in this thesis shows the importance of farm size and household size in the design of policies and interventions aimed at reducing poverty and increasing agricultural production sustainably.

In addition, other factors such as access to markets, infrastructure, services and education also tend to affect agricultural productivity and poverty. Finally, rural development policies and price changes due to either a policy or shifts on demand and supply are also a key element in this system. For example, policies aimed to reduce fertilizer prices may lead to an increase in agricultural productivity and thus would positively affect poverty. A policy such as creating incentives for people to work on other sectors (off-farm income) would contribute directly to poverty. Analyzing and understanding the direct and indirect relationships mentioned above are key to a wellinformed policy design that aims to increase agricultural productivity and reduce poverty and soil depletion rates. The problem is that soil depletion effects occur at a very disaggregated level while poverty indicators are usually looked at a larger scale. Any approach used to analyze these relationships need to account for the direct and indirect linkages across scales.

The key challenge to agricultural sustainability in SSA is to reverse the declining trends of agricultural productivity and the increasing rates of soil nutrient depletion and high levels of poverty. Policy and technological interventions that lead to the "win-win" outcome of reversing the negative trends while increasing agricultural productivity sustainably need to be formulated considering the linkages shown in Figure 6.2. 
Governments and scientists are making efforts to develop policies and technology interventions that will achieve the "win-win" outcome mentioned above and move from the usual "tradeoffs" between poverty-productivity-sustainability to "synergies". Examples of these proposed technologies are the so-called "Sustainable Agricultural Intensification” (The Montpellier Panel, 2013; SDSN, 2013, Garnett et al., 2013) and the "Climate-Smart Agriculture" (McCarthy, Lipper and Branca, 2011). Policy interventions such as the "Strategy for Revitalizing Agriculture 2004-2014" (SRA), and the "Vision 2030" elaborated by the Government of Kenya (GoK, 2004, 2008, 2013) propose a series of policies and activities to improve household livelihoods with the main goal of reducing poverty, increase food security and protecting the environment. The challenge is assessing ex-ante the likely impacts of these proposed interventions or technologies requires of appropriate data and tools that can capture the characteristics of the systems where they are going to be implemented, but also to effectively capture the components and interactions of the technology itself.

\subsection{Modeling Semi-Subsistence Crop-Livestock Systems to solve the Poverty-Productivity-Sustainability Puzzle}

This section provides a summary of the main findings of this thesis and relates them to findings from other studies. This section also discusses aspects that were not included in this thesis but would merit further research.

In Chapter 3 we argue that achieving the goal of sustainable development in semisubsistence African agriculture will require better understanding of the povertyproductivity-sustainability puzzle: why high poverty and resource degradation levels persist in African agriculture. We hypothesize that the answer to this puzzle lies, at least in part, in understanding and appropriately analyzing key features of semi-subsistence crop-livestock systems (CLS) typical of Sub-Saharan Africa: high degree of bio-physical and economic heterogeneity, complex and diversified production system involving a combination of subsistence and cash crops with livestock. We argue that the complexity and diversity of CLS often constrain the ability of policy or technology interventions to 
achieve a "win-win" outcome of simultaneously reducing poverty while increasing productivity sustainably (i.e., avoiding soil nutrient losses).

This thesis describes and uses an integrated modeling approach (TOA, see Chapter 2) designed to deal with these complexities and at the same time, quantify economic and sustainability indicators for policy tradeoff analysis that are key in the poverty, land degradation and agricultural productivity linkages described above. Thus, in this thesis three key indicators of the system's performance were used: the poverty rate (defined as the headcount poverty index with the poverty line set at $\$ 1$ per day), crop yields, and the soil nutrient depletion rate (represented by soil nitrogen loss). Low crop yields could be caused by various factors related to soil degradation and management. However, the low maize yields in Machakos and the fact that farmers in this region use very low fertilizer are reasons to think that $\mathrm{N}$ is a limiting factor.

The concept of Representative Agricultural Pathways and Scenarios (RAPS, Valdivia et al., 2015) was used to represent different future socio-economic scenarios to assess the impacts of policy interventions aimed to move agricultural systems towards meeting sustainable development goals.

One important finding is that the complex behavior of CLS has important implications for the effectiveness of policy interventions. The Machakos analysis provides important findings regarding the implementation and effectiveness of policy interventions addressing poverty and sustainability in Africa and other parts of the developing world. The analysis shows that policy interventions tend to result in much larger benefits for better-endowed farms, implying that farm heterogeneity results in differential policy impacts.

The results are consistent with recent findings by Harris and Orr (2014). They argue that small farms with limited access to markets are not likely to benefit enough from improved technologies to climb out of poverty because returns to these technologies are generally too low. Policy interventions aimed to deal with poverty and sustainability can have unintended consequences if they are not accompanied by a set of policy strategies and investments. For example, increasing the maize price can result in substitution from subsistence crops to maize, without much increase in nutrient inputs, thus increasing soil nutrient losses. The analysis shows that improving soil nutrient 
balances by increasing fertilizer and manure use is critically important, but is not enough to move the system to a sustainable path.

Similar conclusions are found in Kuyvenhoven (2004) and Antle, Stoorvogel and Valdivia (2006), that resilience of agricultural systems is likely to be highly variable and strongly associated with heterogeneity in bio-physical and economic conditions. CLS are complex systems influenced by site-specific bio-physical conditions as well as the larger economic environment. The soil nutrient depletion rates observed in many parts of SubSaharan Africa appear to be caused by many factors, including extremely small farm size and associated extreme poverty that make sustainable management practices difficult to maintain, particularly in an environment of distorted input and output markets.

There is no one factor that can reverse the negative nutrient balances and move the system towards sustainability. Rather, a broad-based strategy is required that stimulates rural development, increases farm size to a sustainable level, and also reduces distortions and inefficiencies in input and output markets that tend to discourage the use of sustainable practices that lead to efficient soil management. The Machakos case shows that a combination of these interventions and strategies, based on the GoK Vision 2030 and the Machakos County plans, could solve the poverty-productivity-sustainability puzzle in this region.

The pathway from tradeoffs to synergies (win-win) seems to be feasible if these interventions and strategies are implemented, however the analysis also shows that some villages may respond better to these strategies than others. The analysis suggests that these interventions may actually benefit most the areas with better initial endowments of soils and climate, a finding consistent with Marenya and Barrett's (2009) analysis of the effects of soil organic matter on fertilizer use. Further research is needed to assess the potential adoption of these systems and their corresponding impacts on economic and environmental outcomes as discussed by Antle, Stoorvogel and Valdivia (2014).

While the results of the analysis result on an optimistic view of the possible impacts of the policy and technology interventions, it is important to note that, as mentioned above, soil nutrient losses is probably the most common cause of soil degradation. However, other soil degradation issues, such as erosion, acidification and other soil process can also constrain crop productivity. Furthermore, it might be the case 
that soils become completely degraded and crops become unresponsive to any level of the common fertilizers (e.g., NKP). In such case, interventions based only on increasing fertilizer use (i.e., increasing $\mathrm{N}$ ) without a broad soil management strategy is likely to fail and would increase the risk of farmers be locked in a poverty trap.

The poverty, land degradation and productivity linkages described above suggest that markets, prices and environmental factors (like climate change) are important part of these linkages. The analysis presented in chapter 3 shows that prices (e.g., maize price) play a key role in the assessment of policy interventions. However, the possible endogeneity of prices was not addressed in that chapter. Similarly, another dimension not included in the analysis that could potentially change the development pathway and impacts of the proposed interventions is climate change. These two issues, market prices and climate change are addressed in chapters 4 and 5 respectively.

There is an increasing recognition that analysis of economic and environmental outcomes of agricultural production systems requires a bottom-up linkage from the farm to market, as well as top-down linkage from market to farm. The analysis presented in Chapter 4 develops this two-way linkage between the TOA model and a partial equilibrium market model (ME). The TOA model links site-specific bio-physical process models and economic decision models, and aggregate economic and environmental outcomes to a regional scale, but treats prices as exogenous.

The resulting TOA-ME allows the effects of site-specific interactions at the farm scale to be aggregated and used to determine market equilibrium. This in turn, can be linked back to the underlying spatial distribution of economic and environmental outcomes at market equilibrium quantities and prices. Market equilibrium is likely to be important in the analysis of agricultural systems in developing countries where product and input markets are not well integrated, and therefore, local supply determines local prices (e.g., high transport costs may cause farm-gate prices be set locally).

Also, changes in the market supply schedules are driven not only by prices but also by changes in farm characteristics in response to policy changes, environmental conditions or socio-economic conditions. For example, in developing countries, urban and rural development policies such as infrastructure investment can affect rural-urban migration and off-farm employment, and thus change farm characteristics such as farm 
size, household composition, and farm family members' health and education (Reardon et al., 1998). These policy-induced changes in the distribution of farm characteristics affect market supply, which together with market demand determines the equilibrium market price. This equilibrium price in turn determines farm-level land management decisions and thus determines the spatial distribution of economic and environmental outcomes. Linking the ME results back to the spatial distribution of economic and environmental impacts (e.g., poverty, land quality, etc.) allows us to understand the magnitude of these impacts at the disaggregate level (i.e., site-specific economic and environmental outcomes).

In Chapter 4 we analyzed policy and technology scenarios aimed at reducing poverty rates and soil nutrient depletion, similar to the study in chapter 3 . Without a ME model, analysts can compare the effects of the policy scenarios on poverty levels and nutrient depletion over a range of plausible prices (e.g., at base maize prices and at selected prices above or below the base prices), but cannot determine which equilibrium prices are likely to result from the technology or policy intervention. The coupling of the TOA analysis to a ME model allows the analyst to determine the equilibrium prices of the system and thus to identify the point on a tradeoff curve that is associated to that equilibrium price, and consequently identify how the change in market prices affects the spatial distribution of economic and environmental outcomes in the region. Our findings suggest that the market equilibrium price associated to a policy intervention could be substantially different than the prices observed without the market equilibrium analysis, and consequently could play an important role in evaluating the impacts of policy or technology interventions.

A possible extension to the analysis in chapter 4 is to do the market equilibrium analysis considering multiple markets. In this particular case, both maize and fertilizer prices are important to the system and key to the proposed policy and technology interventions. Several methodological issues would need to be addressed (e.g., estimate parameters when two prices are jointly varied). However, the analysis and methodology presented in chapter 4 is the basis for future research considering more complex market equilibrium analysis. 
There is a scientific consensus that climate change poses a long-term threat for rural households in vulnerable regions like Sub-Saharan Africa. Policy and technology interventions can have different impacts under climate change conditions. The study in chapter 5 incorporates the impacts of climate change on the agricultural production systems of Machakos. In this study we assessed the economic (i.e., poverty rates), biophysical (crop yields), and environmental (i.e., soil nutrient loss) impacts of climate change and the effectiveness the policy and technology interventions described in chapter 4 . We interpret these interventions as plausible adaptation scenarios in response to climate change.

Climate change impact assessment studies on agriculture initially were mostly focused on assessing the impacts of climate change on crop yields. These studies used simulated weather data from the Global Circulation Models (GCMs) and used crop simulation models (process based or statistical) to predict the impacts and variations of yields in response to different climate scenarios. Most of the studies, however, failed to analyze the resulting effects on the environment and on socio-economic conditions, and the implications of autonomous or proactive (planned) adaptation strategies.

The IPCC Third Assessment Report on Climate Change (2001) pointed out the need for developing methods and models (tools) that include these impacts and adaptation issues in the analysis. In response, analysis of climate change impacts has moved towards the use of more integrated approaches and the use of scenarios to deal with the uncertainty of future conditions (e.g., The Agricultural Model Intercomparison and Improvement Project (AgMIP), Rosenzweig et al, 2013). However, several studies fall short of adequately incorporating adaptation in the analysis, they also fall short of adequately assessing distributional economic and environmental impacts.

Similarly, climate change is likely to change patterns of supply and demand of commodities with a consequent change in prices that could play an important role in designing policies at regional, national and international levels. Therefore, a market equilibrium model should also be incorporated in the analysis to assess how markets react to changing prices due to shifts in supply and demand of commodities. In Chapter 5 we use the TOA-ME to incorporate the elements mentioned above to assess the impacts of climate change. We used data from 5 Global Circulation Models (GCMs) with three 
emission scenarios (SRES, 2000) to estimate the climate change projections and use these projections to perturb weather data used by a crop simulation model to estimate the productivity effects of climate change. We then assessed the land use change and impacts on poverty and nutrient depletion at the market equilibrium using the TOA-ME model.

The simulation was carried out for three scenarios, which are a combination of socio-economic and climate change scenarios: a baseline scenario that represents current socio-economic conditions and climate conditions, a climate change and current socioeconomic scenarios (i.e., future climate change with no policy or technology intervention), and a climate change and future socio economic conditions which are a consequence of rural development policies.

Our findings show that in this particular case, the changes on precipitation, temperature and solar radiation do not show a significant difference among the selected emission scenarios. However, the variability is significant across GCMs. The effects of climate change on crop productivity are negative on average. These results show that policy and technology interventions are needed to reduce this region's vulnerability. Figure 6.3 shows that the socio-economic scenarios based on policy and technology interventions presented in the case study would be effective to offset the negative effect of climate change on the sustainability (economical and environmental) of the system across a range of possible climate outcomes represented by different GCMs. Finally, the results show that ignoring market equilibrium analysis can lead to biased results and incorrect information for policy making, in particular for the scenario based on policy and technology interventions. 


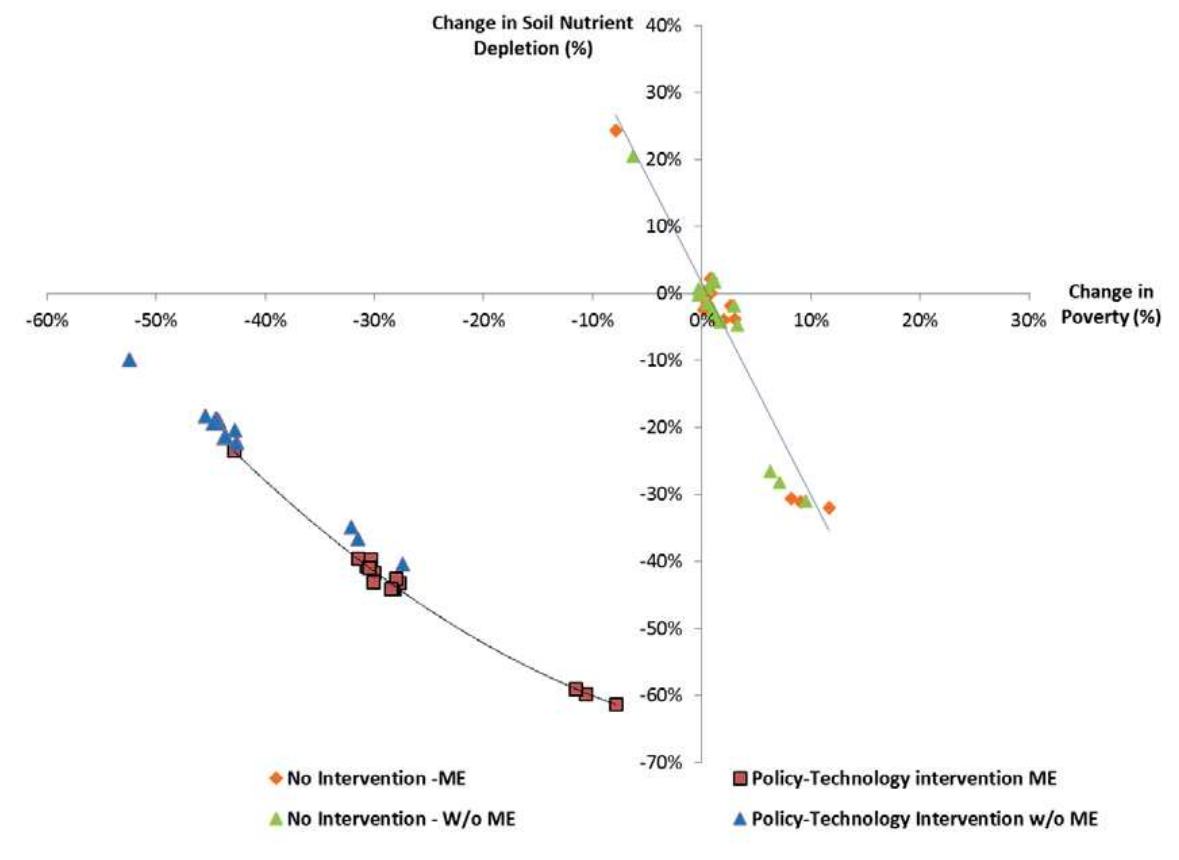

Figure 6.3. Impacts of climate change and socio-economic scenarios on poverty and soil nutrient depletion, Machakos, Kenya. Each point represents a mean change in poverty and soil nutrient depletion for a combination of 5 GCMS, 3 SRES with and without policy and technology intervention at the market equilibrium (ME) prices and quantities, and at the base maize price (without market equilibrium, w/o ME). Positive changes in poverty indicates increase in poverty rates. Positive changes in soil nutrient depletion indicates increase in soil nutrient depletion rates.

\subsection{Discussion and Possible Extensions}

The study discussed above show the possibility of a transition towards a sustainable system where tradeoffs between economic and environmental outcomes are eliminated. Consistent with other studies, one major implication of the analysis in this thesis is that getting enough nutrients into the system (e.g., increasing fertilizer use), can make the system respond positively (i.e., decreasing poverty rate and soil nutrient losses) to economic incentives. However, this is not enough, our results imply that there has to 
be a set of policies, investments and structural reforms that lead to positive development pathways. For example, for the case of Machakos, the results suggest that policy and technology interventions with the right infrastructure in place and good market conditions could solve the poverty-productivity-sustainability puzzle, meaning that the pathways from tradeoffs to synergies seem to be feasible. However, recognizing that heterogeneity is a key factor that characterizes CLS, it would be important to assess the potential adoption and barriers to adoption of the proposed policy and technology interventions and assess the impacts on economic and environmental outcomes considering the population of adopters and non-adopters.

The model used in the thesis captures the interactions and dynamic feedbacks between crops, livestock and the environment because the crops and livestock components are closely coupled. However, the model is loosely coupled to the biophysical crop models because there are no feedbacks from the economic models to the crop models. Similarly, the estimates of nutrient balances provided by the NUTMON model (de Jager, 1999) are not able to predict the dynamic changes in soil nutrients to changes in land use and management. In both cases, improving these models to closely couple them to economic decision models would be an important extension for this analysis.

Model validation is another issue that needs to be addressed. Validation of ex-ante modeling approaches is challenging. There is a need for 'validation sites' where high-quality data is available and where ex-post analysis is feasible based on welldesigned data collection over time (e.g., RCT type of data). Model testing and improvement is another issue. The Agricultural Model Intercomparison and Improvement Project (AgMIP, Rosenzweig et al, 2013) is collaborating with different scientists around the world to conduct model intercomparison tests and based on these, produce improved models to assess the impacts of global changes on food security and sustainability of agricultural production systems.

An important methodological issue is that due to the nature of the model: spatially explicit, a large amount of farm survey data is needed to be able to implement the modeling approach used in this thesis. The challenge, as pointed out in the thesis, is to be able to represent the relationships of complex systems adequately. Data obtained from 
one-time recall household surveys typical from most research projects can't effectively capture these dynamics. Monitoring farms data (like the Nutmon data used in this thesis) that accounts for farms input-output flows over a period of time with detailed management and farm characterization that captures the heterogeneity in a population of farms is ideal. However, this also has implications if one tries to replicate the analysis to other locations using the same modeling approach. It would be expensive and time consuming. For an alternative approach see Antle (2011) and Antle, Stoorvogel and Valdivia (2014) where a more parsimonious approach is used to assess the impacts of similar kinds of policy impacts such as the ones described in this thesis.

The analysis presented in this thesis suggests that the Vision 2030 of the Kenyan government might be the basis for a sustainable development pathway that could solve the poverty-productivity-sustainability puzzle and achieve not only the MDGs but also the proposed SDGs. This important conclusion highlights the importance of assessing the impacts of proposed policy interventions and the need for tools capable of dealing with the several issues that are inherent to complex agricultural systems. Many countries and local R\&D institutions have been developing policy documents like the Kenyan Vision 2030. However, the effectiveness of these policies is rarely assessed in an "ex-ante" sense. With the use of proper methods and tools for ex-ante impact assessment, policy interventions can be analyzed under different scenarios to assess their likely impacts on socio-economic and/or environmental outcomes.

\subsection{Towards a Sustainable Agricultural Development Pathway for CLS}

The semi-subsistence agricultural production system of Machakos has characteristics that are typical to many production systems in SSA and other developing parts of the world. As such, these systems face similar challenges and opportunities to implement policy and technology interventions to achieve the economic and environmental sustainability of the system. The major finding of this thesis as explained above is that there are several there are no single factors that would move the system to a sustainable level. For example, increasing fertilizer may improve the system's conditions 
(e.g., decrease poverty rates and soil nutrient losses), but would not solve the productivity-sustainability-poverty issue. One conclusion of this thesis is that there are several factors that need to be addressed and interventions (e.g., policy, reforms, etc.) that need to be in place in order to follow a sustainable development pathway.

Figure 6.4 illustrates a development pathway (DP) towards the sustainability (environmentally and economically) of the system. The position of the system on the development pathway is jointly determined by a combination of policy-technology interventions (e.g., sustainable intensification), drivers that affect the systems and that are embedded into the RAPs (i.e., socio-economic conditions), and environmental conditions (e.g., the effects of climate change). The inset figures show the transition from tradeoffs to win-win outcomes between the percent of households above the poverty line and soil nutrient gains as a consequence of different policy and technology interventions. These curves are based on the results of chapter 3 and constructed by varying the mean maize price. The bottom-left figure (towards the origin) shows the change from the base conditions to the results of a policy intervention (S1) that increases the percentage of households above poverty line and slightly improves the soil nutrient gains (shift the curve to the right). However, as maize price increase (from left to right) there are more negative effects on soil nutrients. The other two insets show the improvement of the system due to other policy and technology interventions s described in Chapter 3 with the last inset showing win-win conditions between poverty and soil nutrient gains. Those transitions from tradeoffs to synergies are due to a combination of interventions (e.g., sustainable intensification, climate smart agriculture, etc.) and other socio-economic and environmental conditions. However, it is important to highlight that the bio-physical, economic and environmental heterogeneity in a population of farms must be considered when designing policy or technology interventions. It is clear that 'blanket'-type of interventions are more likely to fail compared to targeted interventions. 


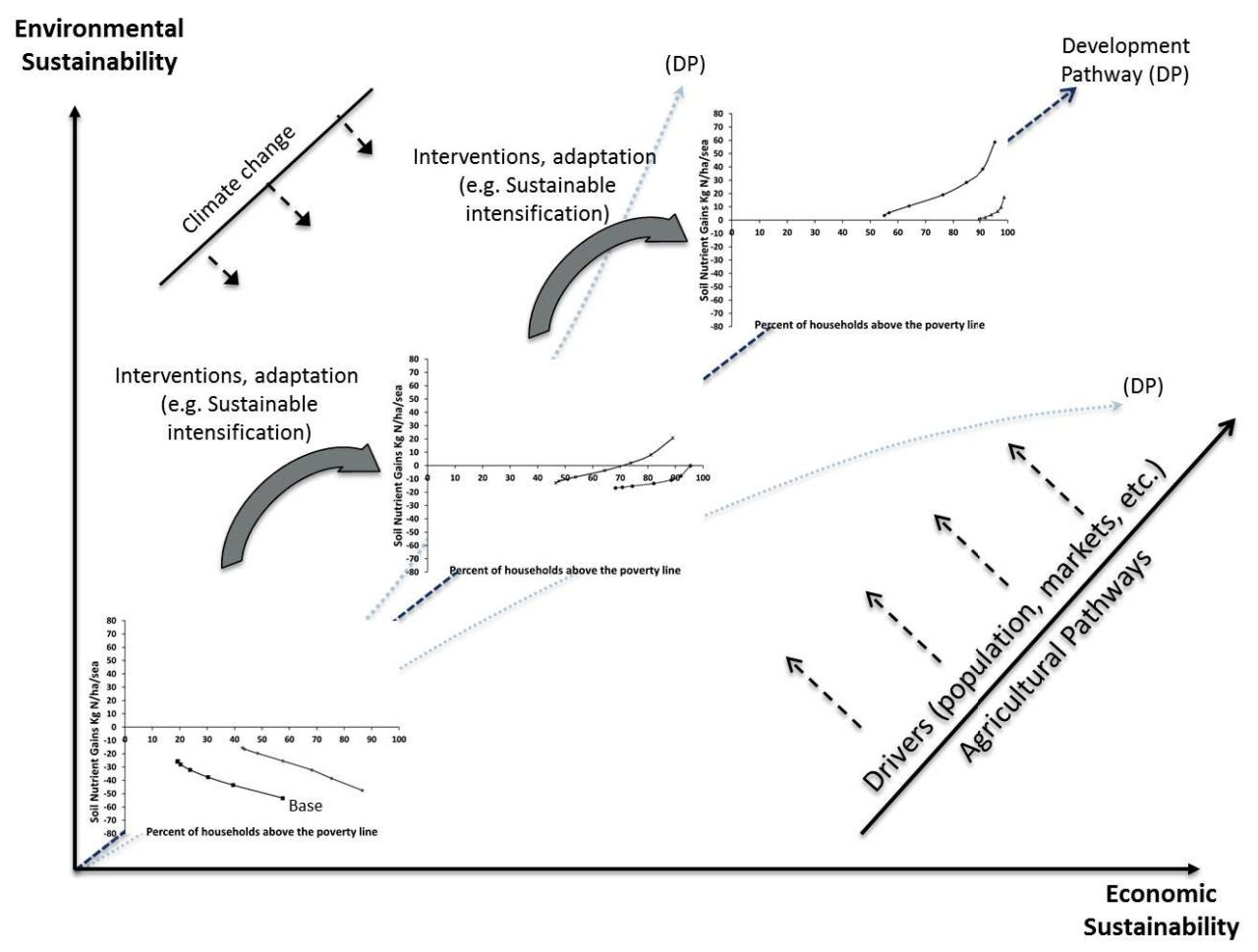

Figure 6.4. Development pathway towards sustainability of the system. The trajectory of the development pathway depends on a combination of interventions (e.g., sustainable intensification) and drivers (e.g., prices, climate) that affect the system. These interactions need to be taken into account when modeling complex systems like the CLS presented in this thesis.

It is important to note that the slope of the development pathway might be affected by other factors. For example, some of the scenarios analyzed in this thesis lead to an increase in livestock holdings, dairy and manure production. Livestock production systems can produce significant amounts of greenhouse gas (GHG) emissions, according to FAO (2006) livestock contributes to $18 \%$ of global anthropogenic GHG emissions, being methane, carbon dioxide $\left(\mathrm{CO}_{2}\right)$ and nitrous oxide $\left(\mathrm{N}_{2} \mathrm{O}\right)$ the main $\mathrm{GHGs}$ sources. If these emissions were accounted for in our analysis, the steepness of the development pathway trajectory in Figure 6.4 would be flatter. However, there are options to reduce and mitigate GHS emissions from livestock, for example it is possible to reduce methane 
emissions by better diets for ruminants and using improved breeds. Better management of manure can reduce N2O emissions (Herrero and Thornton, 2009). Sustainable Intensification technologies based on better feeding strategies, improved breeds that reduce GHS from livestock are being investigated and promoted by ILRI as part of one of their global research challenges.

Another element that could potentially change the slope of the development pathway in Figure 6.4 is climate change, which could affect the system positively or negatively. Our analysis suggests that socio-economic scenarios are important when assessing the economic and environmental impacts of climate change and adaptation policies that could be implemented in response to climate change.

Reducing poverty, improving food security and human health, and reducing environmental damage is a priority on the international research agenda. The agricultural scientific community faces the significant challenge of developing a new generation of data, tools and approaches that capture all the complexities of agricultural production systems to adequately assess the distributional impacts of policy and technological interventions, climate change adaptation and mitigation. Clearly, a coordinated multidisciplinary effort is needed to deal with the complex multi-dimensional challenges of the agricultural sustainable development of the 21 st century. 


\subsection{Highlights}

1. The poverty-productivity-sustainability puzzle remains an important issue in many regions of the developing world as the complex interactions of the typical semi-subsistence crop-livestock systems are poorly understood.

2. I linked the Tradeoff Analysis Model to a market equilibrium model and used this integrated modeling approach to assess (ex-ante) the impacts of policy or technology interventions, market changes and environmental changes (e.g., climate change) on the semi-subsistence crop-livestock systems of Machakos (Kenya).

3. Through a top-down as well as a bottom-up approach it was shown that shifts in market equilibrium conditions have important consequences on the impacts of policy interventions or technology changes.

4. Policy makers need to make informed decisions. There is a need to develop a new generation of data, tools and approaches to support research for agricultural sustainable development and thus, provide policy makers and stakeholders with adequate and timely information.

5. Sustainable development of semi-subsistence mixed crop-livestock systems might be possible with broad-based strategies that involve a set of policy and technology interventions. Ex-ante impact assessment under different scenarios of these policies and interventions would greatly support technology development and policy design. 


\section{References}

Adam, M., Van Bussel, L. G. J., Leffelaar, P. A., Van Keulen, H., \& Ewert, F. (2011). Effects of modelling detail on simulated potential crop yields under a wide range of climatic conditions. Ecological modelling, 222(1), 131-143.

Adams, .M., S.A. Hamilton, and B.A. McCarl.:1986, "The Benefits of Air Pollution Control: The Case of Ozone and U.S. Agriculture." American Journal of Agricultural Economics 68:886-894.

Adams, D.M., Alig, R.; Callaway, J.M.; McCarl, B.; and S. Winnet. 1996, “The Forest and Agricultural Sector Optimization Model (FASOM): Model Structure and Policy Applications" Research paper PNW-RP-495. September 1996. USDAForest Service.

Ade Freeman, H. and John M. Omiti, 2003. Fertilizer use in Semi-arid areas of Kenya: analysis of smallholder farmer's adoption behavior under liberalized markets. Nutrient Cycling in Agroecosystems 66: 23-31. 2003.

Agarwal, Chetan, Glen M. Green, J. Morgan Grove, Tom P. Evans, and Charles M. Schweik. 2002. A Review and Assessment of Land-Use Change Models: Dynamics of Space, Time, and Human Choice. CIPEC Collaborative Report No. 1. USFS Publication GTR-NE-297. Joint publication by the Center for the Study of Institutions, Population, and Environmental Change at Indiana UniversityBloomington and the USDA Forest Service. USDA Forest Service Northeastern Forest Research Station. URL: http://www.srs.fs.usda.gov/.

Agricultural Sector Development Support Programme (ADSP) 2013. Machakos and Makueni statistics. http://www.asdsp.co.ke. Accessed May 23, 2016.

Alila, Patrick O., and Rosemary Atieno. 2006. "Agricultural Policy in Kenya: Issues and Processes”. Paper submitted to the Future Agricultures Consortium Workshop, Institute of Development Studies. Future Agricultures. July 2006. 
Antle J.M., Stoorvogel J.J., Valdivia R.O. Multiple Equilibria, Soil Conservation Investments, and the Resilience of Agricultural Systems. Environment and Development Economics 2006; 11(4):477-92.

Antle, J. and Just, R.. 1991. Effects of Commodity Program Structure on resource Use and the Environment. Chapter 5 in: Agricultural management and Economics: Commodity and Resource Policies in Agricultural Systems. Edited by: R. E. Just and N. Bockstael.

Antle, J. M., \& Stoorvogel, J. J. (2006). Incorporating systems dynamics and spatial heterogeneity in integrated assessment of agricultural production systems. Environment and Development Economics, 11(1), 39-58.

Antle, J. M., B. Diagana, J.J. Stoorvogel, and R.O. Valdivia. 2010. Minimum-data analysis of ecosystem service supply in semi-subsistence agricultural systems. Australian Journal of Agricultural and Resource Economics 54, 601-617

Antle, J. M., Valdivia, R., Claessens, L., Nelson, G., Rosenzweig, C., Ruane, A., and J. Vervoort. 2013. Representative Agricultural Pathways and Scenarios: A TransDisciplinary Approach to Agricultural Model Inter-comparison, Improvement and Climate Impact Assessment. Manuscript available at tradeoffs.oregonstate.edu.

Antle, J., and Capalbo, S.M., 2001. Econometric-process models for integrated assessment of agricultural production systems. American Journal of Agricultural Economics 83 (May), 389-401.

Antle, J., and R.J. Wagenet. 1995. Why Scientists Should Talk to Economists: The Role of Economics in Enhancing the Value of Publicly Funded Agricultural Research. Ames, Iowa: American Agricultural Economics Association.

Antle, J., and Stoorvogel, J. 2001 Integrating Site-Specific Biophysical and Economic Models to Assess Trade-offs in Sustainable Land Use and Soil Quality. In Economic Policy and Sustainable Land Use: Recent Advances in Quantitative Analysis for Developing Countries, N. Heerink, H. van Keulen, and M. Kuiper, eds., Physica-Verlag, New York, pp. 169-184.

Antle, J.; and B. Diagana. 2003. Creating incentives for the adoption of sustainable agricultural practices in developing countries: The role of soil carbon sequestration. Paper presented at the principal paper session on "Issues and 
Options for Carbon Sequestration in Agriculture", AAEA Annual Meetings, Montreal, July 2003.

Antle, J.; Capalbo, S; and Crissman, C. 1998. In Crissman, Antle \& Capalbo. Chapter 2. In Economic, Environmental, and Health Tradeoffs in Agriculture: Pesticides and the Sustainability of Andean Potato Production. Edited by Charles Crissman, John Antle, and Susan Capalbo. Published by Kluwer Academic Publishers in cooperation with the International Potato Center (CIP), 1998

Antle, J.; Capalbo, S.; Elliot, E.; and K. Paustian. 2004c. Adaptation, Spatial Heterogeneity, and the vulnerability of Agricultural Systems to Climate change and CO2 fertilization: An integrated Assessment Approach. Climate Change 64: 289-315. Kluwert Academic Publishers.

Antle, J.; Stoorvogel, J; Crissman, C. and W. Bowen 2000 Tradeoff Assessment as a Quantitative Approach to Agricultural/Environmental Policy Analysis. In Methodologies for interdisciplinary multiple Perspectives. Proceedings of the SAAD-III, Lima Peru.

Antle, J.; Valdivia, R.O.; Crissman, C.; Stoorvogel, J.; and D. Yanggen 2005. Spatial Heterogeneity and adoption of soil conservation investments: Integrated Assessment of Slow Formation terraces in the Andes. To be published in: Journal of International Agricultural Trade and Development, 2005.

Antle, J.M. 2011. "Parsimonious Multi-Dimensional Impact Assessment." American Journal of Agricultural Economics 93(5): 1292-1311.

Antle, J.M. and J.J. Stoorvogel. 2006. Predicting the Supply of Ecosystem Services from Agriculture. American Journal of Agricultural Economics 88, 1174-1180.

Antle, J.M. and S.M. Capalbo. 2010. Adaptation of Agricultural and Food Systems to Climate Change: An Economic and Policy Perspective. Applied Economic Perspectives and Policy 32:386-416.

Antle, J.M., and R.O. Valdivia. 2006. Modelling the Supply of Ecosystem Services from Agriculture: A Minimum-Data Approach. Australian Journal of Agricultural and Resource Economics 50, 1-15. 
Antle, J.M., and S.M. Capalbo. 2001. "Econometric-Process Models for Integrated Assessment of Agricultural Production Systems." American Journal of Agricultural Economics 83(2):389-401.

Antle, J.M., J.J. Stoorvogel, and R.O. Valdivia. 2011. Designing Econometric-Process Models for Semi-Subsistence Agricultural Systems: Analysis of PovertySustainability Tradeoffs in Machakos, Kenya. Unpublished, available at http://tradeoffs.oregonstate.edu.

Antle, J.M., J.J. Stoorvogel, R.O. Valdivia. 2014. "New Parsimonious Simulation Methods and Tools to Assess Future Food and Environmental Security of Farm Populations." Philosophical Transactions of the Royal Society B 20120280. http://dx.doi.org/10.1098/rstb.2012.0280

Antle, J.M., R.O. Valdivia, C.C. Crissman, J.J. Stoorvogel, and D. Yanggen. 2005. "Spatial Heterogeneity and Adoption of Soil Conservation Investments: Integrated Assessment of Slow Formation Terraces in the Andes." Journal of International Agricultural Trade and Development 1(1):29-53.

Antle, J.M., S. Capalbo, and C. Crissman.1998. In Crissman, C., Antle, J.M., Capalbo S. (Eds.), Economic, Environmental, and Health Tradeoffs in Agriculture: Pesticides and the Sustainability of Andean Potato Production. Chapter 2. Tradeoffs in Policy Analysis: Conceptual Foundations and Disciplinary Integration. Kluwer Academic Publishers in cooperation with the International Potato Center (CIP).

Antle, J.M., S.M. Capalbo, E.T. Elliott, and K.H. Paustian. 2004. “Adaptation, Spatial Heterogeneity, and the Vulnerability of Agricultural Systems to Climate Change and $\mathrm{CO} 2$ Fertilization: An Integrated Assessment Approach." Climatic Change 64(3):289-315.

Antle, J.M., S.M. Capalbo, K. Paustian, and M.K. Ali. 2005. Estimating the Economic Potential for Agricultural Soil Carbon Sequestration in the Central United States Using an Aggregate Econometric-Process Simulation Model. Working paper, Department of Agricultural Economics and Economics, Montana State University-Bozeman, February. 
Antle, J.M., S.M. Capalbo, S. Mooney, E.T. Elliott, and K.H. Paustian. 2003. "Spatial Heterogeneity, Contract Design, and the Efficiency of Carbon Sequestration Policies for Agriculture." Journal of Environmental Economics and Management 46(2):231-250.

Ascough II, J.; Shaffer, M.; Hoag, D.; McMaster, G.; Dunn, G.; Ahuja, L.; and M. Weltz. 2001. GPFARM: An Integrated Decision Support System for Sustainable Great Plains Agriculture. In: D.E. Stott, R.H. Mohtar and G.C. Steinhardt (eds).2001. Sustaining the Global Farm. Selected papers from the $10^{\text {th }}$ International Soil Conservation Organization Meeting held May 24-29, 1999 at Purdue University and the USDA-ARS National Soil Erosion Research Laboratory.

Atela, Joanes O., Claire H. Quinn, Peter A. Minang, Lalisa A. Duguma, and Joël A. Houdet. "Implementing REDD+ at the national level: Stakeholder engagement and policy coherences between REDD+ rules and Kenya's sectoral policies." Forest Policy and Economics 65 (2016): 37-46.

Babcock, B., Lakshminarayan, P., Wu, J., Zilberman, D., 1997. Targeting tools for the purchase of environmental amenities. Land Econ. 73, 325-339.

Baron, C., Sultan, B., Balme, M., Sarr, B., Traore, S., Lebel, T., ... \& Dingkuhn, M. (2005). From GCM grid cell to agricultural plot: scale issues affecting modelling of climate impact. Philosophical Transactions of the Royal Society B: Biological Sciences, 360(1463), 2095-2108.

Barrett, C. B., and Carter, M. R. (2013). The Economics of Poverty Traps and Persistent Poverty: Empirical and Policy Implications. The Journal of Development Studies, 49(7), 976-990.

Basso, B., M. Bertocco, L. Sartori, and E.C. Martin. 2007. Analyzing the effects of climate variability on spatial pattern of yield in a maize-wheat-soybean rotation. European Journal of Agronomy 26:82-91.

Battese, G.E. 1997. "A Note on the Estimation of Cobb-Douglas Production Functions When Some Explanatory Variables Have Zero Values.” Journal of Agricultural Economics 48:250-252. 
Bationo, Andre, John Lamers, and Johannes Lehmann. "Recent achievement of sustainable soil management in Sub-Saharan Africa." Nutrient Cycling in Agroecosystems 102, no. 1 (2015): 1-3.

Baumes, H.:1978, “A Partial Equilibrium Sector Model of U.S. Agriculture Open to Trade: A Domestic Agricultural and Agricultural Trade Policy Analysis.” Ph.D. thesis, Purdue University.

Benjamin, D. 1992. "Household Composition, Labor Markets, and Labor Demand: Testing for Separation in Agricultural Household Models." Econometrica 60(2): 287-322.

Berger, T. 2001. Agent-based spatial models applied to agriculture: a simulation tool for technology diffusion, resource use changes and policy analysis. Agricultural Economics 25. 245-260.

Berkhout, E. D., Schipper, R. A., Van Keulen, H., \& Coulibaly, O. (2011). Heterogeneity in farmers' production decisions and its impact on soil nutrient use: results and implications from northern Nigeria. Agricultural Systems, 104(1), 63-74.

Bezlepkina, I., Reidsma, P., Sieber, S., \& Helming, K. (2011). Integrated assessment of sustainability of agricultural systems and land use: methods, tools and applications. Agricultural Systems, 104(2), 105-109.

Biorn, E. \& Skjerpen, T. Aggregation and Aggregation Biases in production Functions: A Panel Data Analysis of Translog Models. Statistics Norway, research department, 2002.

Blackorby, C., \& Shorrocks, A. F. (1996). Separability and Aggregation: The Collected Works of WM Gorman, Volume I. Oxford University Press.

Blundell, R., \& Stoker, T. M. (2005). Heterogeneity and aggregation. Journal of Economic Literature, 347-391.

Britz, W., Verburg, P. H., \& Leip, A. (2011). Modelling of land cover and agricultural change in Europe: Combining the CLUE and CAPRI-Spat approaches. Agriculture, Ecosystems \& Environment, 142(1), 40-50.

Brown, D., 2000. A Review of Bio-Economic Models. Paper prepared for the Cornell African Food Security and Natural Resource Management (CAFSNRM) Program. Cornell University. 
Chang, C.C., B.A. McCarl, J.W. Mjelde, and J.W. Richardson.:1992, "Sectoral Implications of Farm Program Modifications.” American Journal of Agricultural Economics 74:38-49.

Chen, C.C.; McMcarl, B.; and R. Adams. 2001. Economic Implications of Potential ENSO frequency and Strength Shifts. Clim. Change 49, 147-159.

Claessens, L., Antle, J. M., Stoorvogel, J. J., Valdivia, R. O., Thornton, P. K., \& Herrero, M. (2012). A method for evaluating climate change adaptation strategies for small-scale farmers using survey, experimental and modeled data. Agricultural Systems, 111, 85-95.

Claessens, L., J.J. Stoorvogel, and J.M. Antle. 2009. Economic viability of adopting dualpurpose sweetpotato in Vihiga district, Western Kenya: a minimum data approach. Agricultural Systems 99, 13-22.

Cooper, J.; Johansson, R.; and M. Peters. 2001. Some Domestic Environmental Effects of U.S. Agricultural Adjustments under Liberalized Trade. Economic Research Service. U.S. Department of Agriculture. http://www.ers.usda.gov/

Crissman, C.; Antle, J.; and S. Capalbo. 1998. Economic, Environmental, and Health Tradeoffs in Agriculture: Pesticides and the Sustainability of Andean Potato Production. Chapter one: Introduction and Overview. Kluwer Academic Publishers.

Crissman, C.C., J.M. Antle, and S.M. Capalbo, eds. 1998. Economic, Environmental, and Health Tradeoffs in Agriculture: Pesticides and the Sustainability of Andean Potato Production. Boston: Kluwer Academic Publishers, 281 pp.

de Jager, A., D. Onduru, M.S. van Wijk, J. Vlaming, and G.N. Gachini. 2001. Assessing sustainability of low-external-input farm management systems with the nutrient monitoring approach: a case study in Kenya. Agricultural Systems 69: 99-118.

de Jager, A., I. Kariuku, F.M. Matiri,, M. Odendo, and J.M. Wanyama, 1998b. Monitoring nutrient flows and economic performance in African farming systems (NUTMON): IV. Linking nutrient balances and economic performance in three districts in Kenya. Agriculture, Ecosystems \& Environment 71: 81-92. 
De Jager, A., Nandwa, S.M. and P.F. Okoth, 1998. Monitoring Nutrient flows and economic performance in African farming systems (NUTMON). I. Concepts and methodologies. Agriculture Ecosystems \& Environment 71 (1998) 37-48.

Deininger, K., and S. Jin 2008. Land sales and rental markets in transition: Evidence from rural Vietnam. Oxford Bulletin of Economics and Statistics 70: 67-101

Denton, F. T., \& Mountain, D. C. (2004). Aggregation effects on price and expenditure elasticities in a quadratic almost ideal demand system. Canadian Journal of Economics/Revue canadienne d'économique, 37(3), 613-628.

Dixon, J., A. Gulliver, D. Gibbon, and M. Hall, 2001. Farming Systems and Poverty. Improving Farmers' Livelihoods in a changing world. FAO, Rome and World Bank, Washington, 412 pp.

Donovan, G. and Casey, F., 1998. Soil Fertility management in Sub-Sahara Africa. World Bank Technical Paper \#408. World Bank, Washington D.C.

Dowlatabadi, H., and M. Granger Morgan. 1993. A Model Framework for Integrated Studies of the Climate Problem, Energy Policy, 21: 209-221, March 1993.

Dumanski, J; Pettapiece, W.W.; and R.J. McGregor. 1998. Relevance of scale dependent approaches for integrating biophysical and socioeconomic information and development of agroecological indicators. Nutrient Cycling in Agroecosystems Journal. Volume 50: 13-22.

EADD 2013. Gender, dairy production and marketing: Baseline surveys report: Report 6. Nairobi, Kenya: East Africa Dairy Development Project (EADD). URI: http://hdl.handle.net/10568/34456

EADD 2014. East Africa Dairy Development (EADD) II: Sustainable Livelihoods for One Million People in Uganda, Kenya and Tanzania by 2018. Available at http://www.heifer.org/eadd/

Easterling, W.E., 1997. Why regional studies are needed in the development of full scale integrated assessment modeling of global change processes. Global Environmental Change 7, 337-356.

Ewert, F., H. Van Keulen, M.K. Van Ittersum, K.E. Giller, P.A. Leffelaar, and R.P. Roetter. 2006. Multi-scale analysis and modelling of natural resource management options In: Proceedings of the iEMSs Third biennial Meeting 
Summit on Environmental Modelling and Software, Burlington, Vermont, USA, July 2006. International Environmental Modelling and Software Society.

Ewert, F., M.K. van Ittersum, T. Heckelei, O. Therond, I. Bezlepkina, and E. Andersen, 2011. Scale changes and model linking methods for integrated assessment of agrienvironmental systems. Agriculture, Ecosystems \& Environment 142, 6-17. DOI:10.1016/j.agee.2011.05.016.

EXPAMOD: A methodological Tool for linking Farm and Market Models by means of Econometric Response Functions. 12 ${ }^{\text {th }}$. Congress of the European Association of Agricultural Economists - EAAE, 2008, Gent, Belgium.

Feng S.F, AB. Krueger, and M. Oppenheimer. 2010. Linkages among climate change, crop yields and Mexico-US cross-border migration. Proceedings of the NationalAcademy of Science. 107:14257-14262.

Fingleton, B., \& Fischer, M. M. (2010). Neoclassical theory versus new economic geography: competing explanations of cross-regional variation in economic development. The Annals of Regional Science, 44(3), 467-491.

Fischer, G., M. Shah, F.N. Tubiello, and H. van Velhuizen. 2005. Socio-economic and climate change impacts on agriculture: an integrated assessment, 1990-2080. Philos Trans R Soc Lond B Biol Sci. 2005 November 29; 360(1463): 2067-2083.

Fleming, R.A., and R.M. Adams. 1997. The importance of Site-Specific Information in the Design of Policies to control Pollution. Journal of environmental Economics and management 33, 347-358.

Flichman, G., K.Louhichi and J.M. Boisson. 2012. Modeling the Relationship Between Agriculture and the Environment Using Bio-Economic Models: Some Conceptual Issues. In: Flichman, G. (Ed) Bio-Economic Models Applied to Agricultural Systems. Springer. ISBN: 978-94-007-1901-9.

Food and Agriculture Organization of the United Nations (FAO), 2008. Climate Change and Food Security: A Framework Document. FAO, Rome, Italy.

Forni, M., and Lippi, M., 1997. Aggregation and Microfoundations of Dynamic Macroeconomics. Oxford, University Press, Oxford. 
Fox, J.T. and Amit Gandhi. 2009. Identifying Heterogeneity in Economic Choice and Selection Models using Mixtures. Working Paper. University of Michigan. Available at http://citeseerx.ist.psu.edu/viewdoc/summary?doi=10.1.1.177.3276

Freeman, A. H., J.M. Omiti, 2003. Fertilizer use in semi-arid areas of Kenya: analysis of smallholder farmer's adoption behavior under liberalized markets. Nutrient Cycling in Agroecosystems 66, 23-31.

Garnett, T., Appleby, M. C., Balmford, A., Bateman, I. J., Benton, T. G., Bloomer, P., Burlingame, B., Dawkins, Dolan, L., Fraser, D., Herrero, M., Hoffmann, I., Smith, P., Thornton, P.K., Toulmin, C., Vermeulen, S.J., and Godfray, H. C. J. (2013). Sustainable intensification in agriculture: premises and policies. Science, 341(6141), 33-34.

Giller, K. E., P. Tittonell, M. C. Rufino, M. T. van Wijk, S. Zingore, P. Mapfumo, S. Adjei-Nsiah, M. Herrero, R. Chikowo, M. Corbeels, E. C. Rowe, F. Baijukya, A. Mwijage, J. Smith, E. Yeboah, W. J. van der Burg, O. M. Sanogo, M. Misiko, N. de Ridder, S. Karanja, C. Kaizzi, J. K’ungu, M. Mwale, D. Nwaga, C. Pacini, and B. Vanlauwe. 2011. Communicating complexity: Integrated assessment of tradeoffs concerning soil fertility management within African farming systems to support innovation and development. Agricultural Systems 104:191-203.

Goddar, T.; Kryzanowsky, L.; Cannon, K; Izarrualde, C.; and T.Martin. 1996. Potential for Integrated GIS-Agriculture Models for Precision Farming Systems. In Proc. Int. Conf./Workshop on Integrating GIS and Environmental Modeling, Proceedings, 3rd, Santa Fe, NM. 21-25 Jan. 1996 [CDROM computer file]. Natl. Ctr. For Geographic Information and Analysis. Santa Barbara, CA.

Gorman, W.M., 1953. Community preference fields. Econometrica 21, 63-80.

Government of Kenya (2008). Vision 2030 The Popular Version. Retrieved on January 2013: www.vision2030.go.ke

Government of Kenya. 2003. Geographic Dimensions of Well-Being in Kenya: Where are the Poor? From Districts to Locations. Volume 1, Central Bureau of Statistics, Ministry of Planning and National Development, Nairobi, Kenya.

Government of Kenya. 2004. Strategy for Revitalizing Agriculture 2004-2014. The Ministry of Agriculture, the Ministry of Livestock and Fisheries Development and 
the Ministry of Cooperative Development and Marketing, Nairobi, Kenya, 124 pp.

Government of Kenya. 2005. Machakos Strategic Plan 2005-2010 for Implementation of the National Population Policy for Sustainable Development. National Coordination Agency for Population and Development, Ministry of Planning and National Development, Nairobi, Kenya.

Government of Kenya. 2008. Machakos Strategic Plan 2005-2010 for Implementation of the National Population Policy for Sustainable Development. National Coordination Agency for Population and Development, Ministry of Planning and National Development, Nairobi, Kenya.

Grassl, H. 2000. Status and improvements of coupled General Circulation models. Science, 288, 1991-1997.

Gray, K.M. 2005. "Changing Soil Degradation Trends in Senegal with Carbon Sequestration Payments.” M.S. Thesis, Montana State University, Bozeman MT.

Green, G. and Sunding, D. 2000. Designing environmental regulations with empirical microparameter distributions: the case of seawater intrusion. Resource and Energy Economics 222000 63-78

Hajkowicz S. and Prato T. 1998, Multiple Objective Decision Analysis of Farming Systems in Goodwater Creek Watershed, Missouri, Research Report N. 24, Center for Agricultural, Resource and Environmental Systems, University of MissouriColumbia, Columbia. http://www.cares.missouri.edu/about/reports/report24.html

Halvorsen, B., \& Larsen, B. M. (2006). Aggregation with price variation and heterogeneity across consumers". Discussion paper 489. Statistics Norway

Hansen, J.W. and Jones, J. 2000. Scaling-up crop models for climate variability applications: Short Survey. Agricultural Systems 65(2000) 43-72.

Harris, D., and A. Orr. 2014. Is Rainfed Agriculture really a Pathway from Poverty? Agricultural Systems. http://dx.doi.org/10.1016/j.agsy.2013.09.005.

Heckman, J. J. (2001). Micro data, heterogeneity, and the evaluation of public policy: Nobel lecture. Journal of political Economy, 109(4), 673-748.

Herrero, M., Thornton, P. K. (2009). Agriculture and Climate Change: An Agenda for Negotiation in Copenhagen: Mitigating Greenhouse Gas Emissions from 
Livestock Systems. 2020 Vision for Food, Agriculture and The Environment. Focus 16, Brief 6, may 2009. IFPRI.

Herrero, M., Thornton, P. K., Gerber, P., \& Reid, R. S. (2009). Livestock, livelihoods and the environment: understanding the trade-offs. Current Opinion in Environmental Sustainability, 1(2), 111-120.

Herrick, Jeffrey E., and Adam Beh. "A risk-based strategy for climate change adaptation in dryland systems based on an understanding of potential production, soil resistance and resilience, and social stability." In Sustainable Intensification to Advance Food Security and Enhance Climate Resilience in Africa, pp. 407-424. Springer International Publishing, 2015.

Hertel, T. 1997. Global Trade Analysis: Modeling and Applications (T. Hertel, ed). Chapter one: Introduction and Overview. Cambridge University press.

Hertel, T. Applied General Equilibrium Analysis of Agricultural and resource Policies. Purdue University. 1999.

Hochman, E., Zilberman, D., 1978. Examination of environmental policies using production and pollution microparameter distributions. Econometrica July 739760.

Holden, S. 2005. Bio-economic modelling approaches for natural resource management impact assessment. In B. Shiferaw, H. Ade Freeman and S. Swinton (eds). Natural Resource Management in Agriculture: Methods for Assessing Economic and Environmental Impacts. CABI Publishing, UK, pp.175-196.

Holmoy, E. \& Haegeland, T. Aggregate Productivity and heterogeneous firms. Statistics Norway, 2000.

Houthakker, H. (1955): The Pareto Distribution and the Cobb-Douglas Production Function in Activity Analysis, Review of Economic Studies 23, 27-31.

http://www.ipcc-data.org/ddc_envdata.html

Huffman, W.E. 2001. "Human Capital: Education and Agriculture.” In B.L. Gardner and G.C. Rausser, eds. Handbook of Agricultural Economics, Volume 1A. Amsterdam: Elsevier, pp. 333-381. 
Huq, S., and H. Reid. 2005. Climate change and development: consultation on key researchable issues. IIED, London, UK. Online at http://www.iied.org/CC/projects/ccdevconsultation.html.

IFPRI. 2013. West African Agriculture and Climate Change: A Comprehensive Analysis. A. Jalloh, G. Nelson, T. Thomas, R. Zougmore, and H. Roy-Macauley. IFPRI Policy Brief 75. August, 2013.

Iglesias, A. and M.I. Mínguez. 1995. Perspectives for maize production in Spain under climate change, in: Rosenzweig C., Allen Jr., L.H., Harper, L.A., Hollinger, S.E., Jones, J.W. (ed) Climate Change and Agriculture: Analysis of Potential International Impacts, Vol 13. American Society of Agronomy, Madison, Wisconsin, p 259-273.

Immerzeel, W., J.J. Stoorvogel, and J.M. Antle. 2008. Can Payments for Ecosystem Services Secure the Water Tower of Tibet? Agricultural Systems 96, 52-63.

Intergovernmental Panel on Climate Change (IPCC). 2001. Climate change 2001: the scientific basis. Contribution of Working Group I to the Third Assessment Report of the Intergovernmental Panel on Climate Change. J. T. Houghton, Y. Ding, D. J. Griggs, M. Noguer, P. J. van der Linden, X. Dai, K. Maskell, and C. A. Johnson, editors. Cambridge University Press, Cambridge, UK.

Intergovernmental Panel on Climate Change (IPCC). 2007. Climate change 2007: impacts, adaptation and vulnerability. Contribution of Working Group II to the Fourth Assessment Report of the Intergovernmental Panel on Climate Change. M. L. Parry, O. F. Canziani, J. P. Palutikof, P. J. van der Linden, and C. E. Hanson, editors. Cambridge University Press, Cambridge, UK.

IPCC SRES. 2000. Nakićenović, N., and Swart, R., ed. (book), Special Report on Emissions Scenarios: A special report of Working Group III of the Intergovernmental Panel on Climate Change, Cambridge University Press, ISBN 0-521-80081-1, 978-052180081-5 (pb: 0-521-80493-0, 978-052180493-6).

IPCC-DDC. 2009. Data Distribution centre: Environmental Data and Scenarios. Online at Johansen, L. (1972): Production Functions. An Integration of Micro and Macro, Short Run and Long Run Aspects. Amsterdam: North-Holland. 
Jones, J. W., G. Hoogenboom, C. H. Porter, K. J. Boote, W. D. Batchelor, L. A. Hunt, P. W. Wilkens, U. Singh, A. J. Gijsman, and J. T. Ritchie. 2003. The DSSAT cropping system

Jones, P.G., and P.K. Thornton. 2003. The potential impacts of climate change in tropical agriculture: the case of maize in Africa and Latin America in 2055. Global Environmental Change 13, 51-59

Just, R., Antle, J., 1990. Interaction between agricultural and environmental policies: a conceptual framework. Am. Econ. Rev. 80, 197-202

Kam, SP; Castella, Jean C; Hoanh, Chu T; Trébul, Guy; and Bousquet Francois, 2000. Methodological integration for sustainable natural resources management beyond field/farm level: Lessons from the Ecoregional initiative for the Humid and SubHumid Tropics of Asia. International Workshop on "Integrated Natural Resource Management in the CGIAR: Approaches and Lessons. August 21-25. Penang, Malaysia.

Kamau, F.K.. 2000. A Kenyan experience on R\&D efforts linking crop and livestock improvement, NRM and human health. In: Jabbar M.A., Peden D.G., Mohamed Saleem M.A., Li Pun, H. (Eds). Agro-ecosystems, natural resources management and human health related research in East Africa. Proceedings of an IDRC-ILRI international workshop held at ILRI, Addis Ababa, Ethiopia, 11-15 May 1998. ILRI (International Livestock Research Institute), Nairobi, Kenya.

Karanja, D. D., Jayne, T. S., \& Strasberg, P. (1998). Maize productivity and impact of market liberalization in Kenya. Strategies for raising smallholder agricultural productivity and welfare. Egerton University/Tegemeo Institute of Agricultural Policy and Development.

Karanja, D. K. 2003. The impact of Maize Technologies on Income Distribution in Marginal and High Potential Regions of Kenya. Phd Dissertation. Department of Agricultural Economics, Michigan State University. East Lansing, MI.

Karanja, D.K., M. Renkow, E. Crawford. 2002. The welfare effects of maize technologies in marginal and favored regions of Kenya. Paper presented at the International Conference on Impacts of Agricultural Research and Development, San Jose, Costa Rica, Feb. 4-7, 2002. 
Kaufmann, R.; and S.E. Snell. 1997. A biophysical Model of Corn Yield: Integrating Climatic and Social Determinants. American Journal of Agricultural Economics 79 (February 1999): 178-190.

Kayser, H. 1999. Assessing Research on the impacts of Climate Change on Agriculture. In: Frisvold, G., Kuhn, B. (Eds), Global Environmental Change and Agriculture: Assessing the Impacts. Edward Elgar Publishing, Ltd., Cheltenham, U.K., pp. $221-2$

Kelejian, H.J., 1980. Aggregation and disaggregation of non-linear equations. In: Kmenta, J., Ramsey, J.B. (Eds.), Evaluation of Econometric Models. Academic Press, New York, pp. 135-153.

Key, N., E. Sadoulet, and A. de Janvry. 2000. "Transactions Costs and Agricultural Household Supply Response." American Journal of Agricultural Economics 82: 245-259.

Kirman, Alan P. "Whom or What Does the Representative Individual Represent?" $J$. Econ. Perspectives 6 (Spring 1992): 117-36

Kruseman, G. 1999. Bioeconomic modelling to assess the impact of policy incentives on sustainable land use: Do fertiliser prices and transaction costs matter? Paper presented at the NWO seminar Milieu, Economie en NMP4, Amsterdam, June 4, 1999.

Kruseman, G. 2001. Assessing the effects of Policy Measures on Household Welfare and Agro-Ecological Sustainability: An Overview of Farm Household Modelling Approaches. In: Economic Policy and Sustainable Land Use: recent Advances in Quantitative Analysis for developing Countries. Nico Heerink, Herman van Keulen and Marijke Kuiper, editors. Physica-Verlag.

Kruseman, G.; and J. Bade. 1998. Agrarian policies for Sustainable Land Use: Bioeconomic Modelling to Assess the effectiveness of Policy Instruments. Agricultural Systems, Vol 58, No. 3: 465-481.

Kruseman, G.; Ruben R.; Kuyvenhoven, A.; Hendgsdij, H.; and H. van Keulen. 1996. Analytical Framework for Disentangling the Concept of Sustainable Land Use. Agricultural Systems, Vol 50: 465-481. 
Kuyvenhoven, A.; Ruben R.; and G. Kruseman . 1998. Technology, market policies and institutional reform for sustainable land use in Mali. Agricultural Economics 19:53-62.

Laborte, A.G., M.K. Van Ittersum, and M.M. Van den Berg. 2007. Multi-scale analysis of agricultural development: A modelling approach for Ilocos Norte, Philippines. Agricultural Systems, 94, 862-873.

Lambert, D.K., B.A. McCarl, Q. He, M.S. Kaylen, W. Rosenthal, C.C. Chang, and W.I. Nayda.:1995, "Uncertain Yields in Sectoral Welfare Analysis: An Application to Global Warming." Journal Agricultural and Applied Economics: 423-435.

Lence, S. 2009. “Joint Estimation of Risk Preferences and Technology: Flexible Utility or Futility?" American Journal of Agricultural Economics 91(3):581-598.

Lewandrowski, Jan, Mark Peters, Carol Jones, Robert House, Mark Sperow, Marlen Eve, and Keith Paustian. 2004. Economics of Sequestering Carbon in the U.S. Agricultural Sector. Economic Research Service (ERS), U.S. Department of Agriculture. Technical Bulletin No. (TB1909). Wasthingon, D.C

Lippi, M., 1988. On the dynamic shape of aggregated error correction models. J. Economic. Dynamics and Control

Lobell, D.B. and C.B. Field. 2007. Global scale climate-crop yield relationships and the impacts of recent warming. Environmental Research Letters, 2, 004000 (7pp)

Lubowski, R.N., A.J. Plantinga, and R.N. Stavins. 2006. "Land-Use Change and Carbon Sinks: Econometric Estimation of the Carbon Sequestration Supply Function.” Journal of Environmental Economics and Management 51(2):135-152.

Lubulwa, G., B. Wafula, E. Craswell, I. Willet, and J. Davis, 1995. Dry Land Farming in the Semi-Arid Tropics of Kenya: ACIAR Project Experience. Working paper Series No.19, May 1995. Economic Evaluation Unit, Australian Centre for International Agricultural Research.

Malinvaud, E., 1970. The consistency of non-linear regressions. Ann. Math. Stat. 41, 956-969.

Manne, A.S. and R.G. Richels. 1993. CO2 Hedging Strategies-The Impact of Uncertainty on Emissions, paper presented at the OECD/IEA Conference on the Economics of Climate Change, Paris 14-16 June, 1993. 
Manne, A.S., R. Mendelsohn, and R.G. Richels. 1993. MERGE: A Model for Evaluating Regional and Global Effects of GHG Reduction Policies. Energy Policy, 23(1):17-34.

Marenya, P., and C.B. Barrett. 2009a. State-Conditional Fertilizer Yield Response on Western Kenya Farms. American Journal of Agricultural Economics 91, 9911006.

Marenya, P.P. and C.B. Barrett (2009b), "Soil Quality and Fertilizer Use Among Smallholder Farmers in Western Kenya," Agricultural Economics 40(5): 561572.

Marenya, P.P., W. Oluoch-Hosura, F. Place, and C.B. Barret. 2003. Education, Nonfarm Income, and Farm Investment in Land-scarce Western Kenya. BASIS Brief: Broadening Access and Strengthening Input Market Systems. Number 14, February. Edited by BASIS CRSP, Madison WI, USA.

Mathur, A. 2003 Panel on Climate Change and Sustainable Development. View from the World Bank. In: Munasinghe, M., Canziani, O., Davidson, O., Metz, B., Parry, Harrison, M. (Eds), Integrating Sustainable Development and Climate Change in the IPCC fourth Assessment Report. Proceedings of the IPCC Expert meeting held in Colombo, Sri Lanka 5-7 March, 2003.

McCarl, B. A., X. Villavicencio, and X. Wu. 2008. Climate Change and Future Analysis: Is Stationarity Dying? American Journal of Agricultural Economics, 20:1241-47

McCarl, B.A. and T.H. Spreen.:1980, "Price Endogenous Mathematical Programming As a Tool For Sector Analysis." American Journal of Agricultural Economics 62:87102.

McCarthy, N., Lipper, L., \& Branca, G. (2011). Climate-smart agriculture: smallholder adoption and implications for climate change adaptation and mitigation. Mitigation of Climate Change in Agriculture Working Paper, (3).

Mghenyi, E.W. 2006. Welfare Effects of Maize pricing Policy on Rural Households in Kenya. Master Thesis. Department of Agricultural Economics. Michigan State University.

Mighell, R. L., \& John, D. Black (1951). Interregional Competition in Agriculture. Cambridge, Mass. 
Mora-Vallejo, A., J.J. Stoorvogel, J.M. Antle, and A. de Jager. 2012. "Linking Nutrient Monitoring and Tradeoff Analysis for Policy Analysis." Journal of Land Use Management, submitted.

Muchena, F. N., Onduru, D. D., Gachini, G. N., \& De Jager, A. 2005. Turning the tides of soil degradation in Africa: capturing the reality and exploring opportunities. Land Use Policy, 22(1), 23-31.

Muellbauer, J., 1975. Aggregation, income distribution and consumer demand. Rev. Econ. Stud. 42, 525-543

Mundlak, Y. 2001 Production and Supply. Ch1. Handbook of Agricultural Economics.

Nandwa, S.M., D.D. Onduru, and L.N. Gachimbi. 2000. Soil fertility regeneration in Kenya. In: Hilhorst, T. and Muchena, F.M. (eds.). Nutrients on the move-Soil fertility dynamics in African farming systems. IIED, London.

Ndung'u, N., Thugge, K., \& Otieno, O. 2011. Unlocking the Future Potential for Kenya: The Vision 2030. Office of the Prime Minister Ministry of State for Planning, National Development and Vision 2030, Government of Kenya.

Nelson, G.C, M. W. Rosegrant, A. Palazzo, I. Gray, C. Ingersoll, R. Robertson, S. Tokgoz, T. Zhu, T. B. Sulser, C. Ringler, S. Msangi, and L. You. 2010. Food Security, Farming, and Climate Change to 2050: scenarios, results and policy options. International Food Policy Research Institute (IFPRI).

Nzuma, J.M., and F. Sarker. 2008. An Error Corrected Almost Ideal Demand System for Major Cereals in Kenya. Selected paper presented at the American Agricultural Economics Association Annual Meeting. Orlando, Florida, 2008.

Omoyo, Nyandiko Nicodemus, Jacob Wakhungu, and Silvery Oteng'i. "Effects of climate variability on maize yield in the arid and semi arid lands of lower eastern Kenya." Agriculture \& Food Security 4, no. 1 (2015): 1.

Oxley, T., and H.M. ApSimon. 2007. Space, time and nesting integrated assessment models. Environmental Modelling \& Software 22, 1732-1749.

Park, W.I.; and Garcia, P. 1994. Aggregate versus disaggregate analysis: corn and soybean acreage response in Illinois. Review of Agricultural Economics, vol 16, pp17-26. 
Pautsch, G.R., L.A. Kurkalova, B.A. Babcock, and C.L. Kling. 2001. "The Efficiency of Sequestering Carbon in Agricultural Soils." Contemporary Economic Policy 19(2):123-134.

Pérez Dominguez, I., I. Bezlepkina, T. Heckelei, A. Oude Lansink, E. Romstad, and A. Kanellopuolos. 1996. EXPAMOD: A methodological tool for linking farm and market models by means of econometric response functions. $12^{\text {th }}$. Congress of the European Association of Agricultural Economists - EAAE, 2008, Gent, Belgium.

Pérez Dominguez, I., I. Bezlepkina, T. Heckelei, E. Romstad, A. Oude Lansink, A. and Kanellopuolos. 2009. Capturing market impacts of farm level policies: a statistical extrapolation approach using biophysical characteristics and farm resources. Environmental Science and Policy 12 588-600.

Perroni, C. and R. Wigle. Environmental policy modeling. In: Global Trade Analysis. Modeling and Applications. Edited by Thomas Hertel. Chapter 12, 1997.

Pesaran M.H. (2003): Aggregation of linear dynamic models: an application to life-cycle consumption models under habit formation. Economic Modelling. 20 (2): 383-415

Pingali PL (2012) Green revolution: Impacts, limits, and the path ahead. Proc Natl Acad Sci USA 109:12302-12308.

Pingali, P., Schneider, K., \& Zurek, M. (2014). Poverty, Agriculture and the Environment: The Case of Sub-Saharan Africa. In Marginality (pp. 151-168). Springer Netherlands.

R. Richels and J. Edmonds. 1995. The Cost of Stabilizing Atmospheric CO2 Emissions, Energy Policy, 23(4/5):373-378.

Reardon, T., K. Stamoulis, A. Balisacan, ME Cruz, J. Berdegue, B. Banks. 1998. Rural Nonfarm Income in Developing Countries, Special Chapter in The State of Food and Agriculture 1998, Rome: Food and Agricultural Organization of the United Nations.

Rosegrant, M. W. (2013). IMPACT Development Team, 2012. International model for policy analysis of agricultural commodities and trade (IMPACT) Model Description. Washington DC.

Rosegrant, M. W., Ringler, C., Msangi, S., Sulser, T. B., Zhu, T., \& Cline, S. A. (2008). International Model for Policy Analysis of Agricultural Commodities and Trade 
(IMPACT): Model Description. International Food Policy Research Institute. Washington D.C.

Rosenzweig, C., Jones, J. W., Hatfield, J. L., Ruane, A. C., Boote, K. J., Thorburn, P., ... \& Winter, J. M. (2012). The agricultural model intercomparison and improvement project (AgMIP): protocols and pilot studies. Agricultural and Forest Meteorology

Rygnestad, H.; Jensen, J.D.; and T. Dalgaard. 2002. Integrated economic and spatial analyses of afforestation strategies in Denmark. Danish Journal of Geography Special Issue, 3: 41-48, 2002

Sanchez, P., A.M. Izac, R. Buresh, K. Shepherd, M. Soule, U. Mokwunye, C. Palm, P. Woomer and C. Nderitu. 1997. Soil fertility replenishment in Africa as an investment in natural resource capital, R. Buresh, P. Sanchez, Editors, Replenishing Soil Fertility in Africa, SSSA Special Publication No. 51. Soil Science Society of America, Madison, WI, USA (1997), pp. 1-46.

Sanchez, P., Palm, C., Sachs, J., Denning, G., Flor, R., Harawa, R., Jama, B., Kiflemariam, T., Konecky, B., Kozar, R., Lelerai, E., Malik, A., et al. 2007. The African millennium villages. Proc. Natl. Acad. Sci. USA 104, 16775-16780.

Schaldach, R.; and Alcamo, J. 2003. A GIS-Based simulation Environment for linking Land Use Patterns to Ecosystem Processes. Enviroinfo 2003. Cottbus. Germany.

Schiller, R. 1997. Agricultural Models: "Modeling the Impact of Agricultural Trade Liberalization on Developing Economies". International Trade, Environment and Development Institut, Københavns Universitet.

Schlenker W. and D.B. Lobell. 2010. Robust negative impacts of climate change on African agriculture. Environmental Research Letters: 014010 (8pp)

Schneider, U.A. 2000. Agricultural Sector Analysis on Greenhouse Gas Emission Mitigation in the United States. PhD. Thesis. Graduate Studies of Texas A\&M University.

Schreinemachers, P., \& Berger, T. (2011). An agent-based simulation model of humanenvironment interactions in agricultural systems. Environmental Modelling \& Software, 26(7), 845-859. 
SDSN, 2013. Solutions for Sustainable Agriculture and Food Systems: Technical report for the Post-2015 Development Agenda. Sustainable Development Solutions Network.

Sharples, Jerry. The representative Farm Approach to estimation of Supply Response. The American Economic Review, Vol. 59, No. 2, Papers and Proceedings of the Eighty-first Annual Meeting of the American Economic Association (May, 1969), pp. $168-174$

Shepherd, K. D., and M. J. Soule. 1998. Soil fertility management in west Kenya: dynamic simulation of productivity, profitability and sustainability at different resource endowment levels. Agriculture, Ecosystems and Environment 71:131145.

Shumway, R.; and G. Davis. 2001. Does consistent aggregation really matter? The Australian Journal of Agricultural and Resource Economics, 45:2, pp. 161-194. Blackwell Publishing.

Solow, R., 1962. Substitution and fixed proportions in the theory of capital. Rev. Econ. Stud. June 207-218.

Stephens, Emma C., Charles F. Nicholson, Douglas R. Brown, David Parsons, Christopher B. Barrett, Johannes Lehmann, David Mbugua, Solomon Ngoze, Alice N. Pell, and Susan J. Riha. "Modeling the impact of natural resource-based poverty traps on food security in Kenya: The Crops, Livestock and Soils in Smallholder Economic Systems (CLASSES) model." Food Security 4, no. 3 (2012): 423-439.

Stockle, C. O., M. Donatelli, and R. Nelson. 2003. CropSyst, a cropping systems simulation model. European Journal of Agronomy 18:289-307.

Stoker, T. M. (1986). Simple tests of distributional effects on macroeconomic equations. The Journal of Political Economy, 763-795.

Stoker, T. M. 1984. Simple tests of distribution effects on macroeconomic equations. Sloan School of Management Working paper \#1529-84.

Stoker, T. M. Empirical Approaches to the problem of Aggregation over individuals. Journal of Economic Literature, Vol.31, 1993. 
Stoorvogel, J.; Antle, J.; Crissman, C.; and W. Bowen. 2004b. The tradeoff Analysis Model: Integrated Bio-physical and Economic Modeling of Agricultural Production Systems. Agricultural Systems 80(1):43-66

Stoorvogel, J.J., J.M. Antle, and C.C. Crissman. 2004. Trade-off Analysis in the Northern Andes to Study the Dynamics in Agricultural Land Use. Journal of Environmental Management 72(1-2):23-33.

Strauss, J., and D. Thomas. 1995. "Empirical Modeling of Household and Family Decisions." In J. Behrman and T.N. Srinivasan, eds. Handbook of Development Economics, Volume IIIA. Amsterdam: Elsevier, pp. 1883-2023.

Sunding, D., and D. Zilberman. 2001. "The Agricultural Innovation Process: Research and Technology Adoption in a Changing Agricultural Sector.” B.L. Gardner and G.C. Rausser, eds., Handbook of Agricultural Economics, Volume 1A. Amsterdam: Elsevier, pp. 207-261.

Suri, T. 2011. Selection and comparative advantage in technology adoption. Econometrica, 79(1), 159-209.

Suxia Liu, Xingguo Mo, Zhonghui Lin, Yueqing Xu, Jinjun Ji, Gang Wen, and Jeff Richey. 2010. Crop yield responses to climate change in the Huang-Huai-Hai Plain of China. Agricultural Water Management 97:1195-1209.

Tarawali, S., Duncan, L., Thorne, P., Valbuena, D., Descheemaeker, K., and HomannKee-Tui, S. 2013. Integrated Crop Livestock Systems: A Key to Sustainable Intensification in Africa. $22^{\text {nd }}$. Grassland Congress. Sydney, Australia. September 15-19.

Taylor, J.E. and I. Adelman. 2003. "Agricultural Household Models: Genesis, Theory and Extensions." Review of Economics of the Household 1: 33-58.

Tegemeo Institute. 2013. Tegemeo Agricultural Policy Research and Analysis Project. http://fsg.afre.msu.edu/kenya/. Accessed November 19, 2013.

Tegemeo Institute. 2009. Trends in Kenyan agricultural Productivity: 1997-2007 http://www.tegemeo.org. Accessed May 22, 2016.

The Montpellier Panel. 2013. Sustainable Intensification: A New Paradigm for African Agriculture. London.

Theil, H. Linear Aggregation of Economic Relations (Amsterdam: North-Holland, 1954) 
Thompson, L.M. 1969. Weather and Technology in the Production of Corn in the U.S. Corn Belt. Agronomy Journal 61: 453-456.

Thorne P.J., P.K. Thornton, R.L. Kruska, L. Reynolds, S.R. Waddington, A.S. Rutherford, and A.N. Odero. 2002. Maize as food, feed and fertiliser in intensifying crop-livestock systems in East and southern Africa: An ex ante impact assessment of technology interventions to improve smallholder welfare. ILRI Impact Assessment Series 11. ILRI (International Livestock Research Institute), Nairobi, Kenya.

Thornton P K, P.G. Jones, A. Alagarswamy, and J. Andresen. 2009. Spatial variation of crop yield responses to climate change in East Africa. Global Environmental Change 19:54-65.

Thornton, P. K., \& Herrero, M. (2001). Integrated crop-livestock simulation models for scenario analysis and impact assessment. Agricultural Systems, 70(2), 581-602.

Thornton, P.K., P.G. Jones, T. Owiyo, R.L. Kruska, M. Herrero, P. Kristjanson, A. Notenbaert, N. Bekele, and A. Omolo, A., with contributions from Orindi, V., Ochieng, A., Otiende, B., Bhadwal, S., Anantram, K., Nair, S., Kumar, and V., Kelkar, U. 2006. Mapping climate vulnerability and poverty in Africa. Report to the Department for International Development, ILRI, Nairobi, Kenya, May 2006, $200 \mathrm{pp}$. Online at http://www.dfid.gov.uk/research/mapping-climate.pdf.

Tiffen, M., M. Mortimore, F. Gichuki. 1994. More people, less erosion: environmental recovery in Kenya. Wiley\&Sons, Sussex.

Tittonell, P., B. Vanlauwe, P. A. Leffelaar, E. Rowe, and K. E. Giller. 2005a. Exploring diversity in soil fertility management of smallholder farms in western Kenya. I. Heterogeneity at region and farm scale. Agriculture, Ecosystems and Environment 110:149-165.

Tittonell, P., B. Vanlauwe, P. A. Leffelaar, K. D. Shepherd, and K. E. Giller. 2005b. Exploring diversity in soil fertility management of smallholder farms in western Kenya. II. Within-farm variability in resource allocation, nutrient flows and soil fertility status. Agriculture, Ecosystems and Environment 110:166-184. 
Tsuji, G., G. Uehara, and S. Balas, 1994. DSSAT Version 3. A Decision Support System for Agrotechnology Transfer, International Benchmark Sites Network for Agrotechnology Transfer, University of Hawaii, Honolulu, Hawaii.

United Nations Development Program (UNDP), 2001. Human Development Report 2001. Oxford University Press, Inc., New York.

United Nations. 2014. The Millennium Development Goals Report 2014. New York

United Nations. 2015. The Millennium Development Goals Report 2015. New York

Uthes, S. ; K. Fricke, H.J. König, P. Zander, M. Van Ittersum, S. Sieber, K. Helming, A. Piorr, and K. Müller. 2010. Policy relevance of three integrated assessment tools: a comparison with specific reference to agricultural policies. Ecological Modelling 221, 2136-2152.

Valdivia, R.O. 2002. "The Economics of Terraces in the Peruvian Andes: An Application of Sensitivity Analysis in an Integrated Assessment Model." M.S. Thesis, Department of Agricultural Economics and Economics, Montana State University, Bozeman, MT.

Valdivia, R.O., Antle, J., Rosenzweig, C., Ruane, A., Vervoort, J., Ashfaq, M., Hattie, I., Homman-Kee Tui, S., Mulwa, R., Nhemachena,C., Ponnusamy, P., Rasnayaka, H., and H. Singh. 2015. "Representative Agricultural Pathways and Scenarios for Regional Integrated Assessment of Climate Change Impact, Vulnerability and Adaptation". In Handbook of Climate Change and Agroecosystems, edited by D. Hillel and C. Rosenzweig.

Valdivia, R.O., J.M. Antle, and J.J. Stoorvogel, 2012. Coupling the Tradeoff Analysis Model with a market equilibrium model to analyze economic and environmental outcomes of agricultural production systems. Agricultural Systems, 110 (2012).

Valdivia, R.O.; J.J. Stoorvogel and J.M. Antle. 2012. Economic and Environmental Impacts of Climate Change and Socio-economic Scenarios: A Case Study on a Semi-subsistence Agricultural Production System. The International Journal of Climate Change: Impacts and Responses. Vol. 3, Issue 2.

Van Bussel, L. G. J., Ewert, F., \& Leffelaar, P. A. (2011). Effects of data aggregation on simulations of crop phenology. Agriculture, Ecosystems \& Environment, 142(1), $75-84$. 
Van Delden, H., Van Vliet, J., Rutledge, D. T., \& Kirkby, M. J. (2011). Comparison of scale and scaling issues in integrated land-use models for policy support. Agriculture, Ecosystems \& Environment, 142(1), 18-28.

van den Bosch, H., De Jager, A. \& Vlaming, J. (1998a). Monitoring nutrient flows and economic performance in African farming systems (NUTMON): II. Tool development. Agriculture, Ecosystems \& Environment 71, 49-62.

van den Bosch, H., Gitari, J.N., Ogaro, V.N., Maobe, S. \& Vlaming, J. (1998b). Monitoring nutrient flows and economic performance in African farming systems (NUTMON).: III. Monitoring nutrient flows and balances in three districts in Kenya. Agriculture, Ecosystems \& Environment 71, 63-80.

van Ittersum, M.K., Ewert, F., Heckelei, T., Wery, J., Alkan Olsson, J., Andersen, E., Bezlepkina, I., Brogaard, S., Donatelli, M., Flichman, G., Olsson, L., Rizzoli, A., van der Wal, T., Wien, J.E., Wolf, J., 2008. Integrated assessment of agricultural systems - A component-based framework for the European Union (SEAMLESS). Agricultural Systems 96: 150-165.

van Wijk, M.; Rufino, M.; Enahoro, D.; Parsons, D.; Silvestri, S.; Valdivia, R.; Herrero, M. 2014. Farm household models to analyze food security in a changing climate: a review. Global Food Security. Forthcoming.

Vargas, E.; Schreiner, F.; Tembo, G.; Marcouiller, D. Comnputable General Equilibrium Modelling for Regional Analysis. The Web Book of Regional Science. 1999

Vella, F. 1998. "Estimating Models with Sample Selection Bias: A Survey.” Journal of Human Resources. 33(1):127-169.

Verburg, P. H., and A. Veldkamp. 2005. Spatial Modeling to explore land use dynamics. International Journal of Geographical Information Science19, 99-102.

W. D. Nordhaus. 1991. To Slow or not to Slow: The Economics of the Greenhouse Effect, The Economic Journal, 101:920-37.

W. D. Nordhaus. 1994. Managing the Global Commons: The Economics of Climate Change (MIT Press, Cambridge, Mass., 1994).

Weninger, Q. 2003. "Estimating Multiproduct Costs When Some Outputs are Not Produced." Empirical Economics 28(4):753-765. 
Wigley, T.M.L., and T. Qipu. 1983. Crop-Climate Modeling Using Spatial Patterns of Yield and Climate. Part 1: Background and an Example from Australia. Journal of Climate and Applied Meteorology. Vol. 22(11). pp. 1831-1841.

Wood, S. You, L \& Baitx, W. Dynamic Research Evaluation for Management. DREAM v.3: A User friendly system for estimating the magnitude and distribution of the economic benefits of agricultural research and development. IFPRI, 2001

Wood, S., L. You, and X. Zhang. 2004. Spatial patterns of crop yields in Latin America and the Caribbean. EPTD discussion paper No.124. IFPRI

World Bank. 2005. Introduction to poverty analysis. World Bank Institute, Washington, D.C. <http://siteresources.worldbank.org/PGLP/Resources/PovertyManual.pdf>. Accessed August 1, 2013

World Bank. 2008. World Development Report 2008: Agriculture for Development. Washington DC.

Wossink, GAA, Oude Lansink, AGJM \& Struik, PC 2001, 'Non-separability and heterogeneity in integrated agronomic-economic analysis of nonpoint-source pollution', Ecological Economics, vol. 38, pp. 345-57.

Wu, J., R.M. Adams, C.L. Kling, and K. Tanaka. 2004. "From Microlevel Decisions to Landscape Changes: An Assessment of Agricultural Conservation Policies." American Journal of Agricultural Economics. Vol. 86, No. 1 (Feb 2004), pp 2641

Wu, J.J.; and R. Adams. 2002. Micro versus Macro acreage response models: Does sitespecific information matter?. Journal of Agricultural and resource Economics. Volume 27, number 1, July, 2002.

Wu, J.J.; Zilberman, D.; and B. Babcock. 1999. Environmental and Distributional Impacts of Conservation Targeting Strategies. Working paper 99-WP230, Center for Agricultural and rural Development. Iowa State University.

Zander, P.; and H. Kächele. 1999. Modelling multiple objectives of land use for sustainable development. Agricultural Systems 59: 311-325.

Zhang, Z. and H. Folmer 1998. Economic modeling approaches to cost estimates for the control of carbon dioxide emissions. Energy Economics 20 (1998) 101-120 


\section{Summary}

Sub-Saharan Africa countries face the challenge of reducing rural poverty and reversing the declining trends of agricultural productivity and the high levels of soil nutrient depletion. Despite of numerous efforts and investments, high levels of poverty and resource degradation persist in African agriculture. The Millennium Development Goals Report (MDGR) states that the majority of people living below the poverty line of $\$ 1.25$ a day belong to Sub-Saharan Africa (SSA) and South Asia. About two thirds of the global rural population lives in mixed crop-livestock systems (CLS), typical of SSA, where interactions between crops and livestock activities are important for the subsistence of smallholders. CLS are characterized by high degree of biophysical and economic heterogeneity, complex and diversified production system that frequently involves a combination of several subsistence and cash crops and livestock. Increasing crop productivity is clearly a key element to improve living standards and to take these people out of poverty. However, agricultural productivity in most of SSA has been stagnant or increased slowly. In addition, the likely negative impacts of climate change on agriculture have accentuated the vulnerability of smallholders.

The international research community has once more the eyes on SSA with the recently proposed post-2015 MDGs, the Sustainable Development Goals that emphasize the need to achieve sustainable development globally by 2030 by promoting economic development, environmental sustainability, good governance and social inclusion. Governments and scientists are making considerable efforts to develop strategies that include structural transformations of the different sectors of the economy in search of the recipe to achieve the SDGs. Most of these strategies are based on policy and technology interventions that seek to achieve the "win-win" outcomes and move from the usual "tradeoffs" between poverty-productivity-sustainability to synergies. A key message of this thesis is that achieving the goal of sustainable development in semi-subsistence African agriculture will require better understanding of the poverty-productivity- 
sustainability puzzle: why high poverty and resource degradation levels persist in African agriculture. I hypothesize that the answer to this puzzle lies, at least in part, in understanding and appropriately analyzing key features of semi-subsistence croplivestock systems (CLS) typical of Sub-Saharan Africa. The complexity and diversity of CLS often constrain the ability of policy or technology interventions to achieve a "winwin" outcome of simultaneously reducing poverty while increasing productivity sustainably (i.e., avoiding soil nutrient losses).

This thesis focuses on the Machakos Region in Kenya. Machakos has been the center of many studies looking at soil fertility issues and its implications for poverty and food security, including the well-known study by Tiffen et al. (1994). Recently, the Government of Kenya developed the Kenya Vision 2030, a long-term development strategy designed to guide the country to meet the 2015 MDGs and beyond. The agricultural sector is recognized as one of the economic actors that can lead to reduce poverty if appropriate policies are in place. For the Vision 2030, the key is to improve smallholder productivity and promote non-farm opportunities. The Vision 2030 was used to assess if the implementation of some of the proposed plans and policies can lead to a sustainable agriculture for smallholders in the Machakos region.

This thesis describes and uses the Tradeoff Analysis Model (TOA), an integrated modeling approach designed to deal with the complexities associated to production systems such as the CLS and at the same time, quantify economic and sustainability indicators for policy tradeoff analysis (e.g., poverty indexes and measures of sustainability). The TOA was linked to Representative Agricultural Pathways and Scenarios to represent different future socio-economic scenarios (based on the Vision 2030) to assess the impacts of policy interventions aimed to move agricultural systems towards meeting sustainable development goals.

One important finding is that the complex behavior of CLS has important implications for the effectiveness of policy interventions. The Machakos analysis provides important findings regarding the implementation and effectiveness of policy interventions addressing poverty and sustainability in Africa and other parts of the developing world. The analysis shows that policy interventions tend to result in much larger benefits for better-endowed farms, implying that farm heterogeneity results in 
differential policy impacts and that resilience of agricultural systems is likely to be highly variable and strongly associated with heterogeneity in bio-physical and economic conditions. The results shows that a combination of these interventions and strategies, based on the GoK Vision 2030 and the Machakos County plans, could solve the povertyproductivity-sustainability puzzle in this region. The pathway from tradeoffs to synergies (win-win) seems to be feasible if these interventions and strategies are well implemented, however the analysis also shows that some villages may respond better to these strategies than others. The analysis suggests that these interventions may actually benefit most the areas with better initial endowments of soils and climate.

The analysis also suggested that prices (e.g., maize price) play a key role in the assessment of policy interventions. There is an increasing recognition that analysis of economic and environmental outcomes of agricultural production systems requires a bottom-up linkage from the farm to market, as well as top-down linkage from market to farm. Hence, a two-way linkage between the TOA model and a partial equilibrium market model (ME) was developed. The TOA model links site-specific bio-physical process models and economic decision models, and aggregate economic and environmental outcomes to a regional scale, but treats prices as exogenous. The resulting TOA-ME allows the effects of site-specific interactions at the farm scale to be aggregated and used to determine market equilibrium. This in turn, can be linked back to the underlying spatial distribution of economic and environmental outcomes at market equilibrium quantities and prices. The results suggest that market equilibrium is likely to be important in the analysis of agricultural systems in developing countries where product and input markets are not well integrated, and therefore, local supply determines local prices (e.g., high transport costs may cause farm-gate prices be set locally) or where market supply schedules are driven not only by prices but also by changes in farm characteristics in response to policy changes, environmental conditions or socioeconomic conditions. The results suggest that the market equilibrium price associated to a policy intervention could be substantially different than the prices observed without the market equilibrium analysis, and consequently could play an important role in evaluating the impacts of policy or technology interventions. 
As mentioned above, climate change poses a long-term threat for rural households in vulnerable regions like Sub-Saharan Africa. Policy and technology interventions can have different impacts under climate change conditions. In this thesis the likely economic and environmental impacts of climate change and adaptations on the agricultural production systems of Machakos are analyzed.

Climate change impact assessment studies have moved towards the use of more integrated approaches and the use of scenarios to deal with the uncertainty of future condition. However, several studies fall short of adequately incorporating adaptation in the analysis, they also fall short of adequately assessing distributional economic and environmental impacts. Similarly, climate change is likely to change patterns of supply and demand of commodities with a consequent change in prices that could play an important role in designing policies at regional, national and international levels. Therefore, a market equilibrium model should also be incorporated in the analysis to assess how markets react to changing prices due to shifts in supply and demand of commodities. The TOA-ME was used to incorporate the elements mentioned above to assess the impacts of climate change. Using data from 5 Global Circulation Models (GCMs) with three emission scenarios (SRES, 2000) to estimate the climate change projections, these projections were used to perturb weather data used by a crop simulation model to estimate the productivity effects of climate change. Land use change and impacts on poverty and nutrient depletion at the market equilibrium were then assessed using the TOA-ME model.

The simulation was carried out for three scenarios, which are a combination of socio-economic and climate change scenarios: a baseline scenario that represents current socio-economic conditions and climate conditions, a climate change and current socioeconomic scenarios (i.e., future climate change with no policy or technology intervention), and a climate change and future socio economic conditions which are a consequence of rural development policies.

Our findings show that in this particular case, the changes on precipitation, temperature and solar radiation do not show a significant difference among the selected emission scenarios. However, the variability is significant across GCMs. The effects of climate change on crop productivity are negative on average. These results show that 
policy and technology interventions are needed to reduce this region's vulnerability. Furthermore, the socio-economic scenarios based on policy and technology interventions presented in the case study would be effective to offset the negative effect of climate change on the sustainability (economical and environmental) of the system across a range of possible climate outcomes represented by different GCMs. Finally, the results show that ignoring market equilibrium analysis can lead to biased results and incorrect information for policy making, in particular for the scenario based on policy and technology interventions.

One of the major conclusions of the thesis are that policy interventions aimed to deal with poverty and sustainability can have unintended consequences if they are not accompanied by a set of policy strategies and investments. For example, increasing the maize price can result in substitution from subsistence crops to maize, without much increase in nutrient inputs, thus increasing soil nutrient losses. The analysis shows that improving soil nutrient balances by increasing fertilizer and manure use is critically important, but is not enough to move the system to a sustainable path.

There is no one factor that can reverse the negative nutrient balances and move the system towards sustainability. Rather, a broad-based strategy is required that stimulates rural development, increases farm size to a sustainable level, and also reduces distortions and inefficiencies in input and output markets that tend to discourage the use of sustainable practices. The Machakos case shows that a combination of these interventions and strategies, based on the GoK Vision 2030 and the Machakos County plans, could solve the poverty-productivity-sustainability puzzle in this region. 


\section{About the Author}

\section{Roberto O. Valdivia}

roberto.valdivia@oregonstate.edu

Roberto O. Valdivia is a Research Associate in the Department of Applied Economics at Oregon State University. He graduated from the Universidad Nacional del Altiplano-Puno, Peru with a degree in Economic Sciences. He later pursued a Master of Science degree in Applied Economics at Montana State University and a $\mathrm{PhD}$ at Wageningen University in the Netherlands. Roberto's agricultural economics interest started when he was involved in projects funded by the International Development Research Centre-Canada in Bolivia. He then worked at the International Potato Center in Lima, Peru as a research assistant and consultant to several projects in the Andean region. In 1998 he began working for the Tradeoffs in Sustainable Agriculture Project funded by the U.S. Agency for International Development. He worked as a Research Associate in the Department of Agricultural Economics and Economics at Montana State University until 2011 when he started working for Oregon State University. Roberto's main research focuses on international projects in Africa, Asia, Latin America and Europe and has been consultant to several agricultural research and development institutions such as FAO, Bill and Melinda Gates Foundation, IFAD and several CGIAR centers. He is now co-leader of the regional economics team of the Agricultural Modeling Improvement and Intercomparison Project (AgMIP). Current research interest includes analysis of agricultural production systems and assessing economic and environmental impacts of policy and technologies, as well as climate change impacts. He is also interested in the economics of terrestrial and geological carbon sequestration. 


\section{Relevant Publications}

Homann-Kee Tui Sabine, Descheemaeker Katrien, Masikati Patricia, Chibwana Gama Arthur, Crespo Olivier, Claessens Lieven, Roberto Valdivia. 2016. Re-designing smallholder farming futures for reduced vulnerability to climate change in semiarid southern Africa. Submitted to European Journal of Agronomy.

Shikuku K. Mashisia, Valdivia Roberto, Paul Birthe, Mwongera Caroline, Winowiecki Leigh, Laderach, Peter, Herrero Mario, , Silvestri Silvia. 2016. Towards Climate Smart Livestock Systems in Tanzania: Assessing Opportunities to Meet the Triple Win. Submitted to Agricultural Systems. Special Issue: "Prioritising ClimateSmart Agricultural Interventions at different Scales". Expected publication 2016.

Valdivia, Roberto O., Antle, John M. and Jetse J. Stoorvogel. 2016. In Search of Sustainable Development: Modeling Semi-Subsistence Crop-Livestock Systems to Solve the Poverty-Productivity-Sustainability Puzzle in Sub-Saharan Africa. Submitted to Agricultural Economics.

Valdivia, Roberto O., John M. Antle, Cynthia Rosenzweig, Alex C. Ruane, Joost Vervoort, Muhammad Ashfaq, Ibrahima Hathie, Sabine Homann-Kee Tui, Richard Mulwa, Charles Nhemachena, Paramasivam Ponnusamy, Herath Rasnayaka, Harbir Singh. 2015. Representative Agricultural Pathways and Scenarios for Regional Integrated Assessment of Climate Change Impact, Vulnerability and Adaptation. In Handbook of Climate Change and Agroecosystems: The Agricultural Model Intercomparison and Improvement Project (AgMIP). C. Rosenzweig, and D. Hillel, Eds., ICP Series on Climate Change Impacts, Adaptation, and Mitigation Vol. 3. Imperial College Press, 101156, doi:10.1142/9781783265640_0005.

Rosenzweig, C., J.W. Jones, J.L. Hatfield, J.M. Antle, A.C. Ruane, K.J. Boote, P.J. Thorburn, R.O. Valdivia, C.H. Porter, S. Janssen, and C.Z. Mutter, 2015: Appendix 1. Guide for Regional Integrated Assessments: Handbook of Methods and Procedures, Version 5.1. In Handbook of Climate Change and Agroecosystems: The Agricultural Model Intercomparison and Improvement Project (AgMIP). C. Rosenzweig, and D. Hillel, Eds., ICP Series on Climate Change Impacts, Adaptation, and Mitigation Vol. 3. Imperial College Press, 331386.

Antle, John, Roberto O. Valdivia, Ken Boote, Jerry Hatfield, Sander Janssen, Jim Jones, Cheryl Porter, Cynthia Rosenzweig, Alex Ruane, and Peter Thorburn. 2015. AgMIP's Trans-disciplinary Approach to Regional Integrated Assessment of Climate Impact, Vulnerability and Adaptation of Agricultural Systems. In Handbook of Climate Change and Agroecosystems: The Agricultural Model Intercomparison and Improvement Project (AgMIP). C. Rosenzweig, and D. Hillel, Eds., ICP Series on Climate Change Impacts, Adaptation, and Mitigation Vol. 3. Imperial College Press, doi:10.1142/9781783265640_0002.

Adiku, Samuel G.K., Dilys S. MacCarthy, Ibrahima Haithie, Madina Diancoumba, Bright S. Freduah, Joseph Amikuzuno, P.C. Sibiry Traore, Seydou Traore, Eric Koomson, Alhassane Agali, Jon I. Lizaso, Dougbedji Fatondji, Myriam Adams, 
Lodoun Tigana, Daouda Z. Diarra, Ousmane N'diaye, and Roberto O. Valdivia. 2015. In Handbook of Climate Change and Agroecosystems: The Agricultural Model Intercomparison and Improvement Project (AgMIP), Part 2. C. Rosenzweig, and D. Hillel, Eds. ICP Series on Climate Change Impacts, Adaptation, and Mitigation Vol. 3. Imperial College Press, 355-374, doi: 10.1142/9781783265640_00.

Rao, Karuturi P.C., Gummadi Sridhar, Richard M. Mulwa, Mary N. Kilavi, Anthony Esilaba, Ioannis N. Athanasiadis, and Roberto O. Valdivia. 2014.Impacts of Climate Variability and Change on Agricultural Systems in Eastern Africa. In Handbook of Climate Change and Agroecosystems: The Agricultural Model Intercomparison and Improvement Project (AgMIP), Part 2. C. Rosenzweig, and D. Hillel, Eds., ICP Series on Climate Change Impacts, Adaptation, and Mitigation Vol. 3. Imperial College Press, 355-374, doi:10.1142/9781783265640_002

Beletse, Y., W. Durand, C. Nhemāehena, O. Crespo, W. Tesfuhuney, M. Jones, M. Teweldemedhin, M. Gamedze, P.M. Bonolo, S. Jonas, S. Walker, P. Gwimbi, T. Mpuisang, D.Cammarano, and Roberto O. Valdivia. 2014. Projected Impacts of Climate Change Scenarios on the Production of Maize in Southern Africa: An Integrated Assessment Case Study of the Bethlehem District, Central Free State, South Africa. In Handbook of Climate Change and Agroecosystems: The Agricultural Model Intercomparison and Improvement Project (AgMIP), Part 2. C. Rosenzweig, and D. Hillel, Eds., ICP Series on Climate Change Impacts, Adaptation, and Mitigation Vol. 3. Imperial College Press, 355-374, doi:10.1142/9781783265640_002

Patricia Masikati, Sabine HomannKee-Tui, Katrien Descheemaeker, Olivier Crespo, Sue Walker, Chris Lennard, Lieven Claessens, Arthur Gama, Sebastiao Famba, Andre van Rooyen, and Roberto O. Valdivia. 2014. Crop-livestock Intensification in the Face of Climate Change: Exploring Opportunities to Reduce Risk and Increase Resilience In Southern Africa Using an Integrated Multi- Modeling Approach. In Handbook of Climate Change and Agroecosystems: The Agricultural Model Intercomparison and Improvement Project (AgMIP), Part 2. C. Rosenzweig, and D. Hillel, Eds., ICP Series on Climate Change Impacts, Adaptation, and Mitigation Vol. 3. Imperial College Press, 355-374, doi:10.1142/9781783265640_002.

Ahmad Ashfaq, Muhammad Ashfaq, Ghulam Rasul, Syed Aftab Wajid, Tasneem Khaliq, Fahd Rasul, Umer Saeed, Muhammad Habib ur Rahman, Jamshad Hussain, Irfan Ahmad Baig, Asif Ali Naqvi, Syed Ahsan Ali Bokhari, Shakeel Ahmad, Wajid Naseem, Gerrit Hoogenboom, and Roberto O. Valdivia. 2014. Impact of Climate Change on the Rice-Wheat Cropping System of Pakistan. In Handbook of Climate Change and Agroecosystems: The Agricultural Model Intercomparison and Improvement Project (AgMIP), Part 2. C. Rosenzweig, and D. Hillel, Eds., ICP Series on Climate Change Impacts, Adaptation, and Mitigation Vol. 3. Imperial College Press, 355-374, doi:10.1142/9781783265640_00.

Nataraja Subash, Babooji Gangwar, Harbir Singh, Guillermo Baigorria, Alok Kumar Sikka, and Roberto O. Valdivia. 2014. Integrated Climate Change Assessment 
through Linking Crop Simulation with Economic Modeling - Preliminary Results from the Indo-Gangetic Basin. Impact of Climate Change on the Rice-Wheat Cropping System of Pakistan. In Handbook of Climate Change and Agroecosystems: The Agricultural Model Intercomparison and Improvement Project (AgMIP), Part 2. C. Rosenzweig, and D. Hillel, Eds., ICP Series on Climate Change Impacts, Adaptation, and Mitigation Vol. 3. Imperial College Press, 355-374, doi:10.1142/9781783265640 002.

Paramasivam Ponnusamy, Geethalakshmi Vellingiri, Raji Reddy Danda, Lakshmanan Arunachalam, Dakshina Murthy, Sunandini Prema, Sreenivas Gade, Sonali McDermid, and Roberto O. Valdivia. 2014. Integrated Assessment of Climate Change Impacts on Maize and Farm Household Incomes in Southern India: a Case Study from Tamil Nadu. In Handbook of Climate Change and Agroecosystems: The Agricultural Model Intercomparison and Improvement Project (AgMIP), Part 2. C. Rosenzweig, and D. Hillel, Eds., ICP Series on Climate Change Impacts, Adaptation, and Mitigation Vol. 3. Imperial College Press, 355-374, doi:10.1142/9781783265640_002.

Zubair, Lareef, S.P. Nissanka, W.M.W. Weerakoon, D.I. Herath, A. Karunaratne, A.E. N. Wijekoon, R.M. Herath, A.S.M.P.M.B. Agalawatte, B.V.R. Punyawardhene, S.S.K. Chandrasekara, P. Delpitiya, S. Z. Yahiya, J. Gunaratna, T.M.R.S. Perera, J. Vishwanathan, A.A.I. Gunesekara, P.Gajanayake, K.D.N.Weerasinghe, C.M. Navaratne, P. Wickramagamage, D. Wallach, and R. O. Valdivia. 2014. In Handbook of Climate Change and Agroecosystems: The Agricultural Model Intercomparison and Improvement Project (AgMIP), Part 2. C. Rosenzweig, and D. Hillel, Eds., ICP Series on Climate Change Impacts, Adaptation, and Mitigation Vol. 3. Imperial College Press, 355-374, doi:10.1142/9781783265640_002.

Assad, Eduardo, Fabio R. Marin, Roberto O. Valdivia and Cynthia Rosenzweig. 2014. AgMIP Regional Activities in a Global Framework: The Brazil Experience. In Handbook of Climate Change and Agroecosystems: The Agricultural Model Intercomparison and Improvement Project (AgMIP), Part 2. C. Rosenzweig, and D. Hillel, Eds., ICP Series on Climate Change Impacts, Adaptation, and Mitigation Vol. 3. Imperial College Press, 355-374, doi:10.1142/9781783265640_0023

Antle, J.M., J.J. Stoorvogel, R.O. Valdivia. 2014. "New Parsimonious Simulation Methods and Tools to Assess Future Food and Environmental Security of Farm Populations." Philosophical Transactions of the Royal Society B 20120280. http://dx.doi.org/10.1098/rstb.2012.0280.

John M. Antle; Roberto O. Valdivia; Lieven Claessens; J. Nelson; Joost Vervoort; and Cynthia Rosenzweig. 2013. Representative Agricultural Pathways: A New Approach for Agricultural Model Inter-comparison, Improvement and Assessment of Climate Change Impact and Adaptation. Global Environmental Change. Submitted.

Valdivia, Roberto O., Stoorvogel, Jetse J., and John Antle. 2012. Economic and Environmental Impacts of Climate Change and Socio-Economic Scenarios: A case study on a Semi-Subsistence Agricultural Production System. The 
International Journal of Climate Change: Impacts and Responses. Volume 3, Issue 2 (2012).

Valdivia, Roberto O., Antle, John M. and Jetse J. Stoorvogel. 2012. Coupling the Tradeoff Analysis Model with a market equilibrium model to analyze economic and environmental outcomes of agricultural production systems. Agricultural Systems 110 (2012).

Van Wijk M.T., M.C. Rufino, D. Enahoro, D. Parsons, S. Silvestri, R.O. Valdivia, and M. Herrero. 2012. "A Review on farm household modeling with a focus on climate change adaptation and mitigation". Published by the CGIAR Research Program on Climate Change, Agriculture and Food Security (CCAFS). Copenhagen, Denmark.

Claessens, L., Antle, J. M., Stoorvogel, J. J., Valdivia, R. O., Thornton, P. K., Herrero, M., 2012 A method for evaluating climate change adaptation strategies for smallscale farmers using survey, experimental and modeled data. Agricultural Systems 111, 85-95.

Antle, J.M. and R. O. Valdivia. 2011. "Methods for Assessing Economic, Environmental and Social Impacts of Aquaculture Technology: Integrated AgricultureAquaculture in Malawi."In Liu Liping and Kevin Fitzsimmons Eds. "Better Science, Better Fish, Better Life". Proceedings of the Ninth International Symposium on Tilapia in Aquaculture. Shanghai Ocean University, AquaFish CRSP. Shanghai, China..

Antle, J.M., B. Diagana, J.J. Stoorvogel and R.O. Valdivia. 2010. "Minimum-Data Analysis of Ecosystem Service Supply in Semi-Subsistence Agricultural Systems: Evidence from Kenya and Senegal." Australian Journal of Agricultural and Resource Economics 54:601-617.

Claessens, L.; Stoorvogel, J.; Antle, J.M.; Valdivia, R.O.; Thornton, P.K.; Herrero, M. 2009. Ex-ante assessment of climate change adaptation strategies in resource-poor countries: Study cases from East Africa. Paper submitted for the 15th Triennal Symposium of the International Society for tropical Root crops: Tropical roots and tubers in a changing Climate: A convenient Opportunity for the World. Lima, Peru November 2009.

Valdivia, Roberto O. 2009. Using Exploratory Spatial Data Analysis to explain Cropland Change in the Central United States. Working paper. Mansholt Graduate School, Wageningen University, The Netherlands.

Antle, J.M., Stoorvogel, J.J., and Roberto O.Valdivia. 2010. Tradeoff Analysis of SemiSubsistence Agricultural Systems: Assessing Impacts on Policy and Technology on Sustainability in Machakos, Kenya. Draft manuscript.

Antle, J.M., J.J. Stoorvogel, and R.O.Valdivia. 2007. Assessing the Economic Impacts of Agricultural Carbon Sequestration: Terraces and Agroforestry in the Peruvian Andes. Agriculture, Ecosystems and Environment 122(4):435-445.

Antle, J.M., and R.O.Valdivia. (2006). "Modeling The Supply Of Ecosystem Services From Agriculture: A Minimum-Data Approach". The Australian Journal of Agricultural and Resource Economics, 50, pp 1-15.

Antle, J.M., J.J. Stoorvogel, and R.O.Valdivia. 2006. "Multiple Equilibria, Soil Conservation Investments and the Resilience of Agricultural Systems." Environment and Development Economics. Vol. 11, Issue 4, August 2006. 
Antle, J.M., R.O.Valdivia, C.C. Crissman, J.J. Stoorvogel, and D. Yanggen. (2005). "Spatial Heterogeneity and Adoption of Soil Conservation Investments: Integrated Assessment of Slow Formation Terraces in the Andes." Journal of International Agricultural Trade and Development 1(1):29-53.

Valdivia, Roberto O. The Economics of Terraces in the Peruvian Andes: An Application of Sensitivity Analysis in an Integrated Assessment Model. Thesis to obtain the Master of Science degree. Department of Agricultural Economics and Economics. Montana State University. April 2002. 
Roberto Valdivia

Wageningen School of Social Sciences (WASS)

Completed Training and Supervision Plan

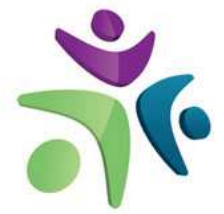

Wageningen School

of Social Sciences

\section{Name of the course}

I. General part

Writing grant proposals

Montana State University

2008

Mansholt Graduate School of

Social Sciences (MG3S)

\section{Mansholt-specific part}

Mansholt Introduction course
Department/Institute

Year

(=28 hrs)

"Coupling integrated assessment models to market AGSAP Conference equilibrium models to analyze economic and agricultural-environment interactions across different scales"

"Evaluation de sistemas agropecuarios de International Conference on

"Relaciones de Intercambio Económicas y Universidad Nacional del 2007 Medioambientales en Sistemas de Producción Altiplano, Puno, Peru Agrícolas: Aplicación del Modelo Tradeoffs Analysis, TOA"

\section{Discipline-specific part}

Writing research proposal

Montana, USA and 2006

Introduction to Spatial Analysis: ARCGIS - ESRI

Wageningen, The Netherlands

Fundamentals of Spatial Econometrics

Montana, USA

Discrete Choice Methods

Portland, Oregon

Conference at the AAEA ${ }^{10}$, WAEA ${ }^{11}$, CAES $^{12}$

Portland, Oregon

Conference at the Annual Energy Forum. Big Sky Bozeman, Montana, US

Carbon Sequestration Partnership, US Department of Energy.

Assessing Crop Production, Nutrient ICASA $^{13}$ \& University of 2008 Management, Climatic Risk and Environmental Georgia

Sustainability with Simulation Models

Spatial Econometrics: Theory and Practice

${ }^{10}$ Americal Agricultural Economist Association;

${ }^{11}$ Western Agricultural Economics Association;

${ }^{12}$ Canadian Agricultural Economics Society

${ }^{13}$ International Consortium for Agricultural Systems Applications; 
Conference at the AAEA and American Council Orlando, Florida on Consumer Interests (ACCI)

Simulation for risk analysis

Orlando, Florida

2008

0.3

Integrated Economic and Environmental Orlando, Florida

Simulation using CEEOT SWAPP

Reviewer of the Journal of Agricultural

Economics, Journal of Agricultural and Applied

Economics, African Journal of Business

Management

Discrete Choice Models: Theory and Applications Imola, Bologna

to Environment, Landscape, Transportation and Marketing.

\section{Teaching and supervising activities}

Course on the Trade Off Analysis approach

Peru

Consulting practitioners on the use of Tradeoffs

Model

Supervising MSc student

Wageningen

${ }^{14}$ CT De Wit Graduate School of Production Ecology and Resource Conservation 
